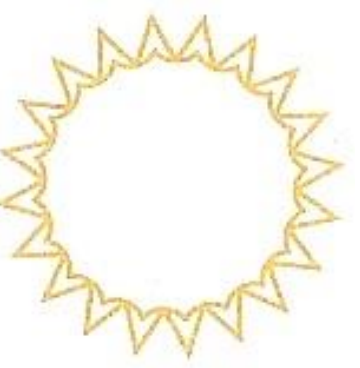

Universidade de São Paulo

Faculdade de Arquitetura e Urbanismo

SILVIA BIGONI

O comportamento de luminárias LED utilizadas em instalações no setor comercial e a sua relação com a temperatura ambiente e umidade relativa do ar.

São Paulo

2020 


\author{
Universidade de São Paulo \\ Faculdade de Arquitetura e Urbanismo
}

\author{
SILVIA BIGONI
}

\title{
O comportamento de luminárias LED utilizadas em instalações no setor comercial e a sua relação com a temperatura ambiente e umidade relativa do ar.
}

Tese apresentada à Faculdade de Arquitetura e Urbanismo da Universidade de São Paulo para obtenção do Título de Doutora.

Área de concentração: Tecnologia da Arquitetura

Orientador: Prof. Dr. Marcelo de Andrade Romero

São Paulo 
Autorizo a reprodução e divulgação total ou parcial deste trabalho, por qualquer meio convencional ou eletrônico, para fins de estudo e pesquisa, desde que citada a fonte.

\section{E-MAIL: silviabigoni@uol.com.br}

Faculdade de Arquitetura e Urbanismo da Universidade de São Paulo

Bigoni, silvia

o comportamento de luminárias LED utilizadas em instalaçōes no setor comercial e a sua relação com a temperatura ambiente e umidade relativa do ar. / Silvia Bigoni; orientador Marcelo de Andrade Romero. - São Paulo, 2020 .

$244 \mathrm{p}$.

Tese (Doutorado) - Faculdade de Arquitetura e Urbanismo da Universidade de São Paulo. Área de concentraçăo: Tecnologia da Arquitetura.

1. Luminária Led. 2. Comportamento do Led. 3. Temperatura Ambiente. 4. Umidade Atmosférica. I. Romero, Marcelo de Andrade, orient. II. Titulo.

Elaborada eletronicamente através do formulário disponivel em: ‘http:/www.fă usp.br/fichacatalografica/s 
Rua do Lago, 876 (05508-080) - Caixa Postal 61523 (05424.970) - São Paulo - Brasil

Tel 1138132511 - Fax 1138132932

http://www.usp.br/fau

\section{CERTIFICADO DE DEFESA DE DOUTORADO NÃO PRESENCIAL}

Certifico que em $20 / \mathrm{MAiO} / 2020$ realizou-se a defesa de Tese não presencial do(a) aluno(a) SILVIA BIGONI

de maneira remota, por meio da seguinte plataforma de conferência online:

CTOOGL MEeT.

Participaram da banca os docentes:

Presidente Prof(a) Dr(a) MARCELO DE ANDRADE ROMERO Prof(a) Dr(a) MARCO ANTO NIO SAIDEL

Prof(a) Dr(a) CLA'UDIA VERÖNICA TORRES BARBOSA

Prof(a) Dr(a) ROBERTA COWSENTINA KRONKA MULLARTH Prof(a) Dr(a) ISAC ROIZENBLATT

A defesa iniciou-se às 14:00 e encerrou-se às 17:30.

Comentários dos membros da banca (opcional):

Resultado final: $\triangle$ ROVAD $\triangle$, conforme Ata por mim preenchida e enviada em anexo.

Solicita-se que, sempre que possível, a depender da plataforma utilizada, a parte da leitura do resultado final seja gravada para registro.

Sobre as informações acima, dou fé.

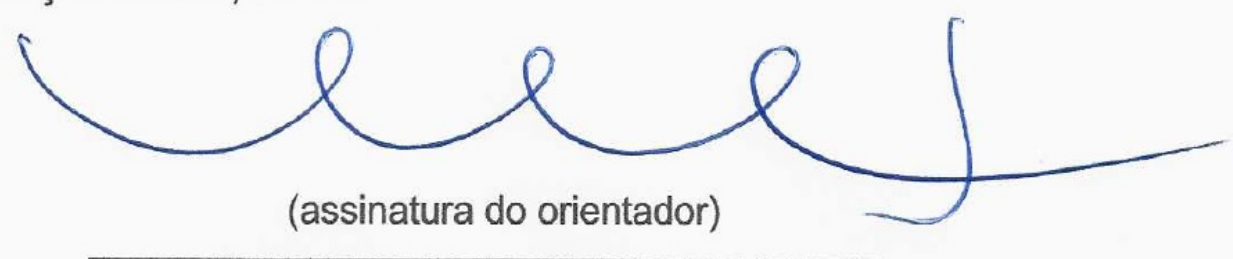

(Nome do Orientador)

marcelo de $\mathrm{d}$. ROMERO 


\section{DEDICATÓRIA}

Aos meus familiares e amigos,

que ajudaram a concretizar esse sonho me apoiando incondicionalmente. 


\section{AGRADECIMENTOS}

Agradeço primeiramente ao meu orientador, Prof. Dr. Marcelo de Andrade Roméro, a quem serei eternamente grata por sua preciosa orientação, compreensão, dedicação e amizade.

Ao grande incentivador amigo e que conquistei ao longo deste trabalho, Eng. Vicente Scopacasa, pelas suas valiosas contribuições técnicas e dedicação incansável.

Aos amigos Me. Ruy Barbosa Soares Filho e Me. Jayme Liande, e a toda a sua equipe, meu profundo agradecimento pela amizade, pelo excepcional apoio na finalização deste trabalho.

À minha colega de mestrado, Dra. Cristiane M. Sato, pela dedicação ativa e, sobretudo, pelas importantes contribuições.

Ao Dr. Isac Roizenblat, por todas as críticas, considerações e discussões, que sempre nortearam a minha vida profissional e acadêmica.

Agradeço, especialmente, ao Sr. Ricardo B. Lucchi e ao Sr. Dante Lucchi, pela paciência ao longo deste trabalho, por doarem o material necessário para a pesquisa e por disponibilizarem o espaço para a execução do trabalho.

A Itaim Lighting Concept, em especial ao Sr. Hugo Hanashiro, que concretizou esse sonho a partir da doação de todas as luminárias, e por possibilitar que as medições tenham sido realizadas no Laboratório de Fotometria da sua empresa. Minha gratidão ao Sr. Willian Izidro por todas as medições ao longo do processo, e ao Sr.Renato Kaue Kanegae Junior, por suas ideias e apoio técnico.

Ao Arq. Leonardo Freire, pela indicação da Fujisan como local para realizar a experimentação e por ser um amigo de todas as horas.

À Fujisan - Centro de Hematologia e Hemoterapia, em especial ao Dr. Guilherme Fujita, por abrir as portas da sua empresa para que os ensaios fossem lá realizados.

Agradeço à minha família, em especial ao meu irmão Sérgio, pelo apoio para finalização dos gráficos, e à minha amiga Paula D'Alessandro, pela correção ortográfica e gramatical desta pesquisa. 


\section{RESUMO}

BIGONI, S. O comportamento de luminárias LED utilizadas em instalações no setor comercial e a sua relação com a temperatura ambiente e umidade relativa do ar. p. Tese (Doutorado). Faculdade de Arquitetura e Urbanismo, Universidade de São Paulo, São Paulo, 2020.

Esta tese teve como objetivo desenvolver uma metodologia de apoio para a avaliação do comportamento de parte dos componentes que compõem luminárias LED, utilizadas em instalações de edifícios comerciais sem condicionamento do ar.

A pesquisa utilizou-se de alguns fatores vitais para a obtenção de resultados representativos, sendo o parâmetro geográfico o primeiro deles. Assim, foram definidas duas edificações, escolhidas em função do critério variações climáticas: temperatura e umidade relativa do ar e demais critérios interligados - tais como pressão atmosférica, intensidade da radiação solar e vento - e processos atmosféricos, que envolvem diversos recursos de emissão, deposição, dispersão de poluentes e aerossóis atmosféricos e marinhos.

O segundo parâmetro foi a determinação das luminárias LED, denominadas neste trabalho de objetos de ensaios.

O terceiro parâmetro foi o temporal, com a definição dos intervalos e duração dos experimentos para as atividades em campo e laboratório. $O$ último critério foi a determinação dos ensaios e medições para obtenção dos dados fotométricos de variações de fluxo luminoso, intensidade luminosa, potência elétrica consumida e eficácia luminosa e dos dados colorimétricos, com o levantamento das coordenadas de cromaticidade " $x, y$ ", IRC, Ra, temperatura de cor correlata (TCC), índice de fidelidade (Rf) e índice de Gamut (Rg).

Para verificação das hipóteses, os resultados das medições foram comparados aos valores definidos, conforme as recomendações IES LM-80-15, IES TM-28-14, LM84-14, CIE 224-17, IES TM-30-18.

Até 6.000 horas de teste, a manutenção de fluxo e as características cromáticas não sofreram variações relevantes. Até 12.000 horas para a instalação de COTIA em consequência de um período maior de operação, constatou-se uma considerável variação no fluxo luminoso e elevação da temperatura de cor TCC, alteração 
caracterizada pelo fenômeno de degradação do fósforo e vazamento da luz azul e identificadas nas medições das coordenadas de cromaticidade " $x, y$ " que apresentaram variações no mesmo sentindo, com direção a temperatura de cor mais fria. No que tange à reprodução de cores, durante todo o período de teste, não foram observadas variações notáveis. As medições de Índice de Fidelidade e Gamut sofreram mínimas variações. Houve pouca influência dos elementos ópticos em todo o processo dos experimentos.

Palavras chave: Componentes LED, luminárias LED, manutenção do fluxo luminoso, IRC, $\mathrm{Ra}$, temperatura de cor correlata, temperatura do ar, umidade do ar. 


\section{ABSTRACT}

BIGONI, S. The behavior of LED luminaires used in installations in the retail sector and their relationship with ambient temperature and relative air humidity.

P. Thesis (Doctorate). Faculty of Architecture and Urbanism, University of São Paulo, São Paulo, 2020.

This thesis aimed to develop a support methodology to assess the behavior of part of the components that make up LED luminaires, used in commercial building installations, without air conditioning.

The research used some vital factors to obtain representative results, being the geographical parameter the first one. Thus, two buildings were defined, chosen according to the climatic variations criterion: air temperature and relative air humidity and other interconnected criteria, such as atmospheric pressure, solar radiation intensity and wind - and atmospheric processes, which involve several resources of emission, deposition, dispersion of pollutants and atmospheric and marine aerosols.

The second parameter was the determination of LED luminaires, called "test objects" in this work.

The third parameter was the temporal one, with the definition of intervals and duration of the experiments for the field and laboratory activities. The last criterion was the determination of the tests and measurements to obtain the photometric data of luminous flux variations, luminous intensity, electrical power consumed and luminous efficacy, in addition to colorimetric data, with the verification of chromaticity coordinates " $x, y$ ", CRI, Ra, correlated color temperature (CCT), fidelity index (Rf) and Gamut index (Rg).

To verify the hypotheses, the results of such measurements were compared to the values defined by the recommendations IES LM-80-15, IES TM-28-14, LM-84-14, CIE 224-17, IES TM-30-18.

The maintenance of luminous flux and chromatic characteristics, up to 6,000 hours of testing, have not undergone significant variations. Up to 12,000 hours in the COTIA installation, as a result of a longer operation period, there was a considerable variation in luminous flux and elevation of the CCT - Correlated Color Temperature alteration characterized by the phosphorus degradation phenomenon and consequent 
leakage of blue light, identified in the " $x, y$ " chromaticity coordinates measurements, which showed variations in the same direction, towards a higher color temperature. Regarding color rendering, no notable variations were observed throughout the test period. The measurements of Fidelity Index and Gamut Index showed slight variations. There was little influence of optics along the experiments.

Keywords: LED components, LED luminaires, luminous flux maintenance, CRI, Ra, correlated color temperature, air temperature, air humidity. 


\section{LISTA DE ILUSTRAÇÕES}

Figura $1 \quad$ Fluxograma objetos de ensaios..................................................... 28

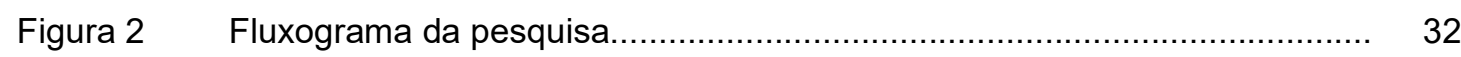

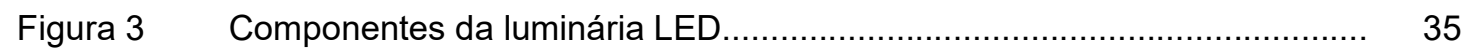

Figura $4 \quad$ Receita global de luminárias LEDs............................................... 37

Figura $5 \quad$ Dados do objeto de ensaio quadrada MINOTAURO com difusor................ 39

Figura $6 \quad$ Dados do objeto de ensaio retangular MINOTAURO com difusor............... 40

Figura $7 \quad$ Dados do objeto de ensaio quadrada MINOTAURO sem difusor................. 41

Figura 8 Dados do objeto de ensaio retangular MINOTAURO sem difusor.............. 42

Figura $9 \quad$ Dados do objeto de ensaio ORBI com difusor....................................... 43

Figura 10 Dados do objeto de ensaio ORBI sem difusor......................................... 44

Figura 11 Fachada Lucchi - Local do experimento Cotia/ SP............................. 46

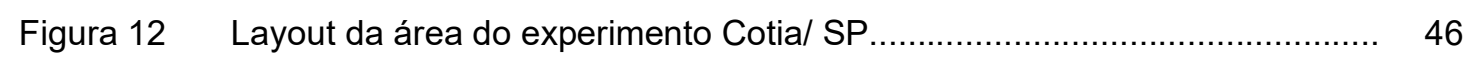

Figura 13 Vista para parte interna CD Lucchi Cotia/ SP.................................. 47

Figura 14 Vista interna da fachada CD Cotia/ SP.......................................... 47

Figura 15 Objetos de ensaios e tripé com data logger Hobo U12-012 Cotia/ SP........ 47

Figura $16 \quad$ Fachada Fujisan - Local do experimento Fortaleza/ CE........................... 49

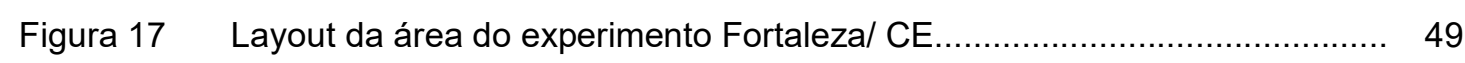

Figura 18 Vista interna da fachada anterior à reforma Fortaleza/ CE....................... 50

Figura 19 Vista interna da fachada posterior à reforma Fortaleza/CE.................... 50

Figura $20 \quad$ Objetos de ensaios Fortaleza/ CE........................................................ 51

Figura 21 Objetos de ensaios e tripé com data logger Hobo U12-012 Fortaleza/ CE... 51

Figura 22 Identificação do prefixo Cotia/ SP ....................................................... 53

Figura 23 Identificação do prefixo Fortaleza/ CE................................................... 54

Figura $24 \quad$ Modelo digital Power Meter PF9811........................................ 58

Figura $25 \quad$ Esfera Integradora Everfine modelo GBT/24824.............................. 59

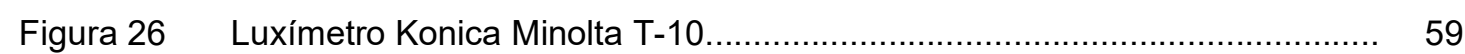

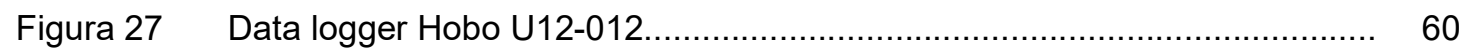

Figura 28 Relatório gerado pela esfera integradora com informações fotométricas, 61

Figura 29 Relatório gerado pela esfera integradora com informações TM30............. 62

Figura $30 \quad$ Penetração do LED (\%) conforme tipologias de aplicação........................... 78

Figura 31 Mercado global de iluminação de 2010 até 2020................................. 79

Figura 32 Processo de fabricação, materiais, medições e testes do LED.................. 81

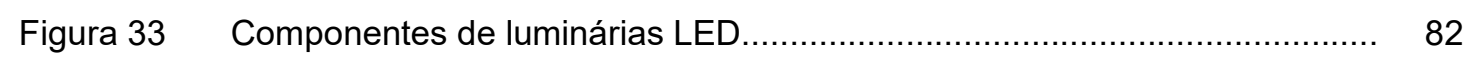

Figura 34 Cinco níveis de integração do projeto............................................ 84 
Figura 35

Figura 36

Figura 37

Figura 38

Figura 39

Figura 40

Figura 41

Figura 42

Figura 43

Figura 44

Figura 45

Figura 46

Figura 47

Figura 48

Figura 49

Figura 50

Figura 51

Figura 52

Figura 53

Figura 54

Figura 55

Figura 56

Figura 57

Figura 58

Figura 59

Figura 60

Figura 61

Figura 62

Figura 63A

Figura 63B

Figura $63 \mathrm{C}$

Figura 64

Figura 65
Processo convencional de fabricação do LED.

Modelos de encapsulamentos...

87

Esquema de construção de MCРCB - Metal Core Printed Circuit Board....... 89

Secção transversal de PCls (1) FR4 com furos metalizados (2) MCPCB (3) 91 cerâmica.

Dissipador passivo.. 93

Dissipador ativo.. 93

Corte transversal com a representação do caminho térmico, desde a sua 94 geração no LED até o ambiente.

Dissipador, interface térmica e holder...... 97

Lente primária. 97

Demonstração do direcionamento da luz emitida por uma lente colimadora 99

Modelos de lentes colimadoras individuais... 100

Modelo de lente colimadora múltipla em PMMA........................................ 100

Lente para arranjos de LED 6 x 2 em silicone........................................... 101

Lente individual de silicone................................................................ 101

Refletor parabólico para COB LED...................................................... 102

Refletores parabólicos lineares em alumínio anodizado............................. 102

Acabamento especular (espelhado), fosco (matt) e acetinado (texturizado) 103

Comportamento do espectral do LED em distintos refletores...................... 104

Comparativo lente colimadora X refletor em relação ao 105

aproveitamento da luz....

Acabamento de difusores - matt (1), texturizado (2), texturizado opaco (3), 106 frisado opaco (4), frisado transparente (5) e prismático (6).

Modelos de luminárias aplicadas em instalações comerciais corporativas... 116

Densidade de corrente do driver....................................................... 117

Saída relativa do lúmen em relação à temperatura de junção...................... 118

Limites teóricos às eficiências luminosas da radiação na luz branca vs. TCC 119 para um determinado CRI.....

IRC/CRI para um determinado TCC ................................................... 120

Representação gráfica do modo de falhas de uma fonte de luz................. 121

Espectro de radiação............................................................................ 125

Curva de luminosidade espectral relativa (visão escotópica e fotópica) ....... 126

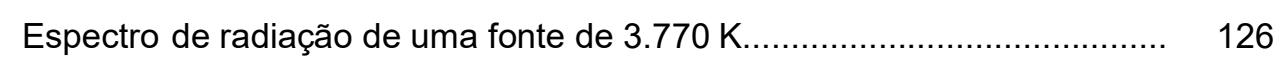

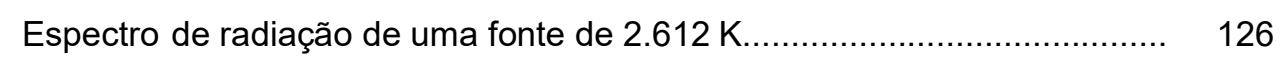

Espectro de radiação de uma fonte de LED azul...................................... 126

Amostras de cores pelo padrão IRC do CIE.......................................... 127

Padrão de amostras com 99 cores adotado pela TM-30-15 ....................... 128 
Figura 66 Coordenadas das 99 amostras de cores no diagrama CAM02-UCS e os ângulos de matiz

Figura 67 Gráfico vetores com duas fontes de luz com diferentes valores de temperatura de cor e índices $R_{f}$ e $R_{g}$.

Figura 68 Perfeição entre os polígonos de uma lâmpada halógena MR16................... 132

Figura 69 Matiz, luminosidade e saturação............................................................... 133

Figura $70 \quad$ Modelo orbital Munsell Color System.................................... 134

Figura 71 Diagrama de cromaticidade CIE 1931................................................... 137

Figura 72 Diagrama de cromaticidade CIE 1931 com as elipses MacAdam................ 139

Figura 73 Diagrama de cromaticidade de uma fonte de LED 2.726K .......................... 140

Figura 74 Exemplificação de elipse 5 SDCM de uma fonte de LED 2.726K................. 141

Figura 75 Exemplificação ANSI C78.377-2017 para uma fonte de LED 2.726K.......... 141

Figura 76 Exemplos de aplicações de temperatura de cor ......................................... 142

Figura 77 Esfera integradora ou esfera de Ulbricht............................................... 144

Figura 78 Planos transversais e longitudinal de uma curva fotométrica...................... 146

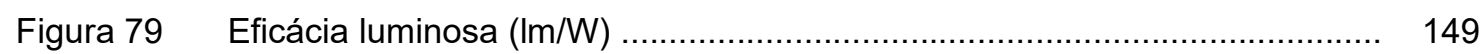

Figura 80 Síntese da classificação climática do Brasil, segundo Köppen e Geiger...... 155

Figura 81 Coletas de dados das estações meteorológicas de Barueri e Mirante de 156

Santana/ SP.

Figura 82 Coletas de dados das estações meteorológicas de Fortaleza/ CE............... 156

Figura 83 Processos e compostos envolvidos na poluição atmosférica........................ 165

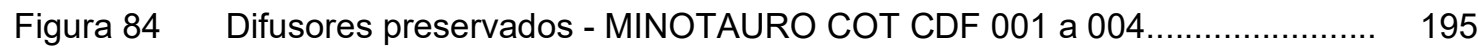

Figura 85 SMDs com escurecimento - MINOTAURO COT CDF 002.......................... 196

Figura 86 Soldagem dos contatos - MINOTAURO COT CDF 002 ............................... 196

Figura 87 Driver preservado - MINOTAURO COT CDF 002

Figura 88 Solda do contato com leve oxidação - MINOTAURO COT SDF 001........... 197

Figura 89 Escurecimento do chip, depreciação do Lead frame - MINOTAURO COT 197

Figura $90 \quad$ Driver, conector e módulos lineares em bom estado de conservação - $\quad 198$

Figura 91 Refletor com manchas - MINOTAURO COT SDF 001............................. 198

Figura $92 \quad$ Holder trincado - ORBI COT CDF 003..................................................... 198

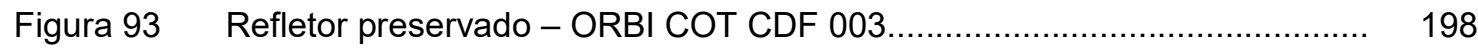

Figura 94 Difusor - ORBI COT CDF 003........................................................... 199

Figura 95 Difusor com leve deformação - ORBI COT CDF 003................................ 199

Figura $96 \quad$ Refletor óptico preservado - ORBI COT SDF 003.................................. 200

Figura 97 COB preservado com pequenas manchas - ORBI COT SDF 003.............. 201

Figura 98 Solda entre contatos - MINOTAURO FOR CDF 001.............................. 201 
Figura 99 Pontos amarelados sobre os SMDs - MINOTAURO FOR CDF 001. 002. 003 Junções preservadas nas áreas de solda - MINOTAURO FOR SDF $001 \ldots$. 002. 004.

Figura 125

Figura 126

Carcaça externa com manchas - MINOTAURO FOR SDF 004. 


\section{LISTA DE TABELAS}

Tabela 1 Períodos de medições do data logger Hobo Cotia/ SP .................................... 48

Tabela 2 Períodos de medições do data logger Hobo Fortaleza/ CE............................. 52

Tabela 3 Metas futuras e variáveis associadas a luminária LED..................................... 80

Tabela $4 \quad$ Classificação dos LEDs brancos ……................................................... 87

Tabela $5 \quad$ Principais características dos difusores ....................................................... 106

Tabela $6 \quad$ Número de etapas do SDCM para uma fonte de 3.000K................................ 139

\section{LISTA DE GRÁFICOS}

Gráfico 1 Exemplo de gráfico apresentado pelo data logger Hobo U12-012 ................. 60

Gráfico 2 Custos típicos para encapsulamento de LEDs High-Power e Mid-Power.......... 88

Gráfico 3 Medições de fluxo luminoso $(\mathrm{Im})$ - MINOTAURO COT CDF e SDF 001, 002, 171 003 e 004

Gráfico 4 Medições de fluxo luminoso (Im) - MINOTAURO FOR CDF e SDF 001, 002, 003 e 004

Gráfico 5 Medições de fluxo luminoso (Im) - ORBI COT CDF e SDF 001, 002, 003 e 004 .

Gráfico 6 Medições de fluxo luminoso (Im) - ORBI FOR CDF e SDF 001, 002, 003 e 004 .

Gráfico 7 Medições de potência total (W) - MINOTAURO COT CDF e SDF 001, 002, 003 e 004 .

Gráfico 8 Medições de potência total (W) - MINOTAURO FOR CDF e SDF 001, 002, 003 e 004

Gráfico 9 Medições de potência total (W) - ORBI COT CDF e SDF 001, 002, 003 e 004.176

Gráfico 10 Medições de potência total (W) - ORBI FOR CDF e SDF 001, 002, 003 e 004.176

Gráfico 11 Medições de eficácia (Im/W) - MINOTAURO COT CDF e SDF 001, 002, 003177 e 004 ..

Gráfico 12 Medições de eficácia (Im/W) - MINOTAURO FOR CDF e SDF 001, 002, 003 e 004 .......

Gráfico 13 Medições de eficácia (Im/W) - ORBI COT CDF e SDF 001, 002, 003 e 004....... 178

Gráfico 14 Medições de eficácia (Im/W) - ORBI FOR CDF e SDF 001, 002, 003 e 004...... 
Gráfico 15 Medições de TCC (K) - MINOTAURO COT CDF e SDF 001, 002, 003 e 004... 179

Gráfico 16 Medições de TCC (K) - MINOTAURO FOR CDF e SDF 001, 002, 003 e 004.. 179

Gráfico 17 Medições de TCC (K) - ORBI COT CDF e SDF 001, 002, 003 e 004............... 181

Gráfico 18 Medições de CCT (K) - ORBI FOR CDF e SDF 001, 002, 003 e 004............... 181

Gráfico 19 Medições de IRC - MINOTAURO COT CDF e SDF 001, 002, 003 e 004.......... 183

Gráfico 20 Medições de IRC - MINOTAURO FOR CDF e SDF 001, 002, 003 e 004.......... 183

Gráfico 21 Medições de IRC - ORBI COT CDF e SDF 001, 002, 003 e 004...................... 185

Gráfico 22 Medições de IRC - ORBI FOR CDF e SDF 001, 002, 003 e 004....................... 185

Gráfico 23 Medições de Ra - MINOTAURO COT CDF e SDF 001, 002, 003 e 004............ 186

Gráfico 24 Medições de Ra - MINOTAURO FOR CDF e SDF 001, 002, 003 e 004............ 186

Gráfico 25 Medições de Ra - ORBI COT CDF e SDF 001, 002, 003 e 004....................... 187

Gráfico 26 Medições de Ra - ORBI FOR CDF e SDF 001, 002, 003 e 004....................... 187

Gráfico 27 Medições de coordenada de cromaticidade "x "- MINOTAURO COT CDF 188 e SDF 001, 002, 003 e 004

Gráfico 28 Medições de coordenada de cromaticidade "x "- MINOTAURO FOR CDF 188 e SDF 001, 002, 003 e 004

Gráfico 29 Medições de coordenada de cromaticidade "x "- ORBI COT CDF e SDF 001 , 002,003 e 004

Gráfico 30 Medições de coordenada de cromaticidade "x "- ORBI FOR CDF e SDF 001, 002, 003 e 004

Gráfico 31 Medições de coordenada de cromaticidade "y "- MINOTAURO COT CDF e SDF 001, 002, 003 e 004

Gráfico 32 Medições de coordenada de cromaticidade "y “- MINOTAURO FOR CDF e SDF 001, 002, 003 e 004

Gráfico 33 Medições de coordenada de cromaticidade "y “- ORBI COT CDF e SDF 001, 002,003 e 004

Gráfico 34 Medições de coordenada de cromaticidade "y "- ORBI FOR CDF e SDF 001, 002, 003 e 004

Gráfico 35 Ponto de cromaticidade "x, y" mediano a zero hora e 12.000 horas MINOTAURO COT CDF

Gráfico 36 Ponto de cromaticidade " $x$, y" mediano a zero hora e 12.000 horas MINOTAURO COT SDF

Gráfico 37 Ponto de cromaticidade "x, y" mediano a zero hora e 12.000 horas - ORBI COT CDF.

Gráfico 38 Ponto de cromaticidade "x, y" mediano a zero hora e 12.000 horas - ORBI COT SDF...... 


\section{LISTA DE QUADROS}

Quadro 1 Comparativo dos principais modelos de PCls ............................................... 91

Quadro 2 Processo ao longo de décadas para a definição das métricas para a 135 qualidade da cor.

\section{LISTA DE FÓRMULAS}

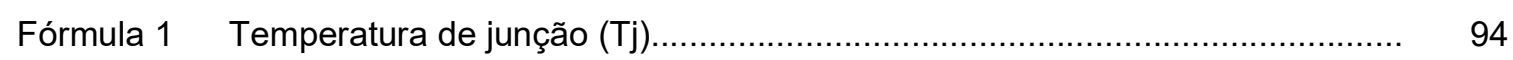

Fórmula 2 Fluxo luminoso............................................................................... 143

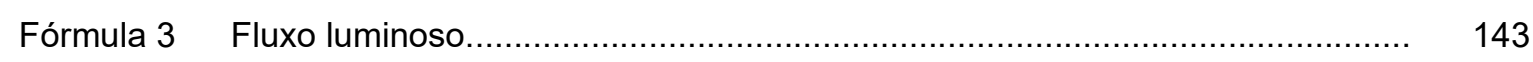

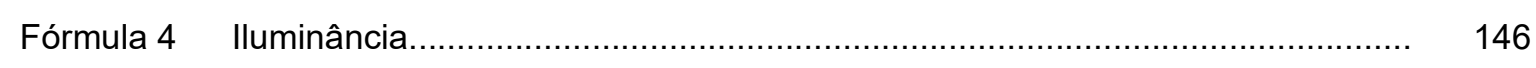

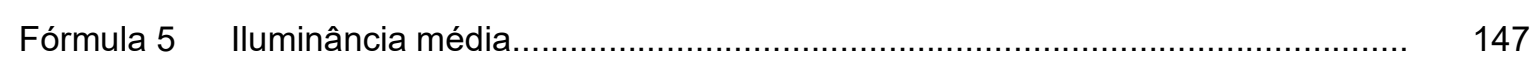

Fórmula 6 Luminância.................................................................................... 147

Fórmula 7 Luminâncias para refletores perfeitos........................................................ 148

Fórmula 8 Coeficiente de reflexão...................................................................... 148 


\section{LISTA DE ABREVIATURAS E SIGLAS}

\begin{tabular}{|c|c|}
\hline ABNT & Associação Brasileira de Normas Técnicas \\
\hline ССT & Correlated Color Temperature \\
\hline CIE & Commission Internationale de l'Éclairage \\
\hline CRI & Color Rendering Index \\
\hline COB & Chip-on-board \\
\hline CONAMA & Conselho Nacional do Meio Ambiente \\
\hline DALI & Digital Adressable Lighting Interface \\
\hline DIN & German Institute for Standardization \\
\hline DOE & U.S. Departament of Energy \\
\hline ELETROBRÁS & Centrais Elétricas Brasileiras \\
\hline IEA & International Energy Agency \\
\hline IEC & International Electrotechnical Commission \\
\hline EPE & Empresa de Pesquisa Energética \\
\hline IES & Illuminating Engineering Society \\
\hline IESNA & Illuminating Engineering Society of North America \\
\hline INMET & Instituto Nacional de Meteorologia \\
\hline INMETRO & Instituto Nacional de Metrologia, Qualidade e Tecnologia \\
\hline IRC & Índice de Reprodução de Cor \\
\hline ISO & International Organization for Standardization \\
\hline loT & Interne of things \\
\hline LED & Light Emitting Diode (Diodo emissor de luz) \\
\hline LSRC & LED System Reliability Consortium \\
\hline MC-PCB & Metal core printed circuit board \\
\hline MOCVD & Metal organic chemical vapor deposition \\
\hline
\end{tabular}


MR

NBR

PCB

PROCEL

SSL

TCC
Multifaceted reflector

Norma Brasileira Regulamentadora

Printed circuit board

Programa Nacional de Conservação de Energia Elétrica

Solid State Lighting

Temperatura de Cor Correlata 


\section{SUMÁRIO}

\section{DEDICATÓRIA}

AGRADECIMENTOS

RESUMO

ABSTRACT

LISTA DE ILUSTRAÇÕES

LISTA DE TABELAS

LISTA DE GRÁFICOS

LISTA DE QUADROS

LISTA DE ABREVIATURAS E SIGLAS

\section{SUMÁRIO}

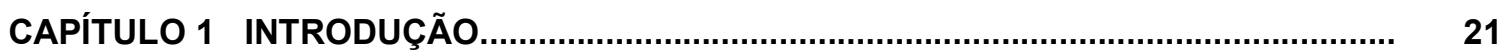

$1.1 \quad$ Justificativa e contexto................................................................ 21

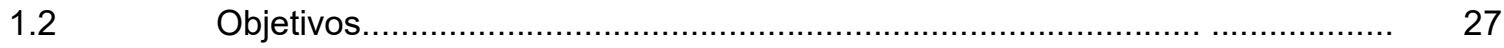

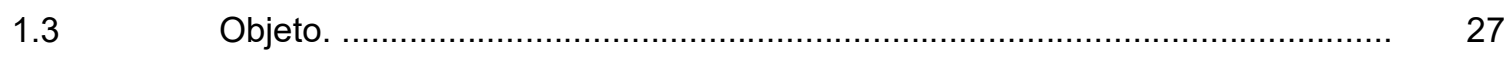

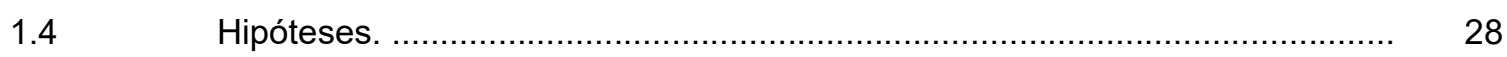

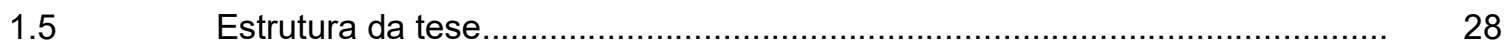

CAPÍTULO 2 MÉTODOS E MATERIAIS................................................................... 31

$2.1 \quad$ Considerações preliminares.................................................................. 31

$2.2 \quad$ Levantamento dos dados secundários................................................... 33

$2.3 \quad$ Levantamento dos dados primários........................................................ 34

2.3.1 Determinação dos sistemas de iluminação..................................................... 34

2.3.1.1 Componentes diretos e indiretos............................................................. 35

2.3.1.2 Determinação dos objetos de ensaios.......................................................... $\quad 36$

$2.4 \quad$ Levantamento dos parâmetros dos dados 45

2.4.1 Local dos experimentos e posicionamento dos objetos de ensaios................ $\quad 45$

2.4.2 Características climáticas das localidades dos experimentos e codificações

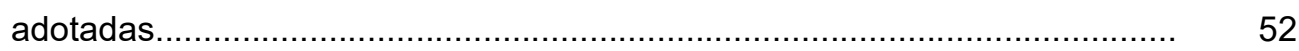

$2.5 \quad$ Levantamento de dados temporais..................................................... 54

2.5.1 Atividades de laboratório e campo.......................................................... $\quad 55$

2.5.1.1 Determinação dos parâmetros fotométricos, elétricos e colorimétricos.............................................................................. 56

2.5.1.1.1 Condições gerais de ensaios................................................................. 57

2.5.1.1.2 Equipamentos de laboratório................................................................ 58

2.5.1.1.3 Equipamentos de campo.................................................................... 60

2.5.1.1.4 Relatórios gerados em laboratório pela esfera integradora............................. 61 


\section{CAPÍTULO 3 ASPECTOS NORMATIVOS, PROCEDIMENTOS E}

3.2 Normas Brasileiras Regulamentadoras (NBRs).

3.2.1 ABNT IEC/TS 62504:2013 - Termos e definições para LEDs e os módulos de LEDs de iluminação geral......

3.2.2 ABNT IEC 62031:2013 - Módulos de LED para iluminação em geral -

Especificação de segurança

ABNT NBR 62722-2-1:2016 - Desempenho de Luminárias - parte 2-1:

Requisitos particulares para luminárias LED. ABNT NBR ISO/CIE 8995-1:2013 - lluminação de Ambientes de Trabalho -

Parte 1: Interior. 66

Recomendações IESNA

IES TM-28-14 - Projecting Long-Term Luminous Flux Maintenace of LED

3.3.2 IES LM-79-08 - Electrical and Photometric Measurements of Solid-State Lighting Products.

3.3.3 IES LM-79-19 - Optical and Electrical Measurements of Solid-State Lighting Products.

3.3.6 IES LM-84-14 - Luminous flux and Color Maintenance of LED Lamps, Light Engines, and Luminaires.

3.3.7 IES TM- 30-18 - Method for Evaluating llght Source Color Rendition.......... 72

Recomendações CIE......................................................................

3.4.1 CIE 224-17 - Color Fidelity Index for Accurate Scientific Use.................... 72

\section{CAPÍTULO 4 COMPONENTES E TECNOLOGIAS APLICADAS EM LUMINÁRIAS}

LED.

$4.2 \quad$ Dados do mercado global para os produtos SSL.......................................... 77

4.3 Eficiência na produção de luminárias LED...

4.4 Componentes aplicados no projeto de luminárias de estado sólido.

4.5 Integração do projeto com tecnologia LED e o desempenho dos seus componentes. 


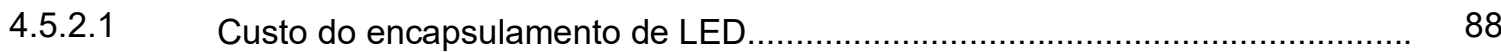

4.5.3 Placa de circuito com LED montado......................................................... 89

4.5.4 O controle e gerenciamento térmico........................................................... 92

4.5.5 Interfaces térmicas e conexões.................................................................. 95

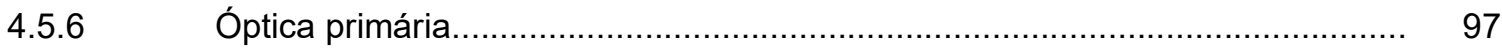

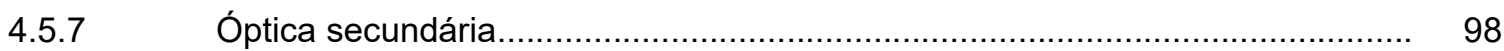

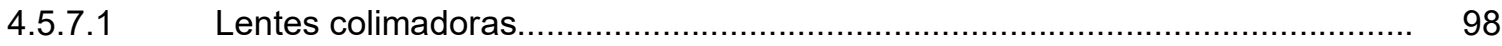

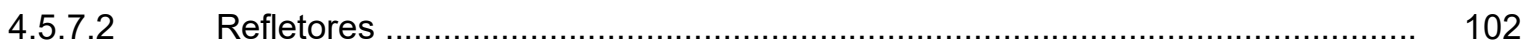

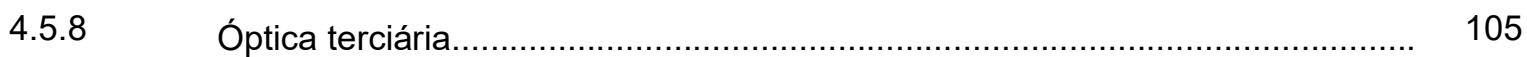

4.5.9 Componentes eletrônicos................................................................. 107

4.6 Recomendações para o desenvolvimento e produção de luminárias

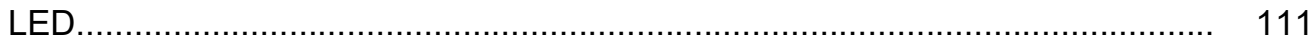

4.6.1 Classificação das luminárias de acordo com o direcionamento do fluxo luminoso............................................................................................... 114

Os desafios do LED ....................................................................... 116

4.8 Definição de vida útil e falhas do LEDs......................................................... 120

CAPÍTULO 5 PROPRIEDADES COLORIMÉTRICAS E FOTOMÉTRICAS.......................... 123

5.1 Considerações preliminares................................................................ 123

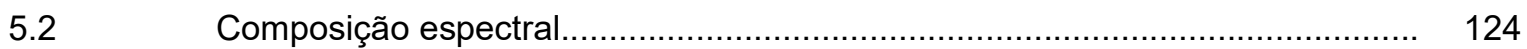

5.3 Índice de Reprodução de Cor (IRC) ou Color Rending Index

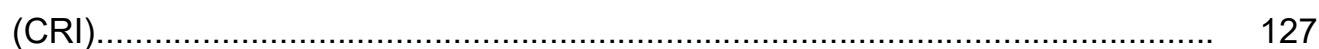

5.3.1 Novos métodos de avaliação do índice de reprodução de cor............................ 128

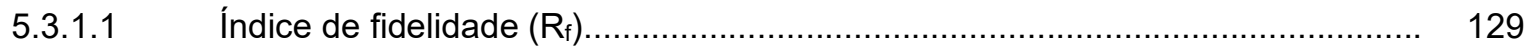

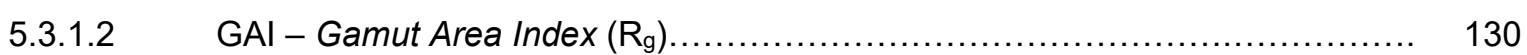

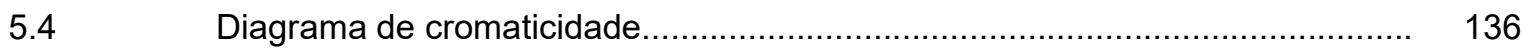

5.4.1 Equipamento de medição das características colorimétricas............................. 140

5.5 Temperatura de cor correlata (TCC) ou Correlated Color Temperature............. 141

$5.6 \quad$ Parâmetros fotométricos ................................................................... 143

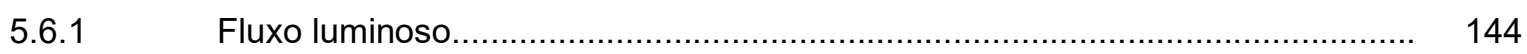

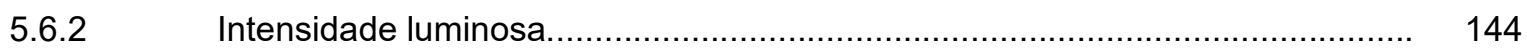

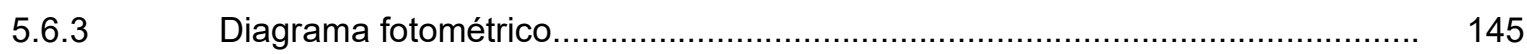

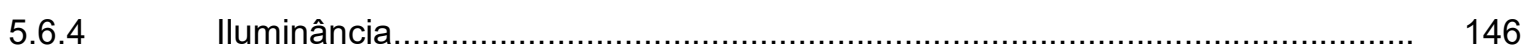

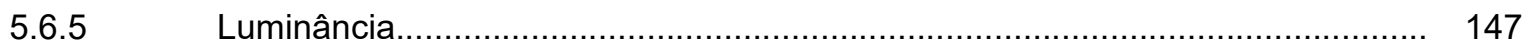

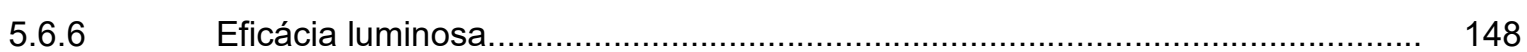

CAPÍTULO 6 FATORES CLIMÁTICOS............................................................................ 151

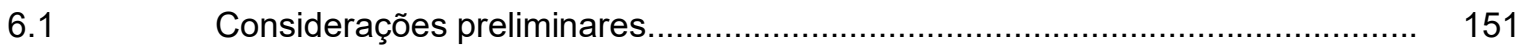

6.2 Fatores do clima e a influência nos experimentos............................................ 152 
6.2.1 Classificação climática dos parâmetros geográficos.

6.3.1 Principais variáveis climáticas - temperatura do ar, umidade relativa do ar, radiação solar, pressão atmosférica, latitude, altitude, ventos, maritimidade e continentalidade.

6.4 Processos atmosféricos da poluição ambiental............................................ 160

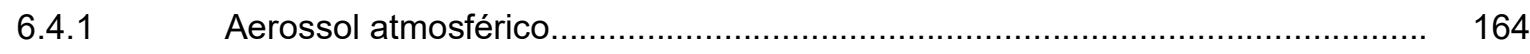

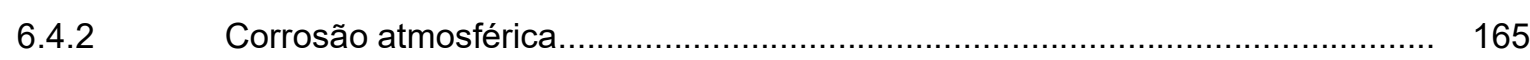

CAPÍTULO 7. RESULTADOS E ANÁLISE DOS DADOS DA EXPERIMENTAÇÃO............... 169

$7.1 \quad$ Considerações preliminares................................................................ 169

7.2 Resultados das medições dos objetos de ensaios.......................................... 170

7.2.1 Medições de fluxo luminoso $(\mathrm{Im})$ dos objetos de ensaios MINOTAURO COT CDF e SDF 001, 002, 003,004 versus MINOTAURO FOR CDF e SDF 001 , 002, 003, 004

7.2.2 Medições de fluxo luminoso $(\mathrm{Im})$ dos objetos de ensaios ORBI COT CDF e SDF 001,002,003,004 versus ORBI FOR CDF e SDF 001, 002, 003, 004.

7.2.3 Medições de potência total (W) dos objetos de ensaios MINOTAURO COT CDF e SDF 001, 002, 003, 004 versus MINOTAURO FOR CDF e SDF 001, 002, 003, 004

7.2.4 Medições de potência total (W) dos objetos de ensaios ORBI COT CDF e SDF 001, 002, 003, 004 versus ORBI FOR CDF e SDF 001, 002, 003, $004 \ldots$.

7.2.5 Medições de eficácia $(\mathrm{Im} / \mathrm{W})$ dos objetos de ensaios MINOTAURO COT CDF e SDF 001,002,003,004 versus MINOTAURO FOR CDF e SDF 001, 002, 003, 004

7.2.6 Medições de eficácia ( $(\mathrm{m} / \mathrm{W})$ dos objetos de ensaios ORBI COT CDF e SDF 001,002,003,004 versus ORBI FOR CDF e SDF 001, 002, 003, 004

7.2.7 Medições de TCC (K) dos objetos de ensaios MINOTAURO COT CDF e SDF 001,002,003,004 versus MINOTAURO FOR CDF e SDF 001, 002, 003, 004....

7.2.8 Medições de TCC $(\mathrm{K})$ dos objetos de ensaios ORBI COT CDF e SDF 001,002,003,004 vs ORBI FOR CDF e SDF 001,002,003,004

7.2.9 Medições de IRC dos objetos de ensaios MINOTAURO COT CDF e SDF 001, 002, 003, 004 versus MINOTAURO FOR CDF e SDF 001, 002, 003, 004.

7.2.10 Medições de IRC dos objetos de ensaios ORBI COT CDF e SDF 001, 002, 003, 004 versus ORBI FOR CDF e SDF 001, 002, 003, 004.

7.2.11 Medições de Ra dos objetos de ensaios MINOTAURO COT CDF e SDF 001,002,003,004 versus MINOTAURO FOR CDF e SDF 001, 002, 003, 004....

7.2.12 Medições de Ra dos objetos de ensaios ORBI COT CDF e SDF 001,002,003,004 versus ORBI FOR CDF e SDF 001, 002, 003, 004. 
7.2.13 Medições de coordenadas de cromaticidade " $x$ " dos objetos de ensaios MINOTAURO COT CDF e SDF 001,002,003,004 versus MINOTAURO FOR CDF e SDF 001, 002, 003, 004.

7.2.14 Medições de coordenadas de cromaticidade " $x$ " dos objetos de ensaios ORBI COT CDF e SDF 001, 002, 003, 004 versus ORBI FOR CDF e SDF 001, 002, 003, 004 .

7.2.15 Medições de coordenadas de cromaticidade " $y$ " dos objetos de ensaios MINOTAURO COT CDF e SDF 001,002,003,004 versus MINOTAURO FOR CDF e SDF 001, 002, 003, 004.

7.2.16 Medições de coordenadas de cromaticidade " $\mathrm{y}$ " dos objetos de ensaios ORBI COT CDF e SDF 001,002,003,004 versus ORBI FOR CDF e SDF 001,002, 003, 004.

7.2.17 Resultados das medições de Índice de fidelidade (Rf) e índice de Gamut dos objetos de ensaios MINOTAURO COT CDF e SDF 001, 002, 003, 004 e MINOTAURO FOR CDF e SDF 001, 002, 003, 004

7.3 Registro fotográfico e análise visual dos objetos de ensaios.

CAPÍTULO 8 CONSIDERAÇÕES FINAIS E CONCLUSÕES.

Considerações finais.

Principais conclusões

REFERÊNCIAS BIBLIOGRÁFICAS

ANEXO 1 


\section{INTRODUÇÃO}

\subsection{Justificativas e contexto}

A arquitetura é uma ciência e uma arte que sintetiza diversos parâmetros. Cabe ao arquiteto interpretar as necessidades do homem dentro do ambiente construído, formado por elementos objetivos e subjetivos, criando valores técnicos que resultam no espaço sensorial e perceptivo como forma, função, cor, ventilação, temperatura ambiental, iluminação e sonoridade, sendo que cada um deles forma o espaço dimensionado, entrando no inconsciente, formando o contexto ambiental (OKAMOTO, 2002).

A iluminação artificial faz parte do ambiente construído, mas nota-se, ainda hoje, uma dissociação dela com a arquitetura; e talvez isso ocorra pelo desconhecimento técnico dos arquitetos e do mercado da principal tecnologia, o LED 1 .

É natural que isso ocorra, uma vez que estamos lidando com uma mudança tecnológica que exige uma transformação de pensamento e de vivência dos arquitetos, instaladores e usuários.

A transformação gerada por esta nova tecnologia pode ser comparada à que ocorreu após o surgimento da lâmpada incandescente, inventada por Thomas Edison em 1879. Segundo Moreira (2015) alguns especialistas do setor afirmam que todos os outros tipos de lâmpadas como halógenas, fluorescentes compactas e tubulares, a vapor metálico, de sódio e mercúrio, nascidas após a incandescente, serviram apenas como escada e ponte para o LED.

Segundo Kraftmakher (2015) e Soares (2018), a iluminação em estado sólido² avançou significativamente na última década $e$, principalmente, no âmbito da eficiência energética com eficácia acima de 200 Im/W, com nítida economia de energia, menor custo total de propriedade ${ }^{3}$, melhor desempenho de iluminação e, em especial, com uma queda significativa nos preços dos componentes que compõem a

\footnotetext{
${ }^{1} \mathrm{O}$ diodo emissor de luz (sigla LED, em inglês: Light-Emitting Diode).

2 Iluminação em estado sólido (sigla SSL, em inglês Solid State Lighting).

${ }^{3}$ É o cálculo geral de todos os custos que envolvem a aquisição de um serviço ou produto.
} 
luminária LED. Assim sendo, se comparadas ao início de sua utilização, luminárias e lâmpadas do tipo LED estão cada vez mais presentes nas instalações e, inevitavelmente, temos a necessidade de conhecer um pouco mais suas especificidades técnicas qualitativas, quantitativas e de consumo energético.

"Com a ajuda da luz, um dos instrumentos mais poderosos, é possível dar vida aos espaços internos" L. C. Kalff (1971)

O Departamento de Energia dos Estados Unidos ${ }^{4}$ (U.S. Department of Energy - DOE), em recente análise do mercado global (2017), constatou que o crescimento tecnológico da iluminação LED tem sido impressionante e pode ser ainda maior por meio de pesquisa e desenvolvimento contínuo ( $P$ \& D).

De acordo com uma recente pesquisa publicada pela Strategies Unlimited (2017), considerando um universo composto por lâmpadas, luminárias e serviços, as luminárias convencionais ocupavam $51 \%$ do mercado global em 2010, diminuindo para $41 \%$ em 2014, com projeção de $11 \%$ para 2020. As luminárias LED, ao contrário, ocupavam apenas 5\% do mercado, passaram a ocupar 15\% em 2014, com projeção de $45 \%$ para 2020.

O aumento dos preços da eletricidade e o desejo de independência energética, estão fazendo com que o mercado global de iluminação se mova para fontes de luz energeticamente mais eficientes. O DOE afirma que a aceitação pelo consumidor da tecnologia LED foi aprimorada pelas melhorias na qualidade da luz e reduções rápidas de preços.

Mas, talvez, um dos aspectos mais importantes da tecnologia de iluminação LED seja o fato de apresentar algumas propriedades marcantes, que abrem uma vasta gama de novos parâmetros, anteriormente impossíveis de serem alcançados pelas fontes tradicionais. Nesse sentido, temos especificamente o controle espectral e as combinações de diferentes LEDs, que criam a capacidade de projetar luminárias

\footnotetext{
${ }^{4}$ Departamento de Energia dos Estados Unidos (DOE) - É um departamento do governo dos Estados Unidos da América responsável pela política de energia e segurança nuclear.
} 
com distintos espectros de radiação, permitindo a entrega do espectro correto de luz para cada aplicação, oferecem a facilidade de controlar a intensidade da luz por meio de fontes eletrônicas chaveadas, sistemas analógicos ou protocolos digitais, bem como a possibilidade de controle e a distribuição óptica, em função das reduzidas dimensões da fonte e a natureza direcional, que permite ser controlada com pequenas ópticas de custo relativamente baixo, selecionando os efeitos de luz desejados de acordo com as intenções de projeto, da atmosfera pretendida e o impacto que a arquitetura deve provocar no observador por meio da iluminação (Departamento de Energia dos Estados Unidos - DOE , 2017).

Podemos dizer que os LEDs são o coração dos produtos de iluminação SSL. Eles oferecem vida útil longa, que dura muito além de 50.000 horas de operação, muito mais do que a maioria das fontes de luz convencionais. O fim da vida útil de todas as tecnologias de iluminação é sinalizado pela perda de luz, mas isso pode ser menos evidente para luminárias LED, nas quais a saída de luz pode diminuir gradativamente, ou a cor pode mudar lentamente, a ponto de esses eventos constituírem falhas práticas (Departamento de Energia dos Estados Unidos - DOE , 2017).

Quando as lâmpadas e luminárias integradas apareceram pela primeira vez no mercado, foi assumido que a depreciação do lúmen do LED poderia ser usada para estimar as características de degradação do produto de iluminação integrado. Embora a vida útil de uma fonte de LED seja um indicador importante da vida útil da luminária LED, as estimativas de vida útil devem considerar todo o sistema de luminárias, não apenas os LEDs. Falhas procedentes dos componentes eletrônicos do driver, tais como resistores, diodos ou transistores, ou deterioração dos componentes ópticos, podem ocorrer muito antes que a depreciação do lúmen do LED seja considerada como falha. Um modelo de confiabilidade do sistema que integre os mecanismos de falha nos vários subsistemas de luminárias criaria uma estimativa de vida útil muito mais precisa por parte dos fabricantes de luminárias LED.

Para enfrentar o desafio de desenvolver estimativas de vida útil precisas, o Departamento de Energia dos Estados Unidos (DOE) criou o SSL Program, formando um consórcio da indústria com a Next Generation Lighting Industry Alliance (NGLIA), e o Led Systems Reliability Consortium (LSRC). Essa associação visa coordenar 
atividades e promover melhor entendimento sobre o tema. O trabalho do LSRC, e de outras atividades de pesquisa e desenvolvimento financiadas pelo DOE SSL Program, é focado no entendimento dos vários mecanismos de degradação, a fim de permitir o desenvolvimento de novos modelos, para que a confiabilidade do sistema possa ser compreendida, modelada, prevista e comunicada com confiança.

A tecnologia LED é apontada como a melhor alternativa para garantir iluminação energeticamente mais eficiente, no curto e longo prazo, e a mais viável para a substituição das fluorescentes compactas e tubulares e, atualmente são utilizadas no setor comercial, caracterizado por intenso grau de pulverização de atividades - englobando hotéis, hospitais e clínicas, shoppings centers, supermercados e hipermercados, edifícios de escritórios, instituições de ensino, bancos, restaurantes e lojas varejistas, bancos e instituições financeiras - tendo, como consequência, um perfil de consumo de energia bastante variado. Segundo dados da Pesquisa de Posse de Equipamentos e Hábitos de Uso (Relatório Classe Comercial - Alta Tensão), ano base 2005 e publicado em 2008 pela ELETROBRÁS/ PROCEL, na distribuição dos consumidores comerciais por tipo de instalação, subgrupo de tensão e faixa de demanda, como reflexo da própria estrutura de consumidores do mercado comercial BT do Brasil, destacam-se os hotéis e motéis $(20,8 \%)$, os supermercados e hipermercados $(19,1 \%)$, os bancos $(17,2 \%)$, os hospitais e clínicas $(14,8 \%)$, as instituições de ensino $(14,0 \%)$, os edifícios de escritórios e consultórios $(8,6 \%)$, e os shopping centers $(4,1 \%)$.

O mesmo relatório apresenta os tipos de lâmpadas mais utilizadas pelos estabelecimentos comerciais, segundo as áreas existentes na instalação, sendo que nas áreas internas predomina a utilização de lâmpadas fluorescentes tubulares e fluorescentes compactas, presentes respectivamente em $72,5 \%$ e $15,8 \%$ das instalações.

As lâmpadas fluorescentes tubulares também são as mais utilizadas nas áreas externas (27,7\% dos casos), acompanhadas das lâmpadas de vapor de mercúrio e mistas, que correspondem respectivamente a 14,0\% e 13,4\% dessas áreas.

Estes dados estão defasados em função de serem referências de 15 anos atrás, mas se assumirmos que gradativamente as fontes tradicionais serão 
substituídas pela tecnologia LED, podemos projetar uma redução significativa no consumo de energia.

Segundo o Departamento de Energia dos Estados Unidos, a redução do consumo de energia desse país com a introdução de tecnologia LED será de $67 \%$ no consumo com iluminação até 2025; desta forma, acredita-se que podemos seguir passos semelhantes no Brasil.

No mercado brasileiro é possível encontrar uma variedade expressiva de produtos LED, de fontes e luminárias LED, que poderão atender a demanda média da carga de iluminação em relação à demanda máxima das instalações dentro das tipologias do setor comercial, uma vez que temos $41 \%$ da carga nas áreas de entretenimento, 35\% em supermercados e hipermercados, 34\% nas instituições de ensino superior, $18 \%$ nas instituições de ensino fundamental, $29 \%$ distribuídas entre as lojas de varejo e atacado, $18 \%$ em shopping centers, $15 \%$ em escritórios, $20 \%$ em hotéis, 13\% em hospitais e 10\% em clínicas (ELETROBRÁS/ PROCEL, 2008).

Segundo a IEA - International Energy Agency (2019), em 2018 os custos de LED continuaram a cair, as vendas de LEDs estão no caminho certo, embora seja ainda necessário um crescimento robusto e contínuo para compensar todo o investimento direcionado a tecnologia.

A projeção de um cenário de vendas global por tipo de tecnologia, apresentado pela IEA (2019) para o período de 2010-2030 mostrou que a iluminação com tecnologia LED em 2010 representava 1\%, as lâmpadas fluorescentes 35\% e outras tecnologias, tais como as incandescentes, halógenas e de descargas, representavam $65 \%$; em 2015 representava $14 \%$, as lâmpadas fluorescentes $52 \%$ e outras $34 \%$; em 2018 a tecnologia LED passou a representar 40\%, as lâmpadas fluorescentes $42 \%$ e outras 18\%. E a projeção para 2025 é de que teremos $68 \%$ de tecnologia LED, $27 \%$ de fluorescentes e $5 \%$ de outras tecnologias; a IEA acredita que, em $2030,80 \%$ da iluminação será em LED e $20 \%$ ainda será de lâmpadas fluorescentes e não teremos mais instalações com outras tecnologias.

O grande desafio desta pesquisa foi propor alguns instrumentos que pudessem contribuir para o aprofundamento do conhecimento e do comportamento da tecnologia LED aplicada em luminárias, em função de uma avaliação do mercado de iluminação e do interesse da autora em sistemas ópticos, que teve início em sua pesquisa de 
mestrado com o título "Eficiência dos conjuntos ópticos de alumínio especular de alto desempenho energético", e que avaliou a eficiência dos conjuntos ópticos de alumínio especular de alto desempenho de lâmpadas fluorescentes tubulares T5 (BIGONI, 2013).

A tecnologia SSL, em função das suas propriedades especiais de necessitar um maior direcionamento de luz em relação às fontes tradicionais, transferindo para os sistemas ópticos uma tarefa importante na composição final da fotometria das luminárias, torna necessária a avaliação e aprofundamento do comportamento dos atuais componentes ópticos disponibilizados no mercado brasileiro.

Os fatores climáticos são de extrema relevância para este estudo, uma vez que atuam de forma intrínseca na natureza; a ação simultânea das variáveis climáticas terá influência direta sobre o ambiente construído que, por sua vez, terá influência sobre a tecnologia LED. O sistema climático e a noção de clima passam a ter um caráter mais específico, havendo diversidade nas suas definições conforme a área de conhecimento que se destina o estudo, impedindo uma única definição do termo. Desta forma, surge o conceito climatologia aplicada, destinada aos mais variados setores da atividade humana e que avalia dois conceitos fundamentais e os fatores climáticos, que são parâmetros fixos e que dão origem as variações dos elementos meteorológicos, que por sua vez, determinam os parâmetros mensuráveis, cujas variações definem o clima (LAMBERTS, DUTRA, PEREIRA, 1997).

Toda essa transformação e avanço tecnológico implicam em estudos mais específicos em relação aos prováveis fatores ambientais e climáticos, que podem influenciar e danificar os sistemas de iluminação LED inseridos nas edificações, uma vez que fatores climáticos diretos delimitaram o estudo em temperatura do ar e umidade relativa do ar e fatores indiretos tais como, radiação solar, pressão atmosférica, latitude, altitude, ventos, e outras possíveis ações de agentes agressivos presentes no meio ambiente, como poluentes atmosféricos, aerossol salino, chuva ácida, etc.

Para obtenção dos objetivos da tese e de seleção dos espaços para as experimentações, é importante citar outro parâmetro. Sabemos que os sistemas artificiais para resfriamento ou aquecimento são indispensáveis nas edificações 
comerciais atuais, sendo os modelos individuais de parede e/ou "split" os mais utilizados. Entretanto, pelo fato deles controlarem simultaneamente a temperatura, a umidade, a pureza e a distribuição do ar, definiu-se que para garantir resultados conclusivos do comportamento dos LEDs, os ambientes não fariam uso da climatização pois, ainda que, segundo Lamberts, Dutra, Pereira (1997), o clima interno em edifícios não condicionados reaja mais largamente à variação do clima externo, a intenção na escolha de ambientes não climatizados foi o de criar situações críticas para análise.

\subsection{Objetivos}

O principal objetivo desta pesquisa foi elaborar uma metodologia de avaliação do comportamento das luminárias LED em instalações comerciais no mercado nacional e de suas interferências ambientais internas e externas, conforme condições climáticas e aspectos meteorológicos, aplicadas nas cidades de Cotia/SP e de Fortaleza/CE em períodos de 6.000 horas a 12.000 horas.

Para atingir os objetivos, foram escolhidos protótipos representativos do mercado, que auxiliaram a identificação da influência de condições ambientais no comportamento das luminárias instaladas em duas áreas experimentais. Além disso, também foram consideradas a projeção da manutenção de fluxo luminoso, da temperatura de cor correlata, IRC e Ra, e das coordenadas de cromaticidade " $x, y$ ", conforme normas, recomendações e ensaios em laboratório.

Outro objetivo da pesquisa foi verificar se a temperatura ambiente e a umidade relativa do ar, em conjunto com a presença de sais marinhos, podem ser elementos de degradação do sistema óptico das luminárias LED em instalações litorâneas.

\subsection{Objeto}

Entende-se o objeto desta pesquisa como objetos de ensaios, denominados conforme Fluxograma 1. 


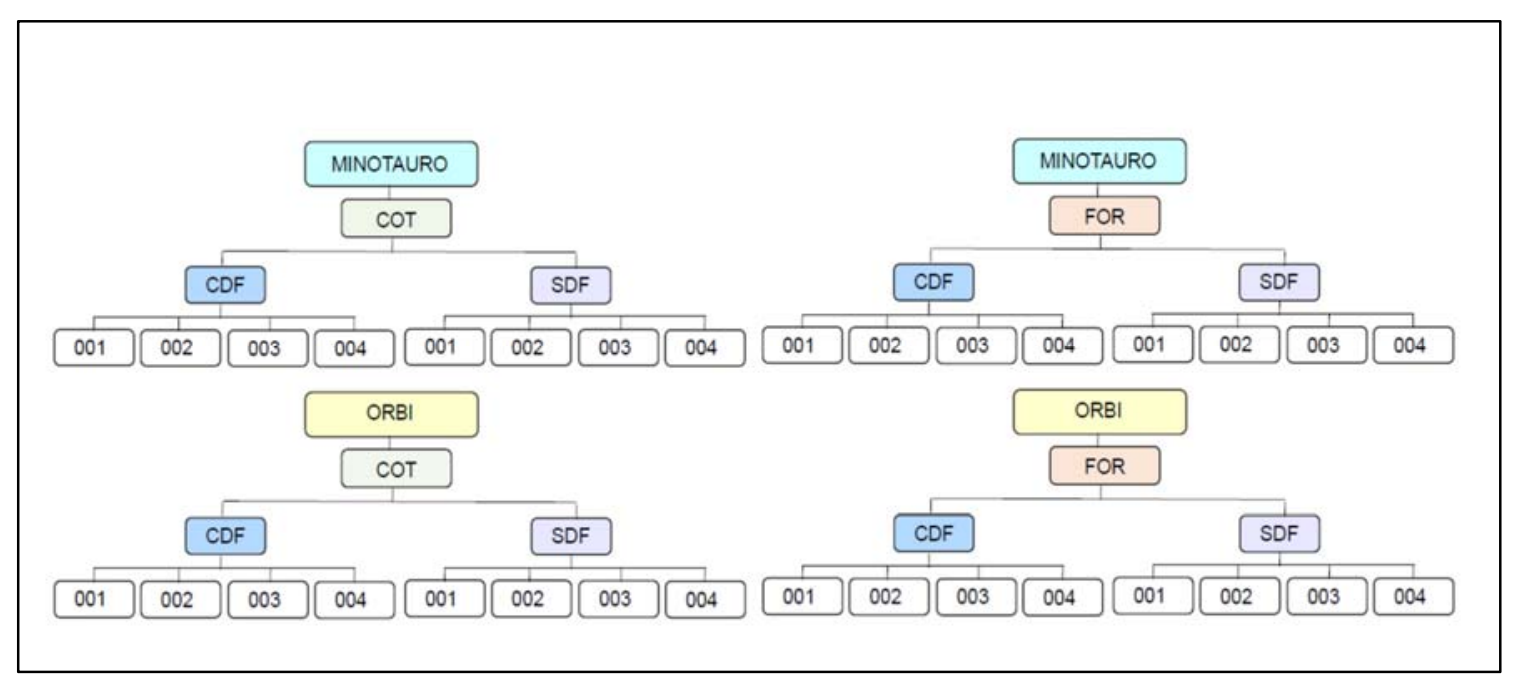

Fonte: a autora, 2019.

\subsection{Hipóteses}

Direcionam o estudo as seguintes hipóteses da pesquisa:

$\rightarrow$ As características atmosféricas ambientais alteram as propriedades fotométricas e colorimétricas das luminárias LED;

$\rightarrow$ As lentes terciárias inseridas nas luminárias LED têm importante função óptica, e de proteção ao elemento emissor de luz;

$\rightarrow$ A oxidação causada pelo aerossol marinho e umidade relativa do ar pode ser diminuída pela inserção de lentes terciárias nas luminárias LED.

\subsection{Estrutura da tese}

O primeiro capítulo apresenta considerações sobre o contexto em que o trabalho se insere, as motivações e justificativas que levaram à escolha do tema, objeto, objetivos e as hipóteses levantadas.

O segundo capítulo indica a metodologia adotada, os procedimentos, métodos de ensaios, prazos para a execução dos experimentos, levantamentos de dados 
primários e dados secundários, com a determinação dos materiais adotados para realização dos ensaios e locais das experimentações.

O terceiro capítulo apresenta os aspectos normativos da ABNT- Associação Brasileira de Normas Técnicas, orientação e procedimentos recomendados pelo IES - Illuminating Engineering Society e fontes de referências da CIE - International Commission on Illumination.

São apresentadas, no capítulo quatro, as principais propriedades dos componentes e tecnologias aplicadas em luminárias LED, a saber: o emissor de luz, as ópticas secundárias e terciárias, os dissipadores térmicos e os controladores eletrônicos, entre outros. Contextualizam-se também neste capítulo, as informações atualizadas do mercado mundial e nacional, a evolução e a viabilização técnica nos materiais semicondutores e nos encapsulamentos, os principais fabricantes e atuação no Brasil, durabilidade, eficiência energética, condições de operação e demais elementos que garantem o desempenho e a qualidade da luminária.

O capítulo cinco apresenta as principais propriedades e grandezas fotométricas e colorimétricas para compreensão da metodologia apresentada e sua contribuição para análise dos dados finais, tais como radiação, distribuição espectral, diagramas de cores CIE (color space), consistência da cor, índice de reprodução de cor, avaliação da cor, temperatura de cor correlata, iluminância mantida, luminância, fluxo luminoso e intensidade luminosa.

O capítulo seis descreve uma visão introdutória sucinta das características das ciências atmosféricas e principais influências no Brasil, e a importância dos fatores climáticos e meteorológicos.

As medições realizadas em laboratório, as análises dos resultados e o levantamento fotográfico dos objetos de ensaios são apresentados no capítulo sete.

O conteúdo do capítulo oito apresenta as considerações finais e conclusões do trabalho, busca respostas às argumentações iniciais, principais conclusões, validação ou contestação das hipóteses apresentadas, contribuição da tese e desdobramentos da pesquisa.

O capítulo nove apresenta a bibliografia referenciada ao longo da pesquisa e a bibliografia consultada, que fez parte da leitura para embasamento da pesquisa, mas não foi referenciada. 
$\mathrm{O}$ anexo 1 exibe as planilhas com as medições e variações dos experimentos extraídas dos relatórios do laboratório e os levantamentos fotográficos das instalações de Cotia/SP e Fortaleza/CE. 


\section{MÉTODOS E MATERIAIS}

\subsection{Considerações preliminares}

Observamos, nos últimos anos, um rápido desenvolvimento da tecnologia LED e sua significativa penetração no mercado em muitas aplicações, como iluminação arquitetural e pública, automotiva e semafórica, horticultura, medicinal, entre outras. Novos processos e novos materiais foram introduzidos, novas tecnologias de driver, controle e detecção foram integrados, observamos a evolução e o desenvolvimento de ópticas aplicadas para direcionamento da luz emitida, novos padrões e métodos de teste foram criados e, também, foram apresentadas novas descobertas na área de confiabilidade do sistema LED. Mas, ainda assim, temos muito a pesquisar, ensaiar e analisar em relação aos componentes críticos inseridos em luminárias LED e todos os elementos que podem degradar ou alterar o seu comportamento.

Os procedimentos metodológicos para essa tese tiveram início com um amplo levantamento de dados secundários, seguido de um levantamento de dados primários, por meio de experimentações e medições para a determinação de indicadores de manutenção de fluxo luminoso, alteração espectral, reprodução de cor, e consistência de cor de luminárias LED aplicadas no setor comercial ${ }^{5} \mathrm{e}$, consequentemente, de uma série de conclusões de resultados, como demonstrado na Figura 2.

Não são de interesse deste estudo o comportamento dos sistemas eletrônicos, controle térmicos, conectores e carcaças das luminárias, considerando que são componentes indiretos da luminária.

\footnotetext{
${ }^{5}$ Setor comercial: abrange uma série de subsetores, como o de comércio de bens, financeiro, escritórios, turismo e hotelaria, educação e lazer, entre outros. Fonte. BEN - Balanço Energético Nacional.
} 
Figura 2: Fluxograma da pesquisa

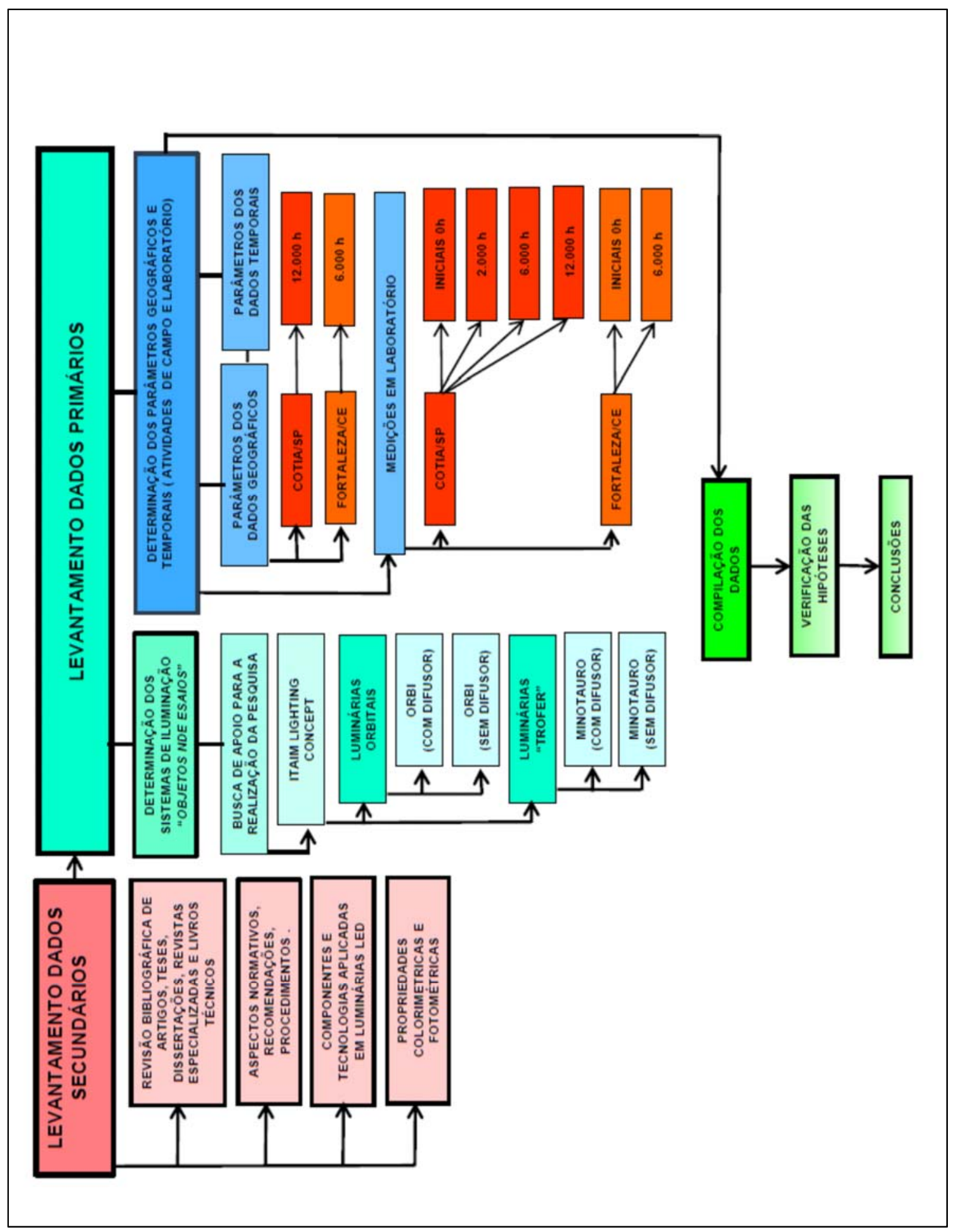

Fonte: a autora, 2019. 


\subsection{Dados secundários}

Esta pesquisa foi realizada por meio de revisão bibliográfica em teses, dissertações, artigos científicos, legislações específicas, normas técnicas, recomendações e outras publicações relacionadas ao tema, componentes aplicados em luminárias em estado sólido, parâmetros técnicos e mercadológicos, processos industriais empregados, critérios quantitativos e qualitativos de desempenho da iluminação, análise dos fatores climáticos e meteorológicos das propriedades físicas, químicas e dinâmicas da atmosfera e seus efeitos diretos sobre os ambientes construídos.

A título de exemplificação, algumas das normas técnicas que embasaram e foram adotadas nesta pesquisa:

- ABNT IEC/TS 62504:2013 - Termos e definições para LED e os módulos de LED de iluminação geral;

- ABNT NBR ISO 62031:2013 - Módulos de LED para iluminação em geral Especificações de segurança;

- ABNT NBR IEC 62722-2-1:2016 - Desempenho de luminárias - Parte 2-1: Requisitos particulares para luminárias LED;

- CIE 224-17 - Colour Fidelity Index for accurate scientific use;

- IES TM-21-11 - Projecting Long Term Lumen Maintenance of LED Light Sources;

- IES TM-28-14 - Projecting Long-Term Luminous Flux Maintenance of LED Lamps and Luminaries;

- IES TM-30-18 - Method for Evaluating Light Source Color Rendition;

- IES LM-79-19 - Optical and Electrical Measurements of Solid-State Lighting Products;

- IES LM-80-18 - Measuring Lumen Maintenance Of LED Light Source;

- IES LM-84-14 - Measuring Luminous Flux and Color Maintenance of LED Lamps, Light Engines, and Luminaires. 


\subsection{Levantamento de dados primários}

Foram considerados como dados primários a determinação dos sistemas de iluminação, denominados de objetos de ensaios, assim como a definição dos parâmetros geográficos, temporais e de laboratório para a obtenção do desempenho fotométrico e colorimétrico dos sistemas. A identificação, codificação, quantidade de amostragens, intervalos e duração dos experimentos das luminárias de testes fazem parte dos dados primários.

\subsubsection{Determinação dos sistemas de iluminação}

Com o avanço do LED no mercado mundial tivemos uma considerável mudança na forma de escolher as luminárias, pois a tecnologia passou a proporcionar vários benefícios, como a baixa emissão de calor, o baixo consumo de energia, a não emissão de radiação ultravioleta (UV) e infravermelha (IR), luz direcionada e emitida diretamente na área esperada, longa vida, baixíssima emissão de $\mathrm{CO}_{2}{ }^{7}$ versus fontes convencionais, e não conter mercúrio nem materiais pesados no seu processo produtivo. Entretanto, para conhecer profundamente a complexidade de projeto do LED temos muito ainda a percorrer, uma vez que alguns cuidados são necessários para a garantia do desempenho e vida útil da luminária.

Segundo Scopacasa (2017), os principais componentes que fazem parte de uma luminária LED são o diodo emissor de luz, a óptica secundária, a óptica terciária, o controlador eletrônico - também chamado de driver ou fonte alimentadora -, o dissipador térmico e o conector.

Para execução deste trabalho foram ensaiadas luminárias completas, sendo que, para efeito de avaliação do comportamento e desempenho dos sistemas, somente parte dos componentes foram considerados como fatores diretos da pesquisa, tendo sido selecionados o emissor de luz LED, individual ou em arranjo, e

\footnotetext{
${ }^{7} \mathrm{O}$ dióxido de carbono é um composto químico constituído por dois átomos de oxigénio e um átomo de carbono.
} 
a óptica secundária, considerando a lente colimadora ou refletor, e a óptica terciária, por meio de difusor frontal.

Os demais elementos foram considerados como indiretos, sendo estes o driver, o dissipador, o conector e a carcaça das luminárias.

A Figura 3 representa os componentes da luminária LED.

Figura 3: Componentes da luminária LED

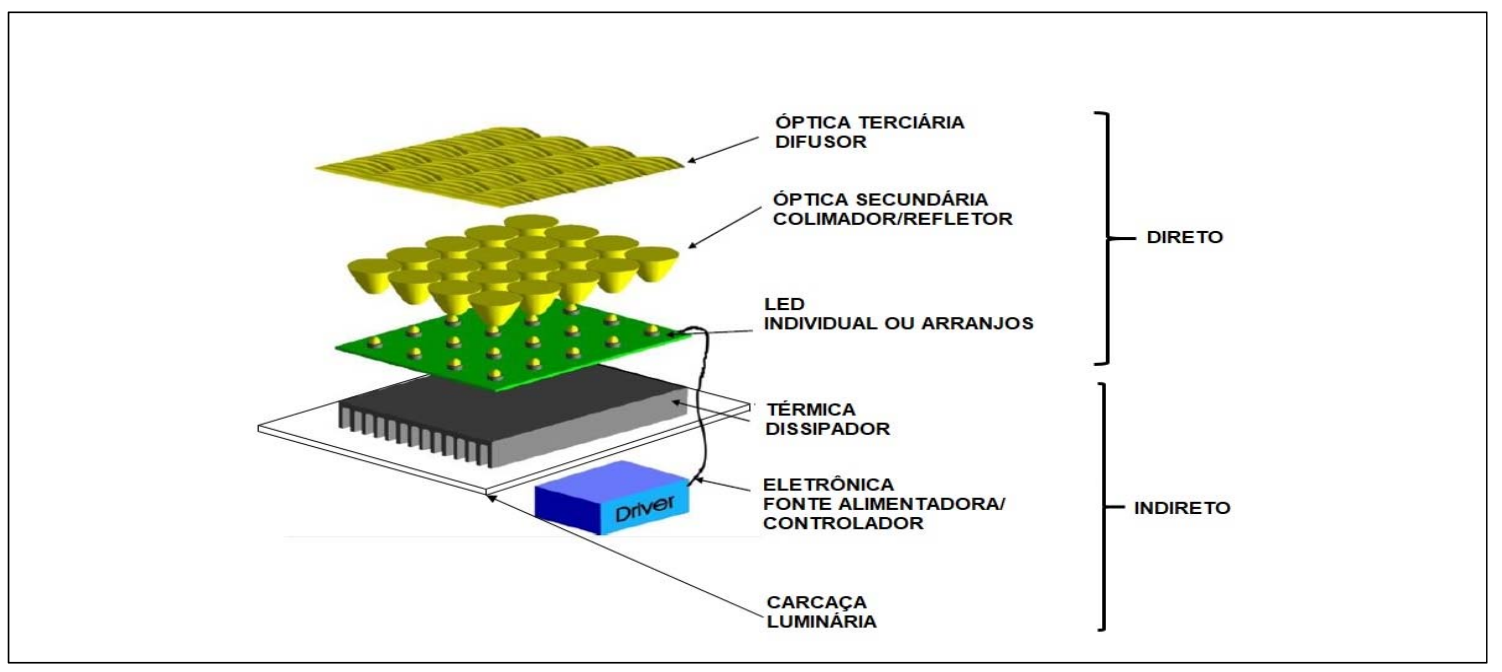

Fonte: Scopacasa, 2017, adaptado pela autora, 2020.

\subsubsection{Componentes diretos e indiretos}

$\rightarrow$ LED $^{8}$ - Diodo emissor de luz de alta potência individualmente fabricado ou montado em placas de circuito impresso de núcleo metálico e inserido em luminárias do mercado (direto);

$\rightarrow$ Óptica secundária - Colimadores moldados e injetados em plástico, refletores em policarbonato com superfície refletora metalizada, ou refletor em alumínio

${ }^{8}$ LED: Conforme ABNT IEC/TS 62504: 2013, o LED é um dispositivo de estado sólido que contém uma junção p-n, que permite radiação óptica quando excitado por uma corrente elétrica. Essa definição é independente da existência de invólucro (s) e de terminais. 
anodizado. As ópticas servem para favorecer o direcionamento do facho luminoso (direto);

$\rightarrow$ Óptica terciária - Difusor produzido em plástico, projetado para controle, difusão e distribuição da luz do LED (direto);

$\rightarrow$ Eletrônica - Driver ou fonte alimentadora, que é um dispositivo de controle de luz que harmoniza as tensões padronizadas da rede de corrente alternada (127 e 220 V) ou outras tensões em corrente contínua conforme, necessária para funcionamento do LED. É um circuito eletrônico para o funcionamento e controle do LED (indireto);

$\rightarrow$ Térmica - Segundo Mello (1980), o controle térmico por meio de dissipador, permite que o diodo dissipe o calor emitido e tenha a temperatura de junção mais baixa que a máxima permissível (indireto);

$\rightarrow$ Carcaça - Os componentes mecânicos que fazem parte do envoltório, a estrutura geral da luminária e os componentes mecânicos para fixar a luminária; normalmente o corpo é produzido em chapa de aço, ou alumínio, com pintura eletrostática (indireto).

\subsubsection{Determinação dos objetos de ensaios}

As luminárias exclusivas para LED são chamadas pelo DOE (2013) de "recessed and surface-mounted dedicated LED troffers" e são responsáveis por mais de $50 \%$ das luminárias instaladas em edifícios de escritórios, consultórios e instituições financeiras, e os modelos do tipo downlight ou spot, que apresentam uma iluminação direcionada e são usadas majoritariamente para aplicações especificas no setor comercial, tiveram um grande crescimento de vendas no setor comercial de varejo.

A Figura 4 apresenta a receita global de luminárias LED.

Figura 4: Receita global de luminárias LEDs 


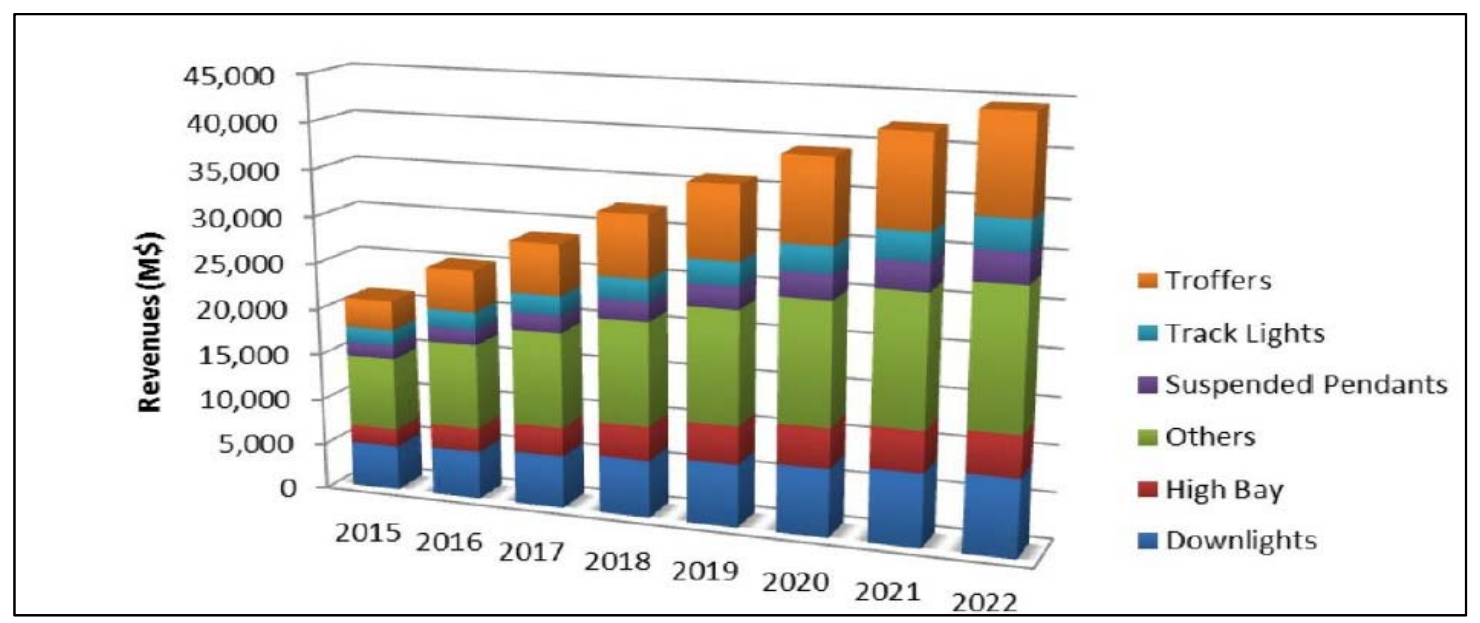

Fonte: SSL - Suggested Research Topics Supplement: Technology and Market Context, 2017.

Adotou-se que o mercado brasileiro seguirá, gradativamente, os passos do mercado norte-americano e europeu, haja visto que as taxas de adoção da tecnologia aumentam drasticamente ano após ano e em função do histórico das tecnologias passadas (NAKAMURA, 2010). Optou-se por quatro tipologias de luminárias para os experimentos.

A escolha das luminárias e busca de apoio para a realização da pesquisa deram-se, também, por meio de uma análise do mercado especificador e da representatividade entre os projetistas de iluminação, arquitetos, especificadores, instaladoras, construtoras, atacadistas e revendas de materiais elétricos.

Os modelos foram escolhidos por serem produzidos, em média e grande escala, por diversos fabricantes conhecidos no mercado nacional, aplicados em instalações bancárias, instituições de ensino, escritórios, lojas e redes de departamento, shoppings centers e hotéis, entre outros.

A empresa Itaim Lighting Concept aceitou participar da pesquisa, doando todos os conjuntos de iluminação e gentilmente cedendo seu laboratório e técnicos para as medições e ensaios fotométricos, elétricos e colorimétricos. O apoio da Itaim LC foi de extrema importância, uma vez que atua há mais de 50 anos no mercado de iluminação, e é reconhecida por produzir soluções e produtos inovadores e por possuir um laboratório muito bem equipado. 
A empresa Lucchi Ltda doou os trilhos eletrificados trifásicos modelos ONETRACK ${ }^{\circledR}$ e os adaptadores com 4 condutores, da empresa italiana A.A.G.Stucchi. s.r.l. u.s. para a conexão elétrica de parte dos objetos de ensaios, em função da necessidade de acoplar e desacoplar facilmente as luminárias spots.

Segue detalhamento dos objetos de ensaios utilizados para a realização da pesquisa, considerando-se as informações em fichas técnicas fornecidas pela Itaim Lighting Concept:

a) Luminária tipo "troffer" quadrada - modelo MINOTAURO com difusor;

b) Luminária tipo "troffer" retangular - modelo MINOTAURO com difusor;

c) Luminária tipo "troffer" quadrada - modelo MINOTAURO com refletor e sem difusor;

d) Luminária tipo "troffer" retangular - modelo MINOTAURO com refletor e sem difusor;

e) Luminária tipo "spot" - modelo ORBI com difusor;

f) Luminária tipo "spot" - modelo ORBI sem difusor.

As características técnicas dos objetos de ensaios, são apresentadas: 
a) Luminária tipo "troffer" quadrada - modelo MINOTAURO com difusor, apresentada na Figura 5;

Figura 5: Dados do objeto de ensaio quadrada MINOTAURO com difusor.

\begin{tabular}{|c|c|}
\hline & $\begin{array}{l}\text { Instalação - Luminária quadrada de } \\
\text { embutir em modulado de perfil 'T' de } \\
\text { aba } 25 \mathrm{~mm} \\
\text { Corpo - Chapa de aço tratada com } \\
\text { acabamento em pintura eletrostática na } \\
\text { cor branca } \\
\text { Difusor - Com difusor frontal em } \\
\text { poliestireno (PS) translúcido } \\
\text { Aba - Chapa de aço tratada com } \\
\text { acabamento em pintura eletrostática na } \\
\text { cor branca } \\
\text { Classe Elétrica: I } \\
\text { Grau de proteção: IP20 }\end{array}$ \\
\hline Código interno & MINOTAURO \\
\hline Prefixos & $\begin{array}{l}\text { COT CDF } 001 \text { / COT CDF 002/ COT } \\
\text { CDF } 003 \text { / COT CDF } 004\end{array}$ \\
\hline Descrição da fonte luminosa & 4 barras de LED $(500 \mathrm{~mm} \times 10 \mathrm{~mm})$ \\
\hline Fabricante & Itaim LC \\
\hline Potência total (W) & 32 \\
\hline Fluxo luminoso (Im) & 3.580 \\
\hline Intensidade luminosa (cd) & 1.350 \\
\hline Temperatura de cor $(\mathrm{K})$ & 4.000 \\
\hline Ângulo de abertura & $110^{\circ}$ \\
\hline IRC & $\geq 80$ \\
\hline Descrição do driver & LCS $-700-31 \mathrm{~W}$ \\
\hline Fabricante & Philips \\
\hline Tensão de alimentação do driver (V) & 220 \\
\hline Corrente de saída do driver $(\mathrm{A})$ & 700 \\
\hline Dimensões & Comp.618 mm; Larg.618; Alt 110 mm \\
\hline Nicho & $605 \mathrm{~mm} \times 605 \mathrm{~mm}$ \\
\hline Modulação & $625 \mathrm{~mm} \times 625 \mathrm{~mm}$ \\
\hline
\end{tabular}

Fonte: Itaim Lighting Concept, 2019. 
Luminária tipo "troffer "retangular - modelo MINOTAURO com difusor, apresentada na Figura 6;

Figura 6: Dados do objeto de ensaio retangular MINOTAURO com difusor.

\begin{tabular}{|c|c|}
\hline & $\begin{array}{l}\text { Instalação - Luminária retangular de } \\
\text { embutir em modulado de perfil 'T' de } \\
\text { aba } 25 \mathrm{~mm} \\
\text { Corpo - Chapa de aço tratada com } \\
\text { acabamento em pintura eletrostática na } \\
\text { cor branca } \\
\text { Difusor - Com difusor frontal em } \\
\text { poliestireno (PS) translúcido } \\
\text { Aba - Chapa de aço tratada com } \\
\text { acabamento em pintura eletrostática na } \\
\text { cor branca } \\
\text { Classe Elétrica: I } \\
\text { Grau de proteção: IP20 }\end{array}$ \\
\hline Código interno & MINOTAURO \\
\hline Prefixos & $\begin{array}{l}\text { FOR CDF } 001 \text { / FOR CDF 002/ FOR } \\
\text { CDF } 003 \text { / FOR CDF } 004\end{array}$ \\
\hline Descrição da fonte luminosa & 2 barras de LED (1200mm x 10mm) \\
\hline Fabricante & Itaim LC \\
\hline Potência total (W) & 32 \\
\hline Fluxo luminoso (Im) & 3.527 \\
\hline Intensidade luminosa (cd) & 1.800 \\
\hline Temperatura de cor $(\mathrm{K})$ & 4.000 \\
\hline Ângulo de abertura & $100^{\circ}$ \\
\hline $\mathrm{IRC}$ & $\geq 80$ \\
\hline Descrição do driver & Element LD30/220-240/700 \\
\hline Fabricante & Osram \\
\hline Tensão de alimentação do driver (V) & 220 \\
\hline Corrente de saída do driver (A) & 700 \\
\hline Dimensões & Comp.1.243 mm; Larg.210; Alt 90 mm \\
\hline Nicho & $195 \mathrm{~mm} \times 1.225 \mathrm{~mm}$ \\
\hline Modulação & $220 \mathrm{~mm} \times 1.250 \mathrm{~mm}$ \\
\hline
\end{tabular}

Fonte: Itaim Lighting Concept, 2019. 
b) Luminária tipo "troffer "quadrada - modelo MINOTAURO com refletor e sem difusor, apresentada na Figura 7;

Figura 7: Dados do objeto de ensaio quadrada MINOTAURO com refletor e sem difusor.

\begin{tabular}{|c|c|}
\hline & $\begin{array}{l}\text { Instalação - Luminária quadrada de } \\
\text { embutir em modulado de perfil ' } T \text { ' de } \\
\text { aba } 25 \mathrm{~mm} \\
\text { Corpo - Chapa de aço tratada com } \\
\text { acabamento em pintura eletrostática na } \\
\text { cor branca } \\
\text { Refletor - Parabólico em alumínio } \\
\text { especular } \\
\text { Difusor - Sem difusor frontal } \\
\text { Aba - Chapa de aço tratada com } \\
\text { acabamento em pintura eletrostática na } \\
\text { cor branca } \\
\text { Classe Elétrica: I } \\
\text { Grau de proteção: IP20 }\end{array}$ \\
\hline Código interno & MINOTAURO \\
\hline Prefixo & $\begin{array}{l}\text { COT SDF } 001 \text { /COT SDF } 002 \text { / } \\
\text { COT SDF } 003 \text { / COT SDF } 004\end{array}$ \\
\hline Descrição da fonte luminosa & 4 barras de LED $(500 \mathrm{~mm} \times 10 \mathrm{~mm})$ \\
\hline Fabricante & Itaim LC \\
\hline Potência total (W) & 32 \\
\hline Fluxo luminoso (Im) & 3.580 \\
\hline Intensidade luminosa (cd) & 1.858 \\
\hline Temperatura de cor (K) & 4.000 \\
\hline Ângulo de abertura & 70 \\
\hline IRC & $\geq 80$ \\
\hline Descrição do driver & LCS $-700-31 \mathrm{~W}$ \\
\hline Fabricante & Philips \\
\hline Tensão de alimentação do driver (V) & 220 \\
\hline Corrente de saída do driver (A) & 700 \\
\hline Dimensões & Comp.618 mm; Larg.618; Alt 110 mm \\
\hline Nicho & $605 \mathrm{~mm} \times 605 \mathrm{~mm}$ \\
\hline Modulação & $625 \mathrm{~mm} \times 625 \mathrm{~mm}$ \\
\hline
\end{tabular}

Fonte: Itaim Lighting Concept, 2020. 
c) Luminária tipo "troffer "retangular - modelo MINOTAURO com refletor e sem difusor, apresentada na Figura 8;

Figura 8: Dados do objeto de ensaio retangular MINOTAURO com refletor e sem difusor.

\begin{tabular}{|c|c|}
\hline & $\begin{array}{l}\text { Instalação - Luminária retangular de } \\
\text { embutir em modulado de perfil 'T' de } \\
\text { aba } 25 \mathrm{~mm} \\
\text { Corpo - Chapa de aço tratada com } \\
\text { acabamento em pintura eletrostática na } \\
\text { cor branca } \\
\text { Refletor - Parabólico em alumínio } \\
\text { especular } \\
\text { Difusor - Sem difusor frontal } \\
\text { Aba - Chapa de aço tratada com } \\
\text { acabamento em pintura eletrostática na } \\
\text { cor branca } \\
\text { Classe Elétrica: I } \\
\text { Grau de proteção: IP20 }\end{array}$ \\
\hline Código interno & MINOTAURO \\
\hline Prefixo & $\begin{array}{l}\text { FOR SDF } 001 \text { /FOR SDF } 002 \text { / } \\
\text { FOR SDF } 003 \text { / FOR SDF } 004\end{array}$ \\
\hline Descrição da fonte luminosa & 2 barras de LED $(1200 \mathrm{~mm} \times 10 \mathrm{~mm})$ \\
\hline Fabricante & Itaim LC \\
\hline Potência total (W) & 32 \\
\hline Fluxo luminoso $(\mathrm{Im})$ & 3.520 \\
\hline Intensidade luminosa $(\mathrm{cd})$ & 1.780 \\
\hline Temperatura de cor (K) & 4.000 \\
\hline Ângulo de abertura & 100 \\
\hline IRC & $\geq 80$ \\
\hline Descrição do driver & Element LD30/220-240/700 \\
\hline Fabricante & Osram \\
\hline Tensão de alimentação do driver (V) & 220 \\
\hline Corrente de saída do driver (A) & 700 \\
\hline Dimensões & Comp.1.243 mm; Larg.203; Alt $90 \mathrm{~mm}$ \\
\hline Nicho & $180 \mathrm{~mm} \times 1.230 \mathrm{~mm}$ \\
\hline Modulação & $212 \mathrm{~mm} \times 1.250 \mathrm{~mm}$ \\
\hline
\end{tabular}

Fonte: Itaim Lighting Concept, 2020. 
d) Luminária tipo "spot" - modelo ORBI com difusor, apresentada na Figura 9;

Figura 9: Dados do objeto de ensaio ORBI com difusor.

\begin{tabular}{|c|c|}
\hline $\begin{array}{l}\text { Nota: Não faz parte da luminária comercial } \\
\text { ORBI da Itaim Lighting Concept o difusor } \\
\text { frontal. Para este experimento foi solicitado a } \\
\text { inserção do difuor em poliestireno com } \\
\text { espessura de } 1,5 \mathrm{~mm} \text { para análise do } \\
\text { comportamento do objeto de ensaio. }\end{array}$ & $\begin{array}{l}\text { Instalação - Luminária tipo spot para } \\
\text { fixação em trilho eletrificado de } 3 \text { circuitos } \\
\text { Corpo - Chapa de aço com acabamento } \\
\text { em pintura eletrostática na cor branca ou } \\
\text { preta } \\
\text { Foco - Alumínio com acabamento em } \\
\text { pintura eletrostática na cor preta } \\
\text { Refletor - Alumínio anodizado } \\
\text { multifacetado } \\
\text { Difusor - Com difusor frontal em } \\
\text { poliestireno (PS) } \\
\text { Alojamento - Polímero injetado na cor } \\
\text { branca ou preta } \\
\text { Classe Elétrica - III } \\
\text { Direcionamento da Luz - Foco orbital } \\
\text { (giro } 360^{\circ} \text { ) } \\
\text { Tilt - 90 } \\
\text { Grau de Proteção - IP20 }\end{array}$ \\
\hline Código interno & ORBI-TR M \\
\hline Prefixo & $\begin{array}{l}\text { COT CDF } 001 \text { / COT CDF } 002 \text { /COT CDF } \\
003 \text { / COT CDF } 004 \text { / FOR CDF } 001 \text { / FOR } \\
\text { CDF } 002 \text { /FOR CDF } 003 \text { / FOR CDF } 004\end{array}$ \\
\hline Descrição da fonte luminosa & COB LED \\
\hline Fabricante & Itaim LC \\
\hline Potência total $(\mathrm{W})$ & $19 \mathrm{~W}$ \\
\hline Fluxo luminoso (Im) & 1.313 \\
\hline Intensidade luminosa (cd) & $600 \mathrm{~d}$ \\
\hline Temperatura de cor $(\mathrm{K})$ & 3.000 \\
\hline Ângulo de abertura & $100^{\circ}$ \\
\hline IRC & $\geq 80$ \\
\hline Descrição do driver & Q7H-500mA-22W \\
\hline Fabricante & Itaim \\
\hline Tensão de alimentação do driver (V) & $220 \mathrm{~V}$ \\
\hline Corrente de saída do driver (A) & 0,091 \\
\hline Dimensões & Diâmetro 86 mm Comp.96 mm \\
\hline
\end{tabular}

Fonte: Itaim Lighting Concept, 2020. 
f) Luminária tipo "spot" - modelo ORBI sem difusor, apresentada na Figura 10.

Figura 10: Dados do objeto de ensaio ORBI sem difusor.

\begin{tabular}{|c|c|}
\hline & $\begin{array}{l}\text { Instalação - Luminária tipo spot para } \\
\text { fixação em trilho eletrificado de } 3 \text { circuitos } \\
\text { Corpo - Chapa de aço com acabamento } \\
\text { em pintura eletrostática na cor branca ou } \\
\text { preta } \\
\text { Foco - Alumínio com acabamento em } \\
\text { pintura eletrostática na cor preta } \\
\text { Refletor - Alumínio anodizado } \\
\text { multifacetado } \\
\text { Difusor - Sem difusor frontal } \\
\text { Alojamento - Polímero injetado na cor } \\
\text { branca ou preta } \\
\text { Classe Elétrica - III } \\
\text { Direcionamento da Luz - Foco orbital } \\
\text { (giro } 360^{\circ} \text { ) } \\
\text { Tilt - } 90^{\circ} \\
\text { Grau de Proteção - IP20 }\end{array}$ \\
\hline Código interno & ORBI-TR M \\
\hline Prefixo & $\begin{array}{l}\text { COT SDF } 001 \text { / COT SDF } 002 \text { /COT SDF } \\
003 \text { / COT SDF } 004 \text { / FOR SDF } 001 \text { / FOR } \\
\text { SDF } 002 \text { /FOR SDF } 003 \text { / FOR SDF } 004\end{array}$ \\
\hline Descrição da fonte luminosa & COB LED \\
\hline Fabricante & Itaim LC \\
\hline Potência total $(\mathrm{W})$ & $19 \mathrm{~W}$ \\
\hline Fluxo luminoso (Im) & 1.839 \\
\hline Intensidade luminosa (cd) & 2.050 \\
\hline Temperatura de cor $(\mathrm{K})$ & 3.000 \\
\hline Ângulo de abertura & $60^{\circ}$ \\
\hline IRC & $\geq 80$ \\
\hline Descrição do driver & Driver Element LD 20/220-240-500 \\
\hline Fabricante & Osram \\
\hline Tensão de alimentação do driver (V) & $220 \mathrm{~V}$ \\
\hline Corrente de saída do driver $(A)$ & 0,098 \\
\hline Dimensões & Diâmetro 86 mm Comp.96 mm \\
\hline
\end{tabular}

Fonte: Itaim Lighting Concept, 2020. 


\subsection{Levantamento dos parâmetros dos dados geográficos}

Para a experimentação foi fundamental a determinação das instalações e do tempo necessário para a obtenção dos dados da pesquisa.

Para a inserção dos objetos de ensaios foram adotadas duas localidades, ou campos de provas, ambas edificações comerciais e sem climatização, com características ambientais distintas. A determinação das localidades buscou as condições ideais e alguns indicadores, conforme características atmosféricas, como: tipo climático e classificação do clima, temperatura do ar, umidade relativa do ar, altitude, latitude e longitude.

\subsubsection{Local dos experimentos e posicionamento dos objetos de ensaios}

\section{1) Cotia/SP}

O local do primeiro experimento foi definido pela escolha de uma área no primeiro pavimento do Centro de Distribuição da Lucchi, empresa de componentes para indústria de iluminação, localizado no Parque Industrial San José - Rua Santa Mônica 1.414, na cidade de Cotia/SP.

Sua área é de $352 \mathrm{~m}^{2}(22,00 \mathrm{~m} \times 16,00 \mathrm{~m})$ com pé-direito de $2,73 \mathrm{~m}$.

O espaço não é atualmente utilizado pela empresa e, portanto, houve total liberdade para dispor os objetos de ensaios na área mais central do salão.

A altura de instalação das luminárias foi 2,60m, sendo que parte dos objetos de ensaios, modelos MINOTAURO, foram instalados no forro modular, composto de placas de fibra mineral de modulação quadrada $0,625 \mathrm{~m} \times 0,625 \mathrm{~m}$ e estruturadas em perfis metálicos, e os modelos ORBI foram instalados por meio de adaptadores específicos, em um trilho eletrificado trifásico de $3 \mathrm{~m}$, sendo esse parafusado na estrutura do forro modular.

O ambiente não é climatizado.

A Figura 11 mostra a fachada da empresa LUCCHI na cidade de Cotia/SP. A fachada principal fica posicionada a noroeste, e a edificação está dentro de um condomínio industrial localizado a menos de $2 \mathrm{~km}$ da Rodovia Raposo Tavares. 
Figura 11: Fachada Lucchi - Local do experimento Cotia /SP.

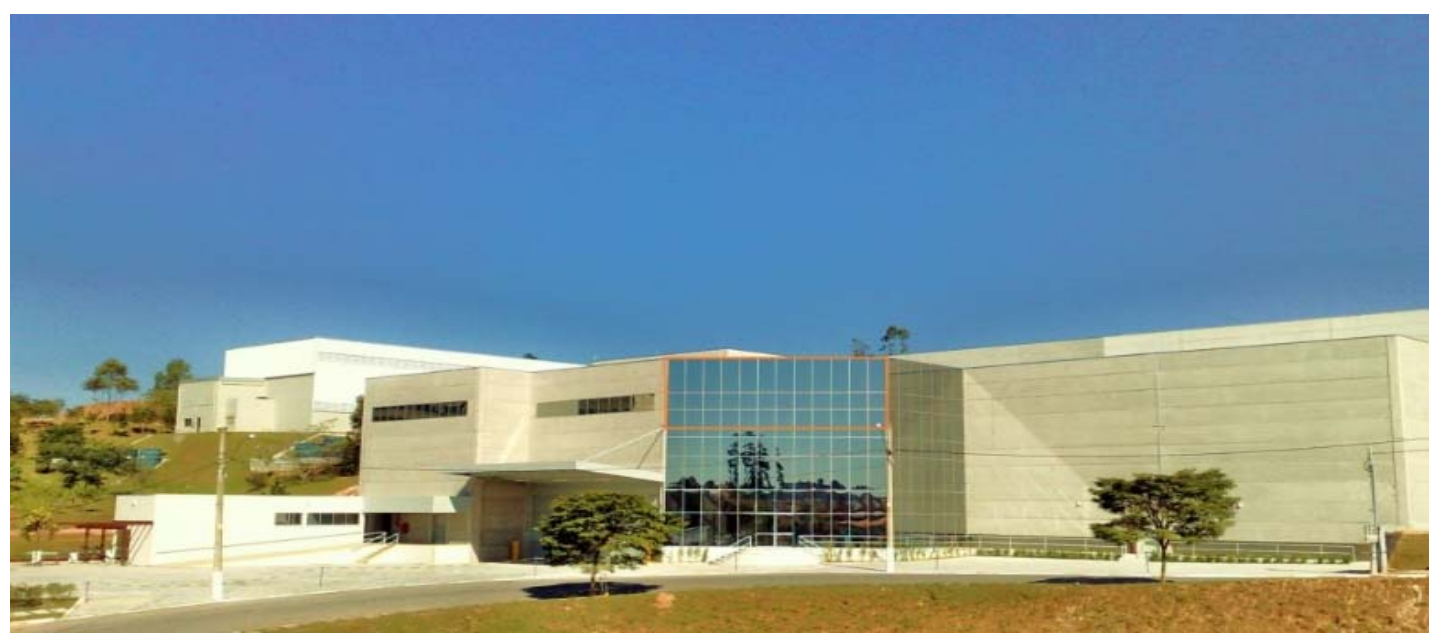

Fonte: Lucchi, 2013.

A configuração de layout das luminárias na área de experimento é apresentada na Figura 12.

Figura 12: Layout da área do experimento Cotia/SP.

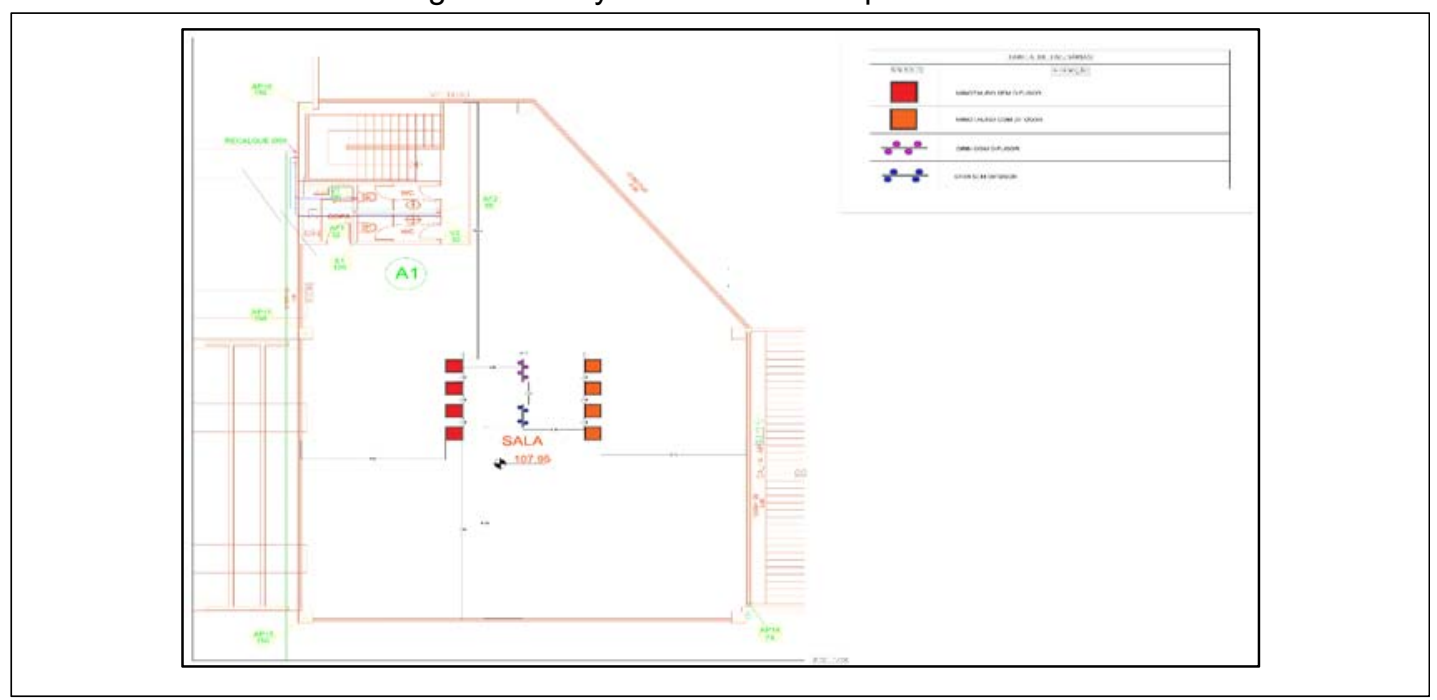

Fonte: WeLight, e a autora 2020.

Sobre o acabamento da sala: piso em cor cinza claro, duas paredes brancas, uma parede envidraçada em sua total extensão (fachada) e outra voltada para a parte interna do Centro de Distribuição, com meia parede em alvenaria e meia com 
esquadria de vidro. Atualmente o espaço está sem uso e não contém mobiliário, conforme pode ser visto nas Figuras 13 e 14.

Figura 13: Vista para a parte interna do CD de Cotia/SP.

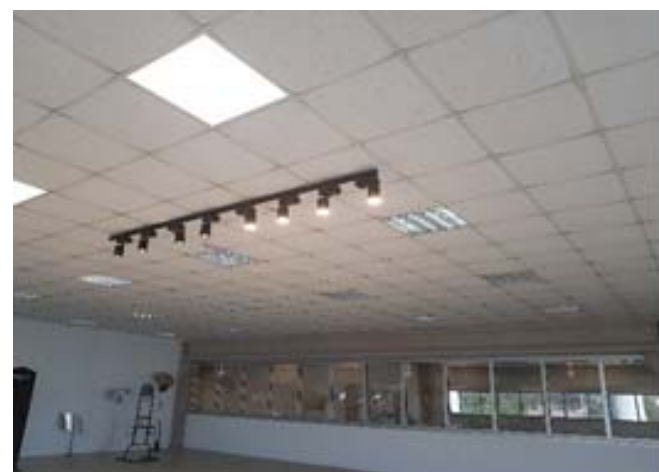

Fonte: a autora, 2019.
Figura 14: Vista interna da fachada do CD de Cotia /SP.

A Figura 15 mostra os objetos de ensaios instalados e um tripé montado centralmente, com altura de 0,75m, e um data logger (Hobo U12-012) - anexado por meio de velcro - para as medições de temperatura e umidade do ar.

Figura 15: Objetos de ensaios e tripé com data logger HOBO U12-012 - Cotia/SP.

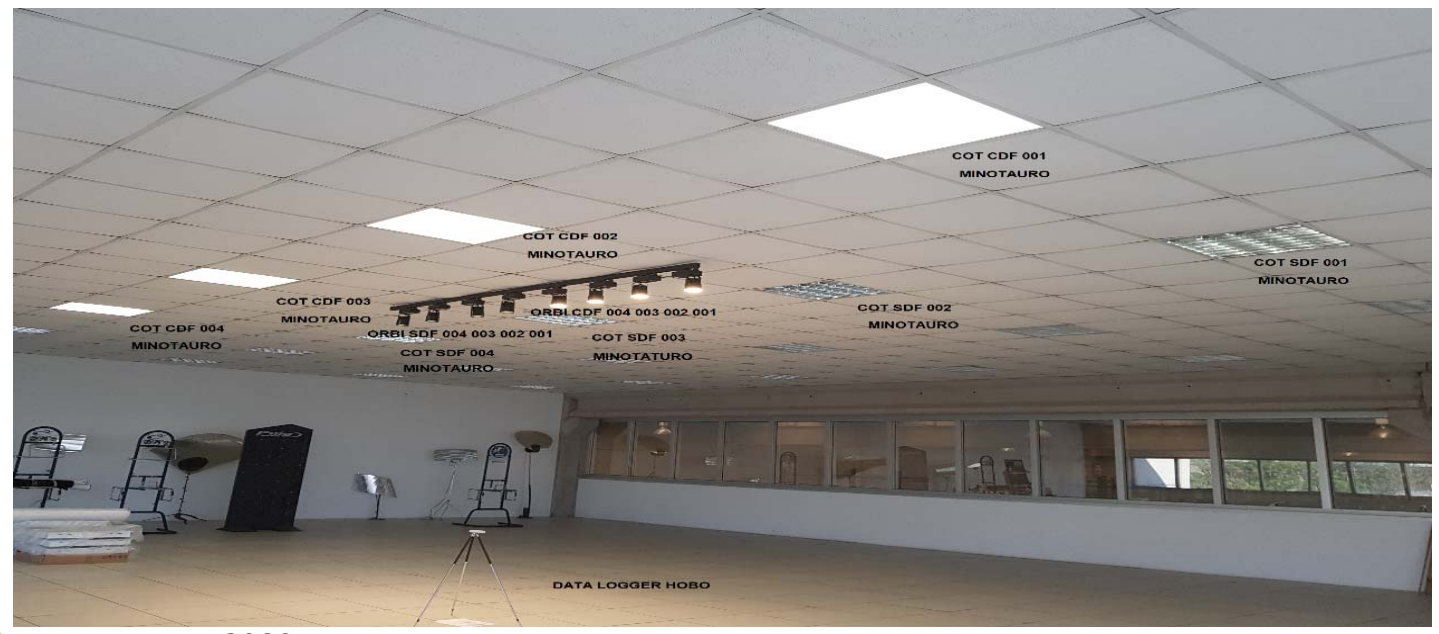

Fonte: a autora, 2020

As informações armazenadas pelo data logger seguiram os períodos definidos nos parâmetros temporais, apresentados na Tabela 1 para a localidade de Cotia/SP. 
Tabela 1: Períodos de medições do data logger Cotia/SP

\begin{tabular}{|l|c|c|}
\hline Períodos & Média temperatura do ar & Média Umidade do ar \\
\hline $06 / 11 / 2017$ a $29 / 01 / 2018$ & $28^{\circ} \mathrm{C}$ & $56,72 \%$ \\
\hline $13 / 03 / 2018$ a $29 / 08 / 2018$ & $22^{\circ} \mathrm{C}$ & $56,53 \%$ \\
\hline $30 / 01 / 2019$ a $10 / 10 / 2019$ & $27^{\circ} \mathrm{C}$ & $58,63 \%$ \\
\hline Valores médios & $25,6^{\circ} \mathrm{C}$ & $57,29 \%$ \\
\hline
\end{tabular}

Fonte: a autora, 2020.

A disposição das luminárias não seguiu a norma NBR-ISO/CIE 8995-1: lluminação em ambientes de trabalho Parte 1, pois não foram considerados os valores de iluminâncias do ambiente para os experimentos. As informações de iluminâncias geradas pelo equipamento Hobo U12-012 foram descartadas.

\section{2) Fortaleza/CE}

O segundo experimento foi realizado na cidade de Fortaleza/CE, sendo uma área de escritório desativada no $6^{\circ}$ pavimento do Centro de Hematologia e Hemoterapia FUJISAN, localizada na Av. Barão de Studart, 2626 - Dionísio Torres.

Possui área de $21,60 \mathrm{~m}^{2}(6,00 \mathrm{~m} \times 3,6 \mathrm{~m})$, pé direito de 2,87m. Trata-se, também, de ambiente não climatizado.

A altura de instalação das luminárias foi de $2,65 \mathrm{~m}$, sendo que parte dos objetos de ensaios, modelos MINOTAURO, foram instalados no forro modular, composto de placas de isopor de modulação retangular $1,25 \mathrm{~m} \times 0,625 \mathrm{~m}$, e estruturadas em perfis metálicos; os modelos ORBI foram instalados por meio de adaptadores específicos, em dois trilhos eletrificados trifásico de 1,0m cada, sendo esse parafusado na estrutura do forro modular. A Figura 16 mostra a fachada da FUJISAN. A fachada principal fica posicionada em face leste e localizada a cerca de $4 \mathrm{~km}$ da orla marítima. 
Figura 16: Fachada Fujisan - Local do experimento em Fotaleza/CE.

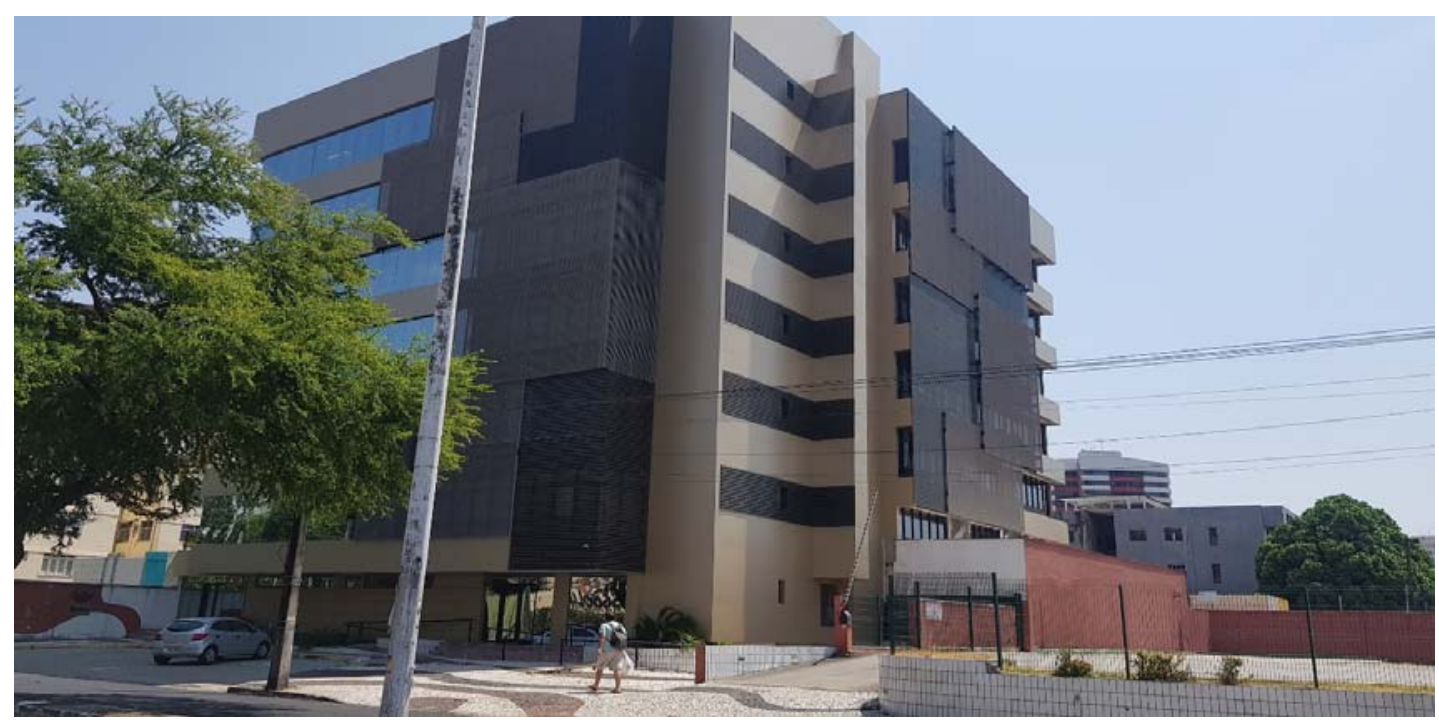

Fonte: a autora, 2019

Configuração de layout das luminárias conforme Figura 17.

Figura 17: Layout da área do experimento Fortaleza/CE

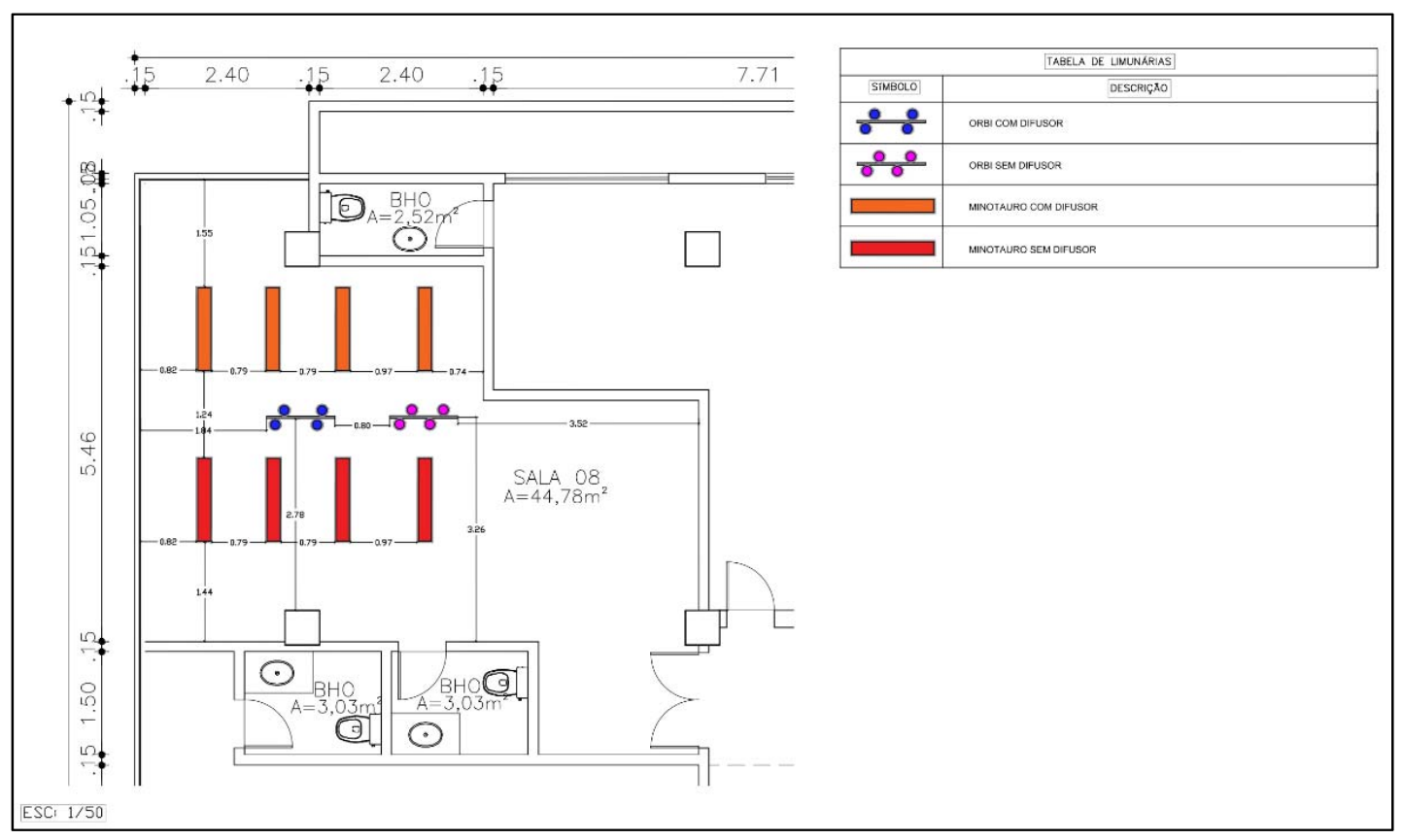

Fonte: WeLight, 2020. 
A sala 6, designada para o experimento, juntamente com toda a edificação, passou por uma revitalização de fachada e sofreu alterações. Quando se deu o início da instalação dos objetos de ensaios, em dezembro de 2018, as esquadrias da fachada eram em vidro azul e, ao longo do ano de 2019, foram retiradas as películas azuis, e substituídas por uma nova fachada em vidro transparente e ACM na cor marrom, posicionada a $0,50 \mathrm{~m}$ da fachada original.

Atualmente o espaço está sendo utilizado como depósito de equipamentos de aeromodelismo por um dos diretores. O piso tem placas de paviflex na cor bege e as paredes são brancas, mas quase todas são tomadas por prateleiras.

Figura 18: Vista interna da fachada anterior à reforma, Fortaleza/CE.

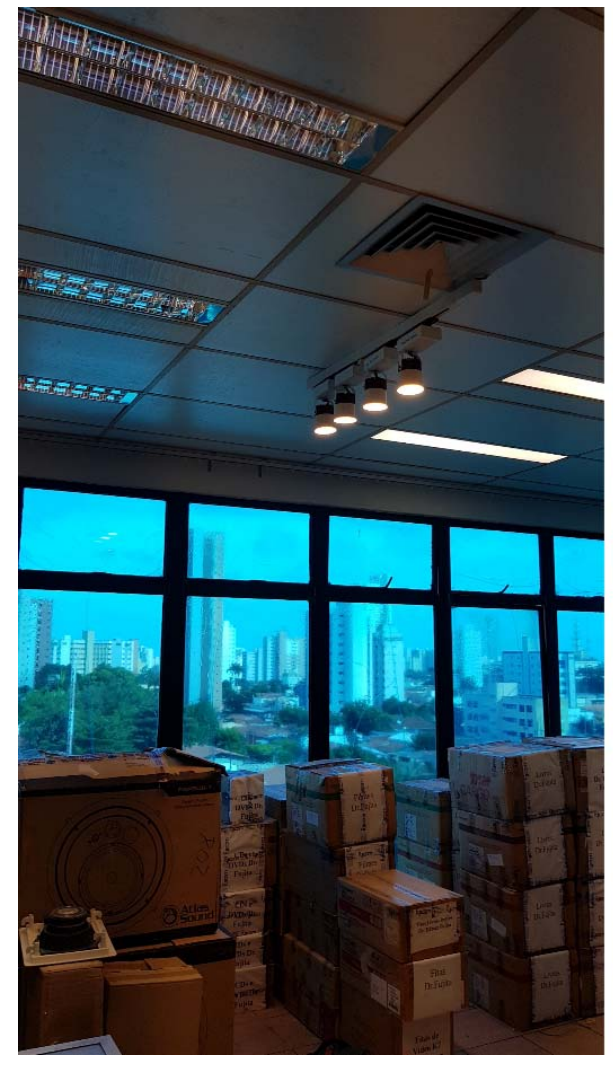

Figura 19: Vista interna da fachada posterior à reforma, Fortaleza/CE.

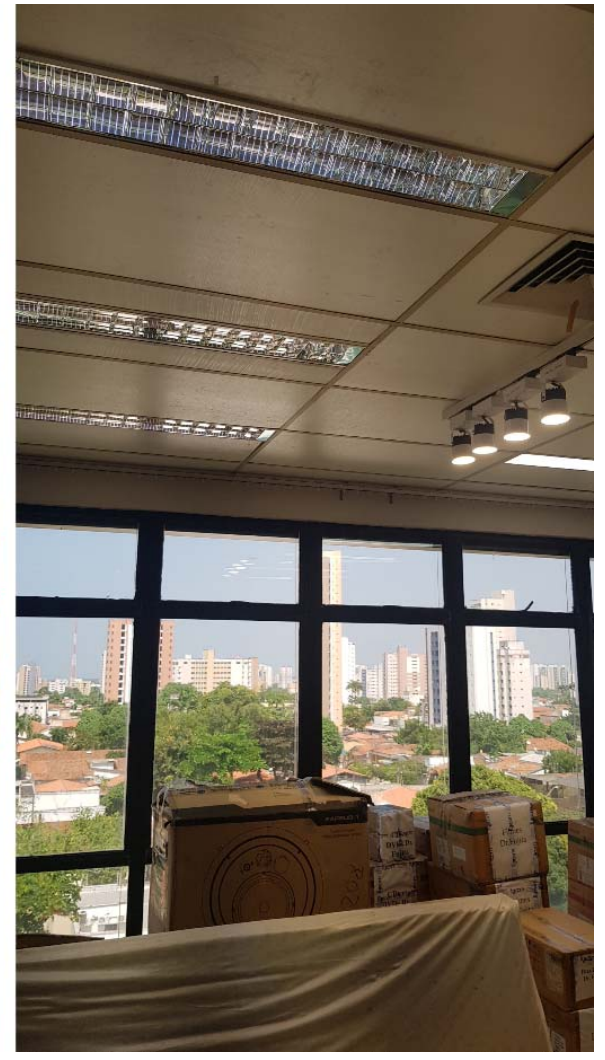

Fonte: a autora, 2019. 
A Figura 20 mostra a distribuição dos objetos de ensaios na área de experimento.

Figura 20: Objetos de ensaios, Fortaleza/CE.

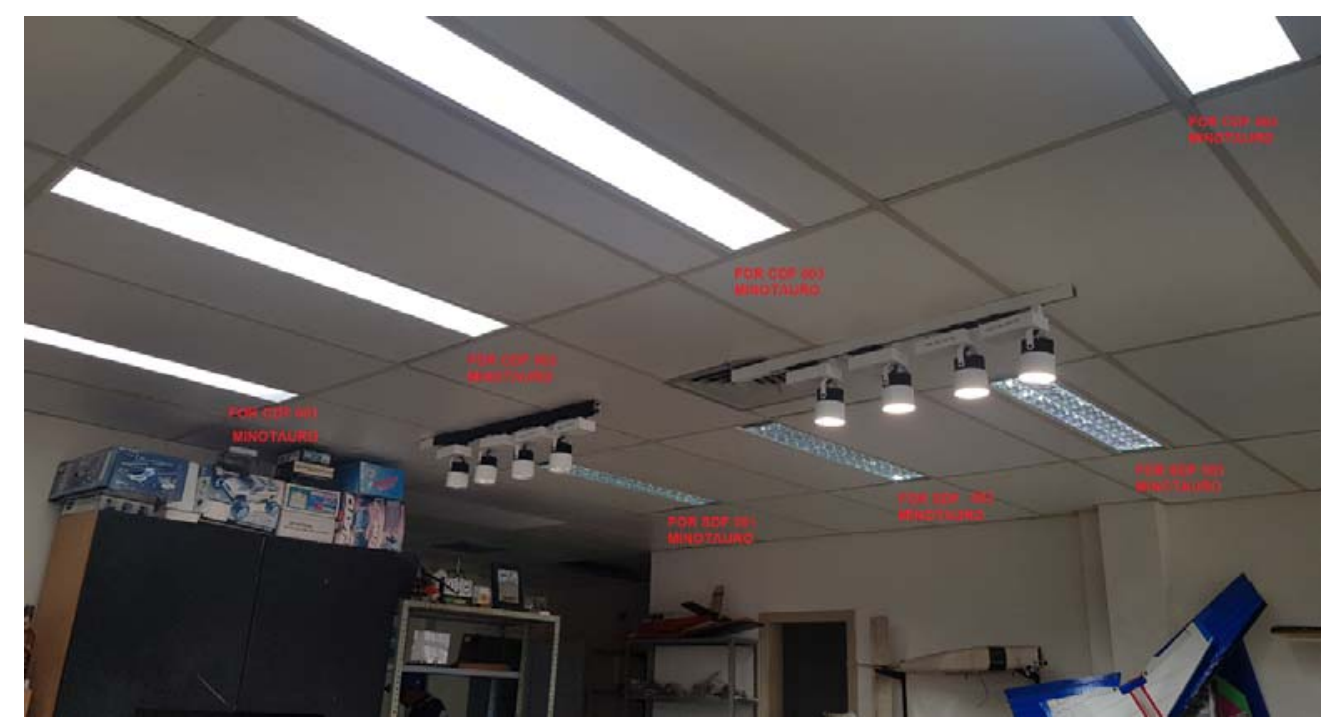

Fonte: a autora, 2019.

A Figura 21 mostra o tripé com o data logger posicionado no centro dos objetos de ensaios para as medições de temperatura e umidade do ar.

Figura 21: Objetos de ensaios e tripé com data logger Hobo U12-012.

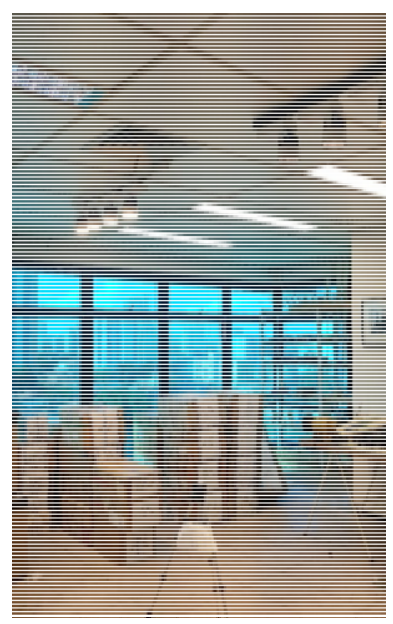

Fonte: a autora, 2019. 
As informações armazenadas pelo data logger seguiram os períodos definidos nos parâmetros temporais, e são apresentados na Tabela 2 para a localidade de Fortaleza/CE.

Tabela 2: Períodos de medições do data logger Fortaleza/CE.

\begin{tabular}{|l|c|c|}
\hline Períodos & Média temperatura do ar & Média Umidade do ar \\
\hline $05 / 12 / 2018$ a $25 / 08 / 2019$ & $30,74^{\circ} \mathrm{C}$ & $68,25 \%$ \\
\hline
\end{tabular}

Fonte: a autora, 2020

\subsubsection{Características climáticas das localidades dos experimentos e codificações adotadas}

Para as duas localidades escolhidas, a fim de facilitar a avaliação dos objetos de ensaios, foram definidos prefixos em relação às localizações e características climáticas, a saber:

1) Cotia / SP - Prefixo - COT.

- Tipo climático: clima temperado - Cfa (clima subtropical úmido)

- Temperatura máxima média/ano $-24^{\circ} \mathrm{C}^{11}$

- Temperatura média registrada pelo data logger Hobo (período de 06/11/2017 a $10 / 10 / 2019)-25,6^{\circ} \mathrm{C}$

- Umidade relativa do ar/ano - 78,4\% ${ }^{12}$

- Umidade relativa registrada pelo data logger Hobo (período de 06/11/2017 a 10/10/2019) - 57,29\%;

- Altitude - 797 metros; Latitude $-23^{\circ} 36^{\prime} 15^{\prime \prime}$ Sul; Longitude $-46^{\circ} 56^{\prime} 27^{\prime \prime}$ Oeste ${ }^{13}$

\footnotetext{
${ }^{11}$ Informações obtidas nos registros do Instituto Nacional de Meteorologia (INMET).

12 Informações obtidas nos registros do Instituto Nacional de Meteorologia (INMET).

${ }^{13}$ Informações obtidas nos registros do Instituto Nacional de Meteorologia (INMET).
} 
A Figura 22 mostra as codificações adotadas para a localidade de Cotia/SP.

Figura 22: Identificação do prefixo - Cotia/SP.

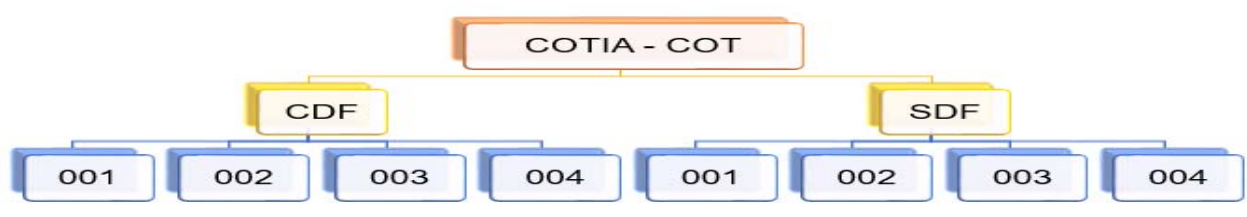

Fonte: a autora, 2019.

2) Fortaleza / CE - Prefixo - FOR

-Tipo climático: clima tropical - Aw (clima savânico)

-Temperatura máxima média/ano - $24,8^{\circ} \mathrm{C}^{14}$

-Temperatura média registrada pelo data logger Hobo (período de 05/12/2018 a

25/08/2019) $-30,74^{\circ} \mathrm{C}$

- Umidade relativa do ar/ano - 76\%.

-Umidade relativa registrada pelo data logger Hobo (período de 05/12/2018 a $25 / 08 / 2019)-68,25 \%{ }^{15}$

- Altitude - 14 metros; Latitude - 3 43' 6" Sul; Longitude - 38 32 ' $36^{\prime \prime}$ Oeste $^{16}$

A Figura 23 apresenta a identificação para a cidade de Fortaleza/CE:

\footnotetext{
14 Informação retirada dos registros do Instituto Nacional de Meteorologia (INMET).

15 Informação retirada dos registros do Instituto Nacional de Meteorologia (INMET).

16 Informação retirada dos registros do Instituto Nacional de Meteorologia (INMET).
} 
Figura 23: Identificação do prefixo - Fortaleza/CE.

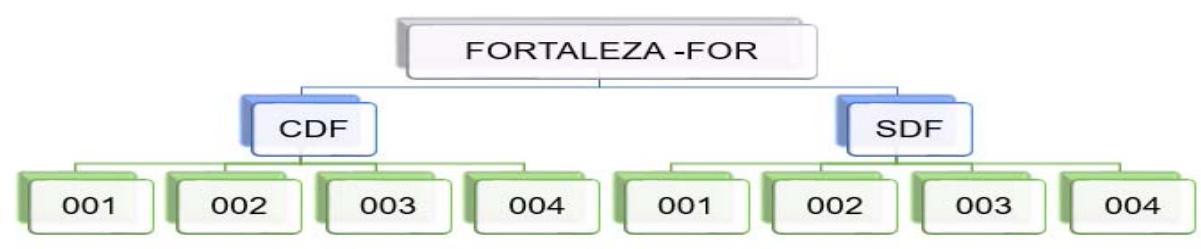

Fonte: a autora, 2019.

\subsection{Levantamento de dados temporais}

Para a determinação do período de ensaios, houve a análise criteriosa de alguns indicadores, em atendimento às recomendações dos memorandos técnicos do IES ${ }^{17}$, sendo eles TM-28-14 ${ }^{18}$ e LM-84-14 ${ }^{19}$, LM-79-19 ${ }^{20}$ e LM-80-18 ${ }^{21}$ para a indicação das perdas luminosas, depreciação das superfícies ópticas e alterações cromáticas dos objetos de ensaios, e sendo definidos os seguintes critérios e períodos:

a) Períodos de testes em campo e laboratório distintos em função da programação do laboratório, logística e distância da instalação, conforme localidade;

b) Objetos de ensaios ligados 24 horas $x 7$ dias, para cumprir os intervalos de testes e duração;

c) Testes foram subdivididos em quatro períodos para o prefixo COT - Cotia/SP, totalizando 12.120 horas; definiu-se esse período maior como possível fator para

\footnotetext{
17 Sociedade de Engenharia de lluminação

${ }^{18}$ Método que permite uma projeção de manutenção de fluxo luminoso em longo prazo para lâmpadas e luminárias com tecnologia LED.

${ }^{19}$ Método para medir fluxo luminoso e manutenção de cores de fontes de luz LED

${ }^{20}$ Medições ópticas e elétricas de produtos de iluminação de estado sólido.

${ }^{21}$ Método que analisa as alterações da cromaticidade com o tempo de uso das fontes de LED e manutenção do fluxo luminoso.
} 
falhas catastróficas ${ }^{22}$, considerando que no processo poderia ocorrer a queima de alguma amostragem:

$\rightarrow 1^{\circ}$ período - Instalação 0 hora (06/11/2017);

$\rightarrow 2^{\circ}$ período -2.016 horas (29/01/2018) - atribuído como 2.000 horas;

$\rightarrow 3^{\circ}$ período - 6.072 horas (29/08/2018) - atribuído como 6.000 horas;

$\rightarrow 4^{\circ}$ período -12.120 horas $(10 / 10 / 2019)$ - atribuído como 12.000 horas;

d) Testes subdivididos em dois períodos para o prefixo FOR - Fortaleza/CE, totalizando 6.000 horas, a saber:

$\rightarrow 1^{\circ}$ período - Instalação 0 hora (05/12/2018);

$\rightarrow \quad 2^{\circ}$ período -6.336 horas $(25 / 08 / 2019)$ - atribuído como 6.000 horas;

e) Medições efetuadas por equipamento modelo HOBO U12-012 para avaliação de temperatura e umidade relativa do ar, com intervalos de 15 minutos, sendo o equipamento colocado sobre um tripé a $0,75 \mathrm{~m}$ do piso, e fotocélula posicionada horizontalmente aos objetos de ensaios.

\subsubsection{Atividades de laboratório e campo}

Para a determinação dos ensaios e medições, definiu-se a necessidade de atender às recomendações do memorando técnico IES LM-80 -18, IES TM-28-14, IES LM-79-19, TM 30-18 25 e CIE 224-1726 para obtenção dos dados de variações de fluxo luminoso, levantamento das coordenadas de cromaticidade e consistência da cor, potência elétrica consumida, eficácia luminosa, entre outros parâmetros.

\footnotetext{
22 Falha que ocorre quando equipamento ou componente queima no período de 1.000 horas (mortalidade da fonte).

${ }^{25}$ Método para avaliar a reprodução de cores da fonte de luz.

26 Índice de fidelidade de cores para uso científico.
} 


\subsubsection{Determinação dos parâmetros fotométricos, elétricos e colorimétricos para as medições em laboratório:}

Determinação dos processos comumente utilizados na determinação das medições, a saber:

$\rightarrow$ Fluxo luminoso em lúmens;

$\rightarrow$ Intensidade luminosa em candelas (no caso das luminárias de foco);

$\rightarrow$ Eficácia;

$\rightarrow$ IRC - Índice de reprodução de cor;

$\rightarrow$ TCC/CCT - Temperatura correlata de cor;

$\rightarrow$ Coordenadas de cromaticidade x,y, conforme CIE 1931;

$\rightarrow$ Rf e Rg, conforme IES TM-30-18 e CIE 224-17.

Em atendimento à recomendação IES LM-79-19, método que descreve os procedimentos e precauções na elaboração das medidas elétricas e fotométricas de produtos SSL, os ensaios foram feitos por meio de fotometria absoluta e com o fotômetro calibrado, considerando as medições na luminária completa, uma vez que estamos lidando com possíveis efeitos térmicos, em virtude de uma tecnologia que necessita de um controlador e dissipador incorporados à luminária.

A precisão e a exatidão das medições estão diretamente ligadas à utilização de procedimentos padrão e bons equipamentos; os parâmetros elétricos foram a energia consumida por luminária, corrente elétrica na saída do driver, tensão na saída do driver e a eficácia do conjunto $(\mathrm{Im} / \mathrm{W})$.

Parte dos ensaios fotométricos e colorimétricos foram realizados por uma esfera integradora de Ulbricht ${ }^{28}$, sendo que para os experimentos de todos os objetos de ensaios MINOTAURO e ORBI instalados na cidade de Cotia/SP, com prefixos COT 002, 003 e 004, para os períodos de 0 hora, 2.016 horas e 6.072 horas, se fez uso

\footnotetext{
${ }^{28}$ Instrumento óptico capaz de medir fluxo luminoso e calibrar dispositivos que respondam ao espectro luminoso, visível ou não.
} 
deste equipamento. Para todos os modelos com prefixos COT 001 se fez uso da esfera integradora e de um goniofotômetro ${ }^{29}$ para as medições de 0 hora.

Os ensaios dos objetos de ensaios instalados na cidade de Fortaleza/CE, prefixos FOR 002, 003 e 004, foram feitos pela esfera integradora, sendo que os modelos MINOTAURO e ORBI prefixo FOR 001 foram ensaiados pelo goniofotômetro para 0 hora e 2.016 horas.

Essa decisão de ensaiar parte dos objetos de ensaios no goniofotômetro e parte na esfera integradora, partiu de um excessivo perfeccionismo que, posteriormente à compilação dos resultados de 2.016 horas, serviram para corroborar com os resultados da esfera integradora.

\subsection{Condições gerais de ensaios}

As medições foram executadas no laboratório de fotometria da empresa Itaim Lighting Concept, pelo responsável técnico Sr. Willian Izidio.

Os equipamentos utilizados em laboratório são calibrados de modo a ter rastreabilidade nas medições.

A precisão e exatidão das medições estão ligadas à utilização de procedimentos padrão e levantamento de variações de fluxo luminoso, coordenadas de cromaticidade, consistência de cor, potência consumida, eficácia luminosa, em conformidade com a recomendação da IES LM-79-08, IES LM-79-19 e TM-30-15 e TM 30-18.

Determinação dos parâmetros fotométricos e elétricos

$\rightarrow$ Fluxo luminoso em lumens;

$\rightarrow$ Intensidade luminosa em candelas (no caso das luminárias de foco);

$\rightarrow$ IRC - Índice de reprodução de cor;

$\rightarrow$ TCC/CCT - Temperatura correlata de cor;

$\rightarrow$ Coordenadas de cromaticidade "x,y", conforme CIE 1931;

$\rightarrow$ Coordenadas de cromaticidade "u',v", conforme CIE 1976;

\footnotetext{
${ }^{29}$ Equipamento para realizar medições fotométricas.
} 
$\rightarrow$ Rf e Rg conforme IES TM-30;

$\rightarrow$ Energia consumida por luminária;

$\rightarrow$ Corrente elétrica na saída do driver;

$\rightarrow$ Tensão na saída do driver;

$\rightarrow$ Levantamento da eficácia luminosa.

\subsection{Equipamentos de laboratório}

Equipamentos para estabilidade elétrica dos padrões de trabalho e utilização dos instrumentos adequados de acordo com as medições, sendo os equipamentos de medições, controles de corrente tensão, análise THD e sub-harmônicos de tensão e corrente atendem aos requisitos da IEC61000-3-2, modelo Digital Power Meter PF9811 - Everfine - Calibrado em 05/2016, apresentado na Figura 24.

Figura 24: modelo Digital Power Meter PF9811

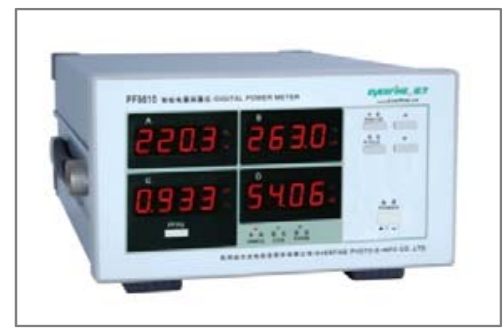

Fonte: Everfine, 2017.

Esfera Integradora, diâmetro de 2.0 metros, modelo GB/T 24824 Everfine, calibrada tipicamente uma vez por mês, utilizando lâmpada de calibração (25/11/201401/12/2014) pelo INMETRO. A Figura 25 mostra o equipamento utilizado para o levantamento de fluxos luminosos dos objetos de ensaios. 
Figura 25: Esfera integradora Everfine modelo GBT/24824.

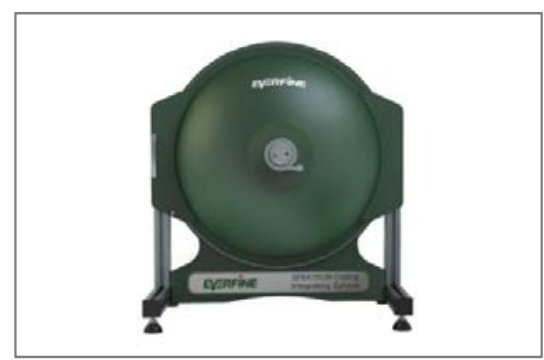

Fonte: http://www.everfine.net/productinfo.php?pid=113\&fid=19, acesso 11/02/2018.

Características da esfera integradora, a saber:

- Métodos termostáticos: ambiente, temperatura constante automática;

- Propriedade de revestimento: revestimento SpektronTM, reflectância difusa e aparece propriedades quase lambertianas (perfeitamente difusas), não tóxicas, duráveis e opticamente estáveis ao longo do tempo.w2s;

- Refletividade de revestimento: revestimento R97, revestimento R80, revestimento UV;

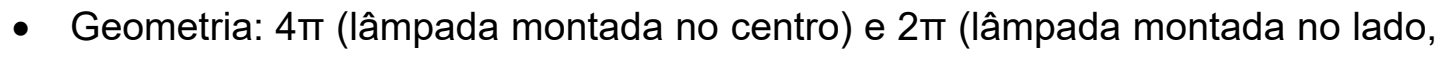
superior ou inferior);

- Goniôfotometro - ITAIM Lighting Concept;

- Software Gerenciador de Fotometria - ITAIM Lighting Concept e Everfine;

- Luxímetro: Medidor de iluminância multifuncional digital com cabeçote receptor separável (Possibilidade de medições de pontos múltiplos, de 2 a 30 pontos), modelo Konica Minolta T-10 calibrado em 31/05/2019, demonstrado na Figura 26.

Figura 26: Luxímetro Konica Minolta T-10.

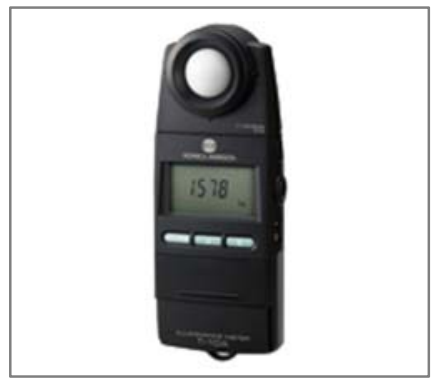

-Fonte: http://sensing.konicaminolta.com.br/products/t-10a-illuminance-meter/acesso 


\subsection{Equipamentos de campo}

Foi utilizado, para as medições de temperatura do ar e umidade relativa do ar nos locais dos experimentos na cidade de Cotia /SP e Fortaleza/CE, o data logger modelo Hobo U12-012, adquirido em setembro de 2017.0 equipamento armazena 43 mil medições e foi programado para executar o levantamento a cada 15 minutos. $\mathrm{Na}$ localidade de Cotia, foi necessária a troca da bateria e reset da memória para compilação de mais dados. O equipamento também pode medir iluminâncias, mas não foi programado para essa função, uma vez que não fazia parte do escopo desta tese. A Figura 27 mostra o equipamento Hobo U12-012.

Figura 27: Data Logger Hobo U12-012.

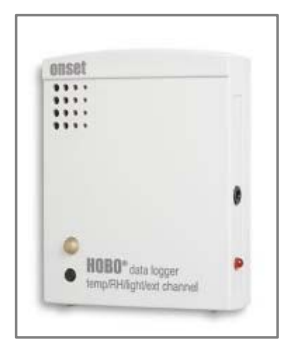

Fonte: http://www.onsetcomp.com/products/data-loggers/u12-012, acesso 12/02/2018

No gráfico 1 temos um exemplo das informações geradas pelo data logger Hobo U12-012, com as referências de temperatura ambiente e umidade relativa do ar, dentro do período de 26/12/2017 a 30/01/2018 da cidade de Cotia/SP.

Gráfico 1: Exemplo de gráfico apresentado pelo data logger Hobo U12-012.

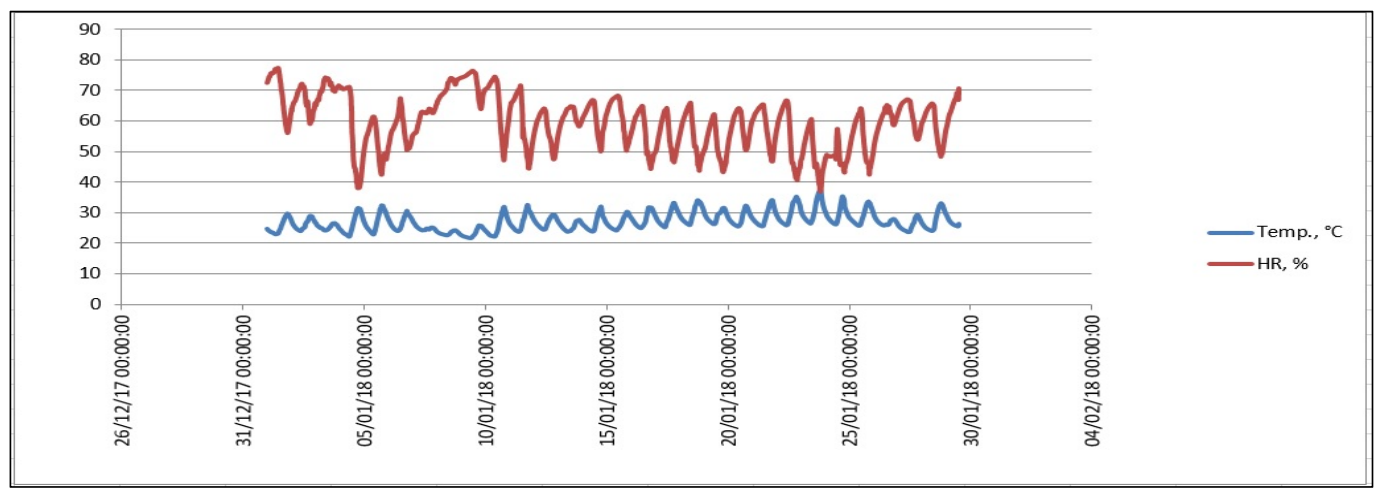

Fonte: a autora, 2018. 


\subsection{Relatório gerado em laboratório pela esfera integradora}

Figura 28: Relatório gerado pela esfera integradora com informações fotométricas, elétricas e colorimétricas.

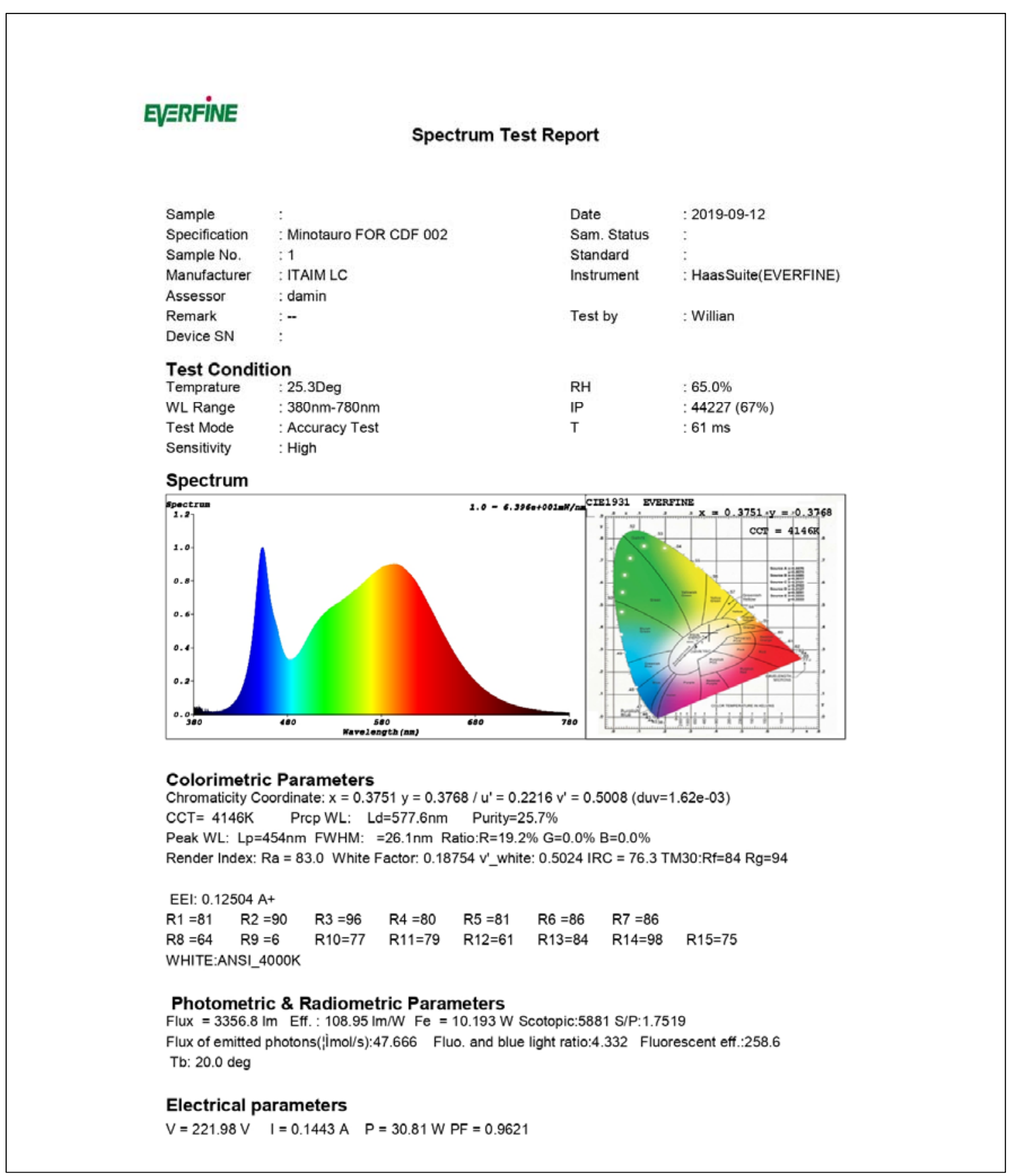

Fonte: Laboratório Itaim Lighting Concept, 2019. 
Figura 29: Relatório gerado pela esfera integradora com informações TM30

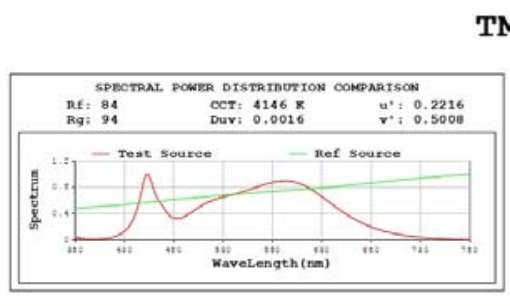

TM30
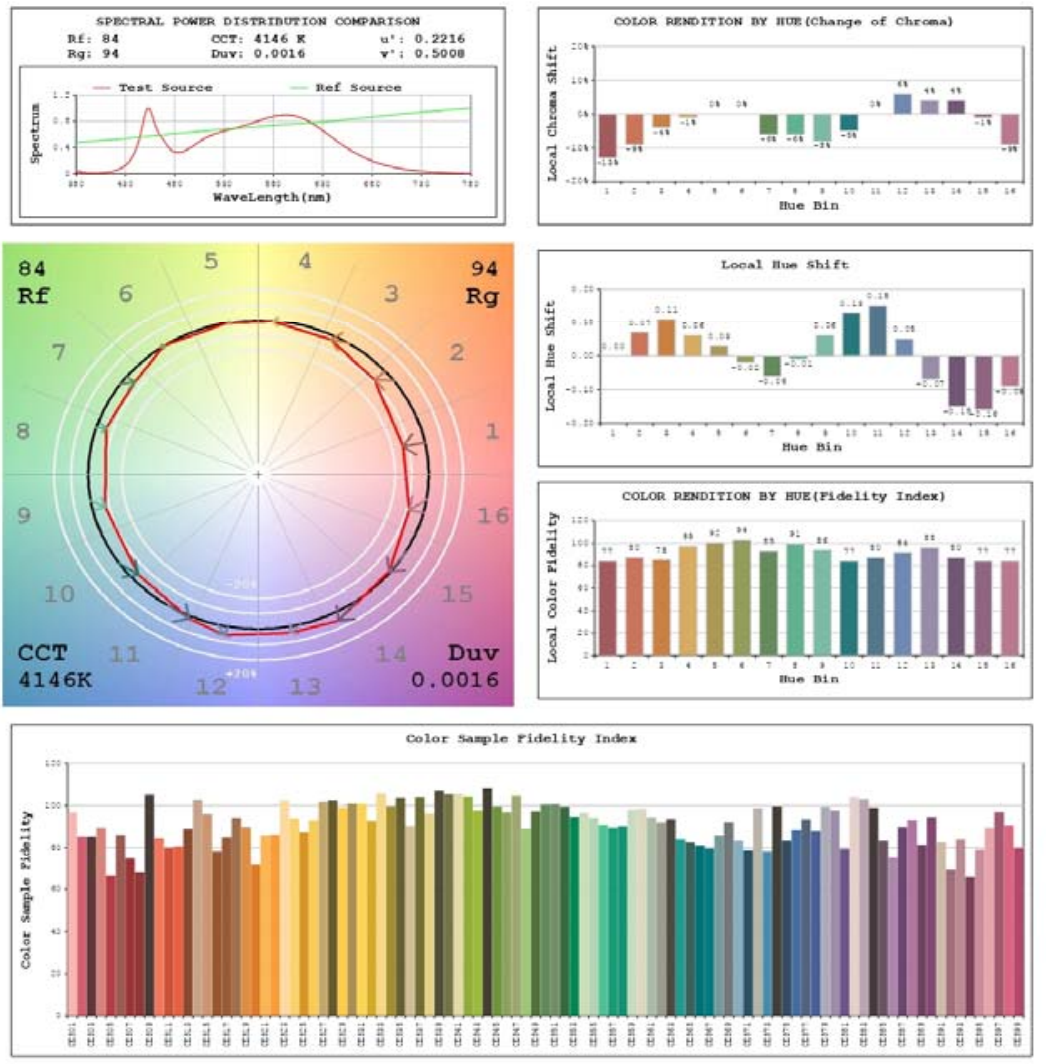

Fonte: Laboratório Itaim Lighting Concept, 2019. 


\section{ASPECTOS NORMATIVOS, PROCEDIMENTOS E RECOMEDAÇÕES}

\subsection{Considerações preliminares}

A Associação Brasileira de Normas Técnicas (ABNT) é uma entidade privada e sem fins lucrativos, que estabelece normas que visam a padronização dos processos produtivos, é membro fundador e representa oficialmente a ISO - International Organization for Standardization - Organização Internacional de Padronização no Brasil. A ISO, juntamente com IEC - International Electrotechnical Commission, desenvolve normas de padronização de tecnologias elétricas e eletrônicas, sendo que o Brasil tende a adotar essas normas em conteúdo técnico, estrutura e redação.

A ABNT, por meio dos seus comitês técnicos, que são órgãos de coordenação, planejamento e execução das atividades de normalização técnica, cria as Normas Brasileiras Regulamentadoras - NBR, podendo ser tanto uma norma técnica $100 \%$ brasileira ou a tradução de uma norma padrão ISO ou padrões ISO/IEC, nestes casos sendo mantidos a referência e o título. Podemos afirmar que as normas asseguram as características desejáveis de produtos e serviços como qualidade, segurança, confiabilidade, eficiência, intercambialidade, de forma sustentável, nas dimensões econômica, social e ambiental.

Esta pesquisa foi realizada por meio da revisão das normas ABNT IEC/TS 62504:2013, que determina os termos e definições para LED e os módulos de LED de iluminação geral, da ABNT IEC 62031:2013, que tipifica os critérios de segurança para os módulos de LED para iluminação em geral e a NBR IEC 62722-2-1: 2016, que especifica os requisitos e desempenho de Luminárias para LED, e a norma NBR ISO/CIE 8995-1, que define os requisitos de iluminação para locais de trabalho internos, e os requisitos para que as pessoas desempenhem tarefas visuais de maneira eficiente, com conforto e segurança durante todo o período de trabalho.

Atualmente, o Brasil segue igualmente os parâmetros, padrões e procedimentos publicados pela Illuminating Engineering Society (IES), sobretudo na publicação IES LM-80-15, substituída pela IES LM-80-18 , que apresenta os métodos para as medições e ensaios de manutenção de fluxo de fontes de luz LED e a IES 
TM-28-2014, que fornece recomendações, orientações e procedimentos para amostragem, intervalos de teste e duração, e um método para projeção de manutenção de fluxo luminoso a longo prazo para lâmpadas e luminárias LED. A publicação IES LM-79-19 define as medições elétricas e fotométricas de produtos de iluminação de estado sólido, quando se considera o sistema completo luminária de LED e a IES TM-21-11 e especifica a forma de extrapolar os resultados dos testes realizados pela IES LM-80-18. Quando temos como objetivo a avaliação da reprodução de cor de fontes de luz, fazemos uso da recomendação apresentada na IES TM-30-18 e da normativa da Comissão Internacional de lluminação - CIE 224-17, pois ambas definem os parâmetros atuais de fidelidade das cores.

A Comissão Internacional de Iluminação - Comission Internationale de I'Eclairage, conhecida como CIE, é uma entidade internacional independente, sem fins lucrativos, e sediada em Viena (Áustria). A origem remonta ao ano de 1913, quando substituiu a Comissão Internacional de Fotometria (C.I.F.), que havia sido fundada em 1900 (Zurique/Suíça), com o objetivo de harmonizar internacionalmente os critérios de medição fotométrica para a iluminação a gás. A fundação da CIE foi necessária para incorporar novos campos de pesquisa, como a iluminação elétrica, a visão, a luz e a colorimetria, e o Brasil participa da comissão.

Reconhecida pela ISO (Organização Internacional de Normalização) e pela IEC (Comissão Eletrotécnica Internacional) como uma organização internacional de caráter normativo, a CIE é a autoridade máxima na área da iluminação. Cerca de 60 países participam da CIE por meio de comitês nacionais, ou como membros associados. O comitê nacional brasileiro (CIE-Brasil) foi estabelecido em 2002 e é coordenado pelo Inmetro.

Seu principal objetivo é o de cooperação internacional e intercâmbio de informações sobre todos os temas relacionados à ciência e à arte da luz e da iluminação, cor e visão, fotobiologia e tecnologia de imagem. 


\subsection{Normas Brasileiras Regulamentadoras - NBR}

\subsubsection{ABNT IEC/TS 62504:2013 - Termos e definições para LED e os módulos de LED de iluminação geral}

Esta especificação técnica é uma tradução idêntica à IEC/TS 62504:2011 Terms and definitions for LED and LED modules in general lighting, e apresenta os termos e definições pertinentes para iluminação com fontes de luz LED. São fornecidos os termos descritivos, como módulo de LED embutido, e termos mensuráveis, como iluminância, coeficiente de temperatura de comprimento de onda dominante em função da temperatura ambiente, além de definir a resistência térmica de um módulo de LED e mostrar os pontos de medição na junção, placa ou ambiente para coleta de informações. A norma apresenta, inclusive, uma visão geral de sistemas compostos de módulos de LED e equipamentos de controle.

\subsubsection{ABNT IEC 62031:2013 - Módulos de LED para iluminação em geral - Especificações de segurança}

Esta norma é uma adoção idêntica das especificações da IEC 62031:2008 LED modules for general lighting - Safety specifications e, traduzida, apresenta os requisitos gerais e de segurança para módulos de diodos emissores de luz da ABNT IEC 62031:2013 - Módulos de LED para iluminação em geral - Especificações de segurança. A norma apresenta e reconhece a necessidade de ensaios pertinentes para a chamada "iluminação de estado sólido". Dois tipos de módulos de LED são abordados, com dispositivo de controle integrado para uso com alimentação corrente contínua até $250 \mathrm{~V}$, ou alimentação corrente alternada até $1.000 \mathrm{~V}$ em $50 \mathrm{~Hz}$, ou 60 $\mathrm{Hz}$, e módulos de LED sem dispositivo de controle integrado para operação sobtensão, corrente e potências constantes. 


\subsubsection{NBR IEC 62722 - 2 - 1: 2016 - Desempenho de Luminárias - Parte 2-1: Requisitos particulares para luminárias LED}

Essa normativa foi relevante para o trabalho de pesquisa, pois trata-se de uma tradução da norma IEC 62722-2-1:2014 Luminaire performance. Part 2-1: Particular requirements for LED luminaires, especifica os requisitos de desempenho para luminárias LED, e representa o conhecimento técnico de especialistas da indústria de semicondutores (chip de LED) e da indústria elétrica de fontes de luz e luminárias, bem como as condições para os ensaios elétricos e características fotométricas, manutenção do fluxo luminoso e vida útil para as luminárias LED de uso geral.

A norma explana as métricas recomendadas para a vida útil, considerando que a vida útil da luminária LED pode ser muito maior do que a realmente verificada na prática nos ensaios, e que a depreciação na emissão de luz pode variar de fabricante para fabricante, fazendo com que o método de suposição geral seja dificultado. Por esse motivo, a norma inseriu categorias de manutenção do fluxo luminoso que cobrem a depreciação inicial do fluxo luminoso, até um tempo operacional estabelecido nas condições gerais de ensaios. Devido a este tempo de ensaio limitado, não é possível ser confirmada a declaração de vida de luminárias LED, mas sim as projeções de manutenção do lúmen das fontes de luz de LED integradas nas luminárias

Por outro lado, a norma também considera que a vida da luminária está diretamente relacionada à confiabilidade dos componentes de uma luminária LED como um sistema, e que dura apenas até a vida mais curta do componente crítico, mesmo que seja um componente crítico com selagem a intempéries, um elemento óptico, um LED, uma fonte eletrônica, ou qualquer outro elemento.

\subsubsection{ABNT NBR ISO 8995-1- Iluminação de Ambientes de Trabalho - Parte 1: Interior}

Esta norma é uma tradução integral da norma ISO 8995-1:2202 Lighting of work place-Part1: Indoor, considerada o estado da arte, por reforçar a importância da prática da boa iluminação, com igual atenção à quantidade e a qualidade da luz. A 
norma define os requisitos de iluminação para locais de trabalho internos e os parâmetros para que as pessoas desempenhem serviços visuais eficientes com conforto e estejam seguros durante todo o período de trabalho. A norma especifica os valores de iluminâncias mantidas (lux), considerados como a iluminância média da superfície especificada que não deverá ser reduzida, independentemente da idade das pessoas e das condições da instalação, além de considerar, como plano de tarefa, a área de atividade laborativa e do entorno imediato, que é uma zona de no mínimo 0,5 m de largura ao redor da área de tarefa dentro do campo de visão do usuário.

Conforme a NBR 8995-1, apesar de ser necessário o fornecimento de iluminância sobre a tarefa, a visibilidade pode depender da maneira como a luz é aplicada, em função das caraterísticas de cor da fonte de luz e das superfícies do espaço a ser iluminado.

Outro critério abordado na norma é a quantidade de ofuscamento produzido pela luminária, sendo que a norma propõe parâmetros para criar condições visuais adequadas; desta forma foi introduzido o conceito do Índice de Ofuscamento Unificado da CIE (UGR), baseado na posição padrão do observador e um valor máximo permitido do nível de ofuscamento unificado de projeto para uma instalação de iluminação.

A norma considera a iluminação direcional para a valorização e destaques de objetos, revelando as texturas e melhorando a aparência de pessoas no interior de um determinado ambiente. Isto está descrito pelo termo "modelagem". A iluminação direcional de um serviço visual pode também realçar sua visibilidade. $\mathrm{Na}$ sua elaboração aproveitou-se para pontuar requisitos de limitação do índice mínimo de reprodução de cor da fonte luminosa e a recomendação de uma temperatura de cor adequada para vários locais de trabalho e em função de tipos de tarefa visual garantindo, assim, um equilíbrio razoável entre o desempenho e a quantidade de iluminância e a qualidade visual. 


\subsection{Recomendações IESNA}

\subsubsection{IES TM - 28 - 14 - Projecting Long-Term Luminous Flux Maintenance of Led} Lamps and Luminaries

A IES TM-28-14 é um memorando técnico que fornece recomendações, orientações e procedimentos para amostragem, intervalos de teste e duração, e um método para projeção de manutenção de fluxo luminoso em longo prazo para lâmpadas e luminárias LED. A intenção do memorando é auxiliar os fabricantes e usuários de produtos, organismos de desenvolvimento padrão e outras organizações, a evitar quaisquer encargos desnecessários relacionados a testes excessivos de produtos. O memorando busca o equilíbrio entre o tempo de teste e esforço, por um lado, e rigor estatístico que seja suficiente, por outro. As diretrizes e procedimentos deste memorando foram primordiais para a definição da metodologia desta tese.

\subsubsection{IES LM-79-08 - Electrical and Photometric Measurements of Solid-State Lighting Products}

É um documento que recomenda o método publicado e aprovado pela lluminating Engineering Society of North America (IESNA) para medições de características elétricas e fotométricas de iluminação de estado sólido - SSL. O documento descreve os procedimentos e as precauções a serem observados na realização de medidas de fluxo luminoso total, energia elétrica, distribuição de intensidade luminosa e cromaticidade, de produtos de iluminação de estado sólido (SSL) para fins de iluminação, em condições padrão, e abrange os produtos SSL em forma de luminárias (luminárias que incorporam fontes de luz), bem como lâmpadas LED integradas. A LM-79-08 não abrange dispositivos elétricos projetados para produtos SSL vendidos sem fonte de luz, mas descreve os métodos de teste para produtos SSL individuais, não abrangendo a classificação de desempenho dos produtos, nos quais as variações individuais entre os produtos devem ser consideradas. Para os ensaios e medições em laboratório, se fez uso dos 
procedimentos e características elétricas e fotométricas recomendadas para a luminária com a fonte de luz incorporada.

\subsubsection{IES LM-79-19 - Optical and Electrical Measurements of Solid-State Lighting Products}

Este método, aprovado em 2019, descreve os procedimentos a serem seguidos e as precauções a serem observadas na realização de medições precisas do fluxo luminoso total, radiante ou de fótons, energia elétrica, eficácia do sistema, distribuição de intensidade luminosa, radiante ou de fótons; e quantidades de cores e / ou espectro de produtos de iluminação de estado sólido (SSL) para fins de iluminação, sob condições padrão. Este método abrange luminárias LED, luminárias OLED, lâmpadas LED integradas, lâmpadas OLED integradas, lâmpadas LED não integradas operadas com um driver designado pelo número de identificação do fabricante, ou por um circuito de referência [ANSI], todos os que serão chamados de produtos SSL ou dispositivo em teste (DUT). Os produtos SSL, excluindo lâmpadas LED não integradas, destinam-se a se conectar diretamente à rede elétrica CA ou a uma fonte de alimentação de tensão CC para operar.

\subsubsection{IES LM-80-18 - Measuring Lumen Maintenance of Led Light Source}

A LM-80-15 é um procedimento que teve a sua primeira edição no ano de 2008 pela IESNA, e tem como principal objetivo a definição dos parâmetros de teste para LED e módulos de LED. A recomendação não considera as ópticas, os controladores, os dissipadores, entre outros componentes. Seu objetivo é permitir uma comparação confiável dos resultados de testes entre laboratórios, estabelecendo métodos de ensaios uniformes e visando obter informações sobre a manutenção de fluxo luminoso e alteração da cromaticidade com o tempo, variação da tensão direta, considerando as condições em que os LED são submetidos.

Alguns parâmetros específicos de testes que os fabricantes de LED devem atender são ensaiar cada tipo de LED, ou família de produtos, observando os valores de temperaturas de cores, seguir a recomendação de utilizar no mínimo 20 amostras 
e atender ao tempo mínimo de ensaio de 6.000 horas, devendo, as medições de fluxo luminoso, coordenadas de cromaticidade e tensão direta, serem feitas a cada 1.000 horas.

Na revisão do procedimento, em 2015, foram incorporados e alterados alguns itens, objetivando a devida atualização do procedimento, em função dos crescentes avanços da tecnologia LED. Segundo Scopacasa (2017), a principal alteração foi o fato da LM-80-15 ter passado a ser reconhecida como Norma ANSI $^{32}$ (American National Standards Institute), deixando de ser uma simples recomendação e passando a ter o status de norma. Nesta revisão houve a inclusão de novos sistemas de alimentação, tais como por largura de pulso (PWM), tensão constante DC e tensão AC com regulação. Na revisão, houve alteração no tempo mínimo de teste, que antes especificava 6.000 horas e preferencialmente 10.000 horas ou mais, sendo que houve a remoção deste item em função da opção de o usuário utilizar a TM-21-11 para projeção da vida útil.

A indicação de procedimentos de medições de temperatura do corpo do LED (TS) por meio da utilização de termopares é um parâmetro importante, pois necessita da indicação do fabricante do LED, uma vez que cada encapsulamento pode alterar o ponto de medida de TS, dado que o mesmo é específico, variando entre fabricantes. São apontados dois valores de temperatura de teste, $55^{\circ} \mathrm{C}$, $85^{\circ} \mathrm{C}$, e uma terceira temperatura que fica a critério do fabricante. Ainda nas medições do corpo do LED, a temperatura ambiente do teste deve variar no máximo $5^{\circ} \mathrm{C}$ para cima e para baixo da temperatura TS, a fim de garantir que não exista nenhuma influência do ambiente no resultado dos testes, sendo que o fabricante tem que especificar os valores das correntes elétricas utilizadas nos testes. O fabricante deverá disponibilizar relatórios com todas as condições utilizadas e os resultados obtidos após a realização dos testes. A pesquisa

\footnotetext{
${ }^{32}$ É uma organização particular estado-unidense, sem fins lucrativos, que tem por objetivo facilitar a padronização dos trabalhos de seus membros e representa as necessidades e opiniões das partes interessadas dos EUA em fóruns de padronização em todo o mundo. A ANSI é o órgão membro dos EUA para o ISO e, por meio de do Comitê Nacional dos EUA, a Comissão Eletrotécnica Internacional (IEC) é também membro do Fórum Internacional de acreditação (IAF)
} 
apresentada seguiu as recomendações, visando obter referências confiáveis sobre a manutenção de fluxo luminoso e alteração da cromaticidade ao longo do período de experimento.

\subsubsection{IES TM-21-11 - Projecting Long Term Lumen Maintenance of Led Light} Sources

A IES TM-21-11 é um memorando técnico que descreve como se devem extrapolar os resultados da IES LM-80-15 para além do tempo do teste realizado. Como os LED são fontes de luz com alta vida útil, se faz uso dos da LM-80-15, que avalia a manutenção de fluxo luminoso e alteração da cromaticidade e, por meio de de uma extrapolação matemática, se calcula o número de horas para alcançar $70 \%$ da manutenção de lúmens do LED (L70). Como a extrapolação dos dados é um método matemático baseado nas informações coletadas na LM-80-18, é passível de erros. A TM-21-11 estabelece como garantia máxima do fluxo para ensaios de 6.000 horas, 6 vezes o tempo de teste, considerando amostragem igual ou superior a 20 unidades, e 5.5 vezes para amostragem inferior a 20 unidades.

\subsubsection{IES LM-84-14 - Luminous Flux and Color Maintenance of Led Lamps, Light Engines, and Luminaires}

A LM-84-14 é um método para medir fluxo luminoso e manutenção de cores de fontes de luz LED e foi documentado no procedimento IES LM-80-08 e IES LM-8015. O sistema de iluminação de estado sólido (SSL) faz parte de uma lâmpada LED, módulo de LED ou de uma luminária LED, mas outros componentes do sistema podem contribuir para a degradação do fluxo luminoso e mudança de cor ao longo do tempo. O desempenho do sistema muda ao longo do tempo e pode ser testado diretamente no SSL. Este documento aborda a avaliação das mudanças no desempenho dos sistemas SSL ao longo do tempo, e pode ser uma ferramenta útil para avaliações de engenharia e manutenção de fluxo luminoso para luminárias inteiras, quando as considerações ambientais e a variabilidade para a depreciação podem ser afetadas por variáveis operacionais e ambientais, tais como ciclo 
operacional, condições impostas por equipamentos auxiliares e acessórios, temperatura ambiente e fluxo de ar. Este método de teste foi desenvolvido para estabelecer condições consistentes e ambientais em todos os laboratórios, a fim de se obter resultados reprodutíveis e permitir uma comparação confiável dos resultados.

\subsubsection{IES TM-30-18 - Method for Evaluating Light Source Color Rendition}

A TM-30-18 é o novo método para avaliação da reprodução de cor de fontes de luz com abordagem objetiva e estatística, por meio da quantificação da Fidelidade representado por $\mathrm{R}_{\mathrm{f}}$ (proximidade com a referência) e, outro critério, definido como Gamut (aumento e diminuição da saturação), representado por $\mathrm{R}_{\mathrm{g}}$. O método utiliza o padrão de cores (color space) CAM02-UCS.

Este método tem também como base a comparação das cores reproduzidas por uma determinada fonte em comparação com uma fonte padrão sob um determinado iluminante, na mesma temperatura de cor correlata. Esta abordagem é compatível com o processo de projeto de iluminação, onde a temperatura de cor é decidida anteriormente à consideração da reprodução de cor.

Diferentemente do processo de IRC, esse método adota 99 amostras de cores estatisticamente selecionadas de um grupo de mais de 100.000 objetos medidos. Em função disso, podemos considerar que estas 99 amostras de cores são representativas das muitas possíveis cores disponíveis, tais como objetos naturais, pinturas, têxteis, plásticos e tons de peles, dentre outros.

\subsection{Recomendações CIE}

\subsubsection{CIE 224-17 - Color Fidelity Index for Accurate Scientific Use}

A CIE 224-17 é um relatório técnico de pesquisa que descreve um índice médio geral de fidelidade de cores, Rf, como uma medida cientificamente precisa da fidelidade de cores em relação a um iluminante de referência. Esse índice de fidelidade de cores é baseado no índice de fidelidade da Illuminating Engineering 
Society da América do Norte, definido no TM-30-15, e aborda aspectos parciais das limitações do $\mathrm{CRI}^{33}$.

No entanto, o relatório aponta várias imprecisões do CRI como uma medida de fidelidade das cores.

Os critérios apresentados pela CIE 224-17, são descritos no capítulo 5.

${ }^{33}$ Color Rendering Index, definido na CIE 13.3-1995 é o índice geral de reprodução de cores Ra, sendo amplamente adotado e utilizado pela indústria da iluminação. A NBR ISO/CIE 8995-1- Iluminação de ambientes, adotou a mesma terminologia, fazendo uso do termo em português Índice de Reprodução de Cor (IRC), sendo que o valor máximo de Ra é 100. 


\section{COMPONENTES E TECNOLOGIAS APLICADAS EM LUMINÁRIAS LED}

\subsection{Considerações preliminares}

A luz do século XXI foi criada nos laboratórios da General Electric em Syracusa, em 1962 por Nick Holonyak Jr, enquanto trabalhava como consultor no campo da optoeletrônica na conversão de corrente elétrica em luz. Seu colega na General Electric, Robert N. Hall, desenvolveu um laser usando diodo semicondutor, mas o laser de Hall emitia unicamente radiação infravermelha, que está além da visão humana. Holonyak decidiu criar um dispositivo de diodo que emitisse luz visível, usando o material semicondutor fosfeto de arsenieto de gálio (GaAsP) e, por meio da técnica de emissão estimulada, conseguiu o primeiro dispositivo de LED, sendo na cor vermelha, e inicialmente utilizado apenas em indicadores. Holonyack ganhou a honra de ser chamado de "Pai do diodo emissor de luz" por sua contribuição à tecnologia.

Com o avanço da tecnologia com os LEDs de luz vermelho-alaranjado e verde pálido, e a combinação de dois cristais de GaP, um de luz vermelha e outro de luz verde, foram criados os LEDs duais produzindo a luz amarela (PIMENTA, 2006). Numa impressionante evolução, conquistando um crescimento veloz e contínuo de potência por meio da elevação de fluxo luminoso e brilho, da eficácia luminosa ( $\mathrm{m} / \mathrm{W})$, da variedade de emissão de luz com diferentes comprimentos de ondas e do incremento da longevidade, iniciou-se a formação de um grande mercado, pois a aceitação foi geral, mesmo tendo, na época, algumas restrições de uso. Na década de 80 surgiu a primeira geração de LED de potência, composto de Fósforo, Arsênio, Alumínio e Gálio (GaAIAsP), produzindo primeiramente luz vermelha e depois amarela e verde, com níveis de iluminação dez vezes superiores aos modelos anteriores.

Mas o principal feito ocorreu em 1993, quando o Dr. Shuji Nakamura, juntamente com os colegas Isamu Akasaki e Hiroshi Amano, inventou o LED azul, na época em que trabalhava na Nichia Chemical Industries Ltd. Em entrevista na REVISTA LUME ARQUITETURA, 2017, ed. 71, o Dr. Shuji Nakamura, descreveu a pesquisa sobre diodos emissores de luz azuis, iniciada em 1989, usando nitreto do 
grupo III ${ }^{34}$ e, em 1993 e 1995, nesta ordem, com o desenvolvimento dos primeiros LED de nitreto azul e verde do grupo III e os primeiros nitretos do grupo III, baseados em diodo laser violeta (LDs). Os semicondutores à base de nitreto representaram uma das conquistas mais importantes na ciência dos materiais dos últimos trinta anos, referindo-se especificamente à descoberta de que os filmes GaN tipo-p poderiam ser obtidos pela dopagem do tipo p em nitreto de gálio ( $\mathrm{GaN}$ ) com Mg (magnésio), com sucessivos recozimentos pós-térmicos em ambientes de nitrogênio a temperaturas acima de $400^{\circ} \mathrm{C}$ que, combinados com o desenvolvimento de filmes de InGaN (nitreto de gálio-índio) de alta qualidade de cristais, permitiam alcançar os dispositivos azuis brilhantes emissores de luz de heteroestrutura dupla.

Em 2014, o Dr. Shuji Nakamura recebeu, juntamente com os dois colegas, os japoneses Isamu Akasaki e Hiroshi Amano, o Prêmio Nobel de Física, premiação que é entregue aos eminentes pesquisadores que se destacam na produção de conhecimentos inovadores no domínio da área da física. De acordo com o júri do Prêmio, "é uma nova fonte de luz eficaz do ponto de vista energético e benéfica ao meio ambiente" (IFSC/USP, 2014), mostrando a relevância dos diodos emissores de luz azul e que nos levou a fabricação de LED de luz branca, com alto brilho, longa durabilidade e economia de energia.

Desta forma, mesmo o LED existindo há várias décadas, foi somente nos últimos vinte e cinco anos que houve a viabilização técnica nos materiais semicondutores e nos encapsulamentos, proporcionando maior potência, eficiência e maior vida útil, e passando a ter muito mais vantagens que outras tecnologias, como as lâmpadas de descarga em baixa e alta pressão.

Com a expectativa de economia de energia que os LEDs proporcionam, os governos dos países produtores da tecnologia, como Estados Unidos, Japão, China, Coreia do Sul, entre outros, tendem a subsidiar diversas pesquisas, de forma a possibilitar economicamente o avanço e as melhorias necessárias, particularmente em relação a consistência da cor entre fontes e ao longo da vida útil, a elevação da

\footnotetext{
${ }^{34} \mathrm{AIN}, \mathrm{GaN}, \mathrm{InN}$ e suas ligas ternárias e quaternárias são também conhecidos como semicondutores do grupo III-V
} 
reprodução de cor, em virtude do aperfeiçoamento do fósforo e, o controle espectral da luz visível e das radiações ultravioleta (UV) e infravermelha (IR).

Segundo Jacob (2008), o mercado de iluminação já vem sofrendo um grande impacto positivo com a substituição da iluminação por LED, com a diminuição de mais de $10 \%$ do consumo global de eletricidade, redução da necessidade de geração de 1.100 bilhões de kWh/ano, redução da emissão global de carbono em 200Mton/ano e economia de US\$100 bilhões/ano.

\subsection{Dados do mercado global para produtos SSL}

A capacidade de produção, de investimento e de participação de grandes empresas fabricantes no mercado em termos das vendas, está basicamente subdividida entre 10 fabricantes, sendo responsáveis por $58 \%$ do mercado. A empresa japonesa Nichia Corporation detém 13\%, a empresa alemã Osram Opto Semiconductors $\mathrm{GmbH}$ apresenta 8\%, duas empresas norte-americanas, Lumileds Holding B.V. com $8 \%$ e a Cree Inc. com 4\%, quatro empresas sul-coreanas, Seoul Semiconductor com 5\%, Samsung com 5\%, LG Innotek com $4 \%$ e Lumens com $2 \%$, e duas empresas chinesas, sendo a Everlight Chemical Industrial Corp. 4\% da República da China e a MSL Co. Ltd com 5\% da República Popular da China.

Há uma enorme oportunidade global para produtos SSL e para as empresas voltadas a esses produtos. O aumento dos preços da eletricidade e o desejo de independência energética estão fazendo com que o mercado global de iluminação busque fontes de luz com eficiência energética. Mesmo em economias emergentes, como na Índia, atualmente o setor de iluminação concentra quase todas as suas atividades em P\&D e novas instalações de fabricação em SSL. A aceitação dos LEDs pelos consumidores foi ampliada pelas melhorias na qualidade da luz e pelas rápidas reduções de preços.

"Sempre haverá novos dogmas aparecendo no campo da iluminação. Felizmente, nem todos se tornarão seus discípulos." - Howard M. Brandston, 2010. 
Conforme dados de pesquisas de 2017 do programa SSL da DOE, muitas das principais empresas de iluminação relataram que as lâmpadas e luminárias LED representam mais de $50 \%$ de sua receita, incluindo as empresas norte-americanas Acuity Brands (67\%) e Hubbell (55\%), a alemã OSRAM (65\%), a holandesa Philips $(61 \%)$ e a austríaca Zumtobel (73\%).

O DOE publicou a última edição de seu relatório bienal, demonstrativo de que a economia de energia da iluminação LED, até 2035, atingirá 569 TWh anualmente, se as metas do programa de P\&D da DOE Lighting forem atingidas. Espera-se que até 2035, as lâmpadas e luminárias LED ocupem a maioria das instalações de iluminação, compreendendo $84 \%$ de todas as aplicações, tendo impulsionamento pelo aumento do uso de iluminação LED em edifícios comerciais e industriais e aplicações de iluminação externa, pois são as principais aplicações caracterizadas por alta emissão de luz e longas horas de operação. A Figura 30 demonstra a penetração do LED em percentual, conforme as tipologias, com projeção até o ano de 2035.

Figura 30: Penetração do LED (\%) conforme as tipologias de aplicação.

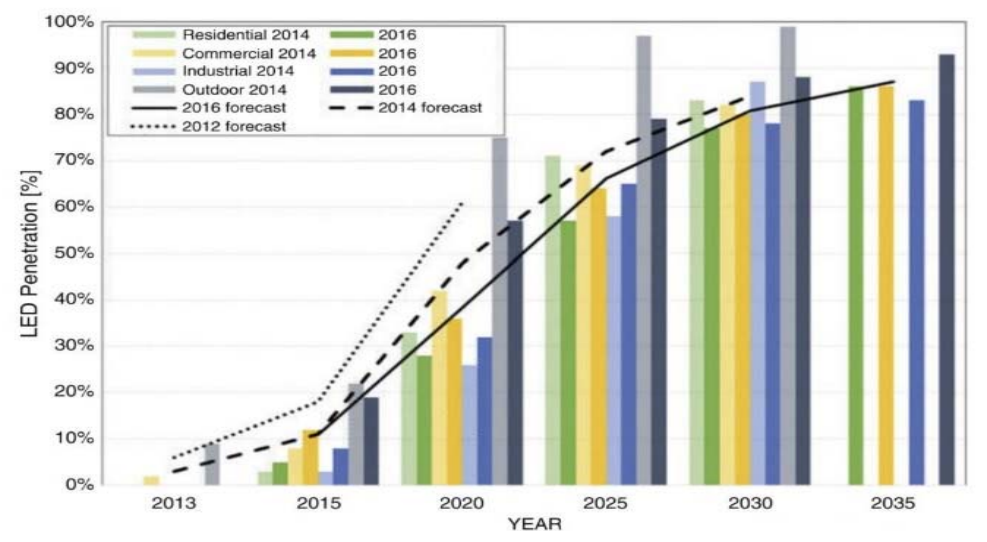

Fonte: SSL - Suggested Research Topics Supplement: Technology and Market Context, 2017

Ainda segundo o DOE (2017), a intensa concorrência de preços nos mercados de fontes de luz, lâmpadas e luminárias, levou muitas empresas a iniciar o fornecimento de sistemas e serviços de iluminação completos. No entanto, a análise 
do Boston Consulting Group, mostrada na Figura 31, prevê que as vendas de luminárias continuarão sendo a maior fonte de receita até 2020, e serão dominadas por luminárias exclusivas para LEDs, sendo que o mercado global de iluminação continua em constante crescimento, tendo tido receita superior a US \$112 bilhões em 2014.

O maior segmento, como apontado pelo Boston Consulting Group, é o segmento de luminárias profissionais e sistemas associados, responsáveis por US\$ 43 bilhões (ou 39\% de participação de mercado), seguido de iluminação automotiva em US\$ 21 bilhões (participação de mercado de 19\%) e luminárias e sistemas voltados ao consumidor, com US \$ 19 bilhões (participação de mercado de 17\%).

Segundo o relatório, o crescimento se dará, predominantemente, pelo desenvolvimento em mercados emergentes, em função das economias em rápido desenvolvimento, como China e países da América Latina, que representaram cerca de $70 \%$ do crescimento da indústria de iluminação nos últimos cinco anos.

Figura 31: Mercado global de iluminação - 2010 até 2020

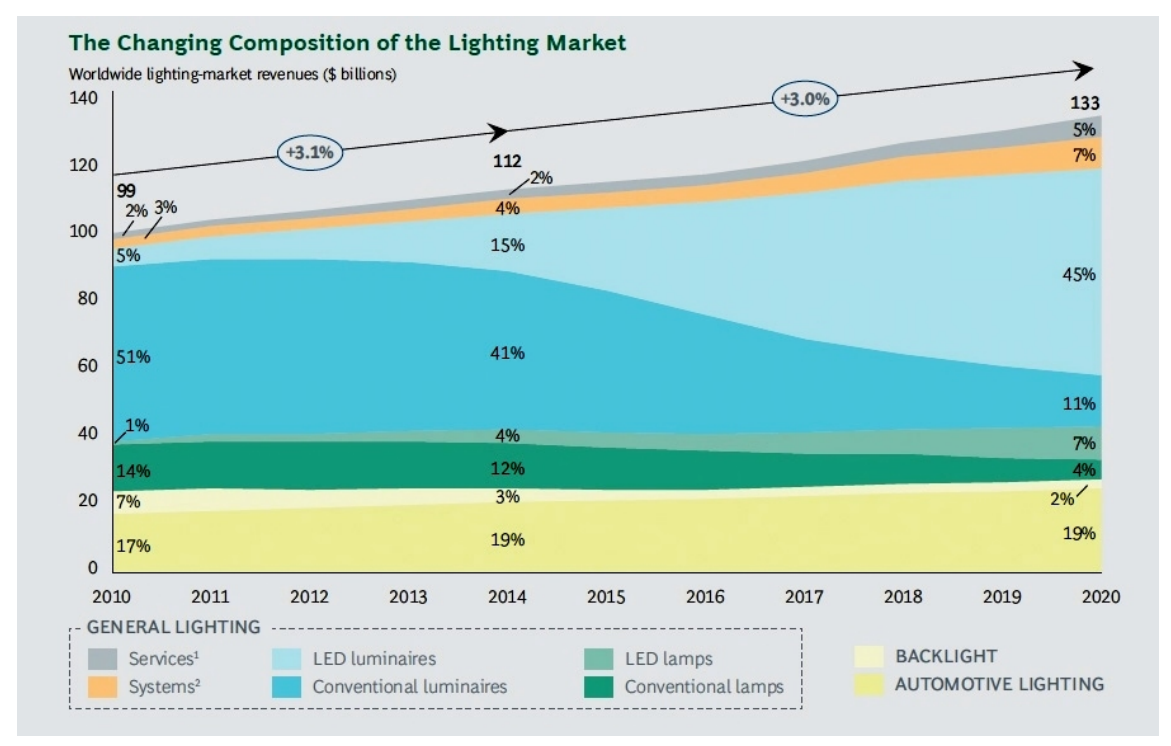

Fonte: https://www.consultancy.uk/news/3117/led-eating-market-share-in-110-billion-lighting-market. 


\subsection{Eficiência na produção de luminária LED.}

Segundo DOE (2017), a eficiência na produção de uma luminária LED considera variáveis, desde a projeção de luz por meio do conjunto montado (encapsulado) de uma ou mais pastilhas de LED, como outras partes importantes da luminária - a fonte de alimentação, o gerenciamento mecânico e térmico, a eficiência dos dispositivos elétricos e ópticos - que podem contribuir com perdas adicionais do sistema. A Tabela 3 apresenta metas futuras e variáveis associadas à luminária LED, considerando a eficácia luminosa do conjunto LED, a temperatura ambiente $\left(25^{\circ} \mathrm{C}\right)$, a queda da eficiência térmica devido à temperatura operacional mais alta $\left(85^{\circ} \mathrm{C}\right)$ e a eficiência do equipamento óptico.

Tabela 3: Metas futuras e variáveis associadas a luminária LED.

\begin{tabular}{|l|c|c|c|c|c|}
\hline Metas de eficiências & 2016 & 2018 & 2020 & 2025 & Objetivo \\
\hline Projeção de eficácia do LED (Im/W) & 137 & 175 & 208 & 237 & 255 \\
\hline Eficiência do controle térmico & $88 \%$ & $91 \%$ & $93 \%$ & $95 \%$ & $95 \%$ \\
\hline Eficiência do driver & $88 \%$ & $91 \%$ & $93 \%$ & $95 \%$ & $95 \%$ \\
\hline Eficiência do dispositivo elétrico e óptico & $90 \%$ & $92 \%$ & $94 \%$ & $95 \%$ & $95 \%$ \\
\hline Eficiência geral da luminária & $70 \%$ & $76 \%$ & $81 \%$ & $86 \%$ & $86 \%$ \\
\hline Eficácia da luminária (Im/W) & $95 \%$ & $133 \%$ & $169 \%$ & $203 \%$ & $218 \%$ \\
\hline
\end{tabular}

Fonte: SSL-Suggested Research Topics Supplement: Technology and Market Context (2017), adaptado pela autora, 2019.

\subsection{Componentes e processos aplicados no projeto de luminárias de estado sólido}

O aparelho que distribui, filtra ou transforma a luz emitida por uma ou mais fontes de luz é chamado de "luminária" e compreende, com exceção das próprias fontes emissoras de luz, todas as partes imprescindíveis para sustentar, fixar e protegê-las e, quando necessário, os equipamentos auxiliares, bem como os meios para ligá-los à rede de alimentação (BIGONI, 2013). 
A cadeia de suprimentos que abrange todo o processo logístico de uma luminária LED, desde o processo de fabricação (matéria-prima) até a entrega ao consumidor final, é de suma importância para a compreensão e gerenciamento da produção. De forma geral, os processos podem ser definidos por uma sequência de etapas relativamente independentes, mas combinadas entre si, onde temos o fornecimento de equipamentos de fabricação, materiais e testes, sendo que essa cadeia de suprimentos está sempre em processo de transformação e mudança, evoluindo e amadurecendo.

Atualmente temos alguns processos integrados ocorrendo ainda verticalmente dentro da indústria, mas à medida que o setor de manufatura amadurece, é provável que a cadeia de suprimentos se torne mais independente, para otimizar a eficiência do processo; a cadeia de suprimentos evoluiu e está diretamente ligada ao desenvolvimento da tecnologia e do design de produtos, que é orquestrada pelo mercado consumidor.

A Figura 32 apresenta o processo de fabricação de luminárias LED, onde as caixas sombreadas em azul e as setas azuis descrevem o fluxo principal de fabricação.

Os elementos de suporte da cadeia de suprimentos são divididos em processo, materiais e equipamentos de testes e medições, sendo indicado pelas setas relevantes.

Figura 32: Processo de fabricação, materiais, medições e testes

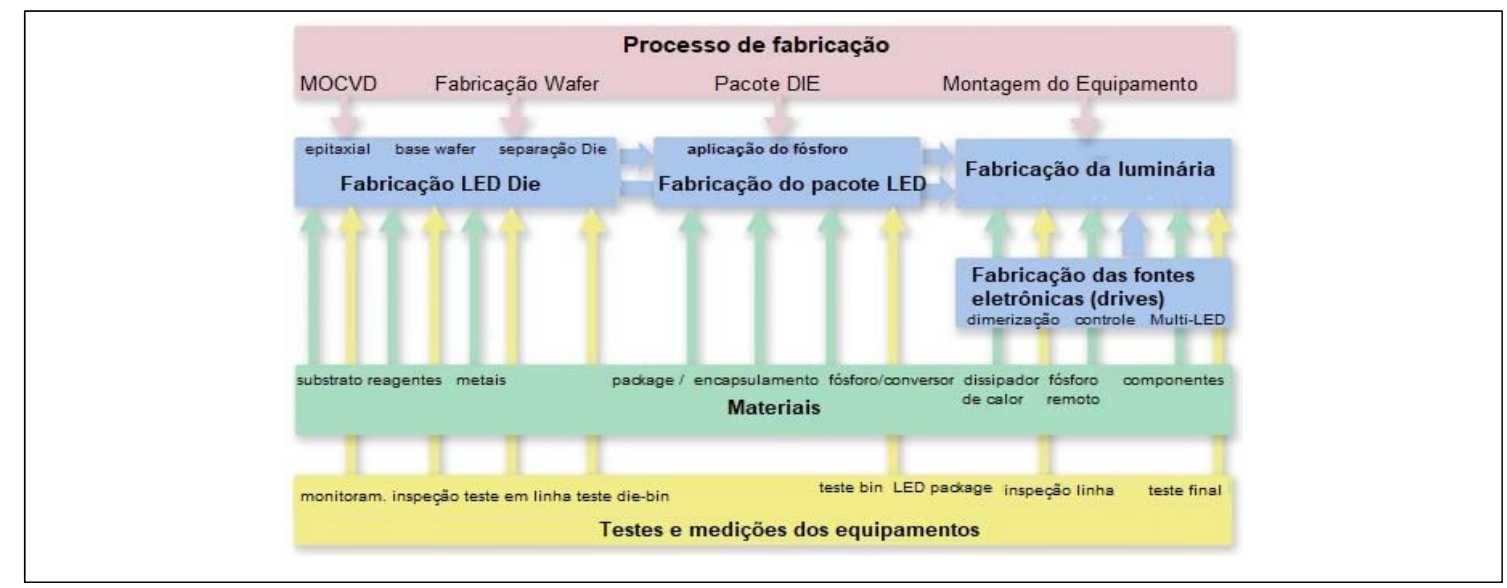

Fonte: SSL - Suggested Research Topics Supplement:Technology and Market Context (2017), adaptado pela autora, 2019. 
O processo de fabricação está em constante evolução à medida que componentes individuais são aprimorados e novos são desenvolvidos, ou processos são introduzidos; desta forma, o fluxo ideal do processo, o desempenho e vida útil de uma luminária LED, não dependem somente do emissor de luz, mas estão diretamente relacionados à confiabilidade dos componentes, como controladores eletrônicos, dissipadores térmicos, lentes, conectores, etc.

Cada dispositivo tem comportamento específico, que pode contribuir favorável ou negativamente para o bom desempenho do sistema. Segundo Scopacasa (2017), o LED é o componente mais confiável de todo o sistema, mas não significa que a luminária pode ter a sua vida útil definida e baseada em seu desempenho; consequentemente todos os demais componentes devem ser avaliados cuidadosamente.

$\mathrm{Na}$ Figura 33, apresentamos os componentes que fazem parte de uma luminária com LED ou arranjos de LED.

Figura 33: Componentes da luminária LED.

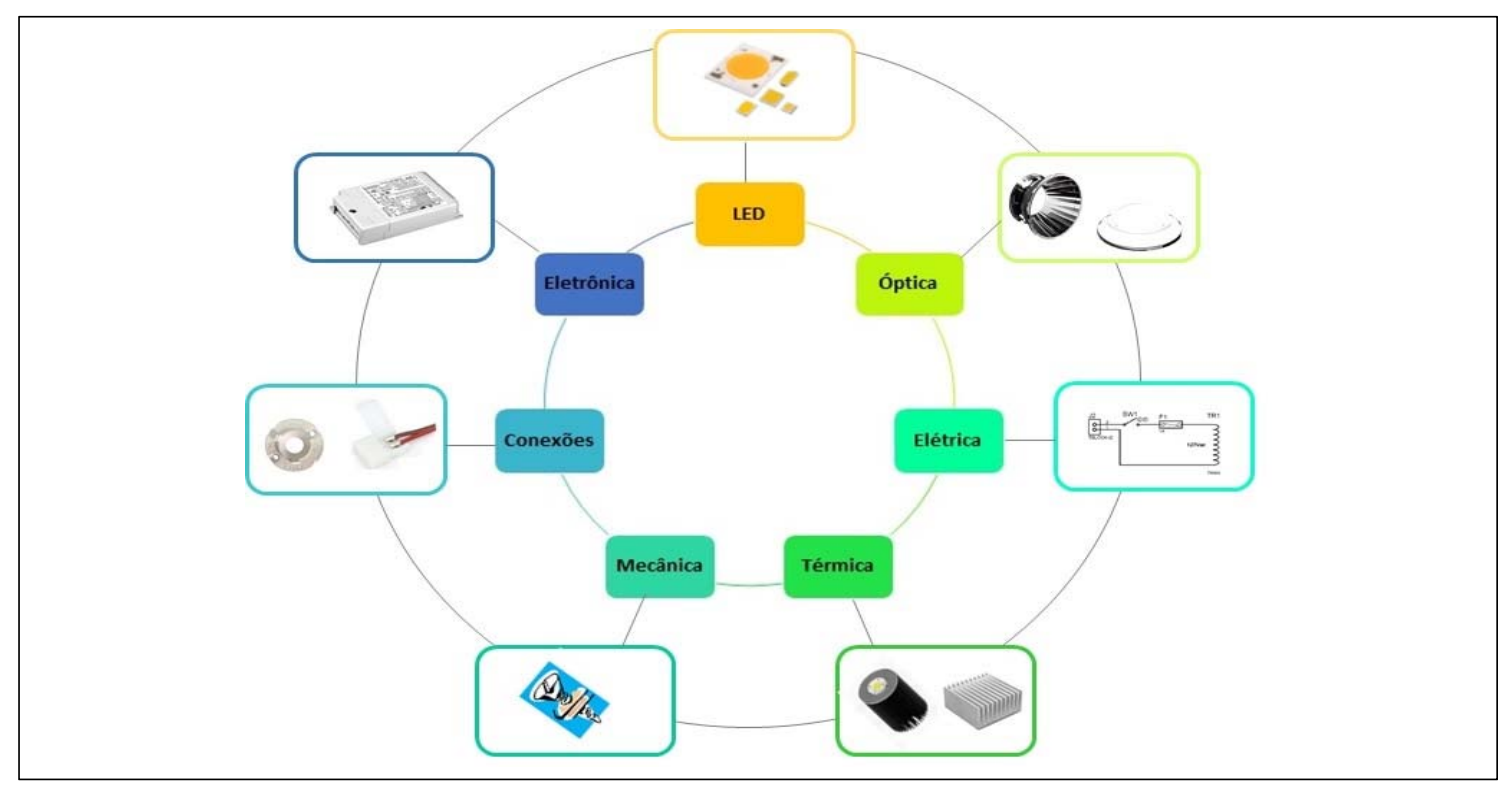

Fonte: Scopacasa, 2017, adaptado pela autora, 2020. 


\subsection{Integração do projeto com tecnologia LED e o desempenho dos componentes.}

A integração do projeto é dividida em cinco níveis, sendo que esses dados nos levam ao entendimento de todos os parâmetros importantes para a construção de uma luminária LED, uma vez que existem vários tipos de LEDs com diferentes características elétricas, mecânicas, ópticas e térmicas, e não necessariamente com o mesmo nível de desempenho (SCOPACASA, 2017).

Cuidados extras deverão ser utilizados na análise e escolha de todos os componentes que fazem parte do projeto, conforme condições apresentadas:

$\rightarrow$ O nível 0 (zero) é efetivamente o diodo semicondutor (chip) que emite luz, sem nenhum tipo de encapsulamento, lente ou terminais;

$\rightarrow$ O nível 1 (um) é o encapsulamento de uma ou mais pastilhas (chips ou die) de LED, com terminais elétricos, podendo conter ou não a lente primária, estando prontos para serem montados em um circuito impresso, sendo que dentre os principais tipos estão os LED High Power, Mid Power e Low Power;

$\rightarrow$ O nível 2 (dois) são os diodos emissores de luz, podendo conter conector, cabos, resistor e demais componentes já montados em placa de circuito impresso. O COB (chip-on-board) é um exemplo;

$\rightarrow$ O nível 3 (três) é a montagem do nível 2 (dois), com a inserção do dissipador de calor e ou driver;

$\rightarrow$ O nível 4 (quatro) considera todos os elementos compostos no nível 3 (três), mais a mecânica e a estrutura da carcaça. Trata-se da luminária, pronta para uso final;

$\rightarrow$ O nível 5 (cinco) é o dispositivo de controle de luz que harmoniza as tensões padronizadas da rede de corrente alternada (127 e 220V), ou outras tensões em corrente contínua, necessárias ao funcionamento do LED. Instalação de outros periféricos, tais como controle de dimerização, temporizados, controles de acionamento e Internet das Coisas (IOT) etc.

A Figura 34 apresenta os cinco níveis de integração do projeto. 
Figura 34: Os cinco níveis de integração do projeto.

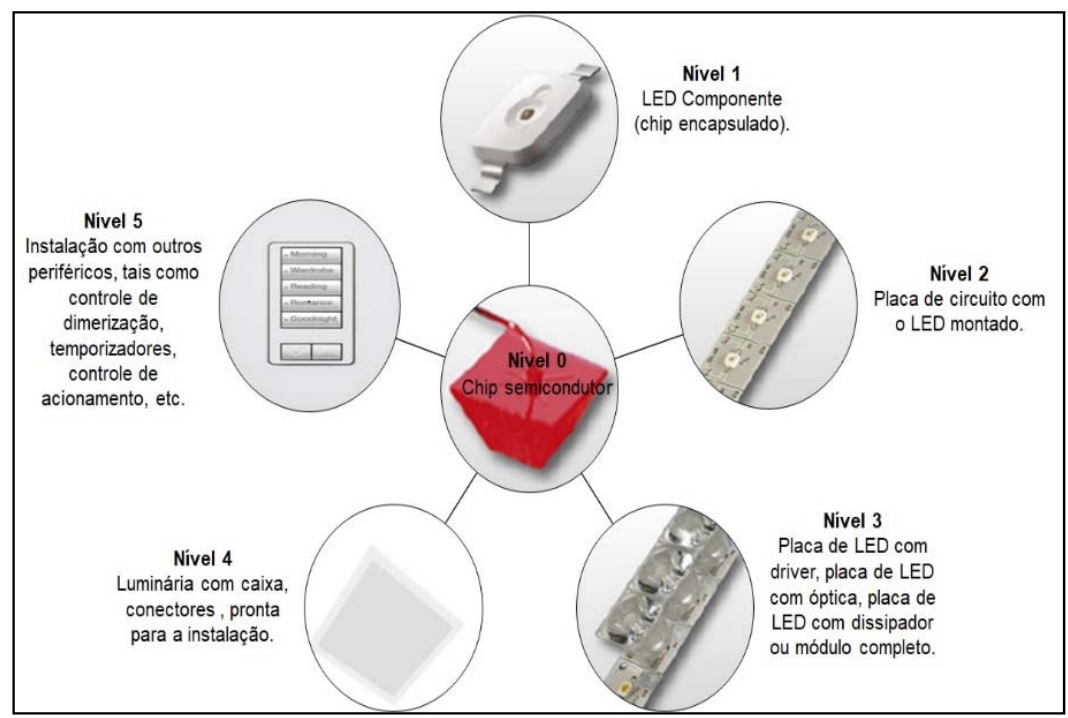

Fonte: Scopacasa, 2017, adaptado pela autora.

\subsubsection{O comportamento do diodo emissor de luz}

Conforme a norma ABNT IEC/TS 62504:2013 35 , o diodo emissor de luz ou LED (Light Emitting Diode) é um dispositivo de estado sólido que contém uma junção p-n, que emite radiação óptica quando excitado por uma corrente elétrica.

Esta transformação é diferente da encontrada em lâmpadas convencionais, que utilizam filamentos metálicos (incandescente e halógena), e descarga de gases (fluorescentes, vapor metálico e sódio), entre outras formas. No LED, a transformação da energia elétrica em luz é feita no sólido, sendo que, por isso, a tecnologia é chamada de estado sólido.

Mais especificamente, o LED é uma estrutura cristalina composta de dois tipos de materiais. O primeiro chamado de tipo "n", é um material rico em elétrons e que são portadores da carga, ou seja, as partículas que participam da condução elétrica são

\footnotetext{
${ }^{35}$ ABNT IEC/TS 62504:2013 - Título da norma "Termos e definições para LEDs e os módulos de LED de iluminação geral". Apresenta os termos e definições pertinentes para a iluminação com fontes de luz LED.
} 
elétrons livres, ao mesmo tempo em que o segundo, chamado de semicondutor tipo "p", sendo um material pobre em elétrons, são lacunas livres, de carga positiva. Em semicondutores dopados, os elétrons e lacunas são provenientes de átomos dopantes. Na junção de um material tipo" n" e "p", os elétrons próximos à junção difundem da região "n" para a "p", enquanto as lacunas difundem no sentido contrário. Quando os elétrons e lacunas se encontram, eles se recombinam, deixando na interface uma região com íons positivos e negativos dopantes. Sempre que isso acontece, temos a liberação de energia em forma de fótons.

Essa luz liberada é monocromática e depende dos níveis de energia necessários para os elétrons se combinarem com as lacunas; desta forma, materiais diferentes possuem níveis de energia diferentes, e as variações monocromáticas emitidas pelos LEDs estão diretamente relacionadas aos materiais que compõem os elementos semicondutores de cada LED.

O LED convencional é fabricado por meio da deposição de várias camadas de material semicondutor sobre uma base (wafer) em um substrato de safira ou carbeto de silício adicionados às impurezas INGaN (Índio Nitreto de Gálio), que permite a obtenção do LED na faixa de radiação entre 390 e 505 nm (nanômetros) - luz azul e ciano e GaN (Nitreto de Gálio) - que passou a ser usado com a vantagem de ser mais adaptável às impurezas, e com maior estabilidade. O processo de deposição do material semicondutor sobre o "wafer" é chamado de "Epitaxial", que posteriormente é cortado em pequenos quadrados (chips ou pastilhas), medindo por exemplo 1 × 1 $\mathbf{m m}^{\mathbf{2}}$, encapsulados no invólucro final do LED. Na Figura 35 temos o processo de deposição dos materiais semicondutores.

Figura 35: Processo convencional de fabricação do LED.

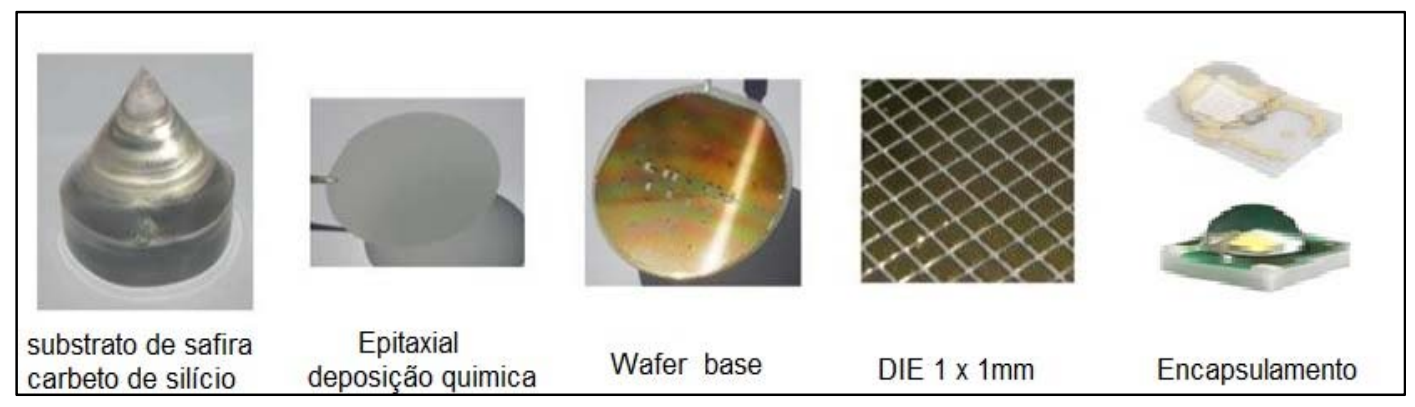

Fonte: Larson, Soraa, 2015. 
O Diagrama de Cromaticidade da CIE1931 demonstra os diversos comprimentos de onda dentro do espectro visível, com os elementos químicos referentes aos principais componentes utilizados na produção do LED. No capítulo cinco, intitulado "Propriedades Colorimétricas e Fotométricas", descrevemos que não há uma faixa específica de luz na cor branco, uma vez que os componentes químicos garantem cores monocromáticas e há a necessidade da obtenção do branco a partir de outras cores. A forma mais promissora de produção do branco é a partir de uma pastilha que emite luz azul e a luz branca, obtida por meio do uso de uma cobertura de fósforo de fótons de várias cores, o que provoca a percepção visual da luz branca. Variações no comprimento de onda da luz azul e da largura da banda de emissão associadas às variações do fósforo ocasionam grande dispersão da cor resultante em torno da curva do corpo negro (BBL).

Em função disto, segundo Scopacasa (2017), os fabricantes de LEDs costumam dividir esta área total de branco no diagrama de cores em áreas menores a fim de que, dependendo da aplicação, seja possível escolher e trabalhar com distribuições menores garantindo, assim, maior consistência na cor. Este processo é conhecido como binning.

Por meio de da codificação do binning, a seleção ocorre no processo de fabricação da pastilha semicondutora do LED, considerando que, em um mesmo lote, podem ocorrer variações de características de um chip para outro. Para uniformizar estas características e separar os LEDs em parâmetros similares, cada LED é separado conforme três características importantes:

$\rightarrow$ Fluxo luminoso;

$\rightarrow$ Comprimento de onda ou aparência de cor (LED branco);

$\rightarrow$ Tensão direta.

Dentro da análise do processo de produção do chip semicondutor, definimos como nível 0 (zero) do projeto de integração da luminária LED. 


\subsubsection{Os tipos de encapsulamentos}

Com o decorrer dos anos, vários tipos diferentes de encapsulamento foram desenvolvidos, sempre observando a capacidade de dissipação térmica, pois, cada vez mais, os chips semicondutores foram elevando a capacidade de emissão de fluxo luminoso, porém com a necessidade de maior controle térmico. Temos aqui o nível 1 (um) de integração do projeto, uma vez que o chip recebe um encapsulamento específico, conforme potência de entrada, corrente de entrada, dimensões, fluxo luminoso, etc. A Figura 36 apresenta alguns modelos de encapsulamentos.

Figura 36: Modelos de encapsulamentos.

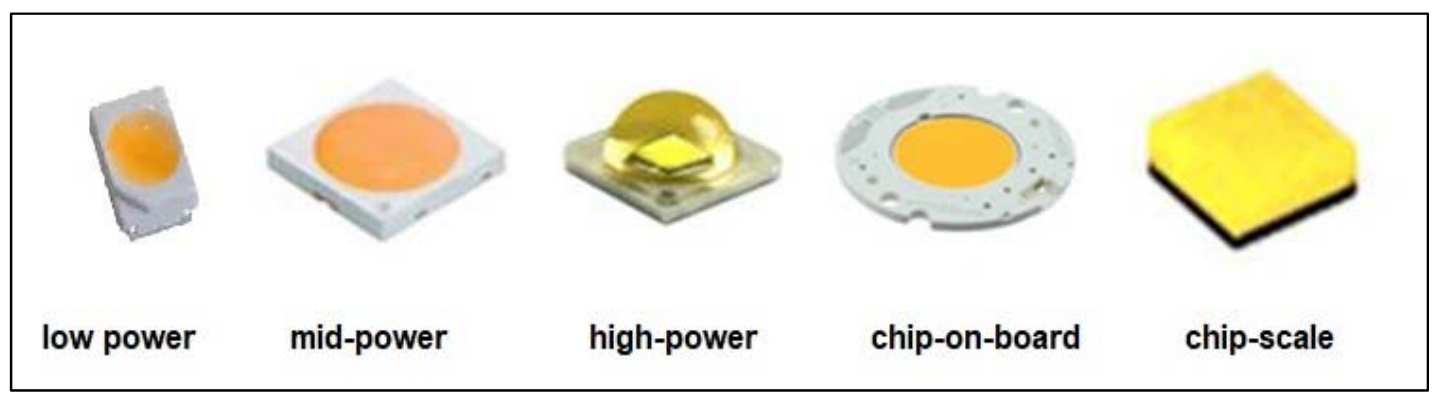

Fonte: Scopacasa, 2017, adaptado pela autora.

A Tabela 4 apresenta a classificação dos LEDs brancos, divididos em quatro grandes grupos, considerando suas potências elétricas e corrente de entrada, e fazem parte do nível 1 (um) de integração do projeto, a saber:

Tabela 4: Classificação dos LEDs brancos.

\begin{tabular}{|l|c|c|c|}
\hline Divisão de produtos & $\begin{array}{c}\text { Corrente de entrada } \\
(\mathbf{m A})\end{array}$ & $\begin{array}{c}\text { Potência de entrada } \\
(\mathbf{W})\end{array}$ & $\begin{array}{c}\text { Fluxo luminoso } \\
(\mathbf{I m})\end{array}$ \\
\hline Low power & $5-30$ & $>0.1-0.1$ & $0.1-15$ \\
\hline Mid power & $30-150$ & $0.1-0.5$ & $10-100$ \\
\hline High power & $20^{\star *}-1.500$ & $>0.5-<5$ & $50+$ \\
\hline Super high power & Variável & Variável & $400+$ \\
\hline
\end{tabular}

Fonte: Scopacasa, 2017, adaptado pela autora. 


\subsubsection{Custo do encapsulamento do LED}

Os dados do encapsulamento do LED de alta potência pressupõem a fabricação em grande volume de uma matriz de $1 \mathrm{~mm}^{2}$ em substratos de safira com $100 \mathrm{~mm}$ de diâmetro. O conjunto de encapsulamento de um chip branco quente de média potência, assume um tamanho de $0,5 \mathrm{~mm}^{2}$ com base plástica de dimensões semelhantes. A repartição de custos do pacote de LED de alta potência permanece praticamente inalterada em comparação com 2016, embora haja uma redução geral de custos de cerca de $20 \%$, o que está amplamente associado a reduções nos custos de matérias-primas e melhorias de rendimento. $\mathrm{O}$ custo da matriz e o custo do pacote são muito mais baixos para o pacote de potência média, enquanto o fósforo ainda é aplicado em uma área semelhante; portanto, sua importância relativa para o custo total aumenta. Normalmente, o custo do pacote de energia intermediária será 5-10x menos, dependendo da área da matriz, e isso se reflete em um diferencial de preço semelhante. A divisão de custo do encapsulamento do LED modelos High-Power e Mid-Power são apresentados no Gráfico 2.

Gráfico 2: Custos típicos para encapsulamento de LEDs High-Power e Mid-Power.

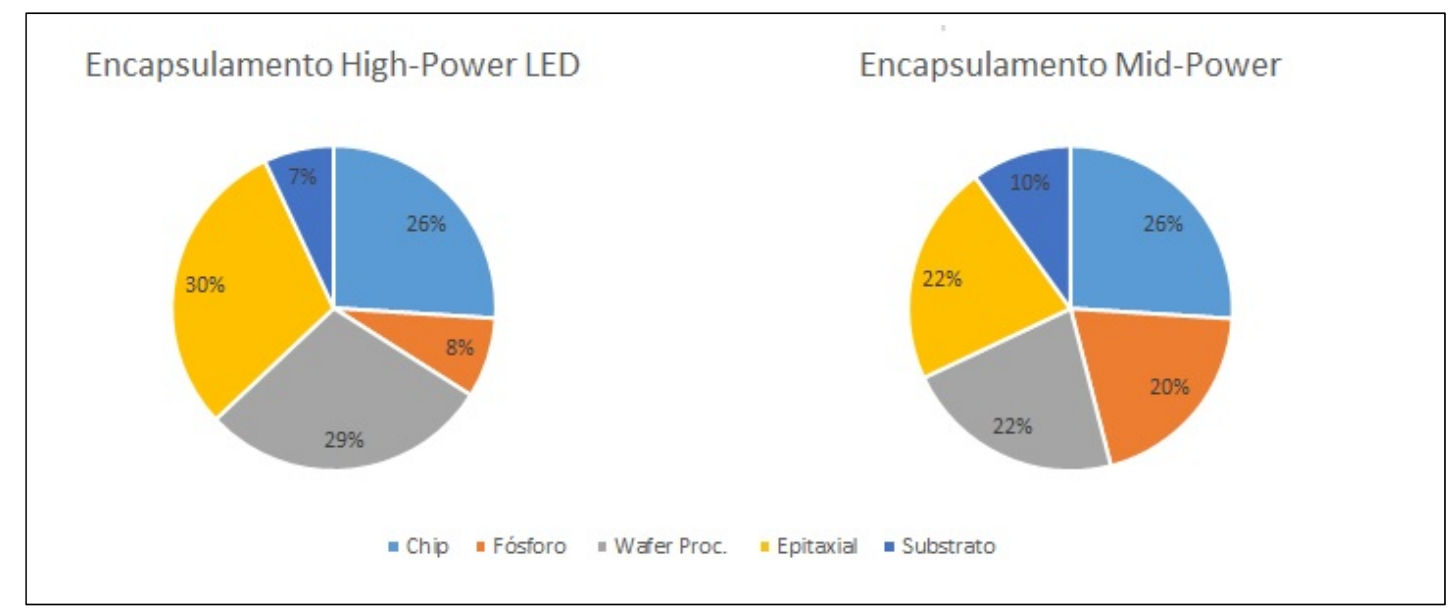

Fonte: SSL - Suggested Research Topics Supplement:Technology and Market Context,2017, adaptado pela autora, 2020. 


\subsubsection{Placa de circuito com o LED montado}

No nível 2 (dois) as placas de circuito impresso, correspondem a uma parte importante da luminária.

Os PCls são amplamente utilizados em todos os tipos de equipamentos eletrônicos, principalmente quando em sua construção se empregam circuitos integrados, sendo que as versões mais utilizadas para a montagem dos LEDs são os descritos a seguir.

MCPCB (Metal Core Printed Circuit Board), ou placas de circuito impresso com núcleo metálico. O PCB de núcleo de metal, abreviação do MCPCB, é feito de uma camada de isolamento elétrico, placa de metal e folha de cobre, que possui condutividade magnética especial, alta resistência mecânica, excelente dissipação do calor. Segundo Mattos Mehl (2011), o processo construtivo do PCB consiste de uma placa de alumínio com $2 \mathrm{~mm}$ a $3 \mathrm{~mm}$ de espessura, sobre a qual é depositada uma camada de material dielétrico (geralmente óxido de alumínio $\mathrm{Al}_{2} \mathrm{O}_{3}$, obtido por anodização) e uma camada condutora de cobre, conforme mostrado na Figura 37.

Figura 37: Esquema de construção de MCPCB- Metal Core Printed Circuit Board

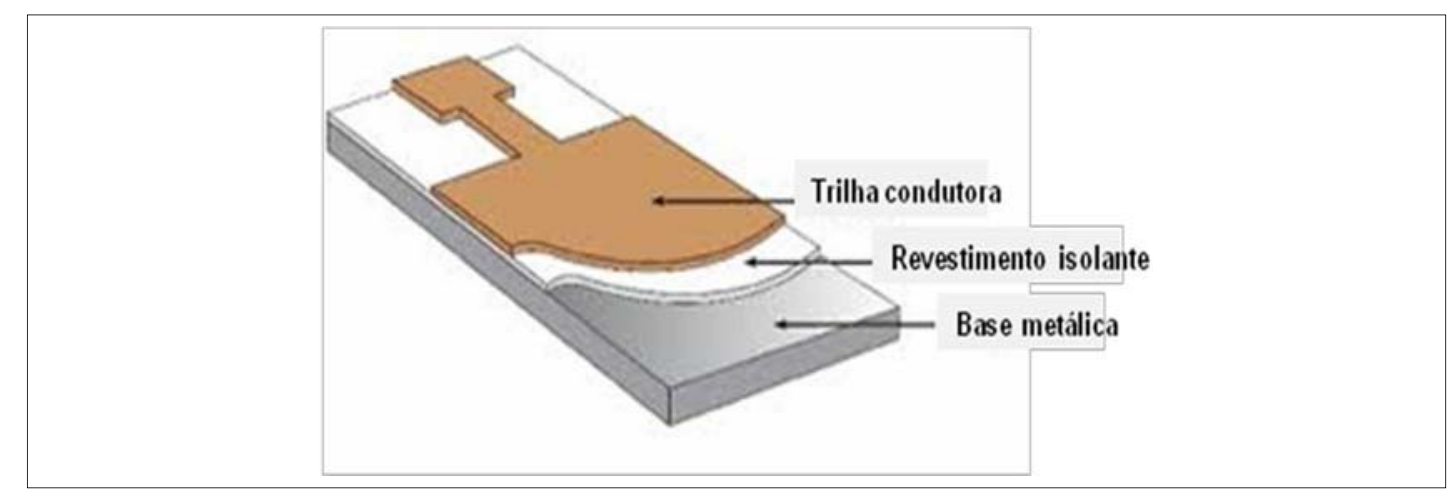

Fonte: Mattos Mehl, 2011

A resina fenólica, ou fenolite, também pode ser empregada na montagem da placa de circuito impresso como, por exemplo, a resina fenólica com carga de papel, que é uma mistura da resina com certa quantidade de papel picado, ou serragem de 
madeira (carga), apresentando cor marrom claro ou escura, dependendo do tipo de carga utilizada. A mistura é moldada e prensada à quente na forma de chapas com diferentes espessuras. O principal problema das chapas de fenolite ${ }^{36}$ para circuitos impressos ocorre em função do uso da carga à base de celulose, que a torna higroscópica ${ }^{37}$, podendo ter suas características isolantes diminuídas, e o risco de deformar. Segundo a norma NBR $8188 / 83^{38}$, essas chapas são referenciadas como FR-2, e a sigla FR vem da expressão em inglês flame resistant, ou seja, resistente ao fogo.

O emprego da resina epóxi e o uso interno de uma fina manta de tecido de fibras de vidro (FV), faz com que as placas de FV sejam totalmente inertes à água, mas, por outro lado, produz uma placa extremamente difícil de ser cortada e furada, fazendo com que sejam necessárias ferramentas especiais para fazer o corte e a furação das placas de circuito impresso. As placas de fibra de vidro são referenciadas como FR-4. Segundo Scopacasa (2016), as placas de circuito do tipo FR4 podem resultar em soluções com custos mais competitivos e termicamente eficientes, quando comparados com MCPCB.

As placas cerâmicas podem ser outra opção, sendo que consistem, basicamente, do uso do substrato cerâmico utilizando compostos com altos valores de condutividade térmica, composto por um pó branco produzido pelo refino da bauxita, chamado de Alumina - $\mathrm{Al}_{2} \mathrm{O}_{3}$ ou óxido de alumínio. Para a construção das placas cerâmicas, exatamente como ocorre no MCPCB, se faz necessário uso de camadas de cobre e máscaras de solda para a composição final do produto. Seu uso é restrito em função da limitação de disponibilidade em nosso mercado; porém, para projetos com alta densidade de luz, são altamente recomendadas, em função do ótimo desempenho e confiabilidade. A Figura 38 apresenta os exemplos e materiais

\footnotetext{
${ }^{36}$ Fenolite - Na verdade o nome fenolite era originalmente a marca comercial de um fabricante de chapas isolantes, muito usada pelos fabricantes de máquinas elétricas e transformadores, sendo mantido como terminologia do mercado

37 Higroscópica-substância que tem como propriedade a capacidade de absorver umidade.

${ }^{38}$ NBR 8188/83- Guia de projeto e uso da placa impressa - Procedimento, cancelada em 2011, mas serve ainda como de referência para os projetos de circuitos impressos.
} 
utilizados na fabricação dos PCls, modelos FR4 - fibra de vidro, MCPCB e o PCB cerâmico.

Figura 38: Secção transversal de PCls - (1) FR4 com furos metalizados, (2) MCPCB, (3) cerâmica.

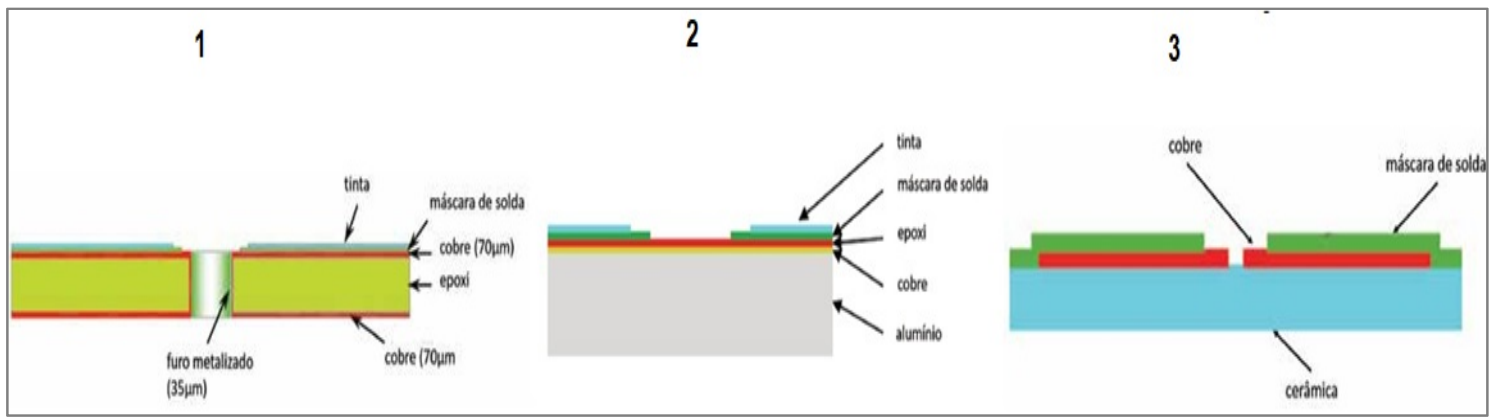

Fonte: Scopacasa, 2016, adaptado pela autora, 2020.

A escolha da placa de circuito impresso é muito importante, uma vez que terá influência no comportamento térmico do sistema, oferecendo maior ou menor desempenho e confiabilidade ao conjunto; além disso, individualmente, apresentam vantagens e desvantagens no que se refere a custos, disponibilidade, manuseio, etc. O Quadro 1 mostra o comparativo detalhado das opções de PCls.

Quadro 1: Comparativo dos principais modelos de PCls.

\begin{tabular}{|c|c|c|c|}
\hline & FR4 & МСРСВ & PCB cerâmico \\
\hline Custo & Baixo para médio & Médio & Alto \\
\hline $\begin{array}{l}\text { Desempenho } \\
\text { térmico }\end{array}$ & Baixo para médio & Médio para excelente & Alto para excelente \\
\hline $\begin{array}{l}\text { Coeficiente de } \\
\text { expansão térmica }\end{array}$ & Bom & Moderado & Bom \\
\hline $\begin{array}{l}\text { Densidade de LEDs } \\
\text { na montagem }\end{array}$ & $\begin{array}{c}\text { Indicado para aplicações } \\
\text { com baixa densidade, alto } \\
\text { espaçamento entre LEDs } \\
\text { e baixa corrente de } \\
\text { operação } \\
\end{array}$ & $\begin{array}{c}\text { Indicado para média } \\
\text { densidade e moderado } \\
\text { espaçamento entre LEDs }\end{array}$ & $\begin{array}{l}\text { Indicado para alta } \\
\text { densidade com o mínimo } \\
\text { espaçamento entre LEDs }\end{array}$ \\
\hline $\begin{array}{l}\text { Montagem } \\
\text { mecânica e } \\
\text { manuseio }\end{array}$ & $\begin{array}{l}\text { Fácil montagem, pois a } \\
\text { placa não quebra } \\
\text { facilmente }\end{array}$ & $\begin{array}{l}\text { Fácil montagem, pois a } \\
\text { placa não quebra } \\
\text { facilmente }\end{array}$ & $\begin{array}{c}\text { Precaução extra para } \\
\text { prevenir a quebra } \\
\text { cerâmica }\end{array}$ \\
\hline Disponibilidade & Alta & Alta & Limitada \\
\hline
\end{tabular}

Fonte: Scopacasa, 2016, adaptado pela autora, 2020. 


\subsubsection{O controle e gerenciamento térmico}

O nível 3 (três) de integração considera o projeto térmico indispensável para garantir as condições ideais de operação e de desempenho do LED. Para isso, se faz uso de dissipadores de calor, interfaces térmicas e demais elementos de controle térmico. Segundo Scopacasa (2016), o controle da temperatura é de vital importância para o desempenho da luminária, assim como também da sua longevidade pois, garantir o controle sobre a temperatura gerada pelo LED, é uma forma de assegurar a maior vida útil do sistema.

Temos dois tipos de calor a serem considerados: o primeiro é o calor dissipado, que é resultante da não transformação da energia elétrica em luz (visível ou não). O segundo é o calor irradiado, que representa a energia presente no feixe de luz, e que no LED é quase ausente. Ainda segundo Scopacasa (2016), o LED emite cerca de $60 \%$ da energia visível e $40 \%$ de calor, sendo que esse calor não pode ser desprezado, por tratar-se de uma parcela considerável; portanto, temos que desenvolver projetos térmicos para garantir as condições ideais de operação e melhores condições de desempenho do produto.

Outra questão a ser considerada é o fato de o fluxo luminoso e a cor serem dependentes da temperatura de operação do LED.

Qualquer fonte luminosa, com o tempo, perde a capacidade de produzir fótons, mas no uso da tecnologia LED o excesso de calor acelera muito esse processo, dado que quanto maior a temperatura menor será o fluxo luminoso.

Outras variáveis podem ser identificadas, tais como a diminuição da eficácia do sistema e possíveis alterações nas coordenadas de cromaticidade.

A exposição a temperaturas elevadas também pode danificar outros elementos do LED como, por exemplo, a camada de fósforo que é necessária para converter a luz gerada em luz branca, ou mesmo os materiais usados para encapsular os chips dentro do dispositivo LED.

O gerenciamento térmico consiste em fazer com que o calor gerado no LED percorra um caminho e seja transferido para o ambiente e para longe dos dispositivos eletrônicos no qual a fonte de luz irá operar. 
A escolha de um dissipador de calor deve considerar os dados térmicos de aplicação do dispositivo, juntamente com as especificações geradas pelos fornecedores de dissipadores de calor e a inserção das interfaces térmicas entre estes componentes. Desta forma, os dissipadores desempenham um papel muito importante nos projetos de luminárias que possuam componentes emitindo calor como subproduto, criando um caminho eficiente para o calor ser transferido para o ar ambiente.

O mercado oferece ampla gama de modelos de dissipadores, sendo utilizado para a sua fabricação um metal sólido, como por exemplo o alumínio, que possui maior facilidade de transmissão e dissipação de energia térmica e com um custo acessível. Com diâmetros, volumes e superfícies de refrigeração diferentes entre modelos, temos muitos exemplares com potência dissipada de até $200 \mathrm{~W}$, sendo que o processo de transferência do calor gerado na placa de LED para o ar ambiente ocorre por meio de uma combinação entre condução, irradiação térmica e convecção natural ou forçada.

A Figura 39 apresenta o dissipador de irradiação térmica conhecido como passivo e a Figura 40 apresenta a versão de controle térmico forçado conhecido por ativo, por possuir uma ventoinha para auxiliar na dissipação.

Figura 39: Modelo de dissipador passivo.

Figura 40: Modelo de dissipador ativo.
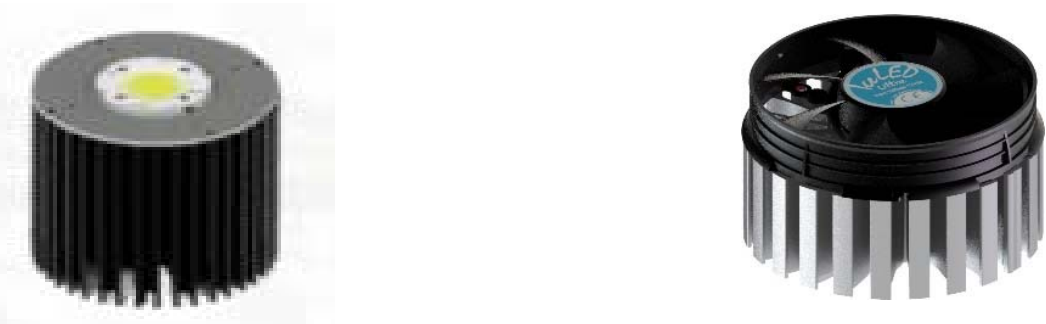

Fonte: Lucchi, 2019.

A Figura 41 é uma representação básica do percurso do calor gerado pelo LED até atingir $\mathrm{o}$ ambiente com as várias interfaces a serem percorridas. $O$ projeto térmico adequado consiste na identificação de todas estas interfaces e no cálculo dos valores das várias resistências térmicas envolvidas, sendo que a unidade é ${ }^{\circ} \mathrm{C} /$ Watt ou ${ }^{\circ} \mathrm{K} /$ Watt e define-se as resistências térmicas em função da dificuldade que o calor 
encontra em seu caminho, desde a junção semicondutora até a carcaça metálica do LED. Ainda segundo Scopacasa (2016), esse dado é de extrema relevância para o cálculo adequado do dissipador para cada aplicação.

A Figura 41 mostra, em corte, o caminho térmico percorrido do LED até o ambiente.

Figura 41: Corte transversal representação o caminho térmico desde a sua geração no Led até o ambiente.

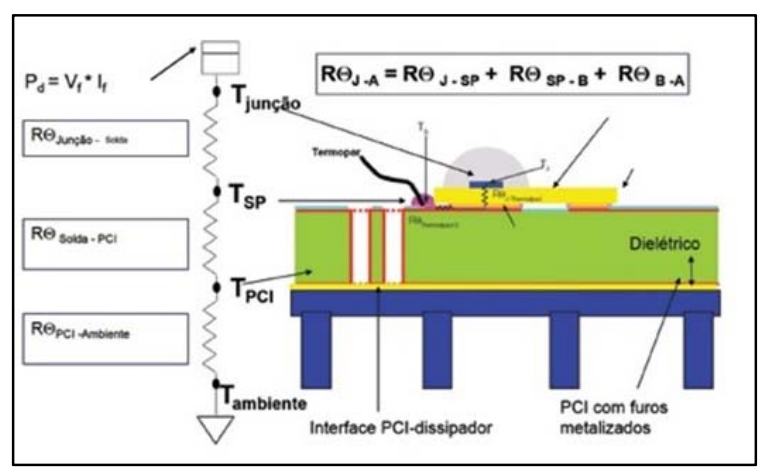

Fonte: Lumileds Holding BV, 2015

- Tj representa a temperatura na junção do Led, temperatura gerada pela parcela da energia elétrica não convertida em luz visível;

- Ta representa a temperatura ambiente;

- Pd representa a potência envolvida, normalmente calculada pela multiplicação do valor da tensão direta do Led pela corrente elétrica a ele aplicada;

- RӨja representa a soma de todas as resistências térmicas do sistema, desde a junção do LED até o ambiente.

$$
\begin{aligned}
& \text { Equação } \\
& T j=T a+P d . \text { RӨja }
\end{aligned}
$$

Fórmula 1 


\subsubsection{Interfaces térmicas e conexões}

O bom funcionamento da luminária de estado sólido depende também das interfaces térmicas, na medida em que sua utilização entre a placa de circuito impresso e o dissipador é vital para promover o melhor acoplamento entre ambos, evitando bolsões de ar entre estas duas superfícies.

O ar é um péssimo condutor de calor e, portanto, temos que preencher estes bolsões de ar com um material com boa condutividade térmica, contribuindo, desta forma, para a diminuição da resistência térmica total do sistema (SCOPACASA, 2016).

A complexidade do projeto térmico é diretamente proporcional ao nível de potência no qual se trabalha.

É possível a realização de projetos sem a utilização de um dissipador de calor físico, principalmente quando se faz uso de LEDs Low-Power, pois o calor gerado pode ser dissipado na própria placa de circuito impresso, utilizando a área de cobre. No caso de luminárias montadas com potências mais altas, como por exemplo com LEDs modelos High-Power, obrigatoriamente o dissipador térmico deverá ser adotado, sendo necessário ser bem dimensionado, pois nem sempre é possível utilizar a própria carcaça metálica da luminária como um elemento de controle térmico.

De qualquer forma, utilizando um dissipador convencional, ou a carcaça da luminária, deverá ser considerada a inclusão da interface térmica. Alguns modelos de interfaces térmicas são disponibilizados pelo mercado, a saber:

$\rightarrow$ Manta de grafite - O material é produzido a partir de fibra de carbono, nano pó de carbono e grafite, sintetizados através de um complexo processo químico e mecânico. Altíssima resistência térmica e velocidade de dissipação, pode ser laminado com filme de poliéster para aumentar a resistência térmica e, também, atuar como isolamento elétrico;

$\rightarrow$ Adesivos líquidos ou pasta térmica são elastômeros ideais para a união de componentes de intensa geração de calor, como PCls a dissipadores, e desenvolvidos para proporcionar excelente condutividade térmica, além da fixação mecânica dos componentes de contato. Após sua cura, fixa fortemente 
os componentes e dispensa o uso de parafusos e grampos, adequando-se perfeitamente às irregularidades das superfícies de contato;

$\rightarrow$ Fitas termo condutoras são fitas adesivas dupla-face com altíssima força de adesão, aumentando a vida útil do LED, excelente barreira isolante. São utilizadas na fixação mecânica da $\mathrm{PCl}$ ao dissipador, dispensando o uso de elementos mecânicos de fixação, tais como parafusos e grampos. Garante baixa resistência térmica de interface, otimizando o fluxo térmico até o ambiente. Especialmente desenvolvida para adesão a alumínio, FR4, etc.

$\rightarrow$ Pads (folhas), é composta por produtos mono e bi-componente, que são aplicados da mesma forma que um adesivo líquido ou pasta térmica, preenchendo com perfeição mesmo os desníveis mais microscópicos das superfícies de contato, sendo que, após a sua cura, adquire a consistência de um elastômero macio e flexível. Excelente estabilidade mecânica e química, elevada absorção de stress mecânico e vibração durante e após montagem, sem migração, sem ressecamento, sem óleo, e a cura pode ser acelerada com aplicação de calor.

Outras condicionantes, além da interface térmica, devem ser consideradas, tais como a espessura, a quantidade e a área da interface térmica, e o torque entre a $\mathrm{PCl}$ e o dissipador, que podem ter acoplados ou não um conector para a devida conexão elétrica.

O sistema de conexão, normalmente feito por meio de um holder ${ }^{39}$, é um componente importante e deve ser montado alinhado ao PCl (COB-Chip-on-board) e dissipador.

A interface térmica é inserida entre o holder e o dissipador térmico, conforme Figura 42.

\footnotetext{
${ }^{39}$ Suporte que garante o contato elétrico, tem a mesma função de um soquete.
} 
Figura 42: Dissipador, interface térmica, holder e COB LED.

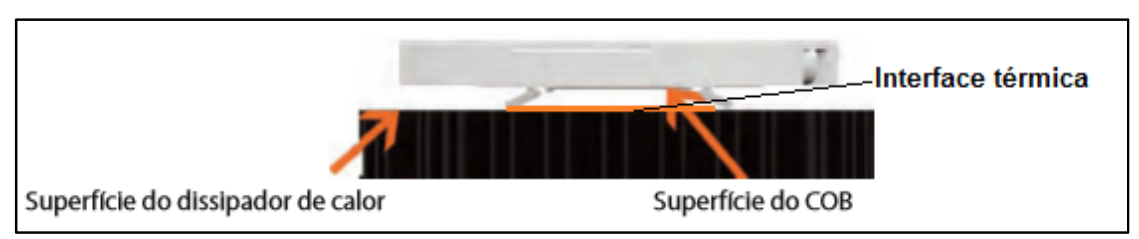

Fonte: A.A.G.Stucchi,srl us, adaptado pela autora, 2020.

\subsection{6. Óptica primária}

Segundo Barbosa (2013), alguns projetos de lentes utilizam a combinação de uma lente de reflexão interna total, TIR (Total Internal Reflection) e lentes refrativas, a fim de direcionar os raios. O uso de lentes TIR em componentes ópticos é vantajoso visto que, além de redirecionar os raios que não incidiriam diretamente nas lentes refrativas, possui elevada taxa de reflexão (ou seja, quase não absorve ou refrata os raios incidentes), é compacto e substitui o uso de revestimentos reflexivos.

A óptica primária faz parte do nível 1 (um) de integração do projeto, em função de estar atrelada frontalmente ao semicondutor, conforme apresentado na Figura 43.

Figura 43: Lente primária.

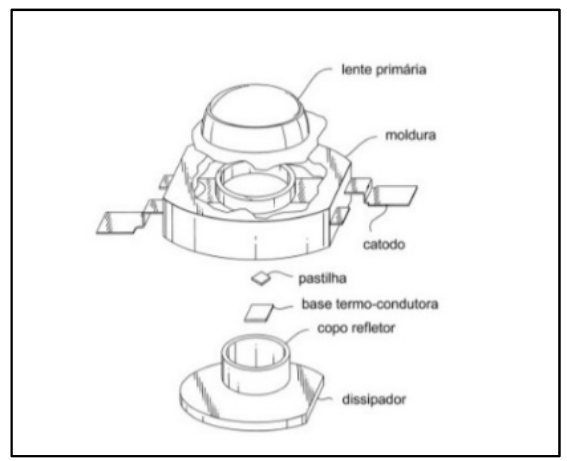

Fonte: Barbosa, 2013. 


\subsection{7. Óptica secundária}

A iluminação direcional requer exigências rigorosas dos fabricantes de LED, uma vez que o mercado se acostumou com feixes de luz controlados de $4^{\circ}$ a $60^{\circ}$, princípios usualmente estabelecidos pela tecnologia antecessora halógena, com cores uniformes ao longo do feixe, sombra única e bem delimitada. $O$ tamanho relativamente maior de algumas fontes de luz em LED transforma isso em um desafio, pois leis fundamentais da óptica definem que fontes com maior capacidade de emissão de luz montadas em áreas pequenas, resultam em fachos com ângulos abertos.

Possíveis variações de cor ao longo da emissão de luz podem ser visualizadas no feixe e fontes de LED em arranjos, que normalmente são utilizados para criar luminárias com maior quantidade de lúmens, tendem a multiplicar as sombras e alteram o resultado pretendido. A engenharia óptica primária integrada no LED, em conjunto com a óptica secundária, garantem resultados de fachos perfeitos, visto que os LEDs de potência, em sua maioria, apresentam fachos de distribuição bem abertos, $120^{\circ}$ em média, fazendo com que sua intensidade seja fraca para os casos de iluminação direcional e funcional. A óptica secundária está integrada no nível 3 (três) do projeto de construção de uma luminária.

\subsubsection{Lentes colimadoras}

Segundo Nascimento (2012), para direcionar esse facho de luz do LED de forma a aumentar a sua intensidade e reduzir a abertura de facho, utiliza-se, à frente do LED, um componente chamado lente colimadora.

Estas lentes possuem alta eficiência, chegando a $90 \%$ de aproveitamento do fluxo; valor este bastante alto quando comparado com os refletores utilizados na iluminação convencional.

Com a facilidade de moldagem, as lentes podem adquirir diversos tamanhos e formatos e distintas características ópticas, o que abre um mundo de possibilidades e arranjos para uso com LEDs, possibilitando ser aplicado de forma coerente à 
iluminação arquitetural. O funcionamento de uma lente colimadora é apresentado na Figura 44.

Figura 44: Demonstração do direcionamento da luz emitida, por uma lente colimadora.

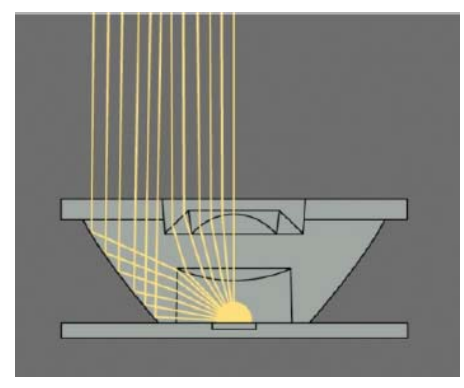

Fonte: Nascimento, 2012.

Normalmente as lentes colimadoras são produzidas utilizando polímeros termoplásticos sintéticos, que são obtidos por meio de reações (polimerizações) de moléculas simples (monômeros), e fabricados comercialmente em grande escala e para diversas aplicações. Como exemplos destes polímeros utilizados para a produção de ópticas secundárias, temos o policarbonato (PC), Polimetil (metacrilato) de Metila ou Acrílico (PMMA). Os polímeros fundem-se e se solidificam várias vezes, sendo alguns deles muito utilizados como sistema óptico.

As lentes estão disponíveis em diversos modelos, como por exemplo lente individual para uso sobre um SMD ou COB LED, ou arranjos de LEDs com lentes duplas, triplas, quádruplas ou multi-lentes, lentes lineares, lentes Fresnel, com ângulos extremamente concentrados até ângulos abertos.

$\rightarrow$ O PMMA é um polímero termoplástico extremamente transparente, obtido por polimerização do monómero metilmetacrilato. Devido à sua transparência, estética e resistência aos riscos, pode ser utilizado como uma alternativa ao policarbonato (PC), caso elevada transparência, resistência aos raios UV e/ou resistência aos riscos sejam requeridas, e desde que as propriedades de elevada resistência ao impacto não sejam cruciais para a aplicação. É também conhecido como acrylic glass. A Figura 45, apresenta modelos de lentes 
individuais em PMMA e a Figura 46 mostra um modelo de lente múltipla para arranjos de LED $6 \times 2$.

Figura 45: Modelos de lentes colimadoras individuais.

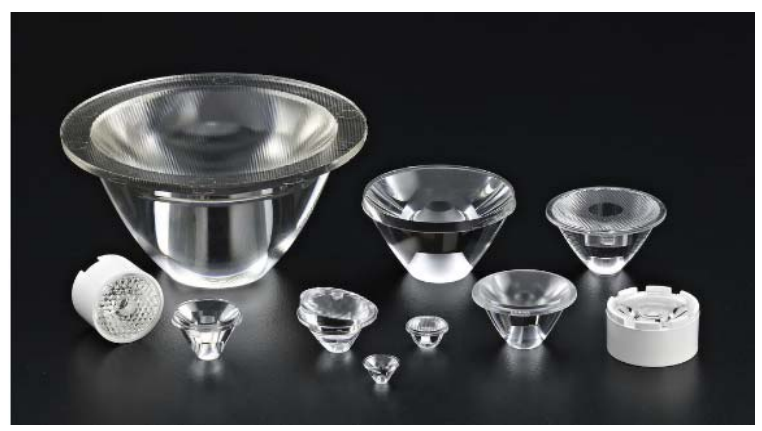

Fonte: Ledlink-Optics, 2019

Figura 46: Modelo de lente colimadora múltipla em PMMA.

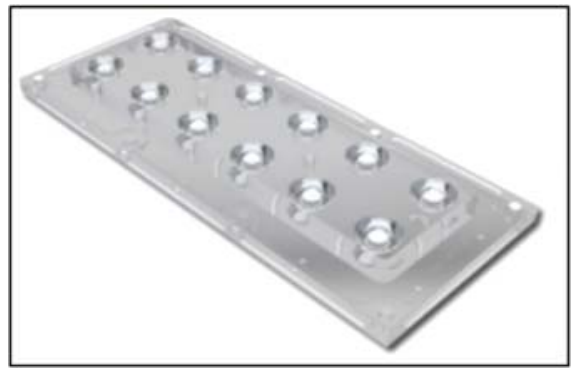

Fonte: Khatod Optoeletronic Srl, 2019.

$\rightarrow$ Os policarbonatos são polímeros de cadeia longa, formados por grupos funcionais unidos por grupos carbonato. São moldáveis quando aquecidos sendo, por isso, chamados termoplásticos. Como tal, estes plásticos podem ser utilizados na confecção de lentes e partes delas. São transparentes, inquebráveis e de alta resistência.

$\rightarrow$ Os silicones são polímeros mistos de material orgânico e inorgânico com a fórmula genérica [R2SiO] $n$, onde $R$ são os grupos orgânicos como metil, etil e fenil. Os polímeros são inertes, inodoros, resistentes à decomposição pelo 
calor, água ou agentes oxidantes, além de serem bons isolantes elétricos. Apresentam excelente transparência, baixa absorção de luz, alta eficiência na distribuição de luz, boa resistência à luz ultravioleta e sem efeito de amarelamento, alta flexibilidade mesmo em baixa temperatura, alta estabilidade térmica, propriedades ópticas isotrópica ${ }^{40}$, facilidade no processo de moldagem por injeção de alta eficiência, e resistente a microfissuras, também sob condições ambientais adversas. A Figura 47 apresenta um modelo de múltiplas lentes em silicone para arranjos de LED 6 × 2 .

Figura 47: Lente para arranjos de LED 6 × 2 em silicone.

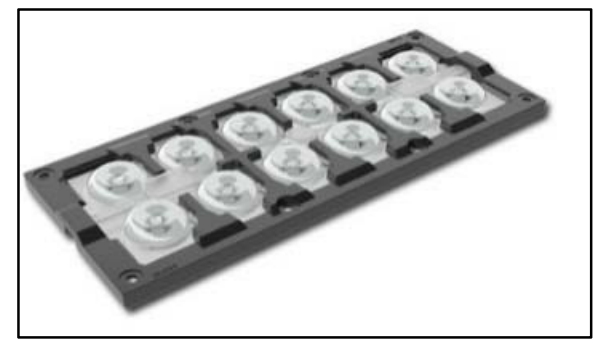

Fonte: Khatod Optoeletronic Srl, 2019.

A Figura 48 mostra uma lente individual para lâmpada MR16 Standard ou para COB LED.

Figura 48: Lente individual em silicone para lâmpada MR16.

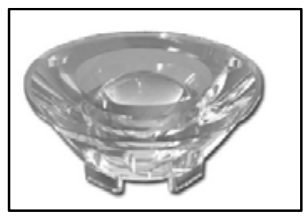

Fonte: Khatod Optoeletronic Srl, 2019.

\footnotetext{
40 Isotrópicos - Em resistência dos materiais o material é dito isotrópico se suas propriedades mecânicas são as mesmas em todas direções. Os metais geralmente são materiais isotrópicos, ainda que, após serem sujeitos a processos de laminagem ou forja, essas propriedades mecânicas passem a ser anisotrópicas.
} 


\subsubsection{Refletores}

O refletor é o dispositivo geralmente feito de alumínio anodizado, ou material plástico metalizado. A forma do refletor é dada de maneira que redirecione a luz emitida pela fonte emissora por reflexão, sendo que pode ter comportamentos distintos, como: refletores parabólicos, que representam a forma mais utilizada no mercado podendo ter a sua radiação concentrada, horizontal, assimétrica, ou com característica batwing, refletores darklight, com efetivo controle de ofuscamento e comumente utilizado para fontes puntiformes de alto brilho como o próprio LED, refletores esféricos, refletores elípticos, entre outros. A Figura 49 mostra o comportamento de um refletor parabólico para LED COB e a Figura 50 apresenta refletores parabólicos em alumínio anodizado para luminárias para módulos lineares de LED, tubo LED ou para lâmpadas fluorescentes tubulares T5 e T8.

Figura 49: Refletor parabólico para COB LED.
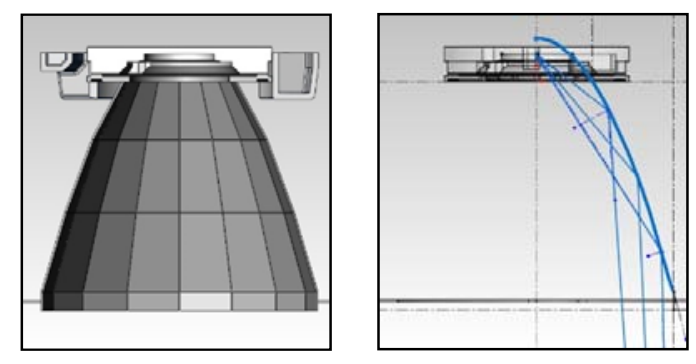

Fonte: Almeco, 2019.

Figura 50: Refletores parabólicos lineares em alumínio anodizado.

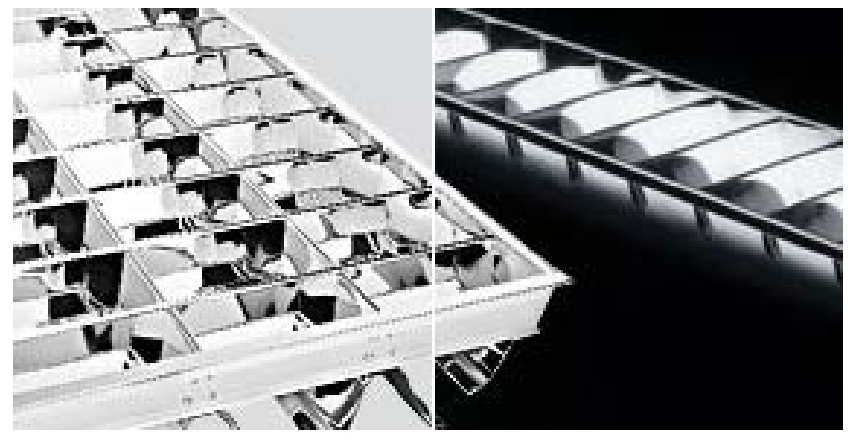

Fonte: Bigoni, 2013, adaptado. 
Os refletores plásticos moldados em policarbonato normalmente recebem um tratamento de metalização a vácuo, em cromo ou alumínio. O processo é simples e de baixo custo, no qual camadas de metal ou de não metal, relativamente frias, são depositadas em alto vácuo sobre superfícies preparadas. Temos algumas limitações, como carga térmica, robustez e desempenho óptico.

Os refletores em alumínio pré-anodizado são mais caros, mas são recicláveis e com maior capacidade de aproveitamento, reflexão e direcionamento da luz. As principais vantagens do alumínio pré-anodizado, em relação ao alumínio natural, estão relacionadas à redução da rugosidade da superfície, à refletância (que se apresenta superior e controlada), e sua resistência à abrasão e à corrosão. Podem causar ofuscamento se não houver um bom projeto do sistema óptico e são atualmente otimizados para uso com os LEDs, garantindo reflexão homogênea em todo espectro visível e com resultados até $15 \%$ superiores aos refletores metalizados.

A Figura 51 apresenta alguns acabamentos de superfícies de alumínio anodizado que são utilizados para a criação dos sistemas ópticos.

Figura 51: Acabamento especular (espelhado), fosco (matt) e acetinado (texturizado).

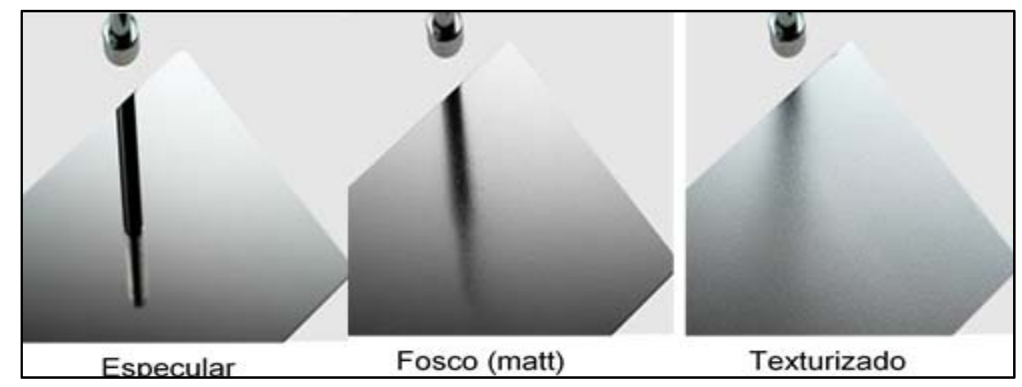

Fonte: Bigoni, 2013.

À procura por outros tratamentos de superfícies possíveis para o alumínio temos, por exemplo, o modelo PVD 95\%, que é baseado na deposição de alumínio à vácuo, proporcionando brilho de alta qualidade sobre superfície de alumínio anodizado, ou o modelo PVD 98\%, que recebe uma camada de prata de $99,99 \%$ de 
pureza. Ambos os modelos reduzem de forma considerável o ofuscamento, graças ao controle de distribuição de luz e o controle de luminâncias.

Vários tipos de refletores podem ser desenvolvidos, conforme a condução pretendida da luz, podendo ser parabólicos, darklight, esféricos, elípticos, entre outros.

A Figura 52 mostra as comparações entre refletor em plástico metalizado e refletores em alumínio por processo PVD 95\%, PVD 98\%, e o comportamento espectral do LED.

Figura 52: Comportamento do espectral do LED em distintos refletores.

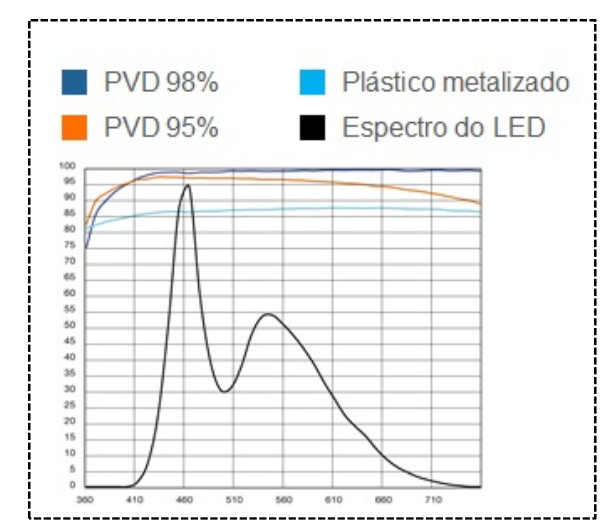

Fonte: Bigoni, 2013.

Temos algumas evidências de certa preferência pelas lentes colimadoras no mercado nacional, por permitirem o melhor controle e direcionamento da luz em algumas aplicações, quando comparados a alguns modelos de refletores de baixo custo, conforme apresentado anteriormente, onde nem sempre é possível controlar toda a luz, em razão de que nem toda a luz emitida toca a superfície do refletor. As lentes colimadoras podem causar grande ofuscamento por criar feixes de alta luminância, sua eficiência dificilmente é superior a $90 \%$ e tem altos índices de produtos rejeitados.

A Figura 53 mostra o aproveitamento da luz de uma fonte de LED que utiliza uma lente colimadora e um refletor. 
Figura 53: Lente colimadora $\mathrm{X}$ refletor em relação ao aproveitamento da luz.

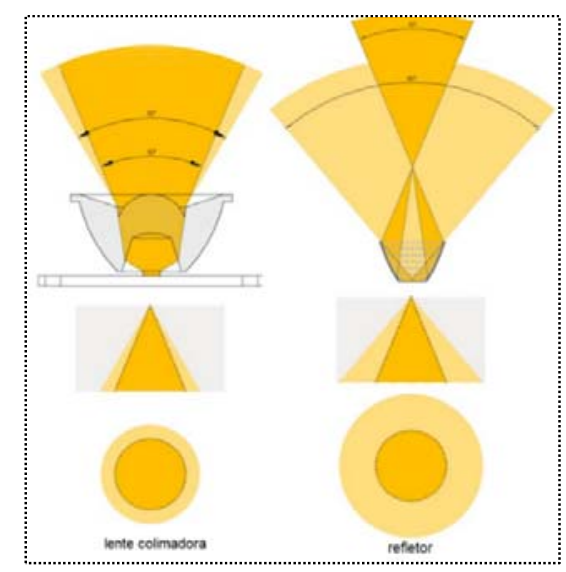

Fonte: Soares, 2017.

\subsection{8. Óptica terciária}

A óptica terciária é também chamada de óptica "difusora", pois tem a função de auxiliar e orientar o fluxo luminoso em uma determinada direção, ou de controlar a luz emitida pela fonte, auxiliando na difusão do efeito pontual do LED. Pode ser utilizada em conjunto com a óptica secundária.

Os difusores são produzidos utilizando polímeros termoplásticos sintéticos como Polimetil (metacrilato) de Metila ou Acrílico (PMMA) e o Poliestireno (PS) com espessuras de $1,2 \mathrm{~mm}$ a $1,8 \mathrm{~mm}$. Oferecem alta transmitância de luz, variando entre $70 \%$ a $99 \%$, com alto nível de difusão e distintos acabamentos: fosco (matt), frisado transparente, frisado opaco, texturizado, prismático, entre outros. A Figura 54 mostra os tipos mais comuns de difusores utilizados em luminárias LED pela indústria nacional. 
Figura 54: Acabamento de difusores - matt (1), texturizado (2), texturizado opaco (3), frisado opaco (4), frisado transparente (5) e prismático (6).

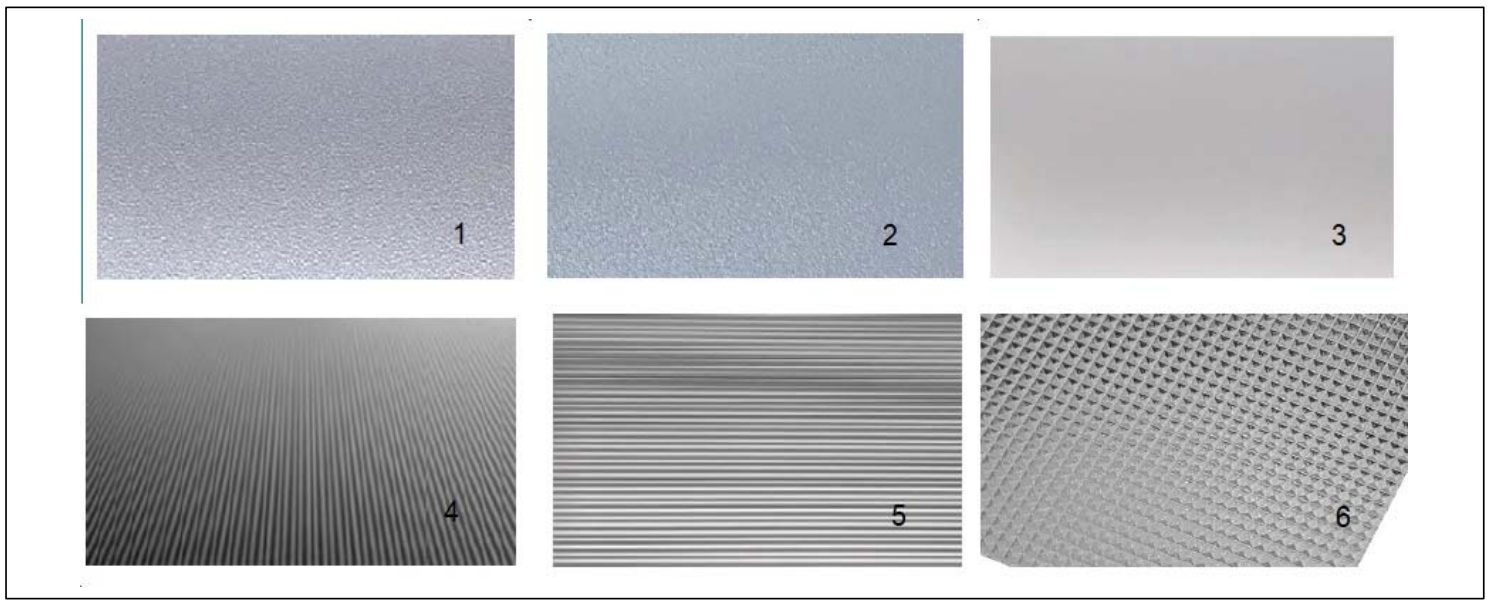

Fonte: Lucchi, 2019, adaptado pela autora, 2020.

A Tabela 5 apresenta a transmitância e difusão da luz (+/- 2\% de tolerância) e características da saída de luz.

Tabela 5: Principais características dos difusores.

\begin{tabular}{|l|c|c|c|}
\hline Acabamento & $\begin{array}{c}\text { Transmitância } \\
\text { da luz }\end{array}$ & $\begin{array}{c}\text { Nível de difusão } \\
\text { da luz }\end{array}$ & $\begin{array}{c}\text { Característica da saída } \\
\text { de luz }\end{array}$ \\
\hline $\mathbf{1}$ (matt - fosco) & $90 \%$ & $88 \%$ & $\begin{array}{c}\text { Difuso, com grande } \\
\text { eficiência }\end{array}$ \\
\hline $\mathbf{2}$ (texturizado) & $85 \%$ & $90 \%$ & $\begin{array}{c}\text { Difuso em ambos os } \\
\text { lados }\end{array}$ \\
\hline $\mathbf{3}$ (texturizado opaco) & $74 \%$ & $91 \%$ & $\begin{array}{c}\text { Muito difuso, } \\
\text { privilegiando o conforto } \\
\text { visual }\end{array}$ \\
\hline $\mathbf{4}$ (frisado opaco) & $90 \%$ & $89 \%$ & $\begin{array}{c}\text { Fresnel, cria fachos } \\
\text { lineares }\end{array}$ \\
\hline $\mathbf{5}$ (frisado transparente) & $90 \%$ & $82 \%$ & $\begin{array}{c}\text { Fresnel, cria fachos } \\
\text { lineares }\end{array}$ \\
\hline $\mathbf{6}$ (prismático) & $99 \%$ & $99 \%$ & $\begin{array}{c}\text { Prisma com elevado } \\
\text { controle visual UGR }<19\end{array}$ \\
\hline
\end{tabular}

Fonte: Lucchi, 2019, adaptado pela autora, 2020. 


\subsubsection{Componentes eletrônicos}

Segundo Nascimento (2012), o LED necessita de uma fonte de energia externa para viabilizar a corrente elétrica que circula por ele, de forma a emitir luz. A fonte deve ser polarizada, pois de outra forma não haverá migração dos elétrons no sentido das lacunas. A capacidade de uma fonte de alimentação de LEDs é dada pela máxima tensão de saída que ela pode fornecer, e por sua corrente, que deve ser constante, independentemente do número de LEDs que colocamos na saída.

Com a fabricação dos LEDs por diversos fabricantes, com valor de tensão direta da ordem de 3 volts, definiu-se uma faixa de 2,70 $\mathrm{V}$ a 3,30 $\mathrm{V}$ e algumas correntes de alimentação tornaram-se padrões de mercado. A princípio, os LEDs podem ser alimentados com outros valores de corrente, respeitando-se o limite superior fornecido em catálogo, em função do tipo de aplicação e a vida que se deseja dar ao LED.

Segundo Jacob (2006), considerando a preocupação global com o consumo de energia elétrica, a maioria das fontes para LEDs é baseada em fontes do tipo chaveada, que incorporam um regulador chaveado, tendo um circuito controlador que liga e desliga a corrente na carga (LED), por meio de um transistor e uma bobina, ligando e desligando rapidamente, de forma a manter uma corrente de saída constante.

Segundo Jacob (2006), quando o transistor é ligado, é fornecida corrente para os LEDs e, ao mesmo tempo, a bobina fica carregada com esta corrente. Ao desligar o transistor, a bobina passa a fazer o papel de fornecer corrente aos LEDs. Ao ligar o transistor novamente, começamos um novo ciclo. Este tipo de fonte apresenta as seguintes características:

$\rightarrow$ Alta eficiência de conversão energética, chegando a 95 \%;

$\rightarrow$ Tamanho compacto, já que não utilizam transformadores grandes e pesados;

$\rightarrow$ Aquecem pouco devido à sua alta eficiência;

$\rightarrow$ Incorporam sistemas de proteção contra curtos e sobrecarga;

$\rightarrow$ Muitas vezes são universais e podem ser ligadas em qualquer rede, $127 \mathrm{~V}$ ou $220 \mathrm{~V}$; 
$\rightarrow$ Mantém a potência na saída constante, independentemente da tensão de entrada;

$\rightarrow$ Entrega corrente constante para os LEDs, ideal para seu funcionamento;

$\rightarrow$ Podem ser comandadas por sistemas de automação e controle;

$\rightarrow$ Permitem facilmente a dimerização dos LEDs;

$\rightarrow$ Podemos considerar as seguintes correntes de funcionamento mais utilizadas no mercado: $350 \mathrm{~mA}(0,35 \mathrm{~A}), 700 \mathrm{~mA}(0,70 \mathrm{~A}), 1.000 \mathrm{~mA}(1,0 \mathrm{~A})$ e $1.500 \mathrm{~mA}$ $(1,5 \mathrm{~A})$.

A maior desvantagem quando do uso de correntes elevadas é a atenção demandada por parte do controle térmico.

Outro tipo de alimentação são fontes de tensão contínua de 12 a 24 Volts, para uso com fitas de LEDs, que funcionam em baixa tensão, ou fornecida por baterias automotivas ou qualquer fonte de tensão contínua de 12 a 24 Volts. Outra alimentação, ainda, é fornecida por um transformador eletromagnético de 12 Volts alternados, normalmente utilizados em lâmpadas dicróicas. A aplicação mais comum é quando se deseja substituir lâmpadas dicróicas por sistemas de LEDs, aproveitando o transformador existente. Não devemos utilizar transformadores eletrônicos para dicróicas nestas fontes para LEDs.

Quando alimentamos a fonte por meio de pilhas ou baterias recarregáveis com tensão bem mais baixa, também polarizamos os LEDs. Neste caso a fonte se encarrega de aumentar a tensão de saída para que possamos ligar um ou mais LEDs e ainda fornecer a corrente necessária para o funcionamento desses. Muitas vezes basta uma única pilha de 1,5 Volts para acender vários LEDs. Encontramos esta fonte em lanternas, sistemas de energia solar e de emergência.

Os LEDs podem ser facilmente dimerizados, independentemente do fato do driver ser de corrente ou tensão constante. A dimerização é efetuada com o acionamento e desligamento da fonte de corrente em uma frequência acima de 100 Hertz (ciclos por segundo), para que a nossa visão não perceba o efeito de ligar e desligar do LED, e a dimerização consiste em controlar o nível de intensidade da luz

O sinal que injetamos na fonte para efetuar o ligar e desligar do LED chama-se PWM, ou modulação por largura de pulso. O sinal PWM é uma onda quadrada de frequência 
fixa em que os tempos de ligado e desligado da onda são variados, de forma a conseguirmos o nível de dimerização desejado.

O LED também pode ser dimerizado se simplesmente variarmos a corrente direta que alimenta o mesmo; porém, ao variarmos a corrente, a cor do Led se altera, saindo muito fora do seu espectro original. Como sabemos, as características do LED são levantadas considerando a sua corrente nominal de funcionamento e, ao variarmos a corrente, estamos alterando suas características.

Com o sinal PWM modulando a fonte de corrente, quando a corrente estiver ligada e fluindo, o LED receberá sua corrente nominal de funcionamento, mesmo que por um pequeno período de tempo; porém sua intensidade irá variar, pois o LED passa e enxergar a corrente média entre os tempos de ligado e desligado.

O sinal PWM é gerado pelo sistema de automação que controlará o LED. Isto é normalmente feito por um microprocessador que tem a função específica de controlar a iluminação por meio de um sistema de controle. Este sinal PWM pode ser encadeado para outras fontes e controlar vários LEDs ao mesmo tempo.

A dimerização pode ser feita de várias formas, dentre as quais destacamos os protocolos analógicos, como por exemplo os modelos "Triac" e fase reversa (trailing edge) e os protocolos digitais, modelos 0/1-10 volts e DALI, dentre outras. Os modelos de dimerização apresentam desempenhos e complexidades específicas, sendo que alguns modelos têm maior aplicabilidade na iluminação residencial, como são os modelos Triac; os modelos fase reversa e 0/1-10V e DALI são mais utilizados em instalações comerciais, escritórios, museus, hospitais, etc., sendo muitas vezes conjugados com sistemas de gerenciamento da luz. As principais características dos modelos são:

$\rightarrow$ Triac - O acionamento do Triac pode ser comparado ao de uma chave. Dependendo do nível de tensão, o Triac começa a conduzir corrente elétrica e contínua até que o nível de tensão diminua para valores abaixo do valor de corte. O circuito é relativamente simples e de baixo custo. Um dos inconvenientes deste tipo de dimerização é a geração de interferências eletromagnéticas (EMI);

$\rightarrow$ Fase reversa (trailing edge) - É comumente utilizado em fontes de luz de baixa 
tensão, sendo muito eficiente para cargas capacitivas. Quase sempre necessitam do fio terra para sua instalação e isto pode representar uma barreira, pois nem sempre o fio terra é disponibilizado, principalmente em prédios mais antigos. Dentre as desvantagens, citamos o seu alto custo comparado com outros controles;

$\rightarrow$ 0/1-10V - Tem sido utilizado em aplicações de iluminação por muitos anos com a facilidade de compatibilizar vários tipos de drivers e controles de diferentes fabricantes, tornando este sistema muito atrativo. Isto é particularmente importante no crescente mercado de sistemas com LEDs, já que a maioria dos fabricantes de drivers não fabrica controles de dimerização e conta com a tecnologia 0/1-10 $\mathrm{V}$ para integrar seus produtos aos sistemas de controle disponíveis.

$\rightarrow$ DALI - (Digital Addressable Lighting Interface) foi originalmente desenvolvido na Europa para controle de reatores de lâmpadas fluorescentes. Os controles DALI são hoje utilizados em todo o mundo, inclusive para drivers de LEDs. Permitem o controle digital individual das luminárias, aumentando a produtividade do usuário. Diferentemente dos sistemas $0-10 \mathrm{~V}$, os fabricantes de controladores DALI oferecem características específicas e proprietárias para que o sistema seja plenamente compatível, de forma a explorar ao máximo a característica de maior robustez deste padrão.

A dimerização gera grandes benefícios e versatilidade aos projetos e instalações, mas pode gerar efeitos indesejáveis com o flicker, principalmente ao utilizar sistemas não compatíveis, sendo que o flicker é definido como variação temporal (potencialmente visível) da luz emitida. Podemos caracterizá-lo também como cintilação da luz e, dependendo da quantidade deste fenômeno, podemos ter impactos nas pessoas, que podem variar de um simples incômodo, distração ou aborrecimento, ou até mesmo a geração de problemas neurológicos. Os efeitos do flicker dependem das características da modulação da luz, das condições da luz ambiente, da sensibilidade dos indivíduos que utilizam os espaços iluminados e das tarefas por elas realizadas. O flicker de baixa frequência pode induzir a convulsões em 
pessoas com epilepsia fotossensível e, também, gerar dores de cabeça, fadiga, visão turva, e consequente redução no nível de desempenho (SCOPACASA, 2017).

Convém que o sistema de iluminação seja projetado com driver "free flicker", principalmente em espaços de caráter laborativo, como escritórios e indústrias, a fim de garantir bom desempenho visual, mesmo sob circunstâncias difíceis e durante longos períodos.

A eficiência da iluminação LED pode ser fomentada com a integração de controles de automação. Empresas como Signify, anteriormente conhecida como Philips Lighting, Bridgelux e Marvell, estão criando produtos com drivers wi-fi ${ }^{41}$, que permitem que as luminárias LED sejam controladas remotamente, com expectativa de grande redução no consumo de energia, principalmente quando aplicada no setor comercial.

A Signify também desenvolveu uma nova gama de luzes $\mathrm{Li}-\mathrm{Fi}^{42}$ de transmissão pela Internet chamada Truelifi, que são capazes de transmitir dados para dispositivos como laptops a velocidades de até $150 \mathrm{Mbps}$ usando ondas de luz, em vez dos sinais de rádio usados por $4 \mathrm{G}$ ou Wi-Fi. Na prática, elas funcionam como roteadores sem fio, só que usando luz. Li-Fi é uma tecnologia que pode servir de base à internet das coisas (Internet of Things - loT), onde tudo o que é eletrônico permanece conectado à internet, sendo que as luzes dos LED's são utilizadas como os pontos de acesso.

$\mathrm{Na}$ integração do projeto com LEDs, os componentes eletrônicos e sistemas de controles da dimerização, estão subdivididos entre o nível 3 (três) e nível 5 (cinco).

\subsection{Recomendações para o desenvolvimento e produção de luminárias LED.}

A eficiência da fonte luminosa e da luminária é um importante indicador da eficiência energética de um sistema de iluminação, mas não conta a história toda. A

\footnotetext{
${ }^{41} \mathrm{Wi}-\mathrm{Fi}$ - é uma marca registrada da Wi-Fi Alliance. É utilizada por produtos certificados que pertencem à classe de dispositivos de rede local sem fios (WLAN) baseados no padrão IEEE 802.11.

42 Li-Fi do inglês "Light Fidelity" (Luz, Fidelidade, tradução individual de cada palavra) refere-se a sistemas de comunicação com luz visível, que empregam luz LED's para transmitir comunicações em alta velocidade, de forma similar como acontece no Wi-Fi.
} 
eficiência total de uma luminária também é definida pela eficiência com que a luz é entregue à área-alvo, com que eficácia e consistência a cor da luz emitida corresponde às necessidades da aplicação, e com que eficácia a intensidade da luz é controlada.

Cada aplicação de iluminação possui seus próprios requisitos e com que eficácia e eficiência o sistema de iluminação atinge os requisitos é que define a eficiência da aplicação.

Para uma iluminação interna típica, a intenção da iluminação é permitir a visão, a acuidade visual e, possivelmente, a estimulação fisiológica não visual. Dependendo da aplicação, a intenção da iluminação interna pode ser ainda mais refinada do que isso, com requisitos como alta fidelidade de cores, espectros ajustados para cores específicas da iluminação conforme aplicação, sendo que outras aplicações poderão ter necessidade distintas para a iluminação. Em um ambiente de trabalho, por exemplo, o objetivo é promover uniformidade e performance visual, selecionando luminárias com dispositivos de controle de luz e garantindo iluminâncias adequadas, dependendo da complexidade da tarefa e do uso do espaço.

Para projetar uma luminária LED é necessário observar uma série de premissas práticas, a saber:

$\rightarrow$ Seguir rigorosamente a norma vigente, principalmente a NBR IEC 62722-21:2016 e demais recomendações que garantam o desempenho do conjunto.

$\rightarrow$ Disponibilização de uma ligação elétrica e circuito de controle para acendimento, dimerização, conexões com controles automáticos;

$\rightarrow$ Alteração da luz emitida pelo LED, que tradicionalmente possui uma abertura de facho de luz de $120^{\circ}$, permitindo o direcionamento para atingir a distribuição necessária com a mínima perda de luz, em função da seleção de material e o projeto de um bom sistema óptico;

$\rightarrow$ Proteção dos componentes, equipamentos eletrônicos e demais sistemas de iluminação das intempéries e outros danos, tais como choque, vibrações, poeira, atmosfera úmida ou muito empoeirada, ambiente hostil ou perigoso;

$\rightarrow$ Garantia de conforto visual ao usuário, controlando o ofuscamento por meio de sistemas ópticos secundários e terciários apropriados; 
$\rightarrow$ Ser visualmente e esteticamente agradável, e consistente com o projeto de arquitetura, por meio da elaboração de um bom design;

$\rightarrow$ Ser facilmente acessível para manutenção, em função da frequência de limpeza e eventual substituição da fonte de luz, acessórios e dos equipamentos auxiliares;

$\rightarrow$ Conceituação clara do que realmente se deseja obter (por exemplo, uma luminária para iluminação funcional, um spot para destaque, um balizador, uma arandela, um projetor para uso externo etc.);

$\rightarrow$ Definição do tipo de LED, cor, quantidade e potência consumida;

$\rightarrow$ Dimensionamento da fonte necessária em função de como os LEDs serão ligados, seja arranjos em série ou associação em paralelo;

$\rightarrow$ Verificação das condições de instalação e utilização da luminária. Uma luminária de uso externo vai receber sol durante o dia e aquecer. Se for para embutir no forro a circulação de ar é limitada;

$\rightarrow$ Determinação da máxima temperatura ambiente de funcionamento e a máxima temperatura de junção que o LED pode trabalhar. Com estes dados devemos calcular o dissipador apropriado para que dissipe o calor indesejável, ajudando a transferir o calor para fora do dispositivo e para o ambiente ao redor;

$\rightarrow$ Realização de teste da eficiência do dissipador em diversas situações de uso. Rever o projeto térmico, se necessário;

$\rightarrow$ Se houver limitação no tamanho da luminária que comprometa o uso do dissipador, procure trabalhar com LEDs de menor potência, ou diminuir a corrente de alimentação;

$\rightarrow$ A vida do LED é um compromisso entre dissipação e corrente de alimentação;

$\rightarrow$ Determinar as condições de instalação do LED e da fonte de alimentação dentro da luminária, de forma a não comprometer seu projeto térmico e a vida útil dos equipamentos;

$\rightarrow$ Em muitas situações a luminária será completamente selada, sendo importante o bom funcionamento do LED e da fonte para que não haja falhas, evitando prejuízos; 
$\rightarrow$ Com equipamentos de uso externo, ao tempo, devemos nos lembrar que o LED e sua fonte de alimentação são componentes eletrônicos, portanto sensíveis à umidade;

$\rightarrow$ Ser economicamente viável e interessante para o mercado e consumidor final, sendo ecologicamente correto e socialmente justo.

\subsubsection{Classificação das luminárias de acordo com o direcionamento do fluxo luminoso}

Conforme Bigoni (2013), as luminárias para iluminação interior são classificadas pela CIE (Commission Internationale de L'Éclairage), de acordo com a percentagem do fluxo luminoso total emitido para o hemisfério superior e inferior da luminária.

lluminação direta: distribui 90 a $100 \%$ do fluxo para o hemisfério inferior. A distribuição pode variar de fachos largos a concentrados, dependendo do material e geometria óptica da luminária.

lluminação semidireta: distribui 60 a $90 \%$ do fluxo para o hemisfério inferior. As características são essencialmente parecidas com as da iluminação direta, com exceção de que o componente do fluxo luminoso superior ajuda a suavizar sombras e a melhorar as relações de brilho do ambiente, tornando o teto mais iluminado.

lluminação difusa geral: distribui 40 a $60 \%$ do fluxo para o hemisfério inferior. Este tipo de luminária distribui a luz aproximadamente igualmente em todas as direções. A iluminação direta / indireta ou mista corresponde a uma categoria especial dentro da iluminação difusa geral, correspondendo às luminárias que emitem pouca luz nos ângulos próximos à horizontal.

lluminação semi-indireta: distribui 60 a 90\% do fluxo para o hemisfério superior. Possui características semelhantes às da iluminação indireta, exceto pelo fato de que a parcela de luz direta pode produzir certa direcionalidade para a tarefa visual, sem uma luminância excessiva do teto, e pode ser usada para adicionar brilho para a luminária. 
lluminação indireta: distribui 90 a 100 \% do fluxo para o hemisfério superior. Em instalações bem projetadas, o teto torna-se a fonte primária de luz, eliminando-se as sombras, uma vez que a luz passa a ser indireta.

Desta forma, em relação ao eixo vertical, as luminárias com fluxo direto são representadas por $0^{\circ} \leq \theta \leq 90^{\circ}$, as luminárias com fluxo indireto são representadas por $90^{\circ} \leq \theta \leq 180^{\circ}$, e as luminárias com fluxo direto e indireto são representadas por $0^{\circ} \leq \theta \leq 180^{\circ}$.

A iluminação direta é o tipo de iluminação mais utilizada em aplicações comerciais e é a mais eficiente energeticamente, por concentrar maior quantidade de luz no plano de trabalho; desta forma, as características da distribuição da luz foram levadas em consideração para a escolha dos modelos para essa pesquisa.

Os principais tipos de luminárias aplicadas no setor comercial apontam a presença de tipos comuns de luminárias entre fabricantes. As luminárias dividem-se em luminárias modelos de embutir, de sobrepor e pendente, e caracterizam-se pela presença ou ausência de componentes de controle de luz (IWASHITA, 2004).

Os principais tipos de luminárias LEDs podem ser caracterizados por:

$\rightarrow$ Luminárias com refletores em chapa de aço pintada de branco;

$\rightarrow$ Luminárias com refletores em alumínio;

$\rightarrow$ Luminárias com refletores em alumínio e aletas planas;

$\rightarrow$ Luminárias com refletores em alumínio e aletas parabólicas;

$\rightarrow$ Luminárias com difusores (translúcidos ou leitosos), por exemplo, painel LED;

$\rightarrow$ Luminárias tipo spot para luz de acentuação, de caráter direcional.

A Figura 55 apresenta algumas versões de luminárias utilizadas em instalações comerciais corporativas. 
Figura 55: Modelos de luminárias aplicadas em instalações comerciais corporativas.

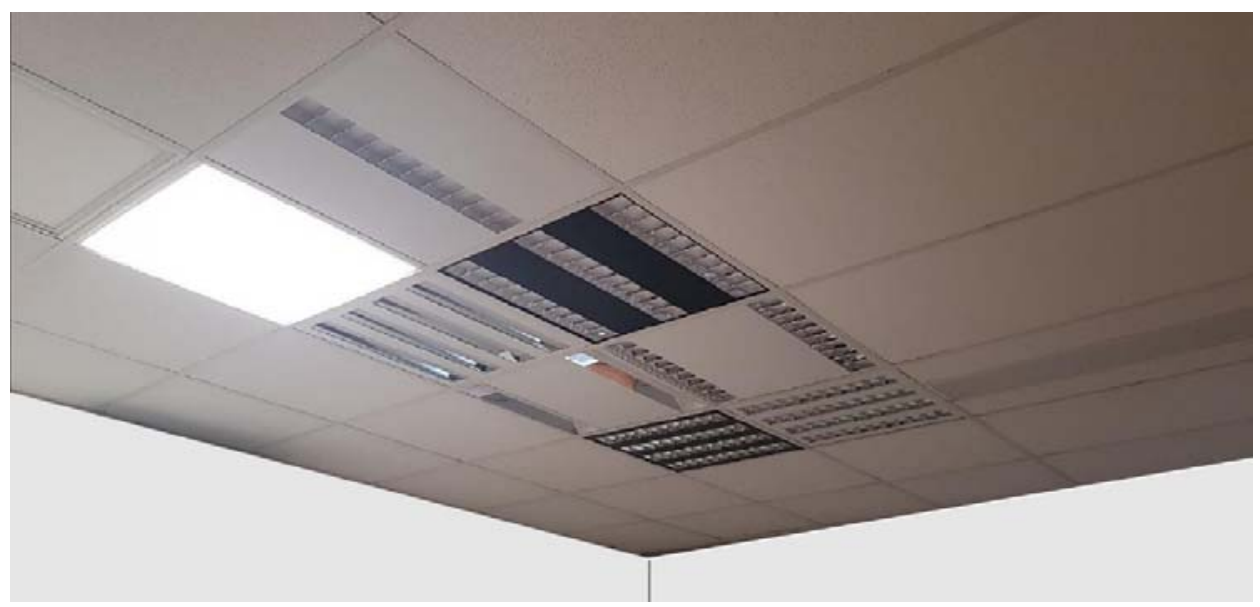

Fonte: Serradura, Light Tool, 2019.

\subsection{Os desafios do LED}

A tecnologia de iluminação LED melhorou drasticamente na última década, a fim de alcançar uma das maiores eficiências de fontes de luz branca disponíveis no mercado global e nacional. As melhorias na fabricação permitiram aos produtos de LED obter, cada vez mais, um custo baixo o suficiente para impulsionar sua adoção em todas as aplicações gerais de iluminação. Apesar desse progresso, outras melhorias são possíveis e desejáveis, como a qualidade da luz, ou a possibilidade de que a luz visível comece no violeta e termine no vermelho, com uma boa representação de luz, que exige a quantidade correta de conteúdo espectral em todos os comprimentos de onda de 380nm a 780nm, melhor aproveitamento da distribuição de luz em função da forma, além de uma maior integração arquitetônica.

A tecnologia de fabricação pode igualmente ser aprimorada para reduzir custos e aumentar a penetração no mercado, resultando na maior economia de energia para o país. 
Segundo o DOE, os principais desafios enfrentados na tecnologia LED também representam algumas das maiores oportunidades de ganhos de desempenho.

Além da produção da luz branca, quatro características importantes de desempenho, quando otimizadas, especialmente simultaneamente, podem introduzir grande impacto: densidade de corrente do driver, temperatura de junção, temperatura de cor correlata, e renderização das cores, descritas abaixo:

$\rightarrow$ Densidade de corrente do driver - a corrente do driver determina a quantidade de fluxo luminoso que está sendo gerada no pacote. Os pacotes de LED comerciais podem atingir eficácia luminosa de $200 \mathrm{~lm} / \mathrm{W}$, mas apenas operando com densidades de corrente mais baixas, o que resulta em menos fluxo luminoso geral e, portanto, um custo mais alto por lúmen. Pacotes acionados com uma densidade de corrente mais alta, no entanto, produzem mais lúmens, devido a um fenômeno conhecido como queda de eficiência do LED, conforme mostra a Figura 56. Para fins de normatização, todas as análises consideram $35 \mathrm{~A} / \mathrm{cm}^{2}$

Figura 56: Densidade de corrente do driver.

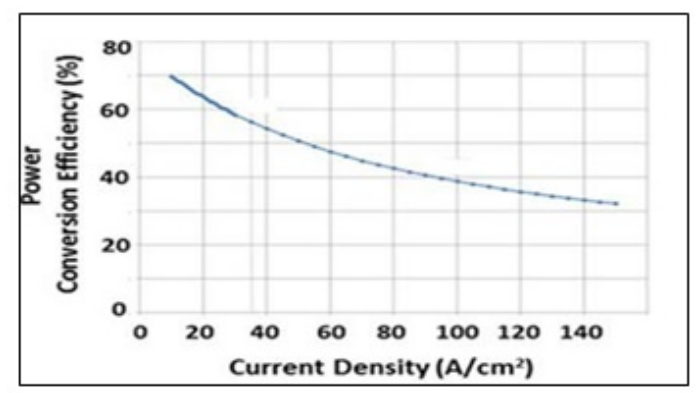

Fonte: SSL - Suggested Research Topics Supplement: Technology and Market Context, 2017, p.59.

$\rightarrow$ A temperatura da junção ocorre entre a junção $p$ e $n$ do semicondutor que forma o diodo durante a operação. Essa temperatura de junção, $\mathrm{Tj}$, afeta a eficácia do dispositivo. O pacote de lúmen (e, portanto, a eficácia) diminui com o 
aumento da temperatura da junção. Esse fenômeno é conhecido como "droop" 43 e de extrema importância no comportamento do sistema. Para consistência com os dados e metas dos anos anteriores, as análises a seguir enfatizam a operação sob condições padrão de temperatura ambiente (Tj igual a $25^{\circ} \mathrm{C}$ ). No entanto, como os encapsulamentos dos LEDs podem ser polarizados em condições mais elevadas do que $35 \mathrm{~A} / \mathrm{cm} 2$, eles também podem operar mais quentes ( $\mathrm{Tj}$ muito acima de $25^{\circ} \mathrm{C}$ ). Portanto, seu desempenho costuma ser de maior interesse que o desempenho em temperatura ambiente, razão pela qual muitos fabricantes de LED testam os LEDs a $85^{\circ} \mathrm{C}$, seguindo a recomendação da IES LM-80-15. A temperatura da junção é afetada pelo projeto de encapsulamento, pelo gerenciamento dos materiais térmicos, corrente de acionamento e temperatura ambiente.

A Figura 57 mostra o pacote de lúmens em relação a temperatura de junção.

Figura 57: Saída relativa do lúmen em relação a temperatura da junção.

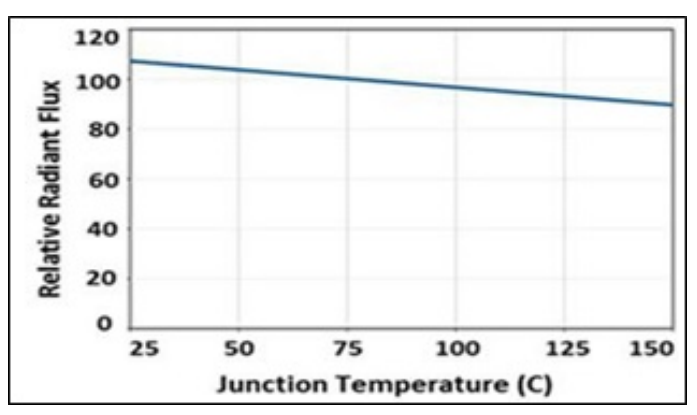

Fonte: SSL - Suggested Research Topics Supplement: Technology and Market Context, 2017, p.59.

$\rightarrow$ Temperatura de cor correlata (branco quente, 3000K). Alcançar eficácias mais elevadas tem sido desafiador para os LEDs brancos quentes, muito mais do

\footnotetext{
${ }^{43}$ Queda do fluxo luminoso do LED em função da elevação da temperatura de junção.
} 
que para os brancos frios, devido à ineficiência relativa dos conversores vermelhos. No entanto, os avanços impulsionados pelo aumento da eficiência dos LEDs brancos quentes provavelmente também beneficiarão os LEDs brancos frios. Embora o branco quente seja atualmente mais "desafiador" do que o branco frio, a máxima eficácia luminosa de radiação alcançável para o quente é um pouco mais alta que a do branco frio. Como pode ser visto na Figura 58, as eficácias luminosas máximas da radiação para o IRC/CRI 80 são ligeiramente mais altas para o branco quente (cerca de $414 \mathrm{Im} / \mathrm{W}$ a $3.000 \mathrm{~K}$ ) do que para o branco frio (cerca de $390 \mathrm{~lm} / \mathrm{W}$ a $5700 \mathrm{~K}$ ). Isso ocorre porque o olho humano é mais sensível ao vermelho do que à luz azul.

Figura 58: Limites teóricos às eficiências luminosas da radiação na luz branca versus. TCC para um determinado IRC

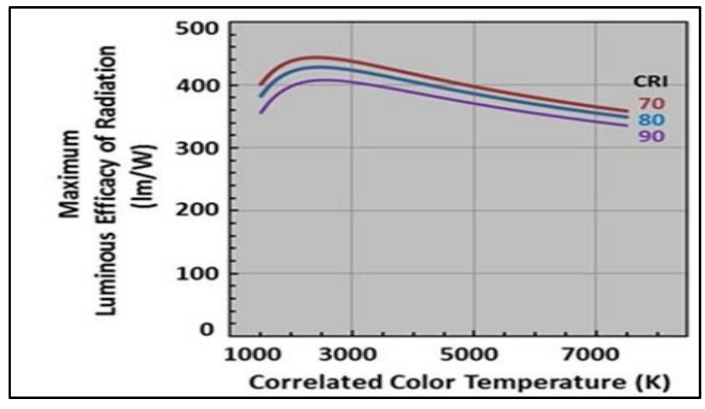

Fonte: SSL - Suggested Research Topics Supplement: Technology and Market Context, 2017, p.61

$\rightarrow$ Renderização das cores (Ra igual a 80, R9 maior que 0). Existe uma relação inversa entre eficácia luminosa e qualidade de reprodução de cores. Como visto na Figura 59, aumentar o IRC/CRI de 80 para 90 diminui a eficácia luminosa máxima alcançável em 10\%. Dados práticos sugerem que a queda seja significativamente maior na arquitetura PC-LED, na faixa de $15 \%$ a $25 \%$, devido a deficiências e amplas larguras de pico nos fósforos vermelhos. Para satisfazer a maioria das aplicações de luz branca, é necessária uma qualidade de renderização das cores relativamente alta, como um CRI "padrão", Ra de 80 , e um valor de R9 maior que 0 (zero) é desejável. No entanto, alguns setores 
do mercado exigem, cada vez mais, qualidade de fidelização de cores ainda mais altas; além disso, os parâmetros de avaliação da qualidade da reprodução de cores é, por si, uma área de estudo ativa, conforme seção 5.2.

Figura 59: IRC/CRII para um determinado TCC

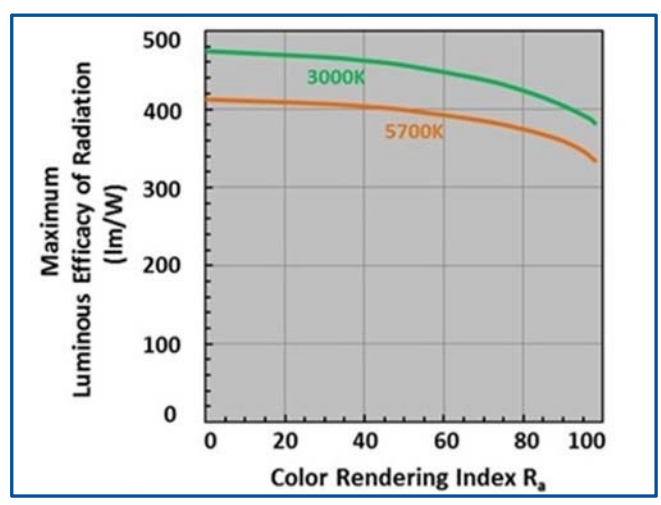

Fonte: SSL - Suggested Research Topics Supplement: Technology and Market Context, 2017, p.61.

\subsection{Definições de vida útil e de falhas dos LEDs.}

A indústria de iluminação pontua os produtos com base na porcentagem de falhas que estes produtos apresentam tendo, como exemplo, B10, que define que a expectativa de falhas seja de $10 \%$ da população. Também se utiliza B50 que representa expectativa de falhas de $50 \%$ da população.

A Figura 60 é uma representação gráfica da indústria de iluminação quanto ao modo de falhas de uma fonte de luz. 
Figura 60: Representação gráfica do modo de falhas de uma fonte de luz

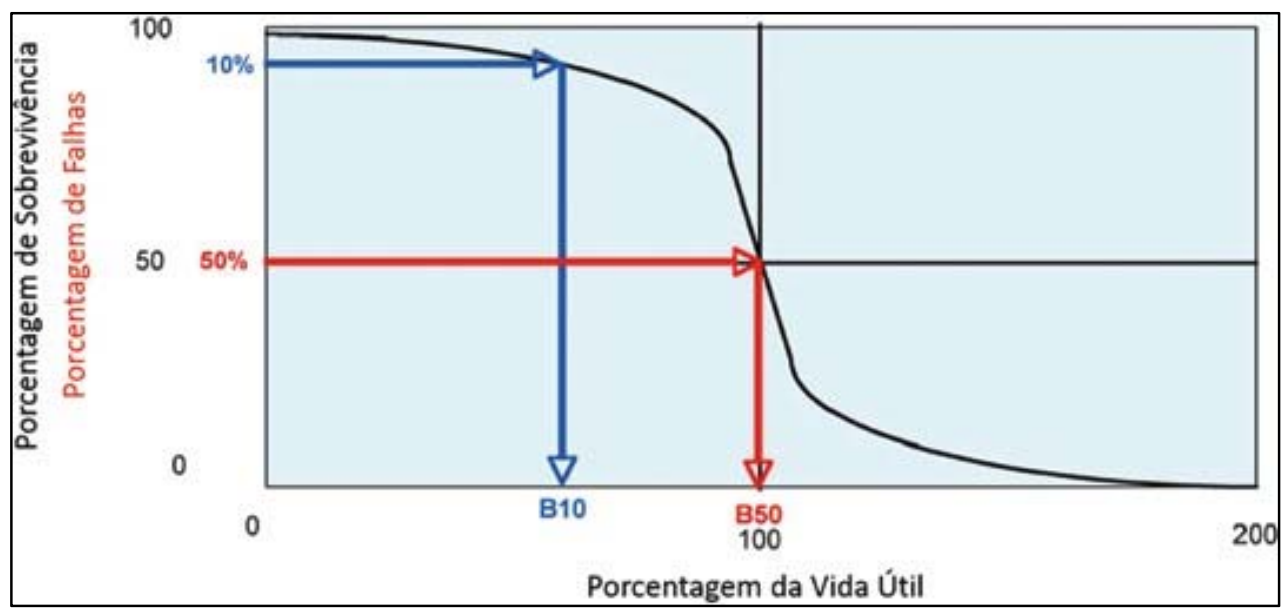

Fonte: Scopacasa, 2015.

Com a mudança de tecnologia e crescente utilização de produtos utilizando LEDs, a indústria estabelece a manutenção de fluxo luminoso como um critério adicional. Segundo Scopacasa (2016), órgãos internacionais de iluminação constataram como critério aceitável a redução em até $30 \%$ do valor inicial, com base no fato de que o olho humano pode detectar redução representada como L70, ou seja, é aceitável, como vida útil, a manutenção de até $70 \%$ do fluxo inicial gerado pela fonte de luz.

Considerando esses dois fatores apresentados, é possível representar como expectativa de vida do LED como BxxLyy, onde:

-xx representa a porcentagem da população e,

- yy representa a porcentagem de manutenção do fluxo luminoso original.

Exemplificando melhor, B50L70 representa que 50\% da população manterão, em média, $70 \%$ do fluxo original. Com a utilização destes parâmetros, o projetista tem condições de estimar a expectativa de vida dos LEDs que está utilizando, pois tais parâmetros são dependentes das condições de corrente e temperatura nas quais foram testados e especificados pelos seus fabricantes. 


\section{PROPRIEDADES COLORIMÉTRICAS E FOTOMÉTRICAS}

\subsection{Considerações preliminares}

Para Balázs (2016) a fotometria e colorimetria são áreas interdisciplinares, capazes de relacionar conceitos de engenharia e de ciências visuais. Do ponto de vista da engenharia, considerando os aspectos fotométricos e colorimétricos, existe um observador padrão; por outro lado, as ciências visuais mostram que, dependendo do observador, o desempenho individual na visão de cores pode ser significativamente diferente. Os mecanismos de visão e distinção de cores, os sistemas de identificação de cores e iluminantes, conforme padrão adotado pela CIE, permitem analisar as propriedades espectrais e a forma como recebemos as informações oriundas das fontes de luz.

Conforme apresentado no capítulo quatro, para cada aplicação necessitamos de iluminação específica e com os seus próprios requisitos, e para maximizar a eficiência da aplicação são necessárias fontes de luz cujas várias distribuições (espectral, intensidade, espacial) devem ser definidas em função a quem o projeto deve servir, quem são os usuários, qual o uso do espaço, qual a ambiência que será oferecida a esses usuários, entre outros requisitos.

A engenharia espectral é um tema central do SSL desde seu início, com atenção significativa às mais comuns métricas, fluxo luminoso, temperatura de cor e índice de reprodução de cor, mas isso é apenas o começo, e muitas aplicações se beneficiarão de uma engenharia espectral mais bem controlada, não apenas para reduzir a energia necessária para a aplicação, mas também para melhorar a produtividade da aplicação.

O uso de um espectro personalizado para a aplicação, maximiza a eficácia da iluminação, assegurando que os componentes necessários do espectro estejam presentes para a aplicação de iluminação específica. Além disso, partes/porções prejudiciais ou desnecessárias do espectro visível podem ser omitidas ou reduzidas. Esse conceito ainda é relativamente novo para aplicativos de iluminação geral, pois foi o advento do SSL que tornou possível o controle efetivo do espectro. Para a maioria 
das aplicações de iluminação, o espectro ideal não é bem compreendido e pesquisas significativas serão necessárias para desenvolver esse entendimento.

Com a consolidação tecnológica do SSL e a promessa de luz sustentável, podemos ser levados a esquecer a importância da qualidade da luz, em detrimento da quantidade, durabilidade e eficiência da luz.

Conforme o departamento de Energia dos Estados Unidos (U.S. Department of Energy), o desenvolvimento de novas medidas para avaliar a reprodução de cores das fontes luminosas tem sido o grande objetivo de uma boa parte das indústrias de iluminação, sendo que o IRC - Índice geral de reprodução de cores (Ra, comumente denominado $\mathrm{CRI}$ ), até o momento, é a métrica oficial e utilizada para avaliar a reprodução de cores; entretanto temos algumas limitações e deficiências métricas.

Em função da tecnologia de estado sólido, que proporciona maiores oportunidades de engenharia espectral em relação às fontes antecessoras, se fez necessária a formação de grupos de tarefas métricas de cores pela llluminating Engineering Society (IES), que formou o grupo de tarefas de métricas de cores, operando sob o IES Color Committee, produzindo o memorando IES TM-30-15: Método IES para avaliação Method For Evaluating Light Source Color Rendition; paralelamente temos a Comission Internationale de l'Eclairage (CIE), que apresentou um relatório técnico de pesquisa CIE 224-17 - Color Fidelity Index for Accurate Scientific, que descreve um índice geral de fidelidade de cores, Rf, como uma medida cientificamente precisa da fidelidade de cores em relação a um iluminante de referência.

\subsection{Composição espectral}

Ao acender uma fonte de luz artificial, ou ao se admirar o Sol, estamos visualizando uma série de radiações eletromagnéticas, que são resultantes da transformação da energia elétrica em outras formas de energia: radiações infravermelhas, ultravioletas e a luz visível.

O espectro eletromagnético apresentado na Figura 61 contém essas radiações, que são fenômenos vibratórios, cuja velocidade $(v)$ de propagação é constante $\left(3 \times 10^{5}\right.$ 
$\mathrm{km} / \mathrm{s}$ ) e que diferem entre si por sua frequência (f) e por seu comprimento de onda $(\lambda)$ tal que $v=\lambda . f($ MOREIRA, 2006).

Figura 61: Espectro de radiação.

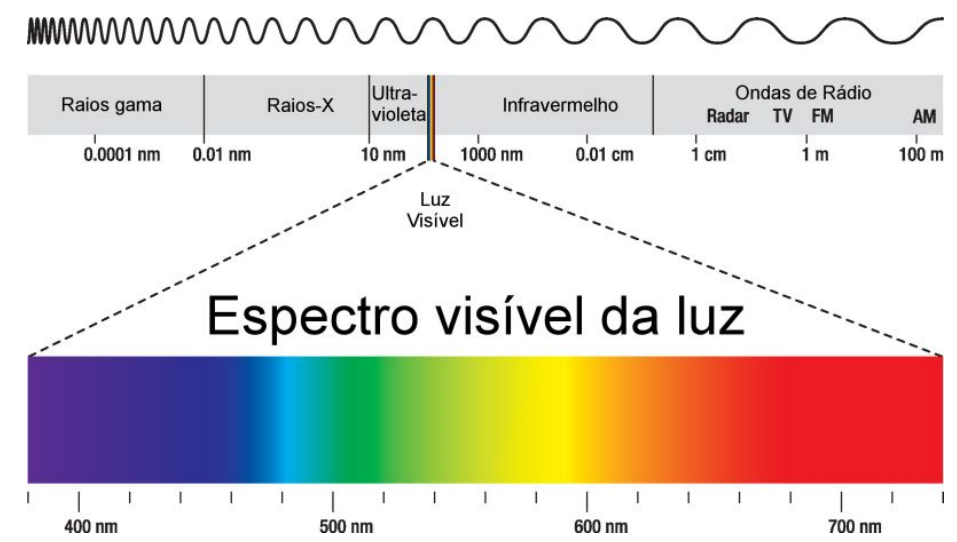

Fonte: https://www.infoescola.com/fisica/espectro-eletromagnetico (acesso 14/01/2020).

O espectro eletromagnético visível está limitado em um dos extremos pelas radiações infravermelhos (de maior comprimento de onda) e, na outra extremidade, pelas radiações ultravioletas (de menor comprimento de onda). Para os estudos de iluminação, é especialmente importante o grupo de radiações compreendidas entre os comprimentos de onda de 380 e $760 \mathrm{~nm}^{45}$, pois possui a capacidade de estimular a retina do olho humano, produzindo a sensação luminosa. Segundo Moreira (2006), além da impressão luminosa, obtemos também a impressão de cor, sendo que essa sensação está intimamente ligada aos comprimentos de ondas das radiações. Diferentes comprimentos de onda (e diferentes cores) produzem diversas sensações de luminosidade; isto é, o olho humano não é igualmente sensível a todas as cores do espectro visível.

A Figura 62 indica como a sensibilidade de um olho humano médio varia aos diversos comprimentos de ondas.

${ }^{45}$ Nanometro $\left(1 \mathrm{~nm}=10-{ }^{9} \mathrm{~m}\right)$. 
Figura 62: Curva de luminosidade espectral relativa (visão escotópica e fotópica).

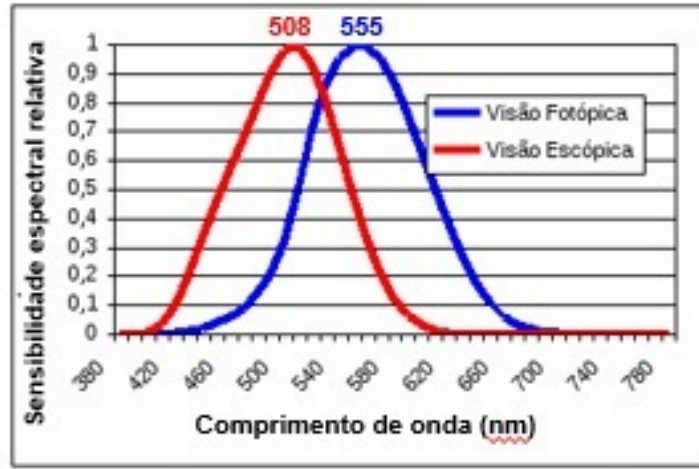

Fonte: http://www.fisic.org/viso-fototpica-e-viso-escotpica.html?page=18, adaptado pela autora, 2020.

Sem dúvida, a manipulação das características espectrais traz benefícios importantíssimos, pois permite personalizar o LED para infinitas aplicações. Apresentamos três espectros de fontes de LED, sendo na Figura 63A o espectro de radiação de $3.770 \mathrm{~K}$, na Figura 63B o espectro de $2.612 \mathrm{~K}$ e, na Figura 63C, o espectro de uma fonte de LED azul, medidos por meio de um espectrofotômetro modelo Lighting Passport ALP-01 - Pro Essence, marca Asensetek.

Figuras 63: Espectro de radiação de uma fonte $3.770 \mathrm{~K}(\mathrm{~A}), 2.612 \mathrm{~K}(\mathrm{~B})$ e LED azul (C).
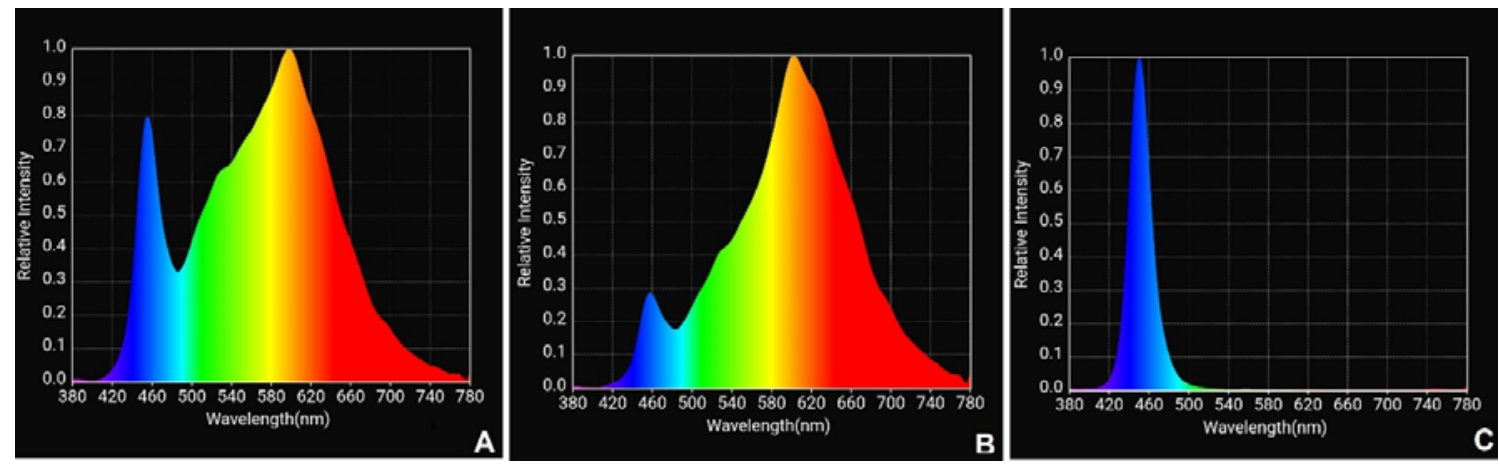

Fonte: Espectrofotômetro Asensetek ${ }^{46}$, a autora, 2020.

\footnotetext{
${ }^{46}$ www.assensetek.com
} 


\section{3. Índice de Reprodução de Cor (IRC) ou Color Rending Index (CRI)}

Segundo Scopacasa (2019), o sistema hoje utilizado para avaliação de cores é o CIE (Commission Internationale de L'eclairage) Color Rending Index (CRI), ou Índice de Reprodução de Cor (IRC). Este método utiliza 15 amostras de cores. onde cada uma delas tem o seu próprio valor. A média das 8 primeiras cores (R1 a R8) é considerada no cálculo do IRC resultando em um índice normalmente identificado como Ra. Cumpre ressaltar que os termos Ra e IRC, são comumente empregados com o mesmo significado, porém, a rigor, são diferentes.

As amostras de cores utilizadas pelo padrão IRC do CIE estão representadas pela Figura 64.

Figura 64: Amostras de cores pelo padrão IRC do CIE.

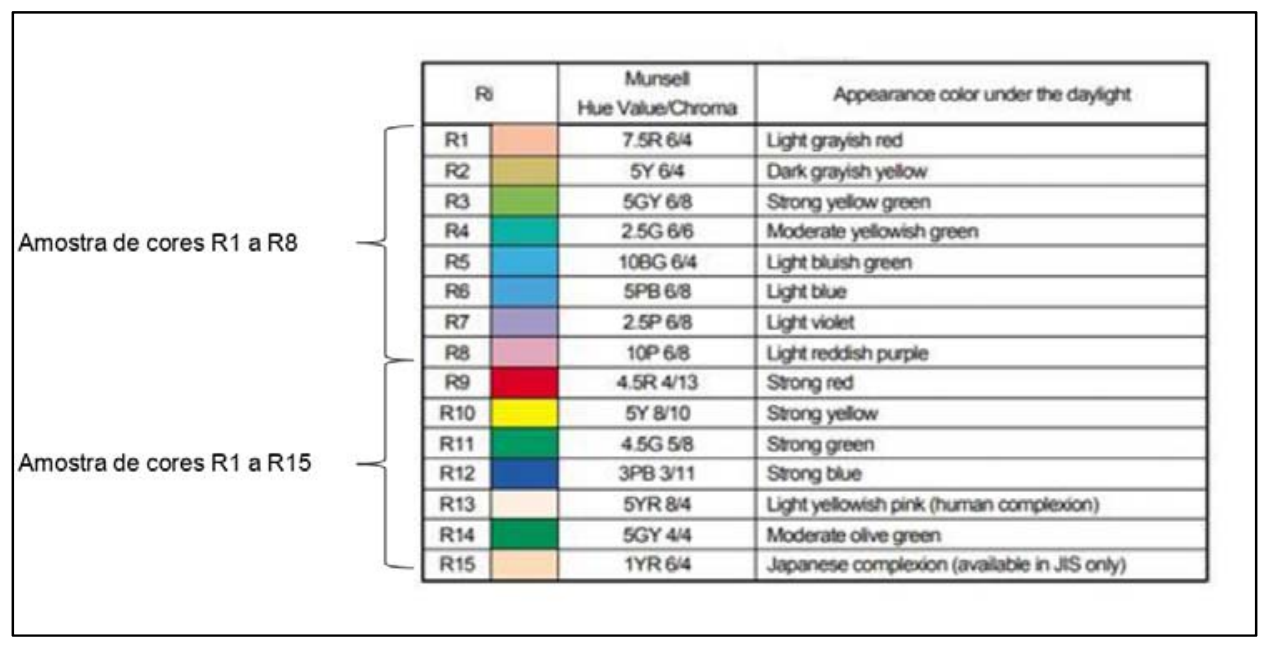

Fonte: Nichia, 2016, adaptado pela autora, 2020.

Quando especificamos somente o parâmetro Ra, desconsideramos o segundo conjunto de 6 cores (R9 ao R15), também importantes na avaliação da reprodução de cor onde destacamos as cores R9 e R13 (vermelho saturado e cor da pele respectivamente), cores estas que algumas fontes de luz apresentam sérias limitações em reproduzir com boa fidelidade. Como exemplo, se considerarmos uma luminária genérica com LEDs onde o valor medido de $\mathrm{Ra}$ foi de 82,7, que leva em consideração somente a média das 8 primeiras cores (R1 a R8), para a mesma luminária, fazendo-se a medição considerando as 15 amostras de cores (R1 a R15) o 
valor de IRC passa a ser 76, comprovando que estamos tratando de avaliações diferentes (SCOPACASA, 2019).

\subsubsection{Novo método de avaliação de reprodução de cor}

Segundo Scopacasa (2018), como uma possível alternativa para tornar a avaliação de cores mais criteriosa, a IESNA - Illuminating Engineering Society North America, introduziu a IES TM-30-15, um novo método de avaliação de cores para fontes de luz. Este método tem como base a comparação das cores reproduzidas por uma determinada fonte em comparação com uma fonte padrão, sob um determinado iluminante na mesma temperatura de cor correlata. Esta abordagem é compatível com o processo de projeto de iluminação onde a temperatura de cor é decidida anteriormente à consideração da reprodução de cor.

Diferentemente do padrão CIE do IRC, esse método adota 99 amostras de cores estatisticamente selecionadas de um grupo de mais de 100.000 espectros avaliados e medidos. Em função disso, podemos considerar que estas 99 amostras de cores são representativas das muitas possíveis cores disponíveis, tais como objetos naturais, pinturas, têxteis, plásticos, tons de peles, dentre outros.

A Figura 65 apresenta o padrão de 99 Color Evaluation Samples (CES) amostras de cores adotadas como padrão pela TM-30-18.

Figura 65: Padrão de amostras com 99 cores, adotado pela TM-30-18.

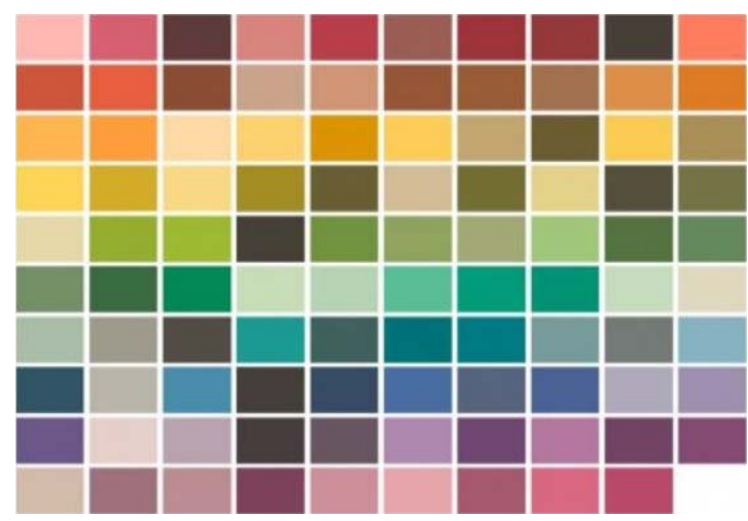

Fonte: IES TM-30-18 - Method for Evaluation, 2018. 
A IES TM-30-18 apresenta um método de avaliação da reprodução de cor com abordagem objetiva e estatística por meio de da quantificação da Fidelidade (proximidade em relação a referência), e outro de Gamut (aumento e diminuição da saturação), aqui representados por $R_{f}$ e $R_{g}$, respectivamente. $O$ método utiliza o padrão de cores (color space) CAM02-UCS.

Este método não indica nenhum tipo de preferência e nem qualquer critério de aceitação quanto ao desempenho e aos valores obtidos, ficando a critério do usuário adotar qual condição é a mais indicada para sua aplicação específica.

\title{
5.3.1.1. Índice de Fidelidade
}

\author{
Unidade - Rf
}

Determina a diferença entre as coordenadas de cromaticidade da fonte de luz com relação ao iluminante de referência. O Ra também é uma medida de fidelidade da cor, sendo que o índice $R_{f}$ foi criado para suprir todas as limitações do $R_{a}$, plenamente documentadas por meio de vários trabalhos científicos publicados. Apesar de tanto o $\mathrm{Rf}$ quanto o Ra utilizarem escalas similares, não podem ser diretamente comparados, e os resultados não podem ser aplicados de um ao outro.

Segundo Scopacasa (2018), cumpre ressaltar que a fidelidade de cor não leva em consideração a percepção humana, pois avalia a média das diferenças medidas entre a fonte de luz em teste, comparada com um padrão para cada uma das amostras de cores, quer seja Ra ou Re, 8 ou 15 cores, respectivamente.

Aspectos importantes sobre o Rf

$\rightarrow$ Considera maior número de amostras / 99 contra 8 do padrão IRC;

$\rightarrow$ Calculado pela média quadrática ao invés de média simples;

$\rightarrow$ Os valores de Rf estão compreendidos entre 0 e 100;

$\rightarrow$ A medição leva em conta a temperatura de cor da fonte, pois a fonte padrão não é fixa;

$\rightarrow$ Até $4500 \mathrm{~K}$, utiliza-se o corpo negro como iluminante;

$\rightarrow$ Acima de 5500K utiliza-se o iluminante "D" (Luz do dia);

$\rightarrow$ Entre 4500 e 5500K, utiliza-se uma mescla dos dois iluminadores acima; 
$\rightarrow \mathrm{R}_{\mathrm{f}}$ somente não identifica uma boa fonte de luz quanto à reprodução de cores;

$\rightarrow \mathrm{R}_{\mathrm{f}}<60$ são considerados não satisfatórios;

$\rightarrow \mathrm{R}_{\mathrm{f}}>90$ caracteriza uma fonte com aspecto de incandescente ou luz do dia, dependendo da temperatura de cor;

$\rightarrow$ Considera média quadrática.

\subsubsection{GAI - Gamut Area Index (Rg) ou Índice de Gamut}

Unidade - Rg

É a divisão entre as áreas dos polígonos das coordenadas a', b' das 99 amostras de cores no padrão CAM02-UCS da fonte de luz em teste, comparado com a referência. Na Figura 66, temos a representação das 99 amostras de cores, divididas em 16 faixas de matiz.

Figura 66: Coordenadas das 99 amostras de cores no diagrama CAM02-UCS e os ângulos de matiz

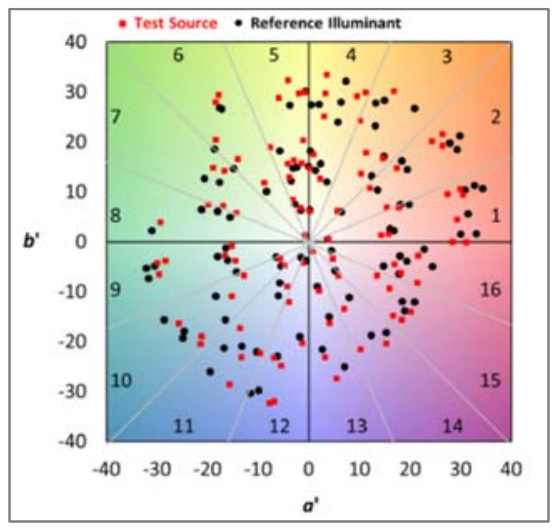

Fonte: Evaluating Color Rendition Using IES TM 30-18, Energy Efficiency \& Renewable Energy, U.S. Department of Energy, p.6

A fórmula para cálculo do $\mathrm{Rg}$ é a razão entre a área do polígono do gamut da fonte de luz em teste pela a área do polígono da referência, multiplicado por 100 . Isto significa que, se o índice $\mathrm{Rg}$ for superior a 100, a fonte de teste tem saturação maior 
do que a referência, e quando o índice $\mathrm{Rg}$ for menor que 100, significa que a fonte de teste é menos saturada do que a referência. Isto pode ser facilmente identificado por meio de da representação gráfica apresentada na Figura 48. O índice $\mathrm{Rg}$ tem relação com a naturalidade da cor, sendo que o valor 100 indica que a fonte de teste é similar à fonte de referência e, portanto, reproduz a cor com naturalidade. A fonte de luz mais saturada do que a referência resulta em cores "artificiais", enquanto a menos saturada resulta em cores que tendem a ser "pálidas".

Ainda segundo Scopacasa (2018), a fim de melhor avaliarmos os valores dos índices e Rg, a TM-30-15 criou uma representação gráfica que auxilia, em muito, a análise do comportamento da fonte de luz em teste, comparada à referência, onde facilmente podemos notar o comportamento Rf quanto à saturação e não saturação da fonte de luz que estamos avaliando. No mesmo gráfico temos também as sutis variações de matiz (hue). Na Figura 67 temos um exemplo de duas fontes de luz com diferentes valores de temperatura de cor e índices Rf e Rg.

Figura 67: Gráfico vetores com duas fontes de luz com diferentes valores de temperatura de cor e índices $R_{f}$ e $R_{g}$.

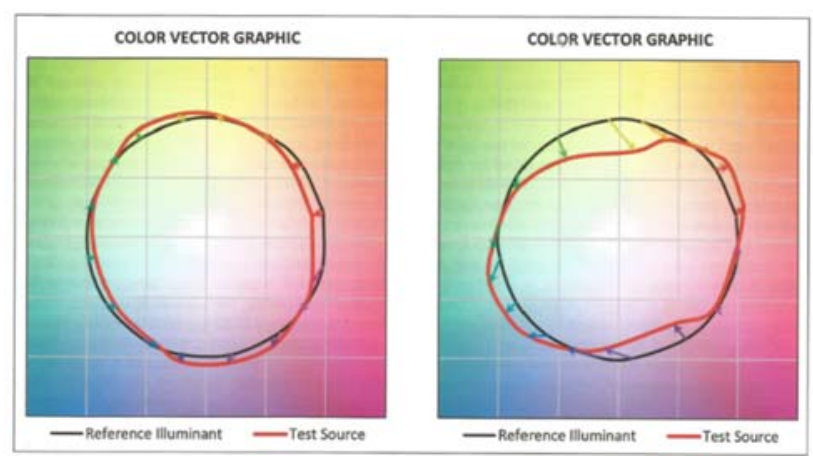

Fonte: Evaluating Color Rendition Using IES TM 30-18, Energy Efficiency \& Renewable Energy,U.S.Department of Energy

Nos dois exemplos de gráficos de vetores, o da esquerda representa uma determinada distribuição de potência com temperatura de cor de $2.662 \mathrm{~K}$, Rf de 83 e $\mathrm{Rg}$ de 99. Esta fonte de luz tende a saturar as cores amarelo e violeta, enquanto tende a não saturar as cores ciano e vermelho. Isto pode ser notado, pois o polígono da fonte de luz em teste (vermelho) excede o polígono de referência na região das cores 
amarela e violeta, enquanto fica inscrito ao polígono de referência na região das cores ciano e vermelho.

O gráfico da direita representa uma fonte de luz com temperatura de cor de 6.496K com Rf de 66 e Rg de 91. Observamos, neste caso, uma considerável não saturação na região das cores amarela, verde e índigo, enquanto satura as cores ciano e laranja.

Além disto, ao observarmos as direções das setas constantes nestes dois gráficos notamos que, se a orientação tende para o centro do gráfico, podemos dizer que houve não saturação da cor; se o sentido das setas for o inverso, indica que houve saturação. Quando a direção da seta é lateral, podemos afirmar que houve mudança de matiz (hue), ou seja, variação real da cor.

Em contrapartida, se analisarmos uma fonte halógena MR 16 representada por uma distribuição de potência com temperatura de cor de 2.988K, Rf de 99 e Rg de 99, perceberemos por meio da Figura 68 a perfeição entre os polígonos.

Figura 68: Perfeição entre os polígonos de uma lâmpada halógena MR16.

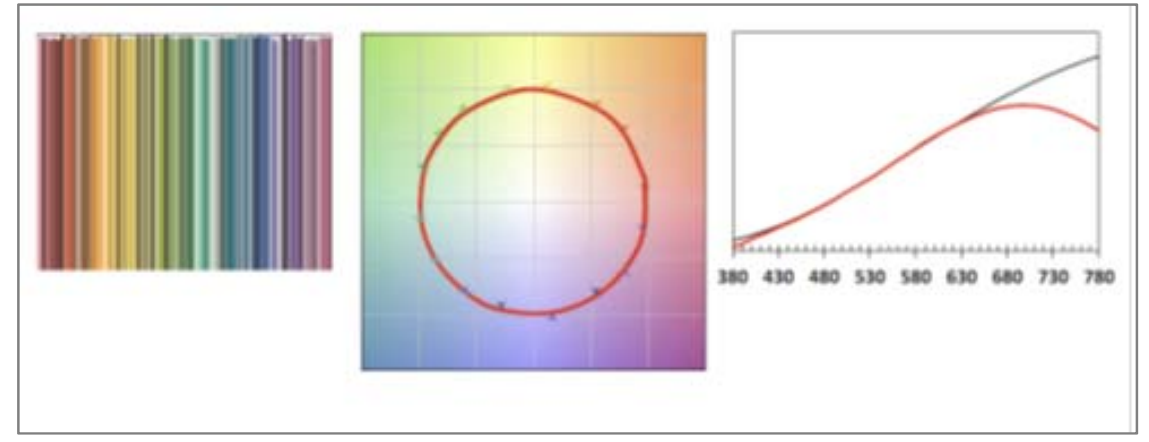

Fonte: DOE+IES Webinar, Understanding and Applying TM-30-15, 2015.

Scopacasa (2018) conclui que a TM-30-18 é um procedimento adotado pela IESNA, porém não pode ser considerado como padrão pela indústria de iluminação, uma vez que a entidade responsável pela normatização de colorimetria é a CEI. Por outro lado, ele também afirma que a TM-30-18 é a melhor forma de avaliarmos o comportamento de uma fonte de luz quanto à sua reprodução de cor e, pode-se 
afirmar, é bem mais precisa do que o sistema IRC atualmente utilizado pela indústria de iluminação.

Ainda segundo Scopacasa (2018), o conceito de Gamut, apesar de não ser recente, nunca foi adotado pela indústria de iluminação, e sim pelas indústrias de display (TV, computadores) e gráfica.

Para reprodução de cor, gamut refere-se à área delimitada por um conjunto de coordenadas de cores de uma amostra, em um determinado "color space" e, isoladamente, esta representação não diz muito; porém, quando comparada com uma outra área (fonte padrão com as mesmas cores), pode nos mostrar alterações relativas da aparência da cor. Desta forma, considera-se o conceito de que a luz não é bidimensional, mas sim tridimensional.

O artista americano Albert Henry Munsell publicou, em 1905, um modelo com notação decimal baseado em três variáveis, que "descrevem a cor de forma racional, sem a utilização de nomes desconexos".

O sistema apresentado baseia-se em três atributos fundamentais: matiz, saturação e luminosidade, conforme Figura 69. A matiz é a qualidade que distingue uma cor da outra R (vermelho); Y (amarelo); G (verde); B (azul); P (púrpura); YR; GY; BG; PB; RP; sendo que a saturação é a presença ou ausência de cor pura, e a luminosidade ou claridade (lightness) diferencia uma cor clara de outra escura, considerando escala de 0 (barnco) a 10 (preto).

Figura 69: Matiz, luminosidade e saturação.

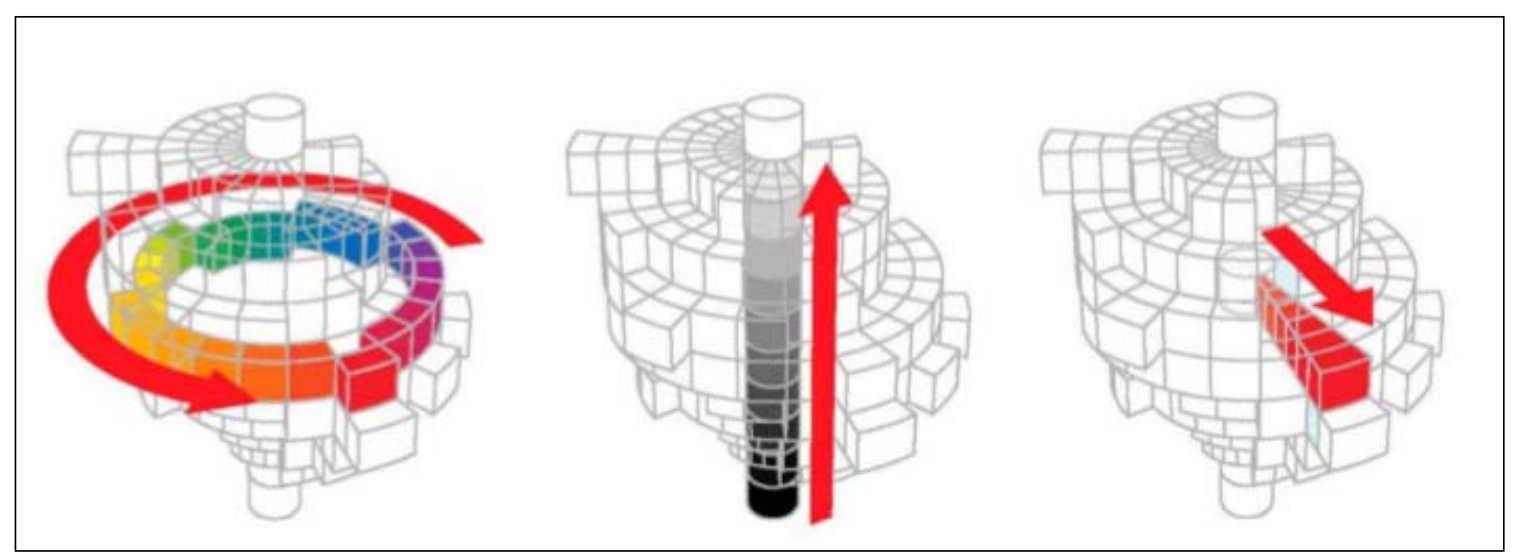

Fonte: Benegate, 2020. 
Segundo Kaiser (2011), Munsell criou na primeira década do século XX um modelo orbital (na realidade uma esfera), no qual bandas de cores giram em torno do equador e o eixo orbital indica uma escala de tonalidade, o Norte apontando para o branco e o Sul para o preto, com um círculo de matizes com luminância 5 e saturação 6, um eixo de luminosidade neutra de 0 até 10; e purezas da cor violeta-azul (PB) c/ luminosidade 5 (5PB). A Figura 70 apresenta o modelo orbital Munsell Color System.

Figura 70: Modelo orbital Munsell Color System.

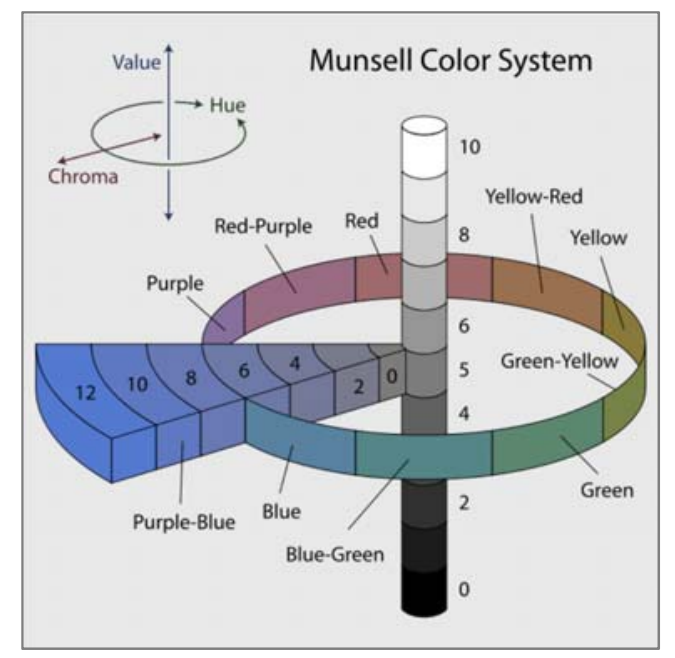

Fonte: Kaiser, 2011.

Paralelamente, o CIE, por meio da TC1-90, desde 2012 está desenvolvendo uma métrica aprimorada de fidelidade de cores (com a intenção original de substituir o CRI). O TC1-90 examinou e adotou o IES TM-30 Fidelity Index (Rf) com pequenas modificações. As 99 amostras de teste e espaço de cores, fórmulas de cálculo são iguais. Assim, semelhante ao índice geral de reprodução de cores $\mathrm{Ra}$, o índice geral de fidelidade de cores Rf, combina as diferenças de cores calculadas para todas as amostras de cores de teste em um único valor médio de índice, e é apenas um aspecto da qualidade da cor, sem considerar a percepção / efeitos de preferência. Portanto, considera-se que tais usos não intencionais de CRI como uma medida geral da qualidade de cores para usuários finais não são mais bem atendidos pelo índice geral de fidelidade de cores cientificamente mais preciso, Rf. Isso ocorre porque a avaliação 
dos usuários é influenciada por fatores além da fidelidade das cores, como efeitos de croma (saturação) e a natureza detalhada de tarefas específicas de iluminação.

O índice geral de fidelidade de cores, Rf, não substitui, portanto, o índice geral de reprodução de cores, $\mathrm{Ra}$, nem para fins de classificação e especificação de produtos, nem para requisitos regulatórios ou outros requisitos mínimos de desempenho. A substituição do CRI será uma questão de estudo e discussão futuras, que incluirão a avaliação do índice geral de fidelidade de cores, $\mathrm{R}_{\mathrm{f}}$, juntamente com o desenvolvimento de um conjunto harmonizado de novas medidas de qualidade de cores para avaliar os efeitos relacionados à percepção, além da fidelidade e prática e os aspectos que atendam aos fabricantes e usuários finais.

Muitos estudos seguem o caminho da escolha do melhor método de avaliação de cor, conforme recomendações apresentadas nas seções 3.3.3. e 3.4.1.

O Quadro 2 mostra a evolução do processo ao longo de quatro décadas para definição das métricas da qualidade da cor.

Quadro 2: Processo ao longo de décadas para definição das métricas para a qualidade da cor.

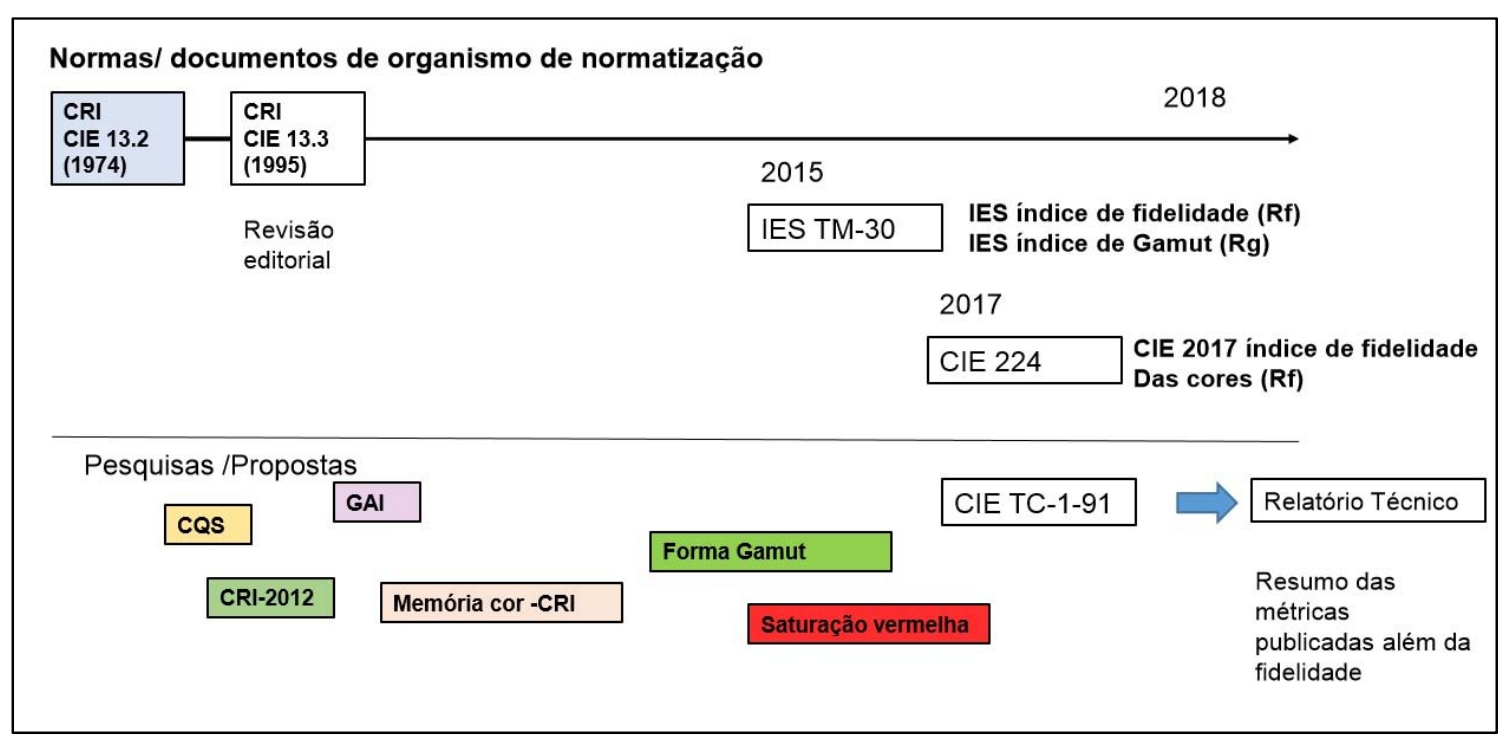

Fonte: Ohno, 2018, adaptado pela autora, 2020. 


\subsection{Diagrama de cromaticidade}

O sistema CIE, conforme exposto anteriormente, é utilizado para descrever a cor. Esta padronização leva em consideração a padronização de iluminantes e observadores. Este sistema de padronização surgiu em 1931. O órgão criou o observador padrão e os iluminantes A, B e C, e desenvolveu fórmulas para calcular os valores tristímulos (XYZ) e as coordenadas de cromaticidade " $\mathrm{x}$ " " $y$ ". O observador padrão foi modificado ao longo do tempo, e os espaços, em termos das coordenadas colorimétricas, também. $\left(L^{*} a^{*} b^{*} e L^{*} u^{*} v^{*}\right)$. Como a cor depende do observador, tornou-se necessário padronizar este elemento e foi criado o padrão de dois graus e, em 1964, criou-se o padrão dez graus. Eles representam a sensibilidade do olho humano com a mistura das três cores primárias: vermelho, verde e azul. Outra padronização importante foi a das fontes de luz, pois elas influenciam diretamente a cor dos objetos.

A distribuição espectral de potência radiante (SPD) é a expressão numérica da potência relativa que esta fonte emite em cada comprimento de onda. A SPD de um iluminante pode ser criada, mesmo que não exista uma fonte real com essa distribuição espectral. As fontes e iluminantes também podem ser caracterizados por sua distribuição espectral e por sua temperatura de cor. Para o CIE, os principais iluminantes são o A e o D65, embora existam outros.

$\mathrm{Na}$ década de 20, foi realizado um estudo experimental para se obter um espaço de cores, com grupos de 15 a 20 indivíduos adultos, com visão de cor considerada normal, submetidos ao seguinte teste: cada indivíduo, olhando através de uma fenda circular com $2^{\circ}$ de abertura, via uma tela branca (100\% de refletância), sobre a qual numa metade era projetada uma cor espectral com uma lâmpada de teste e, na outra, utilizando-se três lâmpadas de mesma potência emitindo radiação monocromática, variavam-se os conteúdos vermelho $(\mathrm{IR}=700,0 \mathrm{~nm})$, verde $(\mathrm{IG}=546.1$ $\mathrm{nm})$ e azul (IB=435 nm) da luz, até se equiparar a cor com aquela projetada pela lâmpada de teste. O procedimento foi repetido para comprimentos de onda entre 380 $\mathrm{nm}$ e $780 \mathrm{~nm}$, registrando-se os componentes RGB. 
Durante os trabalhos de especificação do observador padrão, verificou-se que o modelo RGB apresentava alguns inconvenientes. O principal deles é que o sistema $R G B$, baseado em valores tristimuli $R(I R=700,0 \mathrm{~nm}), G(I G=546,1 \mathrm{~nm})$ e $B(I B=435$ $\mathrm{nm}$ ) obtidos de cores físicas, não consegue representar todas as cores espectrais sem introduzir valores tristimuli negativos.

Em 1931, a CIE concebeu um primeiro modelo, que utiliza somente valores tristimuli positivos, denominado $\mathrm{XYZ}$, obtido do sistema $R G B$ a partir da seguinte transformação linear:

No sistema CIE a curva do valor tristimulus $Y(I)$ do observador padrão corresponde à resposta do olho humano para a potência total da fonte. Por esta razão, o valor de $Y$ é denominado fator de luminância e os valores $X Y Z$ foram normalizados, para que $Y$ sempre assuma o valor 100 . Os valores tristimuli são grandezas puramente matemáticas. O diagrama de cromaticidade, apresentado na Figura 71 , mostra os limites de todas as cores visíveis, que representam as combinações de cores monocromáticas do espectro.

Figura 71: Diagrama de cromaticidade CIE 1931

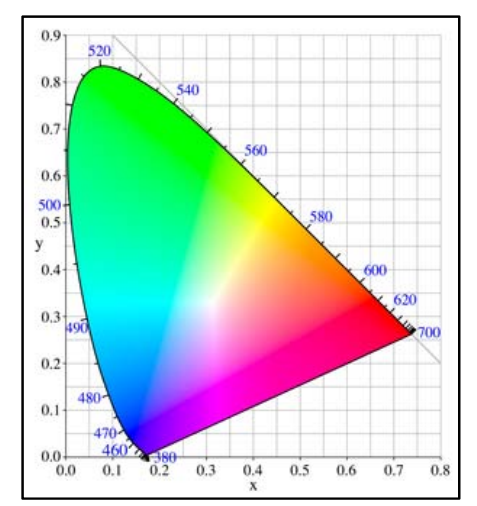

Fonte: Nagy, 2016.

A medição de cores pelo sistema CIE se baseia na possibilidade de matizar qualquer cor como uma combinação de três cores primárias (ou duas). A mistura aditiva tem como cores primárias o vermelho $(R)$, o verde $(G)$, e o azul (B). A soma dessas cores primarias resulta no branco, sendo preto a ausência total da luz. 
A ciência por trás das especificações de diferença de cor foi estabelecida pelo Dr. David MacAdam, em 1942. Os experimentos de MacAdam basearam-se na observação visual da chamada diferença de cor única entre duas luzes coloridas muito parecidas. A diferença apenas visível estabelece-se quando $50 \%$ dos observadores veem a diferença entre as cores, e 50\% dos observadores não veem a diferença.

As zonas com os desvios padrão da correspondência de cores (SDCM) ${ }^{47}$ foram definidas em formas elípticas sobre o diagrama de cromaticidade CIE 1931. O tamanho e a orientação das elipses variaram muito, dependendo da localização no diagrama do espaço de cores. Observou-se que as zonas são maiores entre o verde, e menor entre o vermelho e o azul.

Devido à natureza variável da cor produzida pelos LEDs de luz branca, uma métrica conveniente foi utilizada como a extensão da diferença de cor, dentro de um lote (ou bin), ou o número de SDCM (PHOTOMETRIC \& OPTICAL TESTING, 2013).

Se todas as coordenadas de cromaticidade de um conjunto de LEDs caem dentro de 1 SDCM (ou uma "elipse de MacAdam de 1 passo"), a maioria das pessoas não conseguem ver nenhuma diferença entre cores. Se a variação de cor for tal, que a variação de cromaticidade se estenda para uma zona que é duas vezes maior que (2 SDCM ou uma elipse 2-step MacAdam), começarão a ver alguma diferença de cor. Por exemplo, uma elipse de 2-step MacAdam de 2 passos é melhor do que uma elipse de 3-step MacAdam de 3 passos, e assim por diante. Deve-se notar que as elipses SDCM são frequentemente mostradas no diagrama do espaço de cores CIE em dez vezes, conforme Figura 72.

${ }^{47}$ Sigla em inglês para Standard Deviation Color Matching. 
Figura 72: Diagrama de cromaticidade CIE 1931 com as elipses MacAdam.

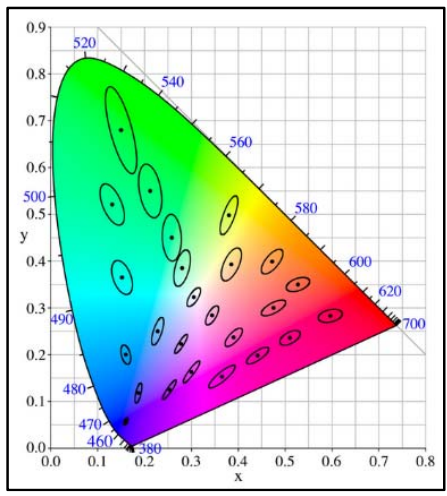

Fonte: Nagy, 2016.

A Tabela 6 relaciona o número de etapas do SDCM elipse ao de coordenadas de TCC e cromaticidade para uma fonte de luz de temperatura de cor de 3.000K.

Tabela 6: Número de etapas do SDCM para uma fonte 3.000K.

\begin{tabular}{|c|c|c|}
\hline SDCM & TCC $-3.000 K$ & $\Delta \mathbf{u}^{\prime} \mathbf{v}^{\prime}$ \\
\hline $\mathbf{1 x}$ & $\pm 30 \mathrm{~K}$ & \pm 0.0007 \\
\hline $\mathbf{2 x}$ & $\pm 60 \mathrm{~K}$ & \pm 0.0010 \\
\hline $\mathbf{4 x}$ & $\pm 100 \mathrm{~K}$ & \pm 0.0020 \\
\hline $\mathbf{7 - 8 x}$ & $\pm 175 \mathrm{~K}$ & \pm 0.0060 \\
\hline
\end{tabular}

Fonte: Photometric \& Optical Testing, 2013, adaptado pela autora, 2020.

Ao definirmos os valores das coordenadas de cromaticidade $(x, y)$ no diagrama de cores 1931, podemos definir com exatidão o ponto onde a cor vai estar localizada no diagrama, e qual é a distância deste ponto com à curva do corpo negro, sendo que quanto menor for o valor deste parâmetro ( $\left.\Delta u^{\prime}, v^{\prime}\right)$, melhor. Segundo Scopacasa (2016), quanto maior for a distância entre o ponto das coordenadas x,y em relação à curva do corpo negro, maior será a interferência das cores na composição da luz branca resultante, fazendo com que tenhamos o fenômeno chamado de "tingimento", sendo que quando a coordenada está distante da curva do corpo negro, e acima da 
curva, podemos notar um tom verde, enquanto se o ponto estiver distante e abaixo da curva, podemos notar um tom rosa (SCOPACASA, 2016).

\subsubsection{Equipamento de medição das características colorimétricas}

O espectrofotômetro é um instrumento de análise amplamente utilizado em laboratórios de pesquisa, capaz de medir e comparar a quantidade de luz (radiação eletromagnética) absorvida, transmitida ou refletida por uma determinada amostra, além de fazer medições das características colorimétricas, tais como: curva espectral de uma fonte, diagrama de cromaticidade, como também parâmetros de temperatura de cor correlata, CRI Ra (R1 a R8), CQS, GAI, TM-30-15 Rf e Rg , R1 ao R15, SDCM e ANSI C78.377-201748. Para exemplificar o quanto esse equipamento faz parte do dia a dia dos projetistas de iluminação, arquitetos e indústria, demonstramos o uso na Figura 73 , que mostra o diagrama de cromaticidade de uma fonte de $2.700 \mathrm{~K}$, mas que precisamente sua temperatura de cor ou aparência é de $2.726 \mathrm{~K}(\mathrm{x}=0,4580$ e y $=$ 0,4107), pequeno desvio aceitável.

Figura 73: Diagrama de cromaticidade de uma fonte de LED 2.726K.

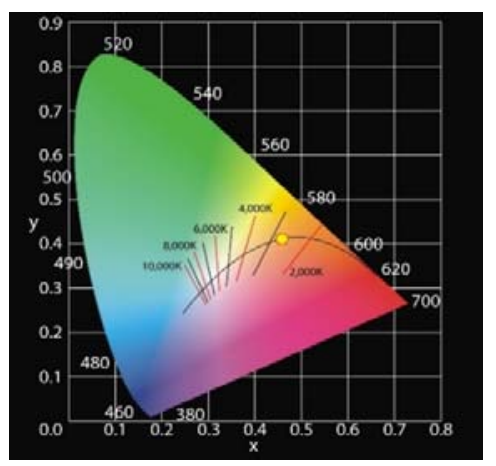

Fonte: Espectrofotômetro Asensetek, a autora, 2020.

A Figura 74 apresenta a "elipse de MacAdam" com SDCM de 5 para a mesma fonte de LED com temperatura de cor de $2.726 K(x=0,4580$ e y $=0,4107)$.

\footnotetext{
${ }^{48}$ Especificações para a cromaticidade de produtos de iluminação de estado sólido pela ANSI.
} 
Figura 74: Exemplificação de elipse 5 SDCM de uma fonte de LED 2.726K.

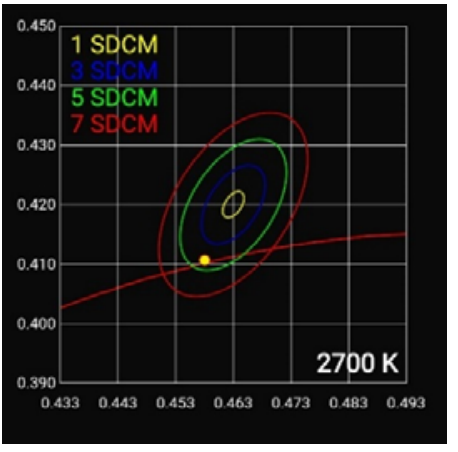

Fonte: Espectrofotômetro Asensetek ${ }^{49}$, a autora, 2020.

A Figura 75 apresenta a métrica ANSI C78.377-2017 para a mesma fonte de LED com temperatura de cor de $2.726 \mathrm{~K}(\mathrm{x}=0,4580$ e y $=0,4107)$.

Figura 75: Exemplificação ANSI C78.377-2017 para uma fonte de LED 2.726K.

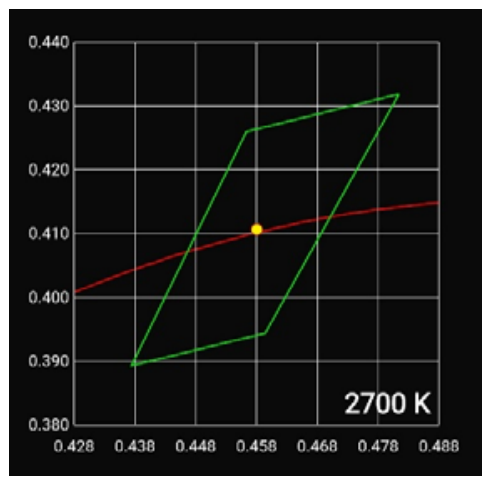

Fonte: Espectrofotômetro Asensetek, a autora, 2020.

\subsection{Temperatura de cor correlata (TCC)}

Unidade: Kelvin

${ }^{49}$ www.assensetek.com 
Segundo a NBR ISO/CIE 8995-1, a temperatura de cor correlata é a "aparência da cor" de uma lâmpada e refere-se à cor aparente (cromaticidade da lâmpada) da luz que ela emite. Pode ser descrita pela sua temperatura da cor correspondente.

A temperatura de cor abaixo de $3.300 \mathrm{~K}$ corresponde à "luz quente" de aparência amarelada; entre 3.300 a $5.300 \mathrm{~K}$ temos as fontes de temperatura intermediária ou neutra e, acima de 5.300K, temos a fontes de "luz fria" com branco azulado, sendo que quanto mais elevada, mais a aparência será de um branco violeta. A "luz branco natural" emitida pelo sol em céu aberto, ao meio dia, tem uma temperatura de cor de $5.800 \mathrm{~K}$.

A Figura 76 apresenta a aparência de cor ou temperatura de cor correlata como exemplificação.

Figura 76: Exemplos de temperatura de cor.

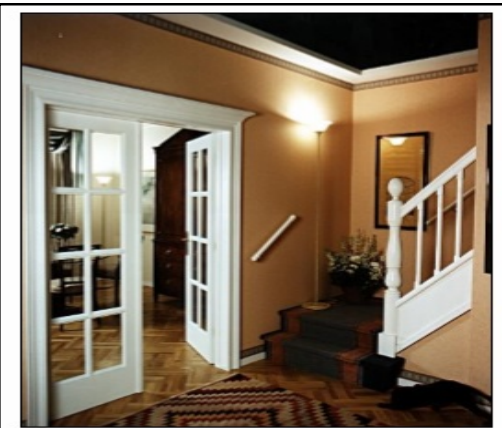

Branco quente $<3300 \mathrm{~K}$

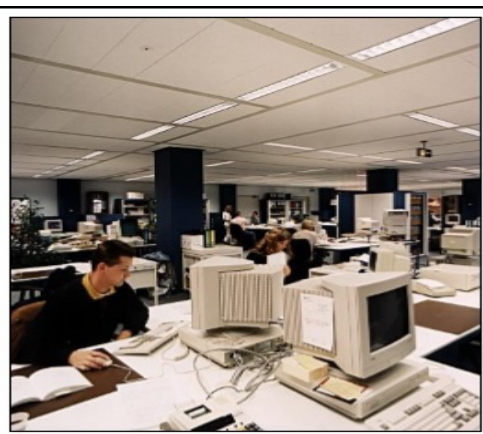

- Branco

Neutro

- 3300 a $5300 \mathrm{~K}$

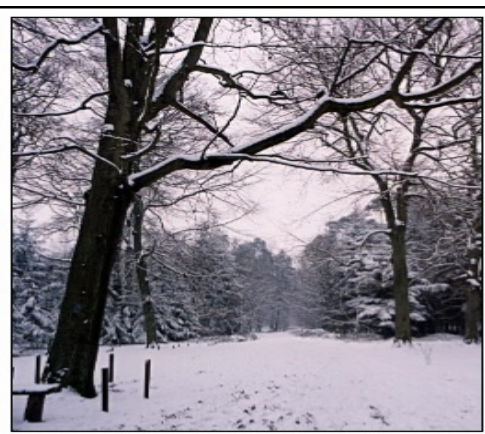

- Branco

Frio

- $>5300 \mathrm{~K}$

Fonte: Nascimento, 2015.

A escolha da aparência da cor é um assunto de psicologia, estética e tudo que é considerado natural. A escolha depende da iluminância, cores da sala e da mobília, clima e aplicação. Em climas quentes, geralmente é preferencial a aparência da cor de uma luz mais fria, e em climas frios é preferencial a aparência da cor de uma luz mais quente (NBR ISO/CIE 8995-1, 2013, p.9). 


\subsection{Parâmetros fotométricos}

A fotometria compreende uma série de métodos e processos de medidas de grandezas luminosas e algumas serão tratadas de forma breve para o devido o entendimento da metodologia e dos resultados desta tese, em função de serem informações técnicas de domínio do mercado de iluminação.

A medição do fluxo luminoso utiliza uma esfera integradora, ou esfera de Ulbricht, para a medição do fluxo luminoso emitido por uma fonte de luz.

A fonte luminosa é posicionada no centro da esfera e um anteparo bloqueia a incidência de luz direta da fonte sobre um sensor de iluminância, instalado numa abertura da esfera. A superfície interna apresenta um revestimento (por exemplo, óxido de magnésio ou sulfato de bário) que a torna um difusor perfeito (cada ponto da superfície tem os mesmos valores de luminância e iluminância).

Desta forma, a luminância da superfície da esfera é proporcional ao fluxo luminoso, independente da distribuição da intensidade luminosa (MOREIRA, 2006).

$$
\begin{aligned}
& \phi=\overline{\mathrm{E}} \cdot \mathrm{A} \cdot \alpha=\overline{\mathrm{E}} \cdot \mathrm{A} \cdot(1-\rho) \\
& \overline{\mathrm{E}}_{\text {ind }}=\overline{\mathrm{E}}-\overline{\mathrm{E}}_{\text {dir }}=\frac{\phi}{\mathrm{A}} \cdot \frac{1}{1-\rho}-\frac{\phi}{\mathrm{A}}=\frac{\phi}{\mathrm{A}} \cdot \frac{\rho}{1-\rho}
\end{aligned}
$$

Fórmula 2

$$
\phi=\overline{\mathrm{E}}_{\text {ind }} \cdot \mathrm{A} \cdot \frac{1-\rho}{\rho}
$$

Fórmula 3

Onde:

A - Área da esfera

E - lluminamento médio da superfície interna.

Eind - lluminamento indireto

$E_{\text {dir }}$ - lluminamento direto

$\rho$ - Coeficiente de reflexão

a- Coeficiente de absorção 
A Figura 77 mostra a esfera integradora ou de Ulbricht semelhante a que foi utilizada para as medições em laboratório.

Figura 77: Esfera integradora ou Esfera de Ulbricht.
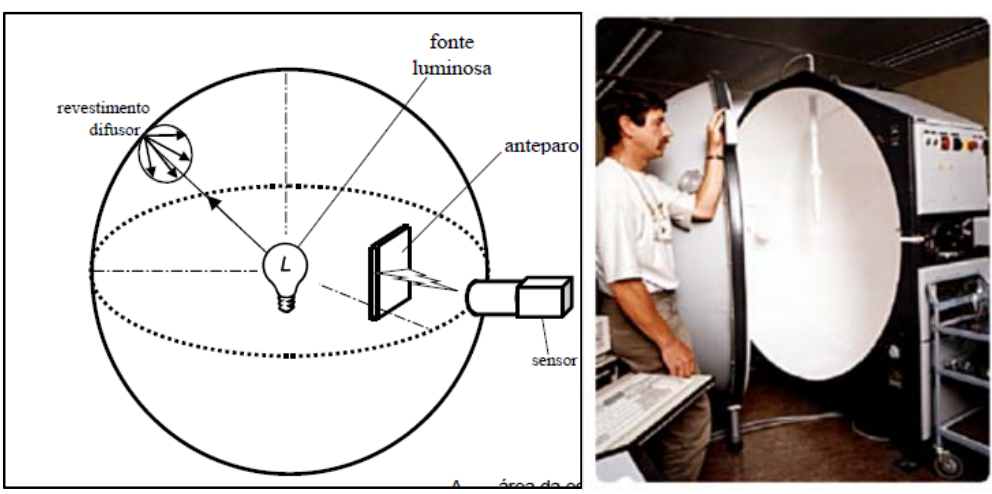

Fonte: Kaiser, 2011.

\subsubsection{Fluxo luminoso}

Unidade: lúmen (Im)

O fluxo luminoso é a grandeza característica de um fluxo energético, expressando a sua disposição de produzir uma sensação luminosa no ser humano, através de estímulo da retina ocular, avaliada segundo valores da eficácia luminosa relativa admitidos pelo CIE. Símbolo $(\Phi)$.

\subsubsection{Intensidade luminosa}

Unidade: candela (cd)

A intensidade luminosa é o limite da relação do fluxo luminoso em um ângulo sólido em torno de uma dada direção e o valor desse ângulo sólido, quando esse ângulo sólido tende a 0 (zero). Candela é a intensidade luminosa de uma fonte 
puntiforme numa certa direção, na qual um ângulo sólido de 1 esferradiano $^{50}$ emite 1 lúmen. Símbolo (I).

\subsubsection{Diagramas fotométricos}

Os diagramas fotométricos são a distribuição de luz realizada por uma fonte e podem ser representados por uma superfície definida pela distribuição espacial dos valores da intensidade luminosa em cada direção. É a chamada superfície fotométrica. Segundo Iwashita (2004), a distribuição das intensidades luminosas de uma luminária revela as características de distribuição da luz e é representada pelas curvas de distribuição de intensidade luminosa ou curva de distribuição luminosa (CDL) e são geralmente representadas em coordenadas polares e mostram a variação da intensidade luminosa num plano que passa através da fonte (lâmpada ou luminária), em função do ângulo medido a partir de uma direção determinada. A Figura 78 representa curvas de distribuição de intensidade luminosas nos planos longitudinal, transversal e diagonal de uma luminária.

Para o levantamento fotométrico de luminárias internas é convencionado que as intensidades luminosas são obtidas variando-se os ângulos nas direções verticais e horizontais, em função da origem nadir, referência perpendicular ao plano formado pela luminária, passando pelo centro dela, no sentido inferior. Os ângulos verticais $(\theta)$ podem variar de $0^{\circ} \leq \theta \leq 180^{\circ}$, e os ângulos horizontais $(\psi)$ de $0^{\circ} \leq \Psi \leq 360^{\circ}$, conforme IESNA, 2000.

Em função da quantidade e características dos planos horizontais $(\Psi)$ que representam a distribuição luminosa das luminárias, estas podem ser classificadas como:

- Simétricas axiais: Representadas apenas para ângulo horizontal $\psi=0^{\circ}$.

- Simétricas quadrilaterais: Representadas para ângulos horizontais $0^{\circ} \leq \Psi \leq 90^{\circ}$

- Simétricas bilaterais: Representadas para ângulos horizontais $0^{\circ} \leq \Psi \leq 180^{\circ}$

- Assimétricas: Representadas para ângulos horizontais $0^{\circ} \leq \psi \leq 360^{\circ}$

\footnotetext{
50 Ângulo sólido que, tendo vértice no centro de uma esfera, subtende na superfície da mesma uma área igual ao quadrado do raio da esfera.
} 
Figura 78: Planos transversais e longitudinal de uma curva fotométrica.

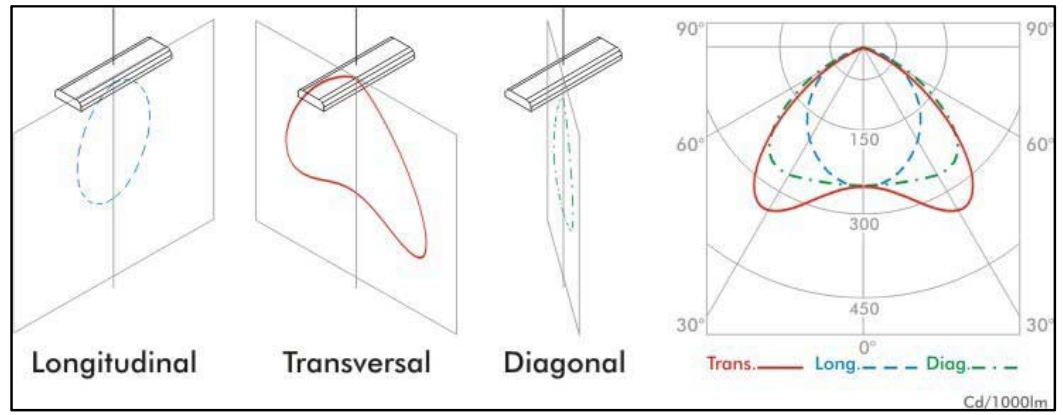

Fonte: Bigoni, 2013.

\subsubsection{Iluminância}

Unidade: lux (Ix)

Por definição, iluminância é o limite da razão do fluxo luminoso d $\Phi$, incidente num elemento de superfície que contém o ponto dado, para uma área $\mathrm{dA}$ deste elemento, quando esta área tende para 0 (zero). Ou seja, é o fluxo luminoso incidente numa superfície por unidade de área. Símbolo $(E)$.

$$
E=\lim _{\Delta A \rightarrow 0} \frac{\Delta \Phi}{\Delta A}=\frac{d \Phi}{d A}
$$

\section{Fórmula 4}

Onde:

$\mathrm{d} \Phi=$ fluxo luminoso $(\mathrm{Im})$

$\mathrm{dA}=$ área $\left(\mathrm{m}^{2}\right)$

$\mathrm{E}=$ iluminância (lux)

Um lux corresponde à iluminância de uma superfície plana de um metro quadrado de área, sobre a qual incide perpendicularmente um fluxo luminoso de um lúmen. Importante notar que a iluminância está ligada a um ponto na superfície que independe da posição do observador. 
Normalmente, nos trabalhos de iluminação, emprega-se a iluminância média, que é dada pela expressão:

$$
E=\frac{\Phi}{A}
$$

Onde:

$\mathrm{E}=$ iluminância média (lux)

$\Phi=$ fluxo luminoso $(\mathrm{Im})$

$$
A=\text { área }\left(m^{2}\right)
$$

\subsubsection{Luminância}

Unidade: candela por metro quadrado $\left(\mathrm{cd} / \mathrm{m}^{2}\right)$ ou nit $(\mathrm{nt})$

É por meio da luminância que as pessoas enxergam, já que os raios luminosos não são visíveis e a sensação de luminosidade é decorrente da reflexão destes raios em uma superfície. A luminosidade visível é chamada luminância.

\section{Logo:}

- lluminância é a luz incidente, não visível;

- luminância é a luz refletida, visível.

A equação matemática que permite a determinação da luminância é:

$$
L=\frac{I}{(A \times \cos \alpha)}
$$

Fórmula 6

Fonte: IEC, 2007

\section{Onde:}

$\mathrm{L}=$ luminância em $\mathrm{cd} / \mathrm{m}^{2}$; (ou em nit)

$\mathrm{I}=$ intensidade luminosa em cd;

$\mathrm{A}=$ área projetada em $\mathrm{m}^{2} \mathrm{e}$

$\alpha=$ ângulo considerado em graus. 
Em caso de desconhecimento do valor da intensidade luminosa, é recomendado o uso da equação matemática abaixo, que só é válida para o caso de difusores perfeitos, ou seja, paredes totalmente brancas, áreas cobertas de neve, entre outros exemplos caracterizados por uma superfície que reflita a luz igualmente a partir de qualquer ponto nela contido.

$L=\frac{(\rho \times E)}{\pi}$

Onde:

$\rho=$ coeficiente de reflexão (número puro);

$E$ = iluminância sobre essa superfície (em lux);

O coeficiente de reflexão ( $\rho$ ) é o quociente do fluxo incidente pelo fluxo refletido pela superfície:

$$
\rho=\rho \mathbf{i} / \rho \mathbf{r}
$$

$$
\text { Fórmula } 8
$$

Este coeficiente varia de acordo com a cor e a textura das superfícies. A luminância está diretamente relacionada com os contrastes. Por exemplo, a leitura de páginas escritas em letras pretas (refletância 10\%) sobre o papel de fundo branco (refletância $85 \%$ ) revela que a luminância das letras é menor que a luminância do fundo, tornando a leitura menos cansativa (JALGBAUER, 2007).

\subsubsection{Eficácia luminosa}

Unidade: lúmen/watt $(\mathrm{Im} / \mathrm{w})$

É a capacidade de conversão de energia elétrica em luminosa, expressa pela razão entre o fluxo luminoso emitido por uma fonte de luz (em lumens) e a potência elétrica consumida por essa mesma fonte (em Watts). A Figura 79 demonstra a evolução da tecnologia Led em relação às tecnologias tradicionais: 
Figura 79: Eficácia luminosa ( $\mathrm{Im} / \mathrm{W})$.

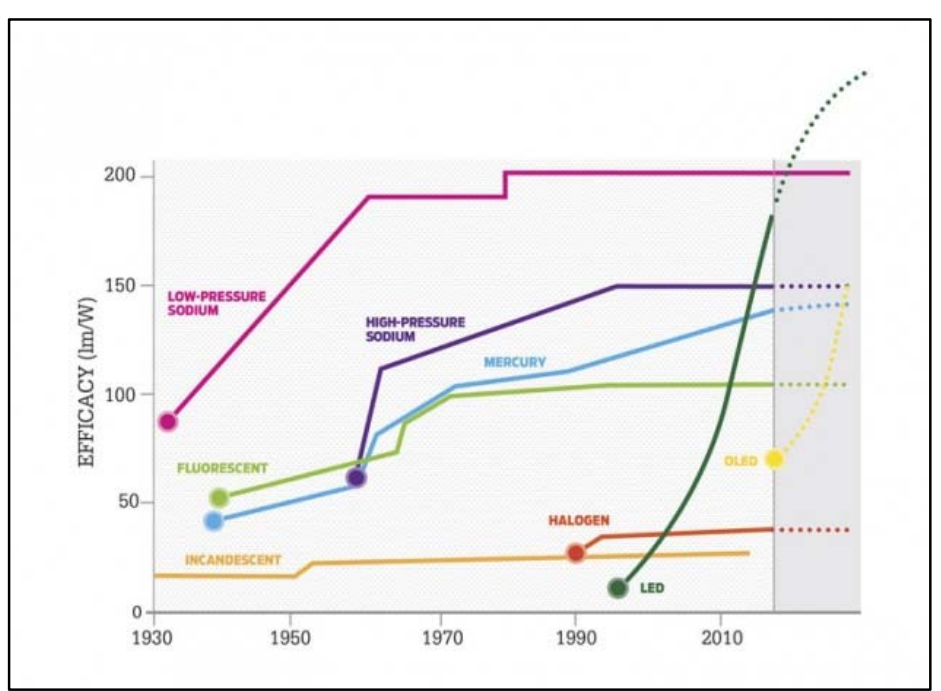

Fonte: Nascimento, 2017 


\section{FATORES CLIMÁTICOS}

\subsection{Considerações preliminares}

A climatologia é a ciência que se ocupa do estudo dos climas e é estruturada a fim de evidenciar os elementos climáticos e os fatores geográficos do clima. Segundo Ambrizzi (2016), as mudanças "rápidas" no estado da atmosfera constituem o que chamamos de "tempo" e características "médias" no estado da atmosfera constituem o que chamamos de "clima". O estudo da climatologia está vinculado ao campo das ciências humanas e naturais (MENDONÇA; DANNI- OLIVEIRA, 2016).

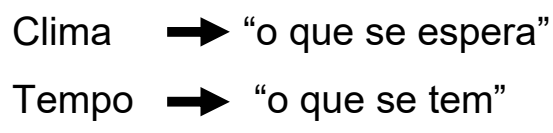

O estudo da climatologia foi subdividido e apresentado por alguns autores, Ayoade (1988) e Vianello e Alves (2012), sendo quatro as mais usadas: a climatologia sinótica, que estuda a relação do tempo e do clima em uma área com relação ao padrão de circulação atmosférica predominante, a climatologia física, que investiga o comportamento dos elementos do tempo ou os processos atmosféricos em termos de princípios físicos, a climatologia dinâmica, que aborda os movimentos atmosféricos em várias escalas, particularmente na circulação geral da atmosfera, e a climatologia aplicada, que estuda a aplicação do conhecimento climatológico nas soluções dos problemas que afetam a humanidade.

De acordo com Ynoue et al. (2017), a meteorologia é a ciência que estuda os processos físicos, químicos e dinâmicos da atmosfera e as interações desses processos com as camadas da atmosfera, sendo, portanto, inserida no contexto das Ciências Ambientais. O estado da atmosfera é definido como tempo atmosférico, ou tempo, em função de um determinado momento e local; para o desenvolvimento desta tese, denominaremos de tempo. Atualmente, a metodologia desenvolvida pela meteorologia permite a realização de previsões fiáveis do estado do tempo em curto prazo, fundamentais para a organização de inúmeras atividades humanas. 
Diversos autores, tais como Ayoade (1988), Vianello e Alves (2012), subdividem o estudo da meteorologia conforme suas áreas de aplicações, sendo a meteorologia sinótica a que trata da descrição, análise e previsão de tempo, a meteorologia física a que estuda os fenômenos atmosféricos relacionados diretamente com a física e a química, a meteorologia dinâmica a que aborda os movimentos atmosféricos e sua evolução temporal, e a micro meteorologia a que estuda as interações da superfície-atmosfera, com os fluxos de calor e massas e com a estabilidade atmosférica.

\subsection{Fatores do clima e a influência nos experimentos}

Mendonça, Danni-Oliveira (2016) afirma que os elementos climáticos são definidos pelos atributos físicos, que representam propriedades da atmosfera geográfica de um dado local. Os mais utilizados para caracterizar a atmosfera geográfica são a temperatura do ar, a umidade do ar e a pressão atmosférica que, influenciados pela diversidade geográfica, manifestam-se por meio de precipitação, radiação solar, vento, nebulosidade, ondas de calor e frio.

A grande variação espacial e temporal da manifestação dos elementos climáticos, é também conhecida como fatores do clima. A estes elementos juntam-se os aspectos dinâmicos do meio oceânico e atmosférico, como as correntes oceânicas, massas de ar e frentes, que atuam em conjunto, e irão qualificar os distintos climas da Terra.

A atmosfera é composta por um conjunto de gases, vapor d'água e partículas diversificadas. Nela, temos a formação da camada de ozônio $\left(\mathrm{O}_{3}\right)$ e, devido a ela, as formas de vida na Terra estão protegidas. Os gases mais importantes da atmosfera são o nitrogênio, o oxigênio, o argônio, o dióxido de carbono, o ozônio e o vapor d' água. Eles atuam como reguladores da temperatura e da umidade da superfície. Além desses gases, é possível encontrar na atmosfera as partículas de pó, as cinzas vulcânicas, a fumaça, a matéria orgânica e os resíduos industriais, que são também chamados de aerossóis (VIANELLO e ALVES, 2012) 
A radiação solar é um fator de extrema relevância e sua força é efetiva, pois compreende o balanço térmico da Terra. Para Ayoade (1988) e Vianello e Alves (2012), a quantidade de radiação solar que incide no topo da atmosfera terrestre depende basicamente de três fatores, que são o período do ano, o período do dia e a latitude.

A latitude é um dos mais importantes fatores climáticos que influenciam a determinação do clima, devido essencialmente ao calor que é recebido em uma área da superfície da Terra, sua intensidade, e a duração da incidência dos raios solares (DIESEL, 2018). Portanto, em relação à latitude, quanto maior ela for, menores serão as temperaturas. A Terra é iluminada pelos raios solares em diferentes inclinações, e isto ocorre em função da sua forma (DIESEL, 2018).

Portanto, quanto mais próximo do Equador menor será a inclinação de incidência dos raios solares na Terra e, desta forma, teremos temperaturas mais elevadas. Quando a latitude for maior, teremos uma inclinação mais acentuada e, portanto, as temperaturas serão menores.

O sistema de classificação climática de Köppen e Geiger ${ }^{51}$ é o mais utilizado para classificar os climas do mundo, sendo que suas categorias são baseadas nas médias anuais e mensais de temperatura e precipitação, e reconhece cinco tipos climáticos principais, sendo cada tipo designado por uma $1^{\text {a }}$ letra maiúscula, que representa a característica geral do clima de uma região, uma $2^{\mathrm{a}}$ letra minúscula, que representa as particularidades do regime de precipitação, e uma $3^{a}$ letra minúscula, que representa a temperatura média característica de uma região. A estrutura geral da classificação é definida como:

- Grupo A: Tropical - clima equatorial - Af ; clima monçônico - Am; clima savânico - Aw e As e clima equatorial - Af;

- Grupo B: Seco (áridos e semiáridos) - clima desértico - BWh e BWk e clima semiárido - BSh e BSk;

\footnotetext{
${ }^{51}$ Classificação climática de Köppen-Geiger, mais conhecida por classificação climática de Köppen, é o sistema de classificação global dos tipos climáticos mais utilizada em geografia, climatologia e ecologia.
} 
- Grupo C: Temperado - climas mediterrâneos - Csa, Csb e Csc; climas subtropicais úmidos - Cfa e Cwa; clima oceânico - Cfb, Cfc, Cwb e Cwc e climas de altitude - Cwb e Cfb;

- Grupo D: Continental e Subártico - climas continentais de verão quente - Dfa, Dwa e Dsa; climas continentais de verão fresco - Dfb, Dwb e Dsb;

- Grupo E: Polar e Alpino - climas de tundra - ET e clima glacial, ou clima de calota de gelo-EF.

\subsubsection{Classificação climática dos parâmetros geográficos}

Conforme parâmetros geográficos adotados para os experimentos de campo, temos a cidade de Cotia, localizada a menos de $30 \mathrm{~km}$ do centro da cidade de São Paulo, e a cidade de Fortaleza, no Estado do Ceará, onde temos as seguintes classificações climáticas pelo método de Köppen e Geiger, e que são apresentadas na Figura 80.

$\rightarrow$ Cotia/SP - Clima temperado e classificado como Cfa (clima subtropical úmido) alternando o úmido e seco: inverno fresco (média mensal em torno de $16^{\circ} \mathrm{C}$ ) e verão quente (cerca de $24^{\circ} \mathrm{C}$ ). A temperatura média é $18.5^{\circ} \mathrm{C}$. A pluviosidade média anual é $1340 \mathrm{~mm}$ sendo que, mesmo no mês mais seco, o índice pluviométrico é elevado.

$\rightarrow$ Fortaleza/CE - O clima é tropical. A classificação do clima é Aw (clima savânico). Chove muito mais no verão que no inverno, e a temperatura média anual em Fortaleza é $26.3^{\circ} \mathrm{C}$. A pluviosidade média anual é $1448 \mathrm{~mm}$. 
Figura 80 :Síntese da Classificação climática do Brasil, segundo Köppen e Geiger.

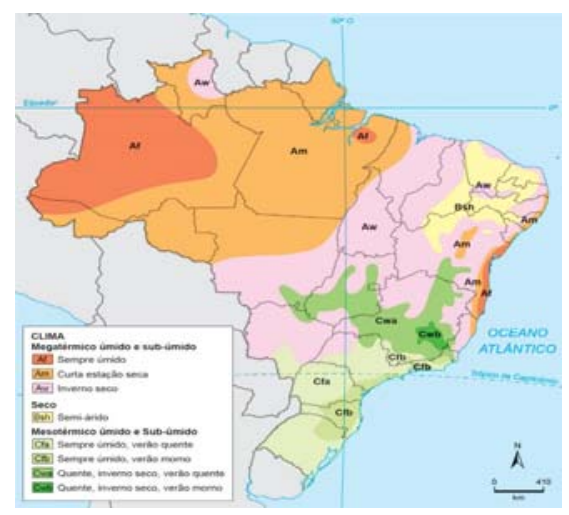

Fonte: <https://goo.gl/kMdCkk>. Acesso em:15 janeiro 2017

As estações meteorológicas de superfície automática são compostas de uma unidade de memória central (data logger Hobo), ligada a vários sensores dos parâmetros meteorológicos (pressão atmosférica, temperatura e umidade relativa do ar, precipitação, radiação solar, direção e velocidade do vento, etc.), e que integra os valores observados, minuto a minuto, e os disponibiliza automaticamente a cada hora.

O Instituto Nacional de Meteorologia (INMET) permite, por meio da sua página na internet ${ }^{52}$, o acesso aos dados de coleta das estações meteorológicas automáticas, disponibilizando algumas variáveis que foram utilizadas para embasamento da pesquisa, a saber:

$\rightarrow$ Temperatura Máxima do Ar;

$\rightarrow$ Temperatura Mínima do Ar;

$\rightarrow$ Umidade Relativa Máxima do Ar;

$\rightarrow$ Umidade Relativa Mínima do Ar;

$\rightarrow$ Radiação Solar.

O levantamento inicial mostrou que a cidade de Cotia não possui uma estação meteorológica e, portanto, se fez uso da estação mais próxima. É importante observar

${ }^{52}$ Instituto Nacional de Meteorologia (INMET) http://www.inmet.gov.br/portal/, 
a hora da coleta (horário universal), pois o quadro em destaque aponta que o registro é das 14 UTC, sendo que, nesse caso, temos duas estações - uma em Barueri e outra em Mirante de Santana, ambas em São Paulo, conforme mostra a Figura 81.

Figura 81: Coleta de dados das estações meteorológicas de Barueri e Mirante de Santana/SP.

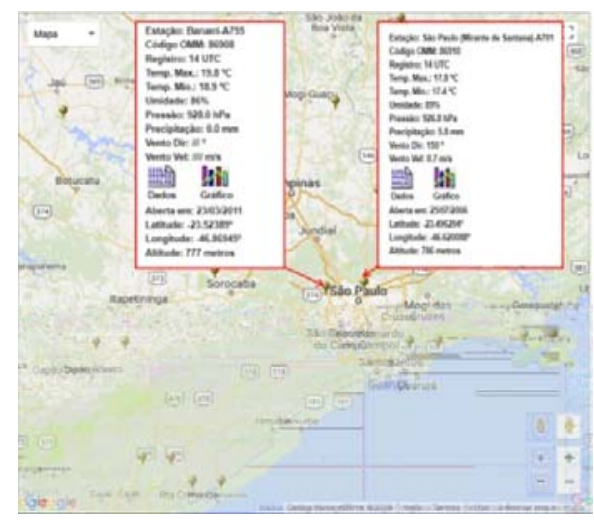

Fonte: http://www.inmet.gov.br/portal/index.php?r=estacoes/estacoesAutomaticas,07/01/2017.

A cidade de Fortaleza tem a sua própria estação meteorológica automática, conforme coleta de dados retratada na Figura 82.

Figura 82: Coleta de dados estação meteorológica de Fortaleza/CE.

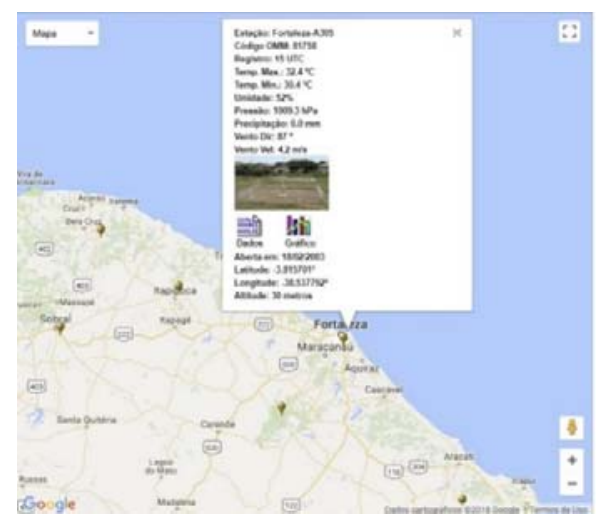

Fonte: http://www.inmet.gov.br/portal/index.php?r=estacoes/estacoesAutomaticas, 07/01/2017. 


\subsubsection{Principais variáveis climáticas - temperatura do ar, umidade relativa do ar, radiação solar, pressão atmosférica, latitude, altitude, ventos, maritimidade e continentalidade}

A temperatura do ar é a medida de calor sensível e mensurada em graus Celsius ou Fahrenheit por meio de termômetros (MENDONÇA; DANNI-OLIVEIRA, 2016). A temperatura do ar é proporcional ao balanço entre a radiação que chega e sai de cada camada atmosférica. Os fluxos de calor latente e sensível também contribuem para modificar a temperatura de cada camada. Desse modo, a temperatura do ar varia de lugar para lugar e com o decorrer do tempo.

Vários fatores físicos influenciam a distribuição da temperatura sobre a superfície da Terra: a quantidade de insolação recebida, as características da superfície, a distância em relação a corpos hídricos, o relevo, a natureza dos ventos predominantes e as correntes oceânicas. A latitude exerce o principal controle sobre a insolação que um determinado lugar recebe. A temperatura pode ser expressa em temperatura máxima, mínima e normal, e é medida pelo termômetro meteorológico. A diferença entre a maior e a menor temperatura chama-se amplitude térmica.

A umidade do ar é definida como a presença de água na atmosfera eé expressa em percentual. Ayoade (1988) a descreve como sendo o componente atmosférico mais importante para a determinação do tempo e do clima. A umidade do ar é o resultado da evaporação das águas da superfície terrestre e hídrica, bem como da evapotranspiração ${ }^{53}$. Ela depende de calor para que seja possível ocorrer a evaporação da água; ou seja, é preciso a existência de água para ser evaporada sendo, então, a relação entre a quantidade de água existente no ar (umidade absoluta) e a quantidade máxima que poderia haver na mesma temperatura (ponto de saturação). Ela é um dos indicadores usados na meteorologia para se saber como o tempo se comportará.

\footnotetext{
${ }^{53}$ Evapotranspiração: O total de água transferida da superfície da Terra para atmosfera. É composto da evaporação do líquido, ou "água sólida”, acrescida da transpiração das plantas.
} 
A pressão atmosférica é exercida pela atmosfera sobre qualquer superfície, em virtude de seu peso. Equivale ao peso de uma coluna de ar de corte transversal unitário, que se estende desde um nível dado até o limite superior da atmosfera. Sua medida pode ser expressa em milibares, em polegadas, ou em milímetros de mercúrio $(\mathrm{Hg})$. É também conhecida como pressão barométrica. A pressão atmosférica varia de lugar para lugar. Essa variação é causada pela altitude e principalmente pela temperatura.

Altitude é a distância vertical medida entre um determinado ponto e o nível médio do mar, sendo que a região terrestre que está mais próxima ao nível do mar apresenta menor altitude e maior pressão atmosférica e, portanto, registra temperaturas mais elevadas. Nas regiões com maior altitude, há menor pressão atmosférica e, por isso, elas se tornam mais frias. Assim, quanto maior a altitude, menor é a temperatura. Quanto menor a altitude, maior é a temperatura. No Brasil são maiores as áreas de baixa altitude e, em algumas áreas, ela determina diferença nas temperaturas. Das regiões brasileiras, segundo Torres e Machado (2008), a mais influenciada pela altitude é a Sudeste, que apresenta o conjunto de terras mais elevadas do Brasil.

Quando ocorre o movimento do ar em relação à superfície terrestre, dizemos que há vento, e esse movimento existe quando há diferença de pressão atmosférica entre dois pontos, já que o vento sopra das altas para as baixas pressões. Nosso conhecimento dos ventos globais provém dos regimes observados de pressão e vento, e de estudos teóricos de movimento dos fluídos. No estudo da meteorologia, costuma-se dividir o vento em suas duas componentes, horizontal e vertical, sendo que a horizontal do vento é representada por intensidade (ou velocidade do vento) $\mathrm{e}$ direção/sentido e, geralmente, é muito maior que a vertical, uma vez que a vertical está associada à estabilidade da atmosfera (ar quente sobe).

Os ventos alísios são originados do deslocamento das massas de ar frio das zonas de alta pressão que se formam nos trópicos, para as zonas de baixa pressão situadas no equador e, devido ao efeito de Coriolis, os ventos nas faixas intertropicais sopram no sentido anti-horário, no hemisfério sul, e no sentido horário, no hemisfério norte. Os ventos "contra-alísios" se dirigem até as zonas dos cinturões anti ciclônicos 
mantendo-se, assim, o sistema de circulação entre zonas tropicais e subtropicais e a zona equatorial.

A maritimidade e a continentalidade são fatores climáticos que estão relacionados com a proximidade que um lugar tem com os mares e oceanos. Nos locais mais próximos às grandes quantidades de água a umidade é maior e, por isso, haverá uma menor variação na temperatura (amplitude térmica). Nas regiões mais distantes das grandes quantidades de água, ou de massas líquidas, a umidade do ar é menor, a continentalidade é que exerce maior influência e, por conseguinte, registrarão altas amplitudes térmicas (DIESEL, 2018).

Os mares e oceanos, além de terem a função de regular a temperatura e a umidade, servem ainda como os "principais fornecedores de água para a troposfera, e controlam a distribuição de energia entre os oceanos e os continentes". Ao trocarem energia entre pontos distantes da Terra, "as correntes oceânicas interagem com a dinâmica das massas de ar, definindo quais serão as áreas secas e as áreas chuvosas". Tal fato ocorre pelo fato de as águas frias superficiais induzirem o ar a se resfriar, inibindo a formação de nuvens, e, por consequência, a ocorrência de chuvas. (MENDONÇA e DANNI-OLIVEIRA, 2016).

Conforme o Instituto Nacional de Meteorologia (INMET), o acompanhamento contínuo das condições térmicas na camada superficial dos oceanos é de extrema importância para os serviços meteorológicos e para as pesquisas climáticas e oceânicas. Ocupando mais de $70 \%$ da superfície do globo terrestre, os oceanos exercem papel preponderante nas condições de tempo meteorológico e no clima do planeta, influenciando diretamente o balanço de energia superfície-atmosfera e o transporte de calor entre as latitudes altas e baixas. O Brasil tem um extenso litoral, com 9.200 $\mathrm{km}$, se forem consideradas as saliências e reentrâncias banhadas pelo oceano Atlântico. A cidade de Fortaleza tem 34 km de litoral, dividido em 15 praias.

Outra importante contribuição dos oceanos, sob o ponto de vista climático global, é a sua condição natural de armazenamento de dióxido de carbono, sendo essa capacidade de retenção de gás carbônico inversamente proporcional à variação da sua temperatura nos diversos níveis de profundidade. Ou seja, oceanos mais quentes indicam menor capacidade de retenção do gás e maior liberação de carbono em direção à atmosfera, sendo o contrário também verdadeiro. 


\subsection{Processos atmosféricos da poluição ambiental}

Muitos gases e aerossóis que podem poluir a nossa atmosfera são parte integrantes dela, e os consideramos como poluentes ambientais quando a sua concentração passa dos níveis comuns para altas concentrações, causando disfunções nos processos físicos e biológicos. Conforme o Conselho Nacional do Meio Ambiente - CONAMA, por meio da Resolução n. 491, de 19 de novembro de 2018, define-se que o poluente atmosférico é qualquer forma de matéria em quantidade, concentração, tempo ou outras características, que tornem ou possam tornar o ar impróprio ou nocivo à saúde, inconveniente ao bem-estar público, danoso aos materiais, à fauna e flora, ou prejudicial à segurança, ao uso e gozo da propriedade, ou às atividades normais da comunidade.

A poluição do ar é resultado do lançamento de enorme quantidade de poluentes gasosos e aerossóis atmosféricos, causando o desequilíbrio dos já existentes. Segundo Fornaro (2017), os poluentes atmosféricos são classificados como poluentes primários, que são aqueles emitidos diretamente pelas fontes de emissão como, por exemplo, dióxido de enxofre, monóxido de carbono, etc., e poluentes secundários, que são aqueles formados na atmosfera através da reação química entre poluentes primários e componentes naturais da atmosfera como, por exemplo, Ozônio $\left(\mathrm{O}_{3}\right)$, mas podem ser divididos entre fontes antropogênicas e fontes naturais, a saber:

As fontes antropogênicas são as derivadas de queima de combustíveis fósseis - $\mathrm{NO}_{x}$ (óxidos de nitrogênio), $\mathrm{SO}_{2}$ (dióxido de enxofre), $\mathrm{CO}$ (monóxido de carbono), HC (hidrocarbonetos); processos industriais em geral - $\mathrm{SO}_{2}, \mathrm{NH}_{3}$ (amônia), $\mathrm{NO}_{x}, \mathrm{Cl}$ (cloro), MP (material particulado) e agricultura, em função do material particulado (MP) - $\mathrm{NH}_{3}$.

$E$ as fontes naturais de poluentes do ar são proveniente de erupções vulcânicas - poeira, vapor de mercúrio, ácido clorídrico $(\mathrm{HCl})$ e ácido sulfídrico $(\mathrm{H} 2 \mathrm{~S})$; emissão biogênica de compostos orgânicos reativos por florestas, grandes plantações e matas em geral e queimadas de florestas - monóxido de carbono (CO), NOx, MP e compostos orgânicos

Um breve levantamento das particularidades dos principais poluentes atmosféricos, permite uma análise de uma possível influência nos ambientes internos das edificações, definidos nos parâmetros geográficos deste trabalho, sendo eles: 
O monóxido de carbono (CO) é um gás levemente inflamável, inodoro e muito perigoso, devido à sua grande toxicidade. Quando os combustíveis à base de carbono como o carvão, a madeira e o petróleo queimam de forma incompleta ou ineficiente, produzem monóxido de carbono. O gás é espalhado por ventos e padrões de circulação em toda a atmosfera inferior (troposfera ${ }^{54}$ ). O monóxido de carbono é um gás traço na atmosfera e não tem efeito direto sobre a temperatura global, como o metano e o dióxido de carbono. No entanto, o monóxido de carbono desempenha um papel importante na química atmosférica e afeta a capacidade da atmosfera para se purificar de muitos outros gases poluentes. Em combinação com outros poluentes e raios solares, também participa da formação de ozônio atmosférico ruim.

O dióxido de enxofre $\left(\mathrm{SO}_{2}\right)$ é um gás incolor e ocorre como uma impureza nos combustíveis fósseis, proveniente principalmente de atividades como queima de diesel nos veículos pesados, carvão e petróleo em usinas de energia, ou de fundição de cobre. Acredita-se que cerca de $80 \%$ do $\mathrm{SO}_{2}$ venha da queima incompleta de combustíveis fósseis. Na natureza, pode ser liberado para o ar a partir de erupções vulcânicas. Ao entrar em contato com o oxigênio, o enxofre se transforma em dióxido e trióxido de enxofre $\left(\mathrm{SO}_{3}\right)$, que reage com a umidade do ar formando o ácido sulfúrico, o qual ainda pode reagir com a amônia do ar e formar sulfato de amônia.

$\mathrm{O} \mathrm{SO}_{2}$ permanece no ar em forma de gotículas (mais comum em ambientes fechados), ou retorna para a terra após processos de oxidação e reação na forma de chuva ácida. Além disso, pode reagir com outros compostos na atmosfera formando o chamado material particulado de diâmetro reduzido. O dióxido de enxofre pode contribuir para o aquecimento do planeta, e sua presença na chuva ácida é perigosa para vegetais e animais, além de corroer alguns materiais e afetar monumentos, construções, estátuas. A chuva ácida diminui o $\mathrm{pH}^{55}$ dos lagos e reduz a concentração

\footnotetext{
54 Troposfera - camada atmosférica mais próxima da superfície terrestre, situada de $10 \mathrm{~km}$ a $12 \mathrm{~km}$ de altitude, na qual a temperatura decresce rapidamente com a altitude e se formam as nuvens e as correntes de convecção.

${ }^{55}$ A sigla pH significa Potencial Hidrogeniônico, e consiste num índice que indica a acidez, neutralidade ou alcalinidade de um meio qualquer. $\mathrm{O}$ pH é uma característica de todas as substâncias determinado
} 
populacional de peixes. Nas plantas, vegetais e flores, compromete a produção e crescimento.

O dióxido de carbono, ou gás carbônico, é um produto químico formado por dois átomos de oxigênio e um átomo de carbono $\left(\mathrm{CO}_{2}\right)$, encontrado naturalmente na atmosfera, produzido pela respiração dos animais e pela queima de qualquer matéria orgânica.

A atmosfera terrestre é formada por uma mistura de gases, entre eles o nitrogênio, que compõe $78,08 \%$ do ar, o oxigênio, que compõe $20,94 \%$ e o dióxido de carbono, que compõe apenas $0,03 \%$ do ar atmosférico. O dióxido de carbono é um dos principais responsáveis pelo efeito estufa na atmosfera, pois forma uma camada que impede que a radiação solar, refletida pela superfície em forma de calor, se dissipe no espaço, o que garante as condições de temperatura e clima necessários para a existência da vida na terra.

As fontes emissoras de dióxido de carbono são semelhantes ao do monóxido de carbono, dentre as quais a queima de combustíveis fósseis, substâncias de origem mineral, formadas pelos compostos de carbono - entre eles, o carvão mineral, o gás natural e os derivados do petróleo, como a gasolina e o óleo diesel, usados para gerar energia elétrica e movimentar veículos de transporte - são os principais responsáveis pela emissão do dióxido de carbono na atmosfera, causando poluição e alteração no equilíbrio térmico do planeta, provocando mudanças no efeito estufa e no aquecimento global. $\mathrm{O}$ desmatamento provocado pela queima das florestas também afeta o equilíbrio do dióxido de carbono na atmosfera pois, além de liberar o gás pela queima da madeira, reduz o número de árvores responsáveis pela fotossíntese, que absorve $0 \mathrm{CO}_{2}$ da natureza.

A chuva ácida é mais um fenômeno causado pela poluição atmosférica e, principalmente, por meio da queima de combustíveis fósseis em indústrias e automóveis. Mas o ser humano também vem lançando uma grande quantidade de gases poluentes, como alguns óxidos.

pela concentração de íons de Hidrogênio $(\mathrm{H}+)$. Quanto menor o pH de uma substância, maior a concentração de íons $\mathrm{H}+$ e menor a concentração de íons $\mathrm{OH}-$. 
Os óxidos são compostos inorgânicos binários, que têm o oxigênio como elemento mais eletronegativo. Entre eles, temos uma classe que são os óxidos ácidos, assim chamados porque reagem com a água, gerando ácidos e também reagem com bases, formando água e sal. Os principais óxidos ácidos lançados na atmosfera, e que reagem com a água das chuvas produzindo as chuvas ácidas, são os óxidos de enxofre $\left(\mathrm{SO}_{2}\right.$ e $\left.\mathrm{SO}_{3}\right)$ e de nitrogênio $\left(\mathrm{N}_{2} \mathrm{O}, \mathrm{NO}\right.$ e $\left.\mathrm{NO}_{2}\right)$. Os maiores vilões são os óxidos de enxofre, pois reagem com a água formando o ácido sulfúrico, o mesmo ácido usado em baterias de automóveis, que é um ácido muito forte.

Esse termo "chuva ácida" foi usado pela primeira vez pelo químico e climatologista inglês Robert Angus Smith, ao descrever a precipitação ácida que ocorreu sobre a cidade de Manchester no início da Revolução Industrial.

Segundo Nogueira (2018), "oxidantes fotoquímicos" é a denominação que se dá à mistura de poluentes secundários formados pelas reações entre os óxidos de nitrogênio e compostos orgânicos voláteis na presença de luz solar, sendo estes últimos liberados na queima incompleta e evaporação de combustiveis e solventes.

O principal produto desta reação é o ozônio, por isso mesmo utilizado como parâmetro indicador da presença de oxidantes fotoquímicos na atmosfera. Tais poluentes formam a chamada névoa fotoquímica ou "smog fotoquímico", que possui este nome porque causa diminuição da visibilidade na atmosfera. Além de prejuízos à saúde, o ozônio pode causar danos à vegetação. Ainda segundo Nogueira (2015), é sempre bom ressaltar que o ozônio encontrado na faixa de ar próxima do solo, onde respiramos, chamado de "mau ozônio", é tóxico; entretanto, na estratosfera (a cerca de $25 \mathrm{~km}$ de altitude), o ozônio tem a importante função de proteger a Terra, como um filtro, dos raios ultravioletas emitidos pelo Sol.

O spray de sal é em grande parte responsável pela corrosão de objetos metálicos próximos do litoral, já que os sais aceleram o processo de corrosão na presença de oxigênio atmosférico abundante e umidade. Os sais não se dissolvem no ar diretamente, mas são suspensos como partículas finas, ou dissolvidos em gotículas microscópicas de água no ar.

A água do mar é uma solução salina uniforme, consistindo predominantemente de cloretos de sódio e magnésio dissolvidos em água; embora muitos outros minerais solúveis estejam presentes em pequenas quantidades, os efeitos individuais e 
cumulativos destes minerais são insignificantes na presença dos cloretos dominantes. Então, a água pode ser considerada equivalente a uma solução $0,5 \mathrm{~N}$ de cloreto de sódio. Nesta concentração a solução de cloreto de sódio tem um pico de corrosão, atuando mais agressivamente sobre o aço.

Outros fatores que afetam a corrosão incluem:

$\rightarrow$ A concentração de oxigênio

$\rightarrow$ Degradação de material biológico

$\rightarrow$ Velocidade e temperatura da água

\subsubsection{Aerossol atmosférico}

Aerossóis atmosféricos são as partículas sólidas e/ou líquidas, que se encontram suspensas na atmosfera e podem ter efeitos diretos e indiretos no clima, como temperaturas mais baixas ou mudanças no ciclo hidrológico. As nuvens são formadas por aerossóis, ou seja, partículas, sendo que eles podem ou ajudar a formar nuvens, ou podem inibir a formação de nuvens, ou refrigerar a superfície, ou aquecêla. O pó soprado pelo vento, sais marinhos, cinzas vulcânicas, fumaça de incêndios florestais e poluição de fábricas, são exemplos de aerossóis; se inalados, alguns aerossóis podem prejudicar a saúde das pessoas.

Vieira da Silva Filho (2015) afirma que a sua composição e tamanho dependem das fontes de emissão e de processos físico-químicos que ocorrem na atmosfera. $O$ tamanho das partículas é, em geral, expresso em relação ao seu tamanho aerodinâmico $\left(D_{a}\right)$, definido como diâmetro de uma esfera, que possui densidade unitária e a mesma velocidade de sedimentação que a partícula em questão, e as dimensões variam de alguns nanômetros a dezenas de micrômetros. 
As partículas de aerossóis atmosféricos participam em processos chave na poluição do ar, na deposição seca, na deposição úmida, Sea-spray ${ }^{57}$, na depleção do ozônio estratosférico ${ }^{58} \mathrm{e}$ nas mudanças climáticas. A Figura 83 representa os processos e compostos envolvidos na poluição atmosférica.

Figura 83: Processos e compostos envolvidos na poluição atmosférica.

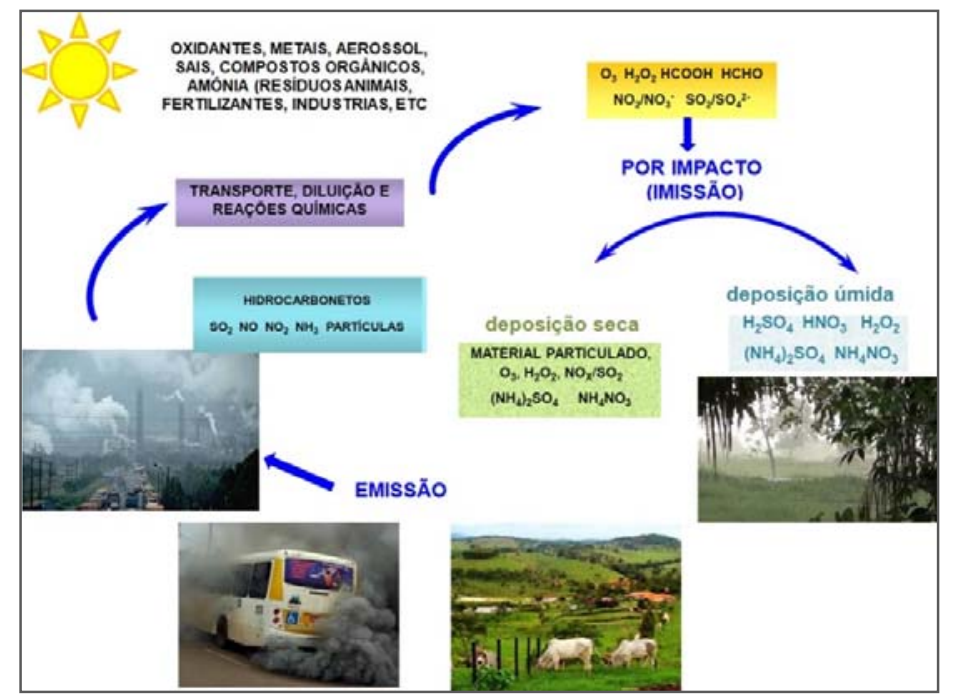

Fonte: Arromba, 2013, adaptado pela autora, 2018.

\subsubsection{Corrosão atmosférica}

Segundo Araújo Ponte (2004), embora as atmosferas possam ser classificadas em quatro tipos básicos - urbana, industrial, marítima ou rural - muitas delas apresentam características mistas, além de não haver uma demarcação definida para cada tipo. Ainda pode haver locais com microclimas de características diferentes da região em que se encontram. Com relação à forma de corrosão atmosférica, esta pode ser classificada em três tipos: seca, úmida ou aquosa. Todos os materiais que possuem uma energia livre negativa de formação de óxido apresentam corrosão

\footnotetext{
${ }^{57}$ Sea-spray: Referente às partículas de aerosol que são formadas no oceano.

${ }^{58}$ É a liberação dos gases clorofluorcarbonos (CFCs) na atmosfera. O ozônio estratosférico é responsável por absorver parte da radiação ultravioleta emitida pelo Sol, a qual é nociva aos seres vivos.
} 
atmosférica seca, na ausência de água. Neste caso, tem-se uma lenta oxidação com formação de produtos de corrosão, podendo o mecanismo ser considerado puramente químico: caso do "tarnish"59, escurecimento de prata ou de cobre por formação de $\mathrm{Ag}_{2} \mathrm{~S}$ e CuS, respectivamente, devido à presença de gás sulfídrico, $\mathrm{H} 2 \mathrm{~S}$, na atmosfera ou meio ambiente. Quando a atmosfera apresenta umidade relativa menor que $100 \%$, forma-se um fino filme de eletrólito sobre a superfície metálica causando um processo de corrosão atmosférica úmida. A velocidade do processo corrosivo dependerá da umidade relativa, dos poluentes atmosféricos e higroscopicidade ${ }^{60}$ dos produtos de corrosão. Quando os materiais estão em contato com uma atmosfera com cerca de $100 \%$ de umidade relativa, ocorre condensação na superfície metálica e tem-se um processo de corrosão atmosférica molhada.

Os produtos de corrosão podem ser solúveis ou insolúveis. Os produtos de corrosão solúveis podem aumentar as taxas de corrosão, quer seja aumentando a condutividade do eletrólito sobre a superfície metálica, ou por agir higroscopicamente, formando soluções quando a umidade ambiental é alta. Por outro lado, os produtos de corrosão insolúveis geralmente reduzem a taxa de corrosão, por atuarem como uma barreira entre a atmosfera e a superfície metálica. Por exemplo, o chumbo $(\mathrm{Pb})$ e o Alumínio (Al) corroem inicialmente, mas os produtos de corrosão posteriormente protegem o substrato. Às vezes os produtos de corrosão insolúveis aumentam a taxa de corrosão, por conservarem a umidade em contato com a superfície metálica.

A água do mar em virtude da presença acentuada de sais é um eletrólito por excelência. Outros constituintes como gases dissolvidos, podem acelerar os processos corrosivos.

Segundo Bigoni (2013), o ambiente marinho é o mais corrosivo de todos os meios naturais, e compreende desde a atmosfera contaminada com sal do mar até regiões mais profundas do oceano e o lodo sobre o fundo do mar. Os componentes e estruturas que estão normalmente expostos a meios marítimos são, por exemplo, as

\footnotetext{
59 Termo em inglês para manchado, embaçado, fosco.

${ }^{60}$ É a propriedade que certos materiais possuem de absorver água. Entre estes materiais pode-se citar sílica-gel, sulfato de cobre, alginato, silicones e madeira.
} 
bombas e tubulações de água do mar, navios, submarinos, cais, estacas e plataformas de petróleo costeiras, sendo que quanto mais próximo da orla marítima, mais elevada é a taxa de corrosão. 


\section{RESULTADOS E ANÁLISE DOS DADOS DA EXPERIMENTAÇÃO}

\subsection{Considerações preliminares}

O desempenho e a vida útil da luminária LED é, na maioria das vezes, muito maior do que a praticada e divulgada pela indústria de iluminação; consequentemente, validar a vida útil por meio de extrapolação de dados é necessário. A depreciação na emissão de luz varia entre fabricantes, e a confiabilidade dos componentes como um sistema integrado da luminária, incluindo os eletrônicos, invólucros, cabos, controles térmicos, conectores e demais elementos também. Conforme a NBR IEC 62722-2-1 - Desempenho de luminárias - Parte 2-1: Requisitos particulares para luminárias LED (2016, p.13), todo o sistema sobrevive apenas até a vida mais curta do componente crítico, mesmo que seja um componente crítico com selagem a intempéries, um elemento óptico, um LED, ou qualquer outra parte. Desta forma, fontes de luz LED são simplesmente um componente crítico entre outros, embora muitas vezes sejam o elemento mais confiável em todo o sistema de iluminação.

Para o desenvolvimento de um projeto de iluminação, os projetistas fazem uso das informações de fator de perda gerada pelas indústrias pois, segundo Sato (2019), em longo prazo, a falta de iluminância na área de tarefa pode acarretar problemas como erros ou atraso na conclusão de tarefas a serem realizadas, e até a perda da visão parcial.

Quanto maior o conhecimento, investigações e pesquisas a respeito do desempenho do LED, mais teremos a garantia da elaboração de bons projetos e igual atenção para a quantidade e qualidade da iluminação prestada pelas luminárias. 


\subsection{Resultados das medições dos objetos de ensaios}

Todas as medições foram feitas na esfera integradora considerando que os objetos de ensaios foram posicionados no centro da esfera, que recebe um anteparo para bloquear a incidência de luz direta da fonte e, conforme comentado anteriormente, a superfície interna apresenta um revestimento de óxido de magnésio ou sulfato de bário que o torna um difusor perfeito (cada ponto da superfície tem os mesmos valores de luminância e iluminância). A luminância da superfície da esfera é proporcional ao fluxo luminoso, independente da distribuição da intensidade luminosa (MOREIRA, 1999).

Os valores de incertezas considerados em relação aos equipamentos de laboratório, foram para as medições de fluxo luminoso na ordem de $\pm 3,2 \%$ e temperatura de cor de $\pm 2 \%$.

Para uma análise representativa da tecnologia LED, o período de 6.000 horas para as cidades de Cotia e Fortaleza, atende as recomendações, e o de $12.000 \mathrm{~h}$ permitiu uma avaliação mais rigorosa do comportamento dos objetos de ensaios; o mercado habitualmente ensaia somente a fonte de luz e não o conjunto completo. Conforme metodologia apresentada, os parâmetros elétricos como voltagem de saída do driver, corrente de alimentação do LEDs, potência elétrica consumida e eficácia do sistema também foram observados, mas se mantiveram praticamente constantes durante as primeiras 2.000 horas de testes, sendo que eventuais diferenças são devidas somente às tolerâncias de medidas dos equipamentos utilizados.

Os valores expressam variações médias para fluxo luminoso, potência total, eficácia luminosa, temperatura de cor correlata TCC (K), IRC, Ra, coordenada de cromaticidade "x,y" e índice de fidelidade (Rf) e Gamut (Rg), considerando os períodos definidos nos parâmetros de dados temporais, apresentados na seção 2.5. Para simplificar o entendimento dos períodos ensaiados assumimos 0 hora, 2.000 horas, 6.000 horas e 12.000 horas.

A análise dos dados é feita a partir do lançamento dos valores parametrizados em tabelas, que estão disponibilizadas no Anexo 1. 


\subsubsection{Medições de fluxo luminoso ( $\mathrm{Im}$ ) dos objetos de ensaios MINOTAURO COT CDF e SDF 001,002,003 e 004 versus MINOTAURO FOR CDF e SDF 001, 002, 003 e 004.}

Gráfico 3: Medições de fluxo luminoso(lm) MINOTAURO COT CDF e SDF 001, 002, 003 e 004
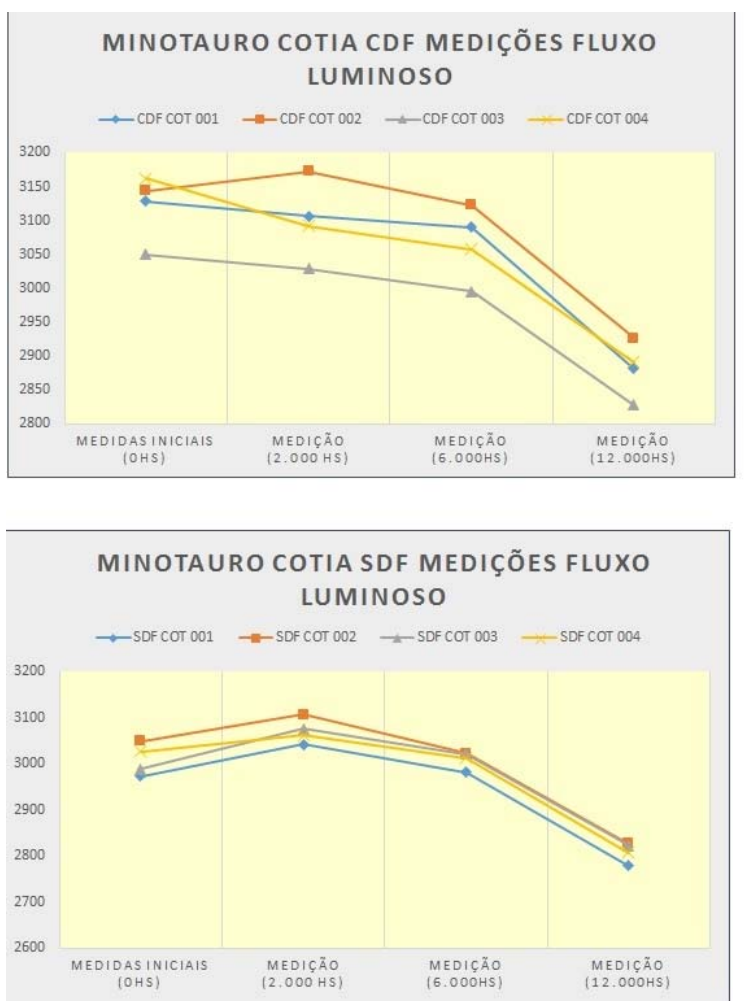

Gráfico 4: Medições de fluxo luminoso(lm) MINOTAURO FOR CDF e SDF 001, 002, 003 e 004

Fonte: a autora, 2020.

Considerando os critérios de análise apresentados anteriormente na metodologia deste trabalho, os resultados entre os objetos de ensaios MINOTAURO COTIA CDF e SDF 001, 002, 003 e 004 não demonstraram variações expressivas até 6.000 horas; contudo, nas medições de 12.000 horas, temos consideráveis perdas de fluxo luminoso, independente de termos o difusor frontal (CDF) ou com refletor e sem difusor (SDF). Em 6.000 horas temos uma pequena elevação do fluxo; já em 12.000 horas temos a diminuição do fluxo em $7,67 \%$. Essa condição é prevista pela LM80-18 
onde temos a elevação do fluxo para posterior queda, com o aumento do tempo de teste.

Essa comparação está sendo apresentada sempre em relação à 0 horas. Entendemos que essas reduções de fluxos luminosos são justificáveis em função do maior período de instalação.

Em referência aos objetos de ensaios MINOTAURO FORTALEZA SDF 001, 002, 003 e 004, temos um erro de medição apresentado em laboratório para 0 hora, percebido somente na conclusão do trabalho. Os objetos de ensaios considerados para as medições na esfera integradora utilizaram, por engano, difusores na estrutura interna dos refletores parabólicos; desta forma todos os valores de fluxos luminosos medidos à 0 hora ficaram bem abaixo dos valores originais dos objetos de ensaios, sendo que as medições em 6.000 horas foram feitas corretamente, sem os difusores, o que explica o aumento médio do fluxo luminoso na ordem de $15 \%$.

Comparando os resultados de 6.000 horas, a MINOTAURO COT CDF teve um comportamento semelhante ao da MINOTAURO FOR CDF quanto a variação de fluxo, com exceção ao objeto de ensaio MINOTAURO FOR CDF 002, que apresentou um crescimento de fluxo luminoso da ordem de 4,97\%. Isso pode ser explicado por desvio de medição ou pela geometria dos objetos de ensaios, uma vez que os modelos MINOTAURO COT são quadrados e MINOTAURO FOR são retangulares.

Comparando os resultados de 6.000 horas, a MINOTAURO COT SDF apresentou uma certa estabilidade de fluxo em 6.000 horas, enquanto a MINOTAURO FOR SDF apresentou aumento de fluxo luminoso; provavelmente isso é decorrente de uma influência ou da geometria do objeto ensaio, conforme citado anteriormente. 


\subsubsection{Medições de fluxo luminoso ( $(\mathrm{m})$ dos objetos de ensaios ORBI COT CDF e SDF 001, 002, 003 e 004 versus ORBI FOR CDF e SDF 001, 002, 003 e 004.}

Gráfico 5: Medições de fluxo luminoso( $(\mathrm{m})$ ORBI COT CDF e SDF 001, 002, 003 e 004.
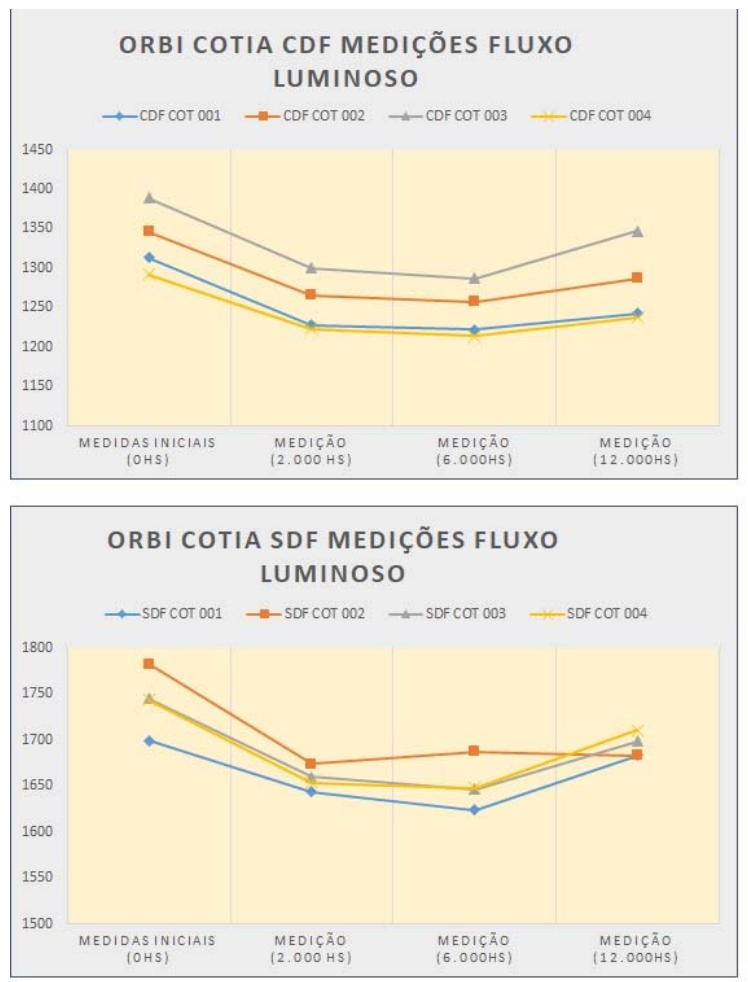

Gráfico 6: Medições de fluxo luminoso( $(\mathrm{m})$ ORBI FOR CDF e SDF 001, 002, 003 e 004.
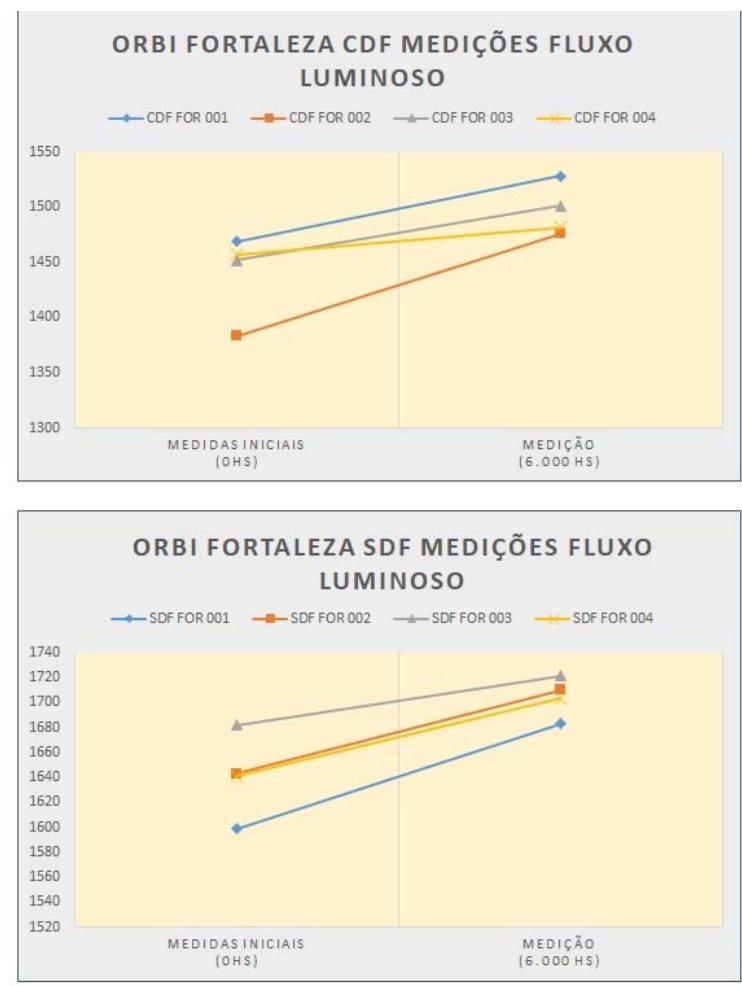

Fonte: a autora, 2020.

Os objetos de ensaios ORBI COTIA CDF e SDF 001, 002, 003 e 004 apresentaram variações maiores de perda de fluxo luminoso, sendo que ambos tiveram quase o mesmo comportamento; entretanto, notou-se uma redução maior nas versões com difusores, de $4,25 \%$, do que nos objetos sem os difusores, de $2,79 \%$.

Isso pode ser explicado pelo fato de que os difusores bloqueiam a passagem de luz, uma vez que, neste caso, temos dois elementos ópticos com maior chance de degradar. Notamos que houve uma deformação nos difusores, conforme apresentado na Figura 94 incluída na seção 7.3, provavelmente causada pela temperatura interna do sistema óptico, que pode ter contribuído para uma maior depreciação do fluxo. 
Em referência aos objetos ORBI FORTALEZA CDF e SDF 001,002,003 e 004, observamos uma elevação no fluxo luminoso até 6.000 horas de teste - que é validado pelos relatórios da LM-80-18 - que explica o aumento do fluxo luminoso até 6.000 horas, mas, conforme verificado nas medições de COTIA para 12.000 horas, esperava-se um decréscimo na manutenção do fluxo luminoso.

Os Gráficos 5 e 6 mostram que, independente de termos frontalmente o difusor ou não, as variações entre eles foram próximas, sendo que modelos com difusores elevaram os fluxos em $3,96 \%$, e os modelos sem difusores os elevaram em $3,85 \%$. 
7.2.3. Medições potência total dos objetos de ensaios MINOTAURO COT CDF e SDF 001,002,003 e 004 versus MINOTAURO FOR CDF e SDF 001,002,003 e 004.

Gráfico 7: Medições potência total (W) MINOTAURO COT CDF e SDF 001, 002, 003 e 004 .
Gráfico 8: Medições potência total (W) MINOTAURO FOR CDF e SDF 001, 002, 003 e 004.
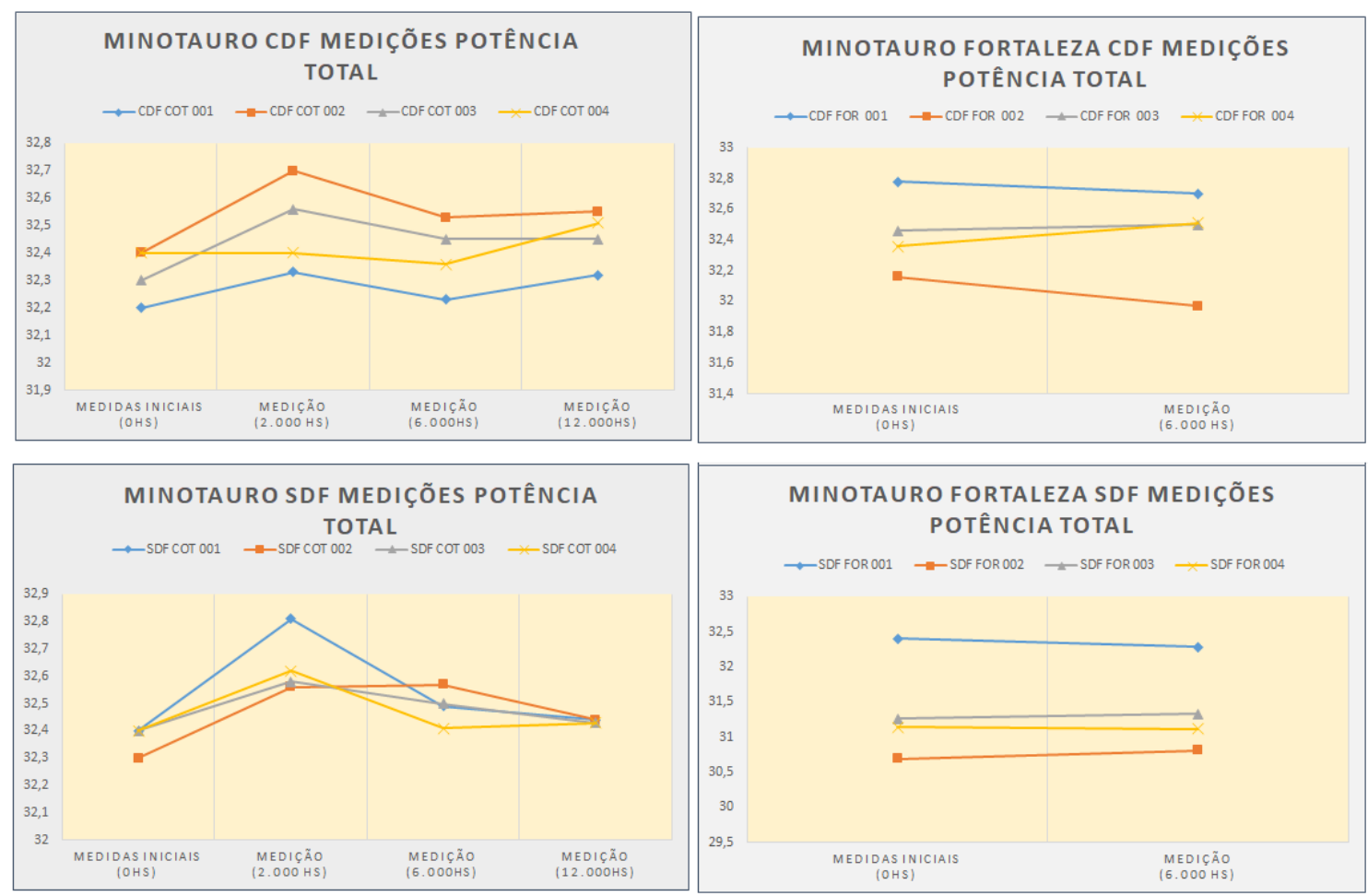

Fonte: a autora, 2020.

Não foram observadas alterações significativas na potência total dos objetos de ensaio, tanto para MINOTAURO COT CDF e SDF 001,002,003 e 004 e MINOTAURO FOR CDF e SDF 001, 002, 003 e 004. 


\subsubsection{Medições potência total dos objetos de ensaios ORBI COT CDF e SDF 001, 002, 003 e 004 versus ORBI FOR CDF e SDF 001, 002, 003 e 004.}

Gráfico 9: Medições potência total (W) COT CDF e SDF 001, 002, 003 e 004
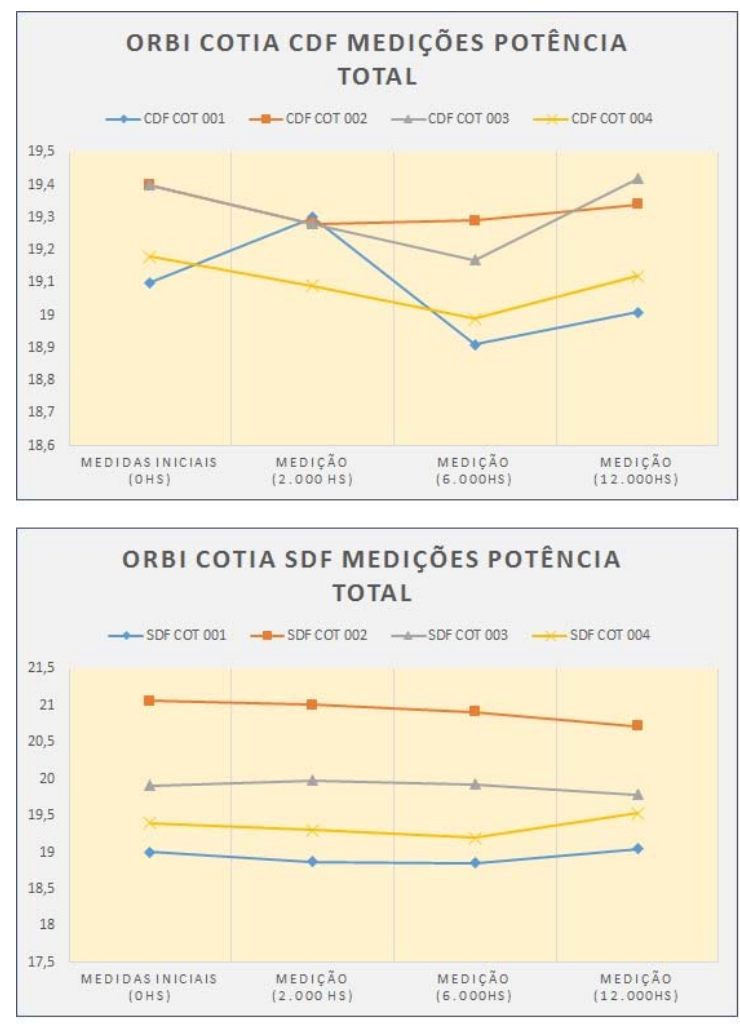

Fonte: a autora, 2020.
ORBI Gráfico 10: Medições potência total (W) ORBI FOR CDF e SDF 001, 002, 003 e 004
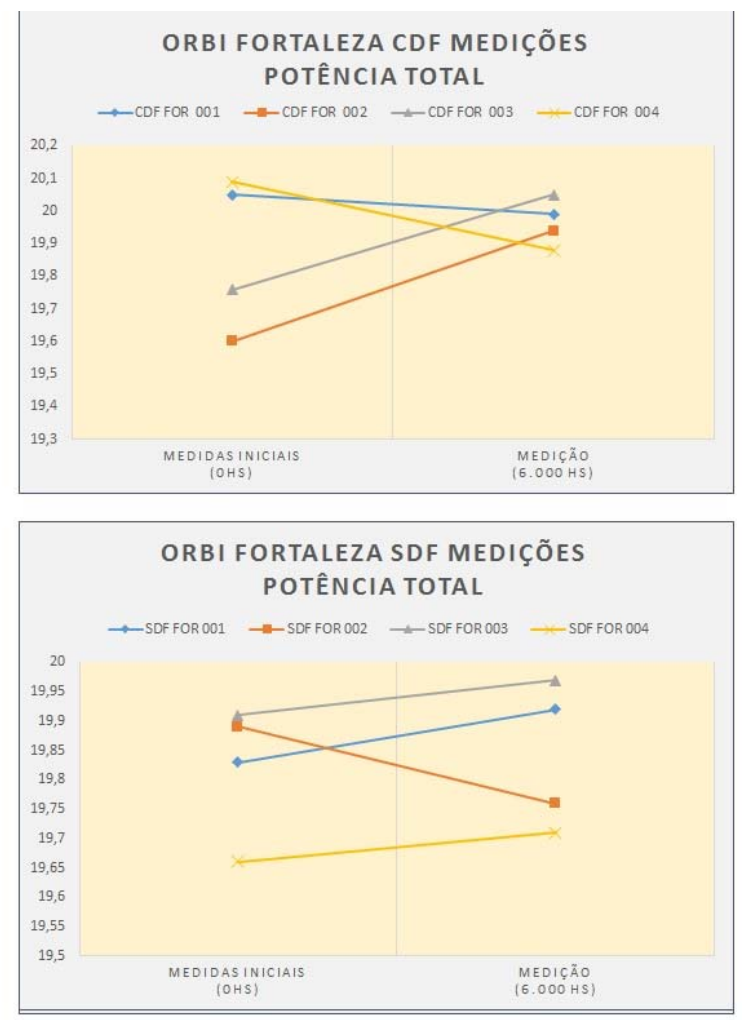

Não foram observadas alterações significativas na potência total dos objetos de ensaio, tanto para ORBI COT CDF e SDF 001, 002, 003 e 004, como para ORBI FOR CDF e SDF 001, 002, 003 e 004. 


\subsubsection{Medições eficácia dos objetos de ensaios MINOTAURO COT CDF e SDF 001, 002, 003 e 004 versus MINOTAURO FOR CDF e SDF 001, 002, 003 e 004.}

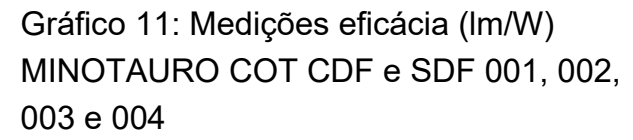

Gráfico 11: Medições eficácia (Im/W) MINOTAURO COT CDF e SDF 001, 002, 003 e 004
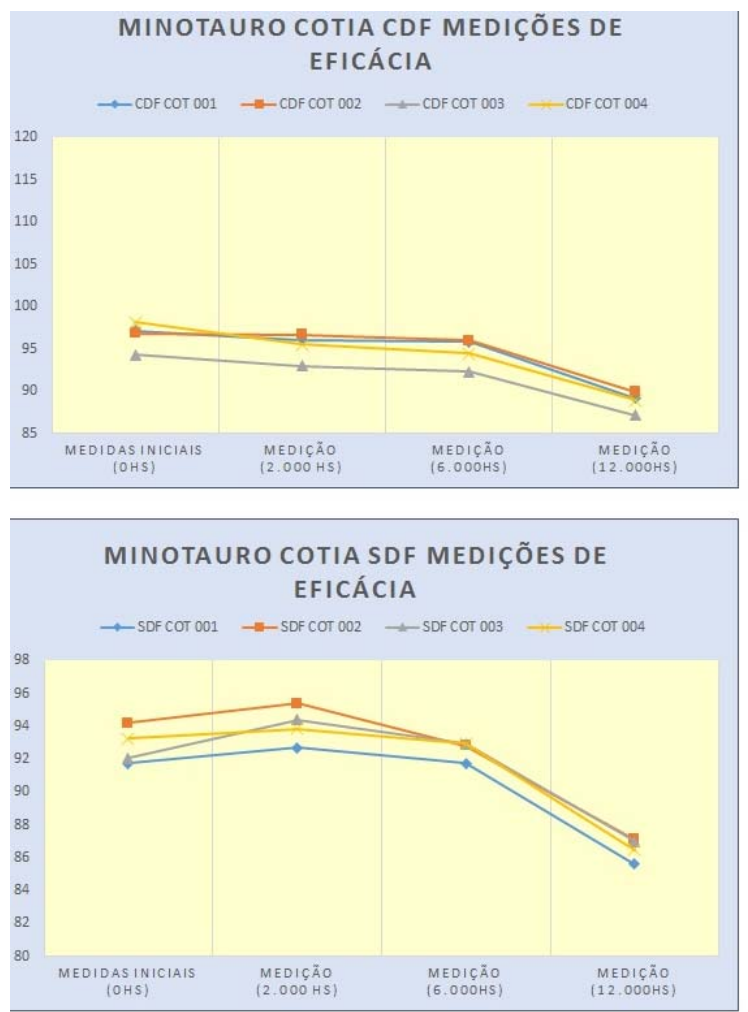

Gráfico 12: Medições eficácia (Im/W) MINOTAURO FOR CDF e SDF 001, 002, 003 e 004
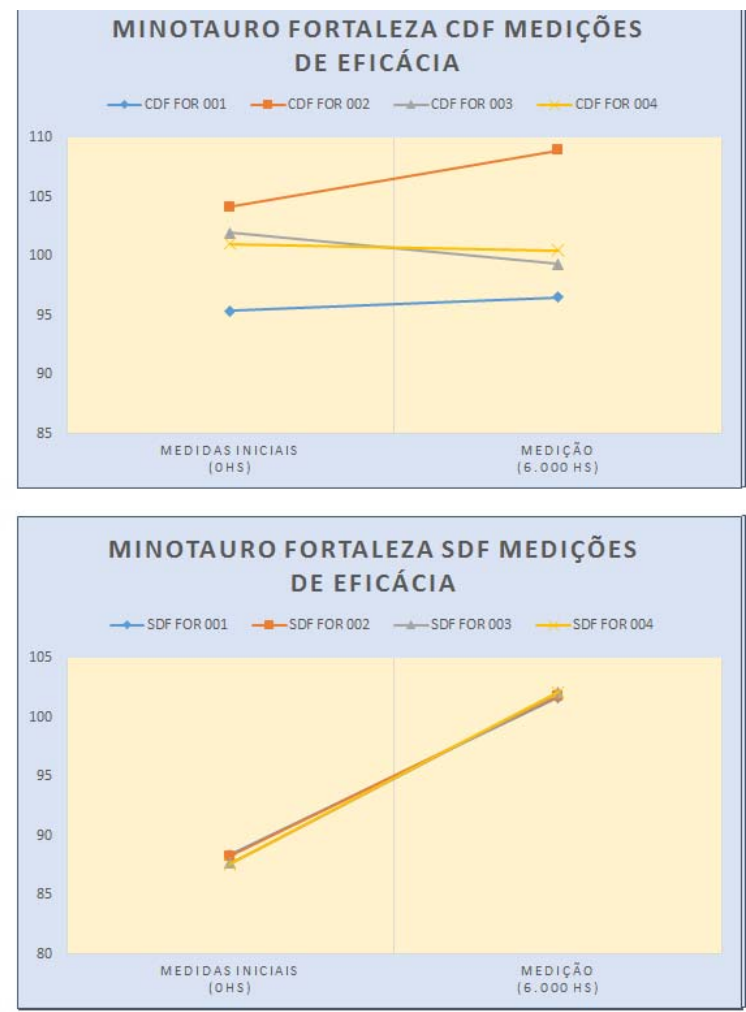

Fonte: a autora, 2020.

Como a eficácia é a relação entre fluxo luminoso e a potência consumida, analisando a variação de fluxo e potência da MINOTAURO COT CDF e SDF 001, 002, 003 e 004 podemos concluir que a variação da eficácia está em conformidade.

Analisando a variação de fluxo e potência da MINOTAURO FOR CDF, podemos concluir que a variação da eficácia também é coesa, uma vez que o fluxo não variou, a potência não variou e a eficácia também não variou.

Com relação à MINOTAURO SDF 001, 002,003 e 004, o aumento de eficácia medido não é real, visto que foi baseado em uma informação errônea do fluxo luminoso a 0 hora, conforme explicação dada anteriormente na seção 7.2.1. 


\subsubsection{Medições eficácia $(\mathrm{Im} / \mathrm{W})$ dos objetos de ensaios ORBI COT CDF e SDF 001, 002, 003 e 004 versus ORBI FOR CDF e SDF 001,002,003 e 004.}

\section{Gráfico 13: Medições eficácia $(\mathrm{Im} / \mathrm{W})$ - \\ ORBI COT CDF e SDF 001, 002, 003 e 004}
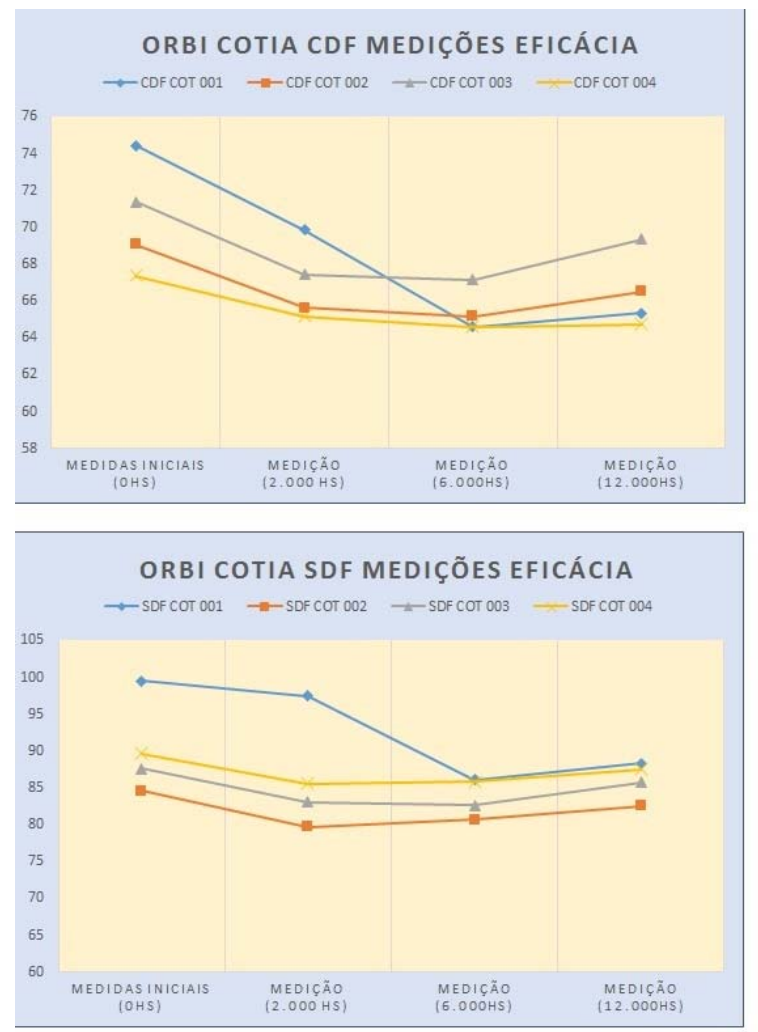

Gráfico 14: Medições eficácia $(\mathrm{Im} / \mathrm{W})$ -

ORBI FOR CDF e SDF 001, 002, 003 e 004
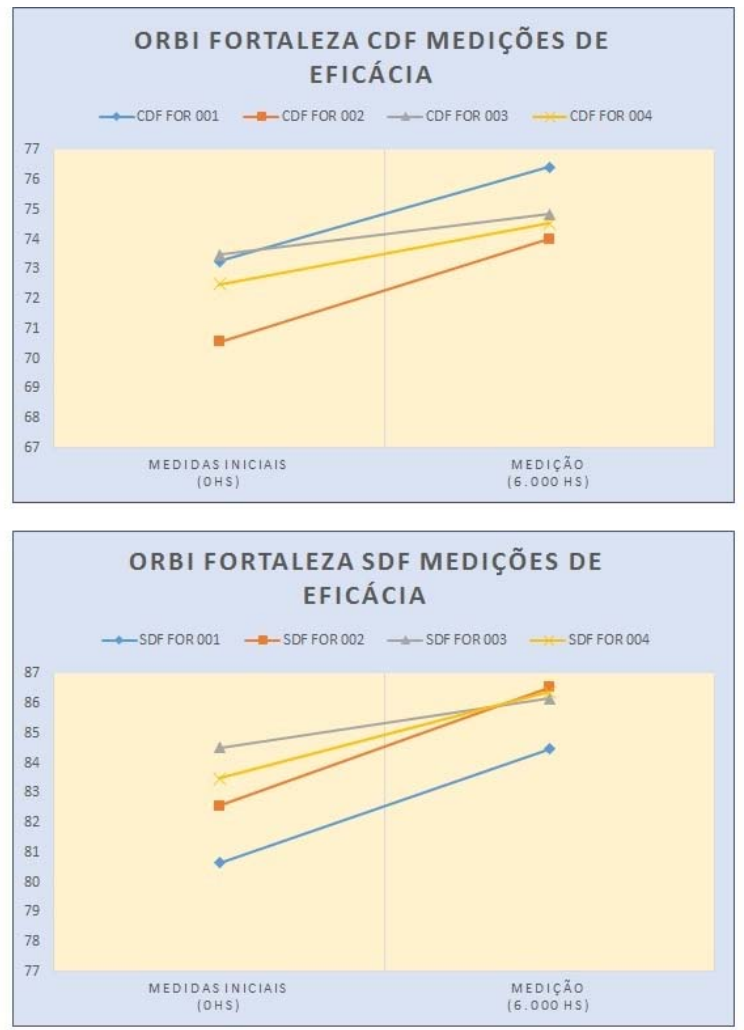

Fonte: a autora, 2020.

Não foram observadas alterações significativas de eficácia dos objetos de ensaios, tanto para ORBI COT CDF e SDF 001, 002, 003 e 004 e ORBI FOR CDF e SDF 001, 002, 003 e 004. 


\subsubsection{Medições TCC (K) dos objetos de ensaios MINOTAURO COT CDF e SDF 001,002,003 e 004 versus MINOTAURO FOR CDF e SDF 001, 002, 003 e 004.}
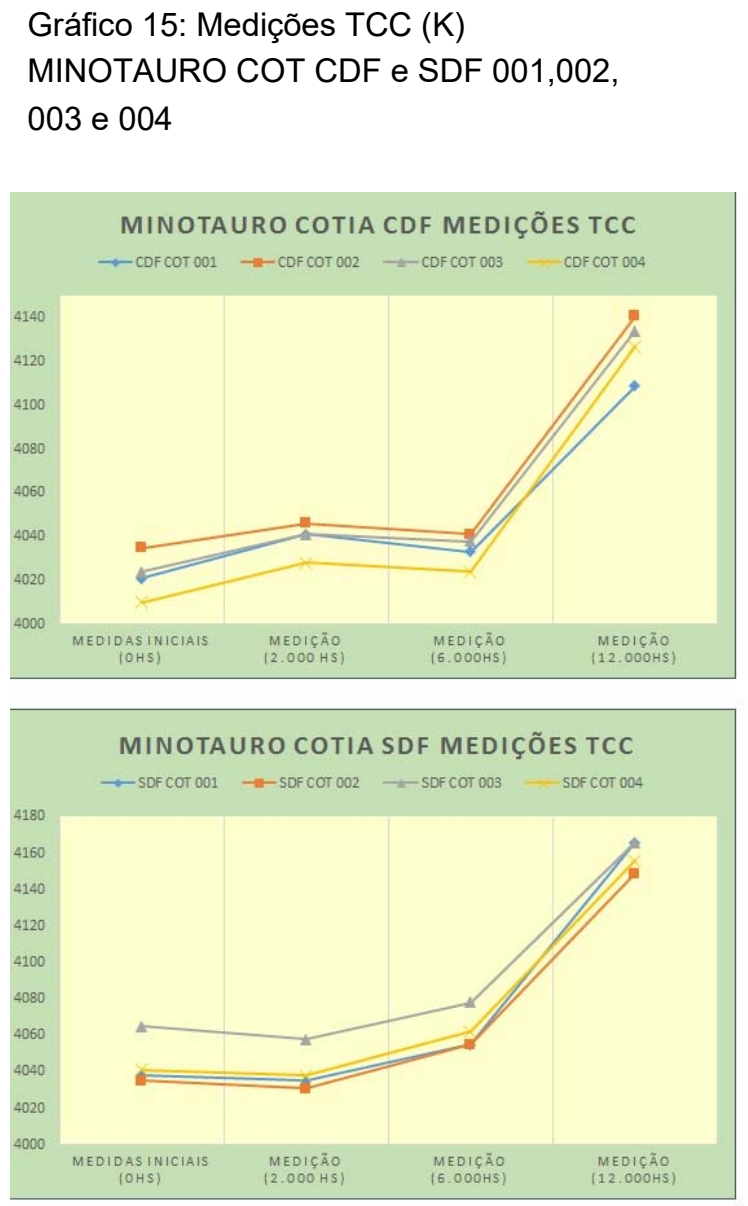

Gráfico 16: Medições TCC (K) MINOTAURO FOR CDF e SDF 001,002, 003 e 004
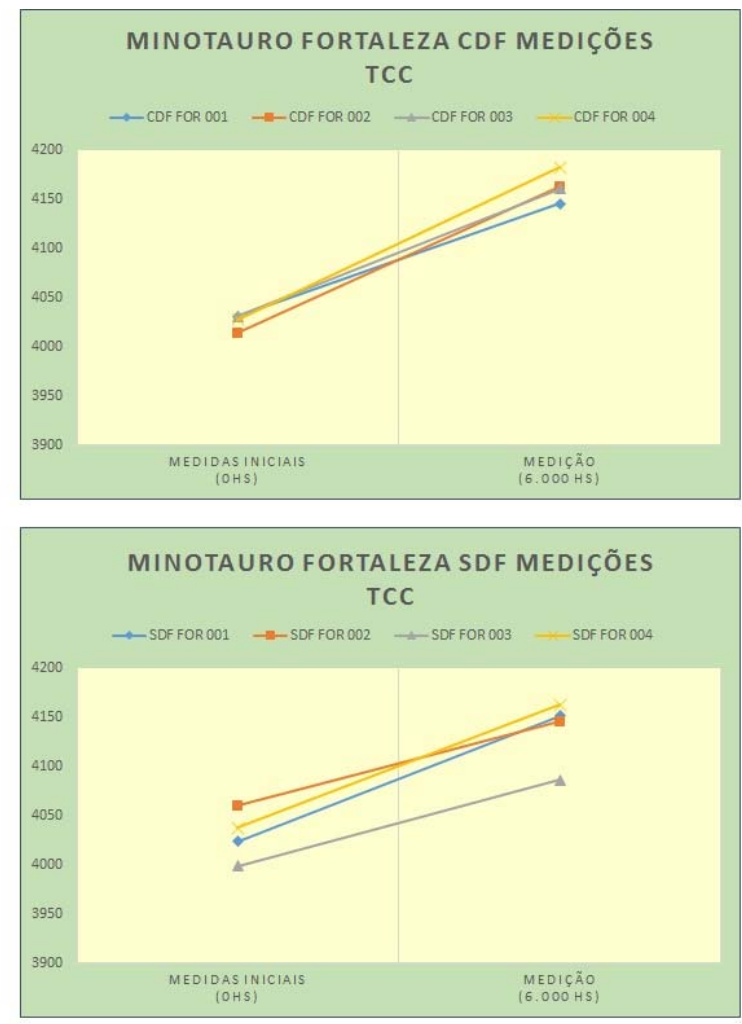

Fonte: a autora, 2020.

As medições da temperatura de cor TCC (K) dos objetos de ensaios MINOTAURO COT CDF e SDF 001, 002, 003 e 004, mostram uma elevação na temperatura de cor ao longo das medições.

Já é de conhecimento do mercado que quanto maior o tempo de funcionamento do sistema, maior será a temperatura de cor, visto que o LED é composto de luz azul por conversão por fósforo, e com a degradação natural ao longo da vida, temos um vazamento maior da luz azul elevando a temperatura de cor.

O nosso estudo comprova essa premissa: o objeto de ensaio MINOTAURO COT CDF nos testes de 6.000 horas apresentou uma variação de $0,29 \%$ e nos de 
12.000 horas observamos 2,62\%. O objeto de ensaio MINOTAURO COT SDF apresentou pouca variação em relação ao modelo MINOTAURO COT CDF, sendo que para 6.000 horas observou-se $0,439 \%$ e para 12.000 horas $2,83 \%$.

Observou-se maior variação no comportamento da temperatura de cor correlata (K) entre os objetos de ensaios, visto que temos uma variação de 3,41\% para MINOTAURO FOR CDF e 2,65\% para MINOTAURO FOR SDF 001, 002, 003 e 004.

Tal variação pode ser justificada pela diferença de temperatura ambiente entre os locais dos experimentos no período de ensaios - temos para COT (Cotia) temperatura média de $25,6^{\circ} \mathrm{C}$ e para FOR (Fortaleza) temperatura média de $30,74^{\circ} \mathrm{C}$ - e pela umidade relativa do ar, que também apresenta diferenças na ordem de $11 \%$, podendo, ambos os fatores, contribuir para uma maior degradação do LED. 
7.2.8. Medições TCC (K) dos objetos de ensaios ORBI COT CDF e SDF 001, 002, 003 e 004 versus ORBI FOR CDF e SDF 001,002,003 e 004.

Gráfico 17: Medições TCC (K)

ORBI COT CDF e SDF 001, 002, 003 e 004

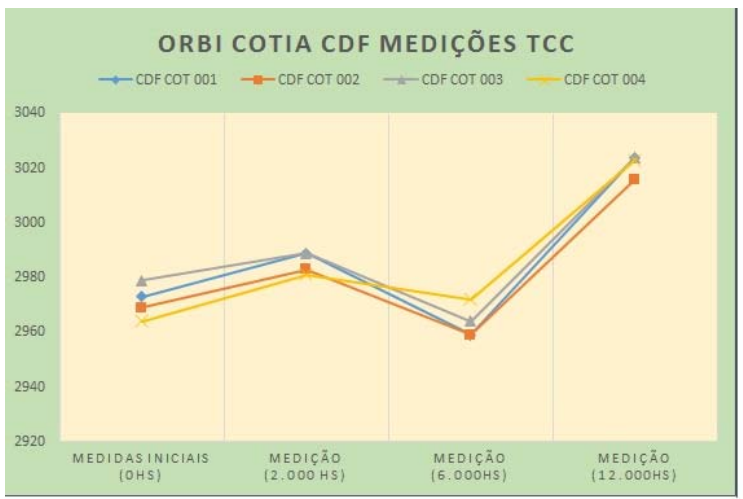

ORBI COTIA SDF MEDIÇÕES TCC

$\rightarrow$ SDF COT $001 \rightarrow$-SDFCOT $002 \leadsto$ SDF COT $003 \longrightarrow$ SDF COT 004

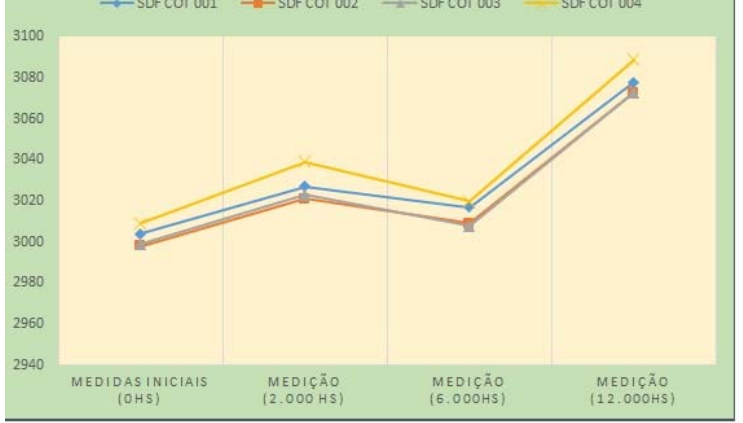

Gráfico 18: Medições TCC $(\mathrm{K})$

ORBI FOR CDF e SDF 001, 002, 003 e 004
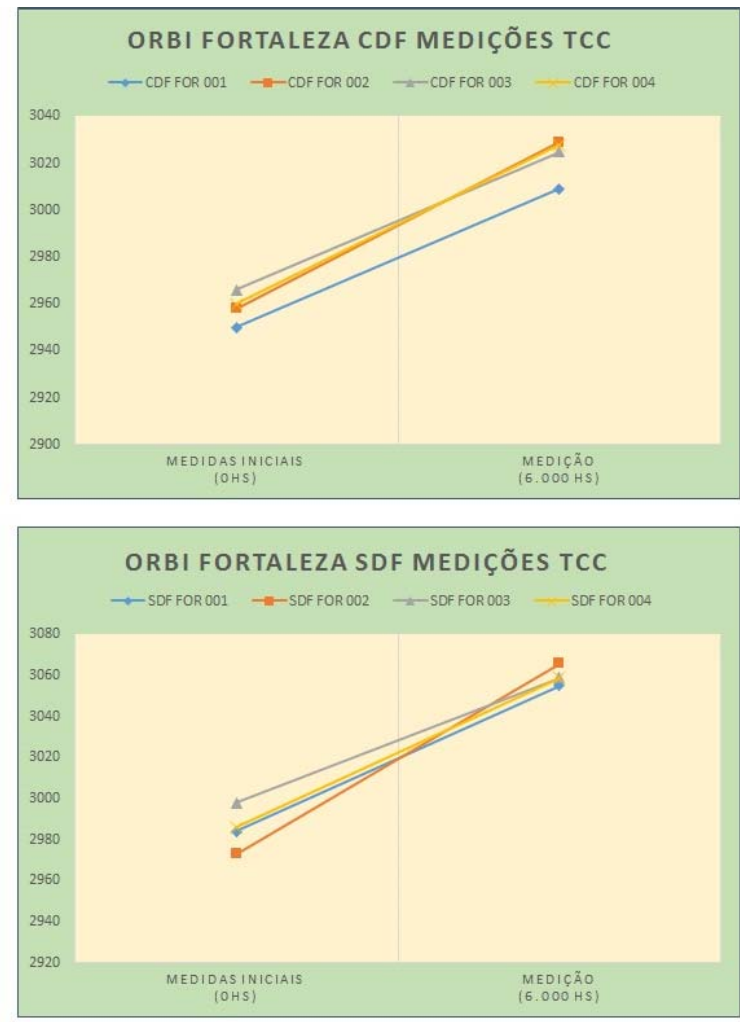

Fonte: a autora, 2020.

As medições da temperatura de cor correlata $(\mathrm{K})$ dos objetos de ensaios ORBI COTIA CDF 001, 002, 003 e 004, mostram uma diminuição média na temperatura de cor em 6.000 horas na ordem de 0,26\%, e ORBI COTIA SDF 001, 002, 003 e 004 uma variação média de 0,37\%.

Os valores dos objetos de ensaios ORBI FORTALEZA CDF 001, 002, 003 e 004, mostram que os modelos com difusores apresentam um acréscimo de $2,17 \%$ versus $2,50 \%$ dos modelos sem difusores. Nesse contexto, temos também uma maior elevação da temperatura ambiente ao longo do período de 6.000 horas, conforme medição do data logger inserido na área de experimentação de Fortaleza. 
Isso justifica-se em função da elevação da temperatura ambiente e da umidade relativa do ar, conforme apresentado na Tabela 2 da seção 2.4.1.

Tais variações são compatíveis com os modelos MINOTAURO FOR, conforme explicação na seção 7.2.7. 


\subsubsection{Medições do IRC dos objetos de ensaios MINOTAURO COT CDF e SDF 001,002,003 e 004 versus MINOTAURO FOR CDF e SDF 001,002,003 e 004.}

Gráfico 19: Medições IRC

MINOTAURO COT CDF e SDF 001, 002, 003 e 004
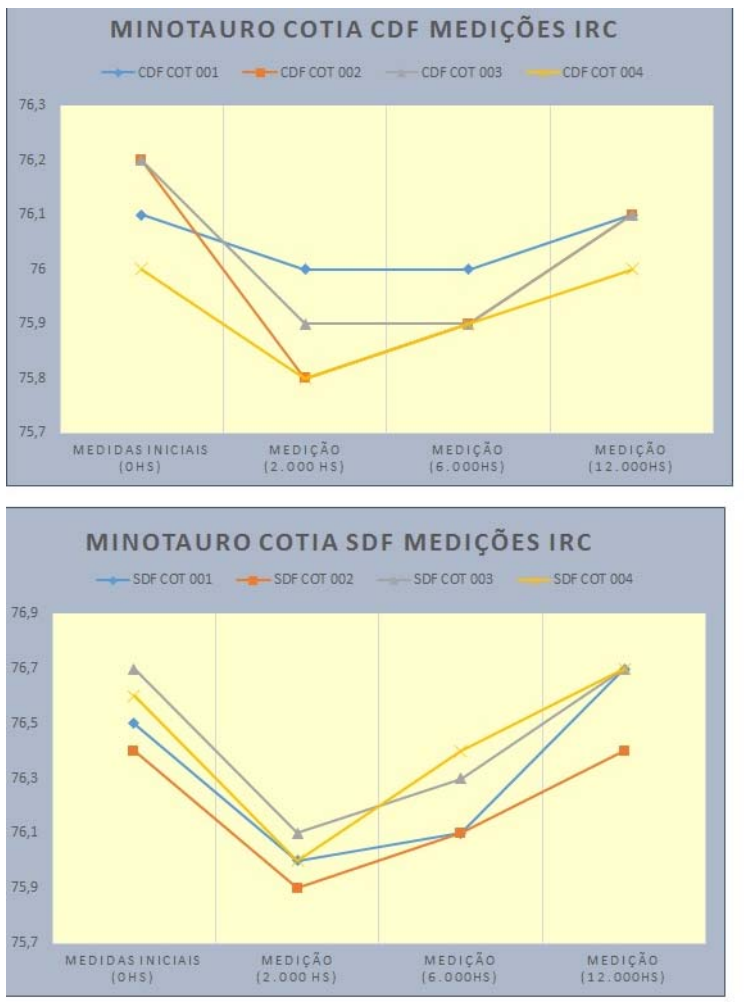

Gráfico 20: Medições IRC

MINOTAURO FOR CDF e SDF 001, 002, 003 e 004
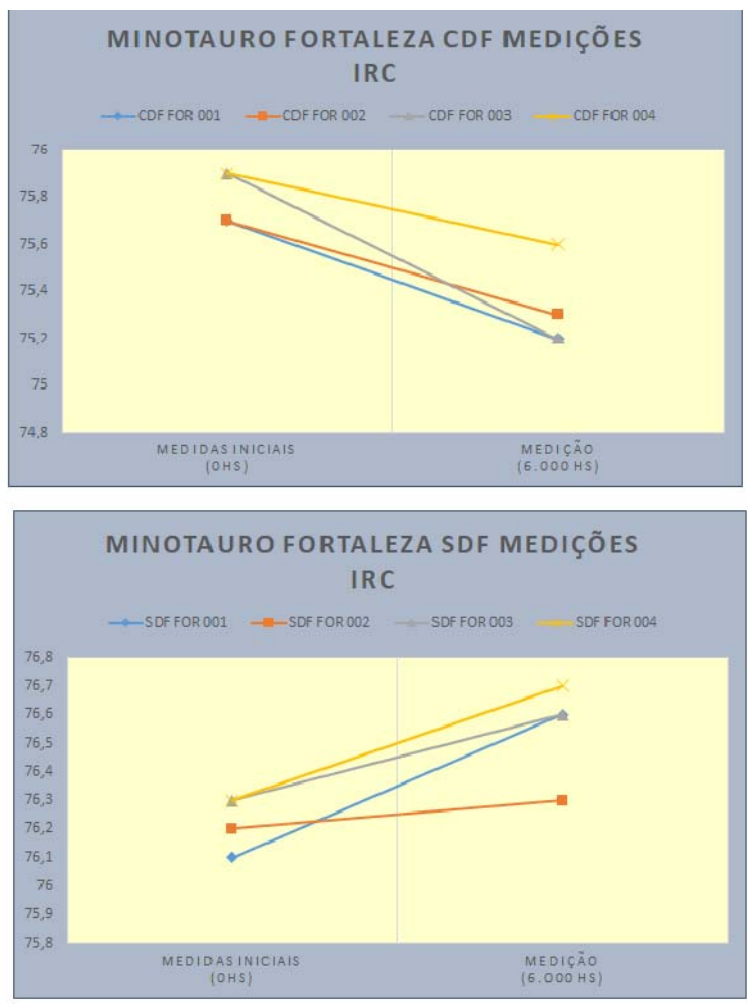

Fonte: a autora, 2020.

As medições do IRC dos objetos de ensaios MINOTAURO COTIA CDF e SDF 001, 002, 003 e 004 mostram que o comportamento entre objetos é igual: uma queda para 2.000 horas e uma elevação nas medições de 6.000 horas, retornando aos valores iniciais em 12.000 horas.

É provável que o índice de reprodução de cores fique estável ao longo do período de vida do LED; desta forma os valores de variações medidos de $-0,07 \%$ para os objetos com difusores, e de $0,098 \%$ para os sem difusores, possivelmente apresentam uma variação em função do desvio do equipamento de medição, neste caso a esfera integradora. Os difusores podem ter prejudicado os valores do IRC, mas em razões que podem ser consideradas desprezíveis. 
As medições dos objetos MINOTAURO FORTALEZA CDF e SDF 001, 002, 003 e 004 mostram que, apesar das diferenças dos modelos com difusores (CDF) e os com refletores e sem os difusores (SDF), as variações foram mínimas. 


\subsubsection{Medições IRC dos objetos de ensaios ORBI COT CDF e SDF 001,002,003 e 004 versus ORBI FOR CDF e SDF 001, 002, 003 e 004.}

Gráfico 21: Medições IRC RBI COT CDF e SDF 001, 002, 003 e 004.
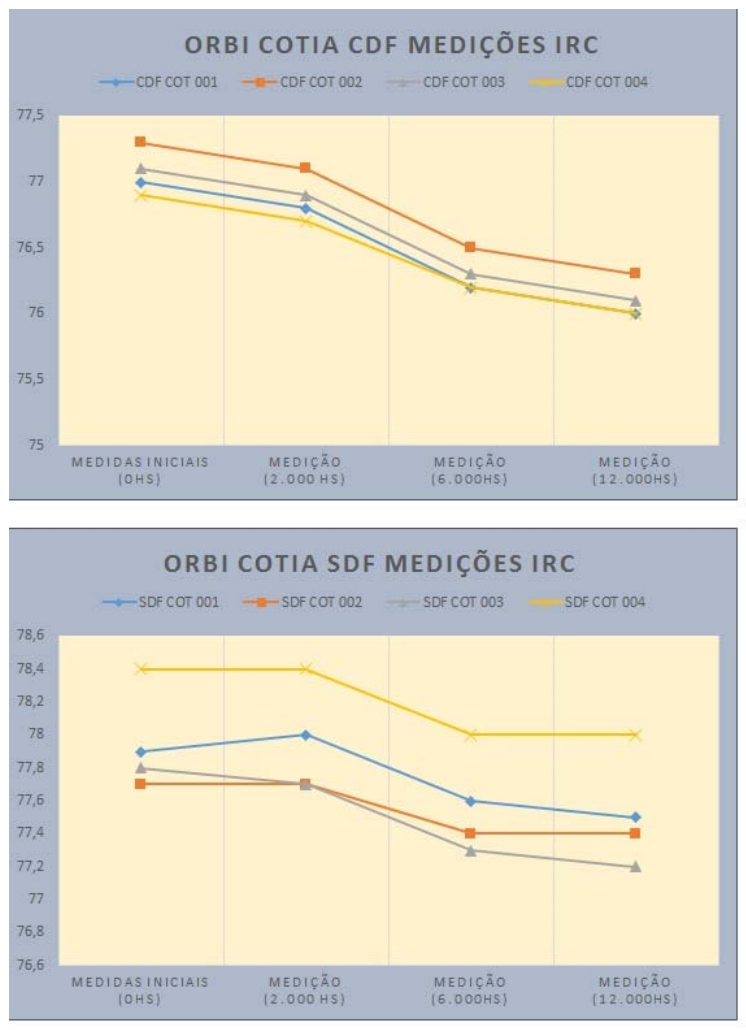

Gráfico 22: Medições IRC ORBI FOR CDF e SDF 001, 002, 003 e 004.
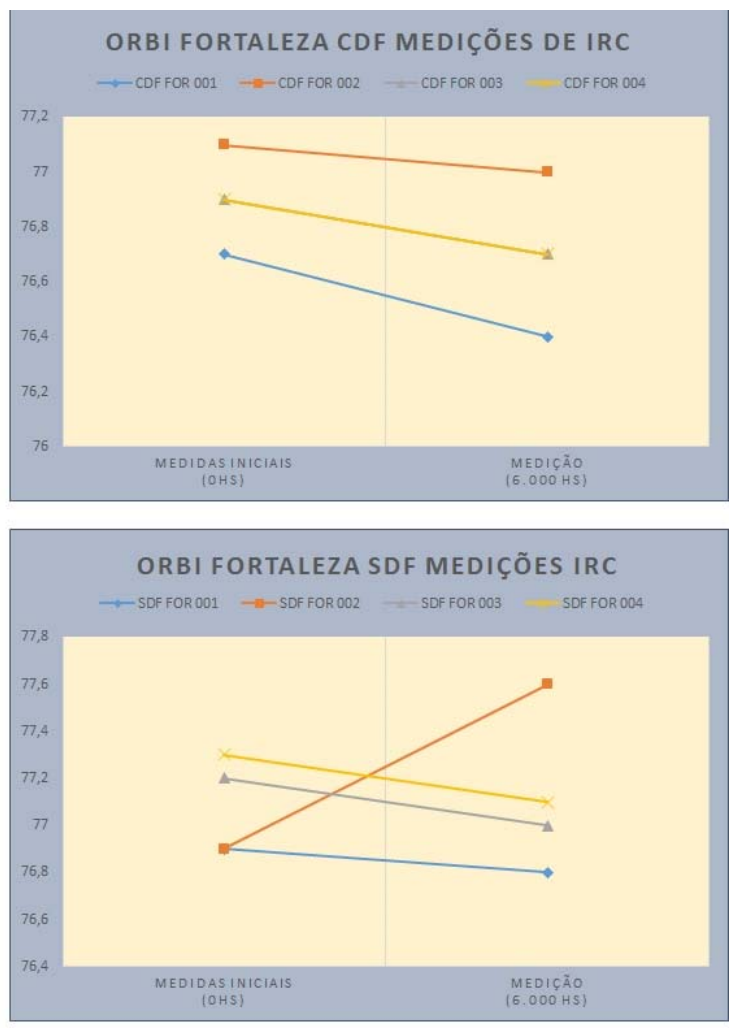

Fonte: a autora, 2020.

As medições do IRC dos objetos de ensaios ORBI COTIA CDF e SDF 001, 002, 003 e 004 mostram que o comportamento destes modelos apresenta menor variação no índice de reprodução de cores, muito provavelmente devido ao fato de termos internamente um COB LED, que reconhecidamente tem uma tecnologia mais aprimorada do que os LEDs Mid-Power, garantindo maior estabilidade do fluxo luminoso e das características de cromaticidade. Observou-se para ORBI COTIA CDF variações de $-1,26 \%$ e para ORBI COTIA SDF $-0,090 \%$, valores inexpressíveis.

As medições dos objetos ORBI FORTALEZA CDF e SDF 001, 002, 003 e 004 denotam que, apesar das diferenças entre os modelos com difusores (CDF) e com refletores e sem difusores (SDF) serem mínimas, os modelos com difusores tiveram uma diminuição ínfima de IRC, da ordem de $-0,26 \%$, versus $-0,066 \%$ dos modelos com refletores e sem difusores. 


\subsubsection{Medições do Ra dos objetos de ensaios MINOTAURO COT CDF e SDF 001,002,003 e 004 versus MINOTAURO FOR CDF e SDF 001, 002, 003 e 004.}

Gráfico 23: Medições RA - MINOTAURO COT CDF e SDF 001, 002, 003 e 004.
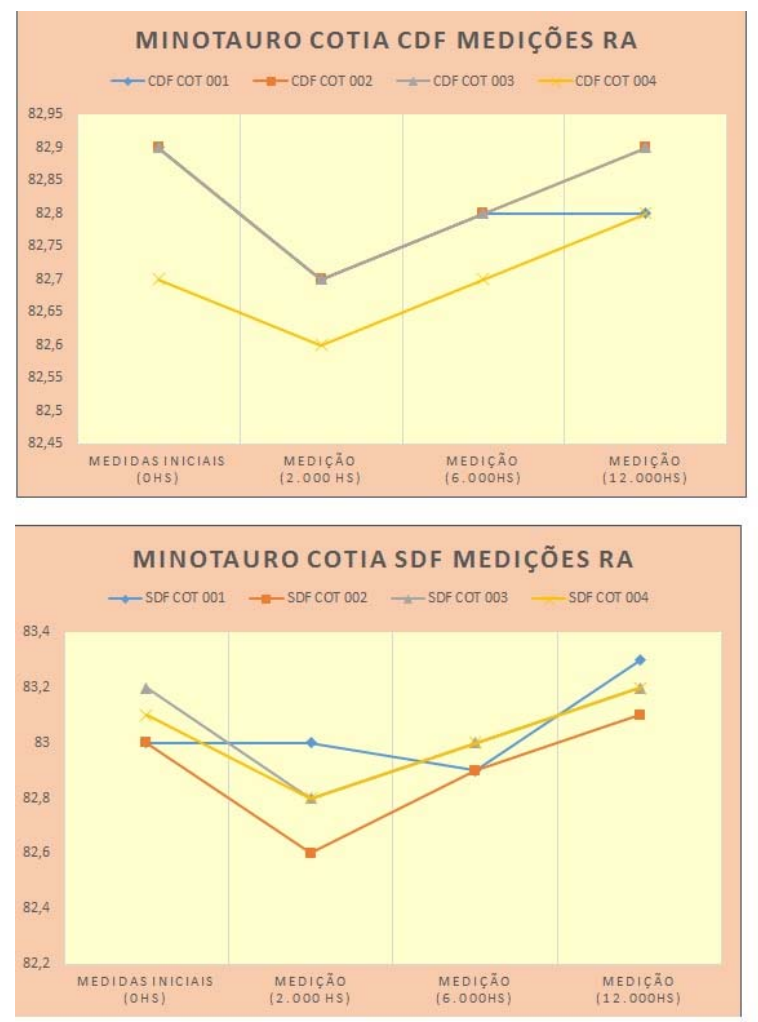

Gráfico 24: Medições RA -MINOTAURO FOR CDF e SDF 001, 002, 003 e 004.
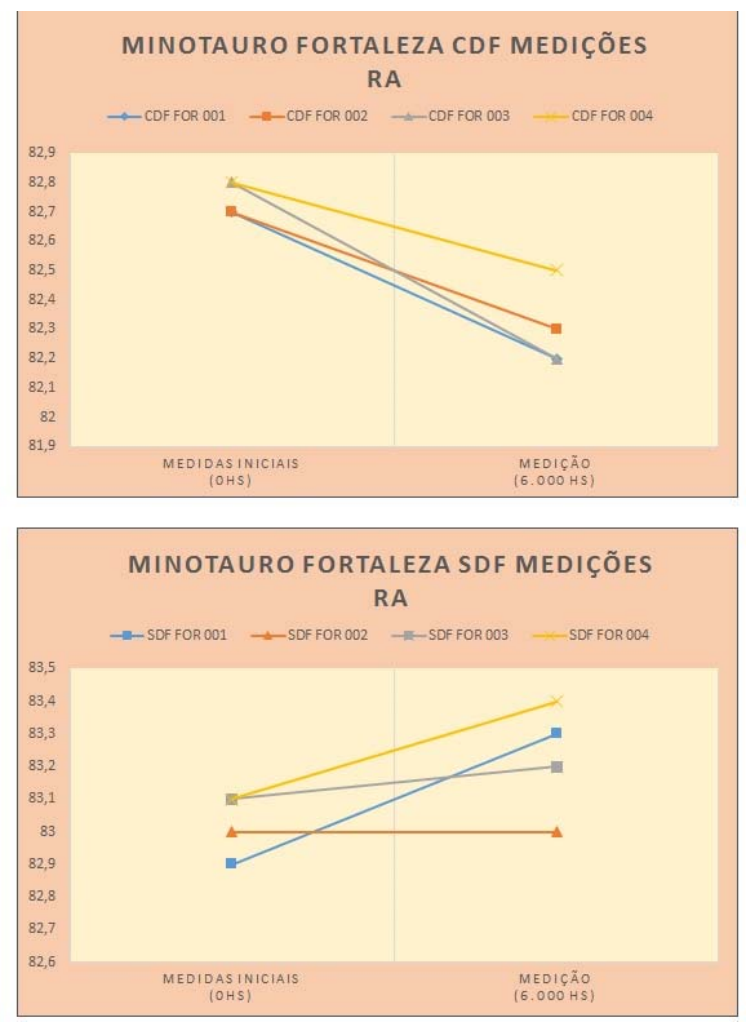

Fonte: a autora, 2020.

As medições do $\mathrm{Ra}$ (referente a oito cores) dos objetos de ensaios MINOTAURO COT CDF e SDF 001, 002, 003 e 004, seguiu o mesmo comportamento apresentado pelas medições de IRC, independente das cores avaliadas

O mesmo ocorre com os objetos de ensaios MINOTAURO FOR CDF e SDF 001, 002, 003 e 004, que mantiveram performance muito similar à dos objetos da cidade de COTIA, independente de termos, ou não, as ópticas terciárias. 


\subsubsection{Medições Ra dos objetos de ensaios ORBI COT CDF e SDF 001, 002, 003 e 004 versus ORBI FOR CDF e SDF 001, 002, 003 e 004.}

Gráfico 25: Medições RA ORBI COT CDF e SDF 001, 002, 003 e 004.
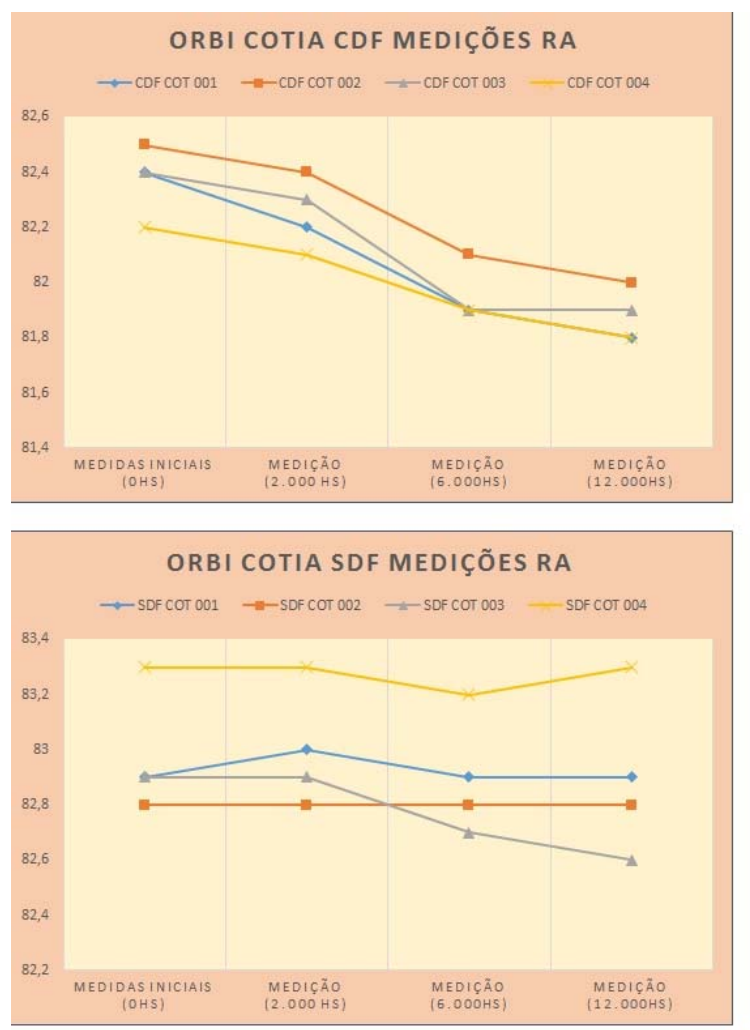

Gráfico 26: Medições RA ORBI FOR CDF e SDF 001, 002, 003 e 004.
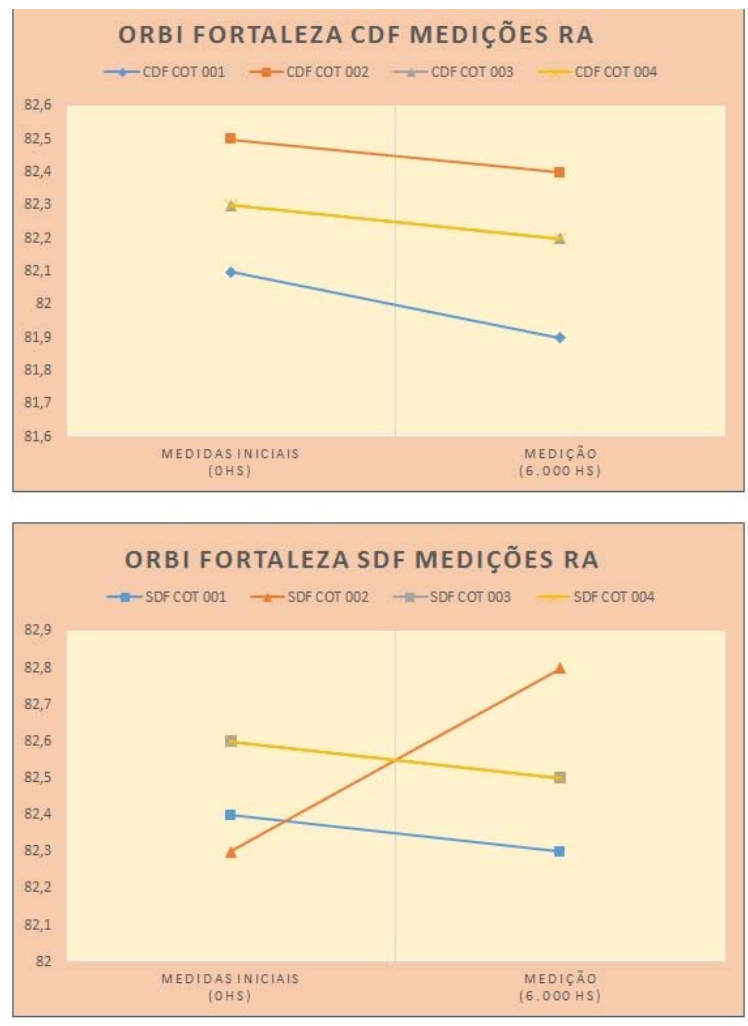

Fonte: a autora, 2020.

As medições do Ra dos objetos de ensaios ORBI COT CDF e SDF 001, 002 , 003 e 004, seguiu o mesmo comportamento apresentado pelas medições de IRC, sem alterações relevantes, sendo que os modelos ORBI COT CDF tiveram uma queda de $-0,61 \%$ e os modelos ORBI COT SDF $-0,090 \%$.

O mesmo ocorre com os objetos ORBI FOR CDF e SDF 001, 002, 003 e 004, que mantiveram a sua performance muito próxima à dos objetos de ensaios da cidade de COTIA, independente de termos ou não as ópticas terciárias. Os modelos ORBI FOR CDF apresentaram uma queda mínima de $-0,15 \%$, e os modelos ORBI FOR SDF uma elevação, desprezível, de $+0,061 \%$. 
7.2.13. Medições de coordenada de cromaticidade " $X$ " dos objetos de ensaios MINOTAURO COT CDF e SDF 001, 002, 003 e 004 versus MINOTAURO FOR CDF e SDF 001, 002, 003 e 004.

Gráfico 27: Medições de coordenadas de cromaticidade " $x$ " MINOTAURO COT

CDF e SDF 001, 002, 003 e 004.

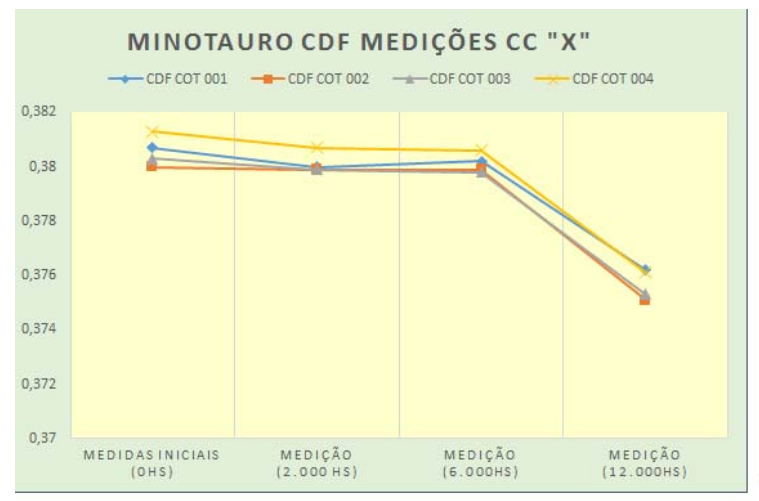

MINOTAURO COTIA SDF MEDIÇÕES CC " $X$ "

$\rightarrow$ SDFCOT $001-$-SDF COT $002 \multimap$ SDF COT $003 \longrightarrow$ SDF COT 004

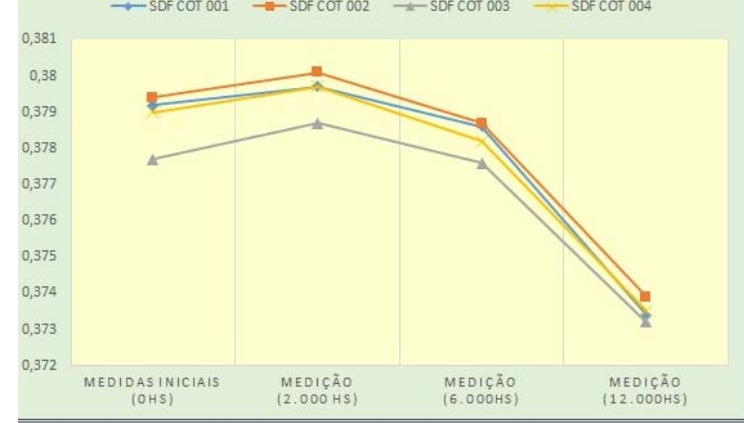

Gráfico 28: Medições de coordenadas de cromaticidade " $x$ " MINOTAURO FOR

CDF e SDF 001, 002, 003 e 004.

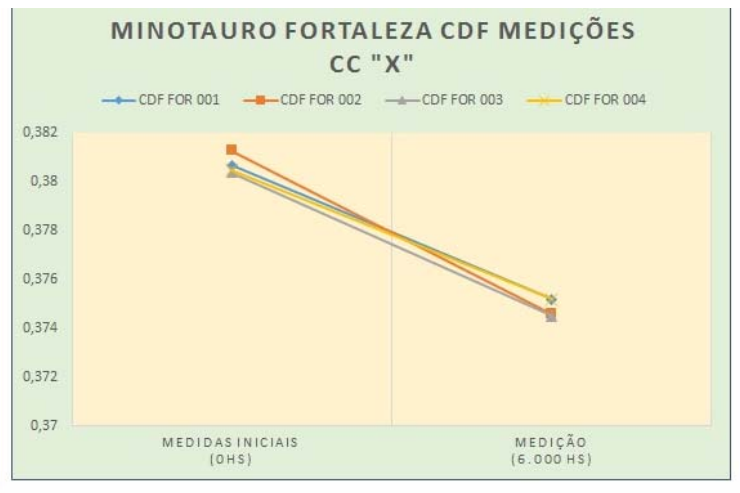

MINOTAURO FORTALEZA SDF MEDIÇÕES CC " $\mathrm{X}$ "
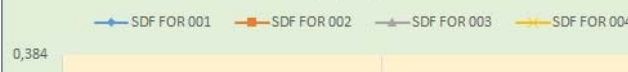

0,382

0,38

0,378

0,376

0,374

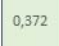

0,37

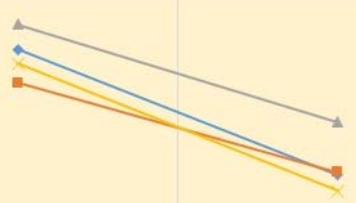

MEDIDASINICIAIS $\mathrm{OHS}$

Fonte: a autora, 2020.

Observamos a diminuição das coordenadas de cromaticidade " $x$ " em todos os modelos MINOTAURO COT CDF e SDF 001, 002, 003, 004, e dos modelos MINOTAURO FOR CDF e SDF 001, 002, 003, 004, indicando que a temperatura de cor correlata se direciona para uma temperatura de cor correlata mais fria (elevada); conforme apontado na seção 7.2.7 pelos gráficos 35 e 36, que apresentam o ponto de cromaticidade " $x, y$ ", considerando os valores medianos de 0 hora e 12.000 horas para MINOTAURO COT CDF e SDF. 
7.2.14. Medições de coordenada de cromaticidade " $X$ " dos objetos de ensaios ORBI COT CDF e SDF 001, 002, 003 e 004 versus ORBI FOR CDF e SDF 001, 002, 003 e 004.

Gráfico 29: Medições de coordenadas de cromaticidade " $x$ " ORBI COT CDF e SDF 001, 002, 003 e 004.
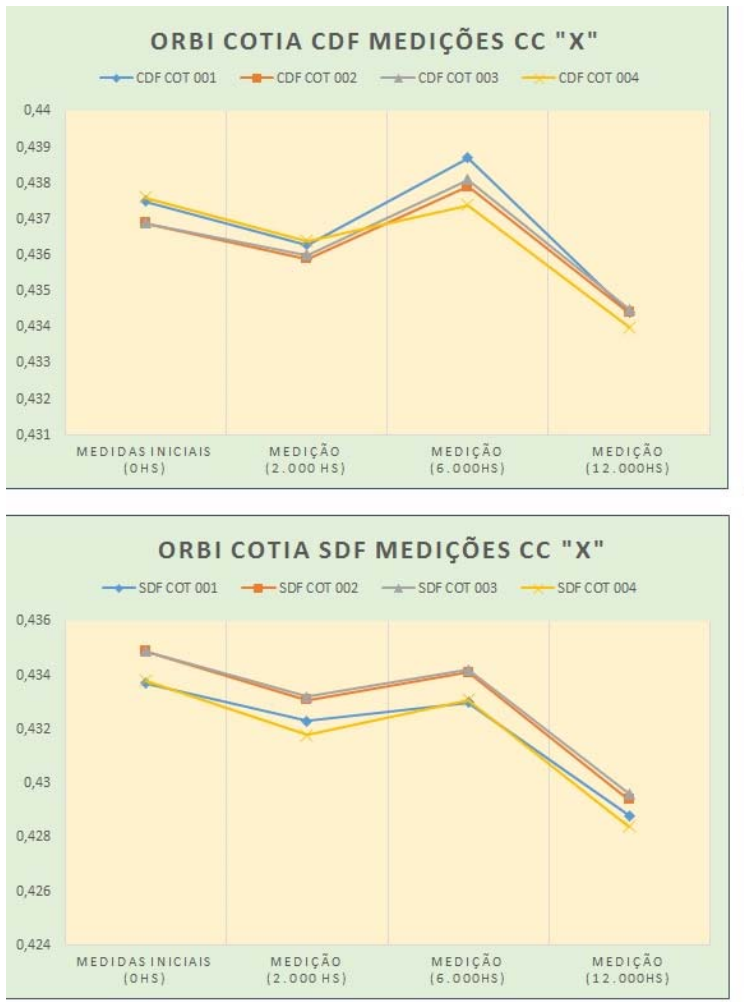

Gráfico 30: Medições de coordenadas de cromaticidade " $x$ " ORBI FOR CDF e SDF 001 , 002,003 e 004.

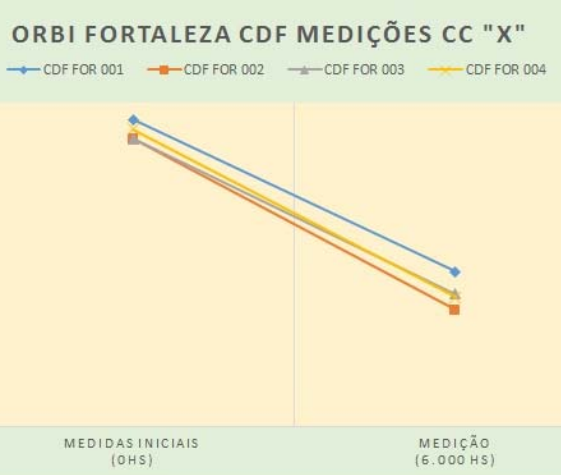

ORBI FORTALEZA SDF MEDIÇÕES CC " $X$ " $\rightarrow$ SDFFOR $001 \rightarrow$-SDFFOR $002 \leadsto$-SDFFOR $003-$ SDF FOR 004

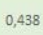

0,436

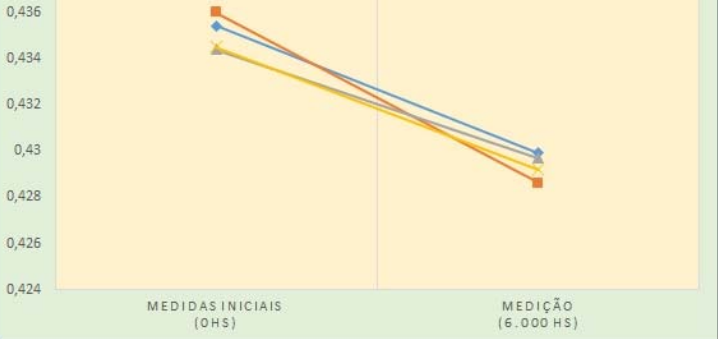

Fonte: a autora, 2020.

Observamos a diminuição das coordenadas de cromaticidade " $x$ " em todos os modelos ORBI COT CDF e SDF 001, 002, 003, 004, e nos modelos ORBI FOR CDF e SDF 001, 002, 003, 004, indicando que a temperatura de cor correlata se direciona para uma temperatura de cor mais fria (elevada), conforme apontado na seção 7.2.8 pelos gráficos 37 e 38, que apresentam o ponto de cromaticidade " $x$, $y$ ", considerando os valores medianos de 0 hora e 12.000 horas para ORBI COT CDF e SDF. 
7.2.15. Medições de coordenada de cromaticidade "Y" dos objetos de ensaios MINOTAURO COT CDF e SDF 001, 002, 003 e 004 versus MINOTAURO FOR CDF e SDF 001, 002, 003 e 004.

Gráfico 31: Medições de coordenadas de cromaticidade "y" MINOTAURO COT

CDF e SDF 001, 002, 003 e 004.
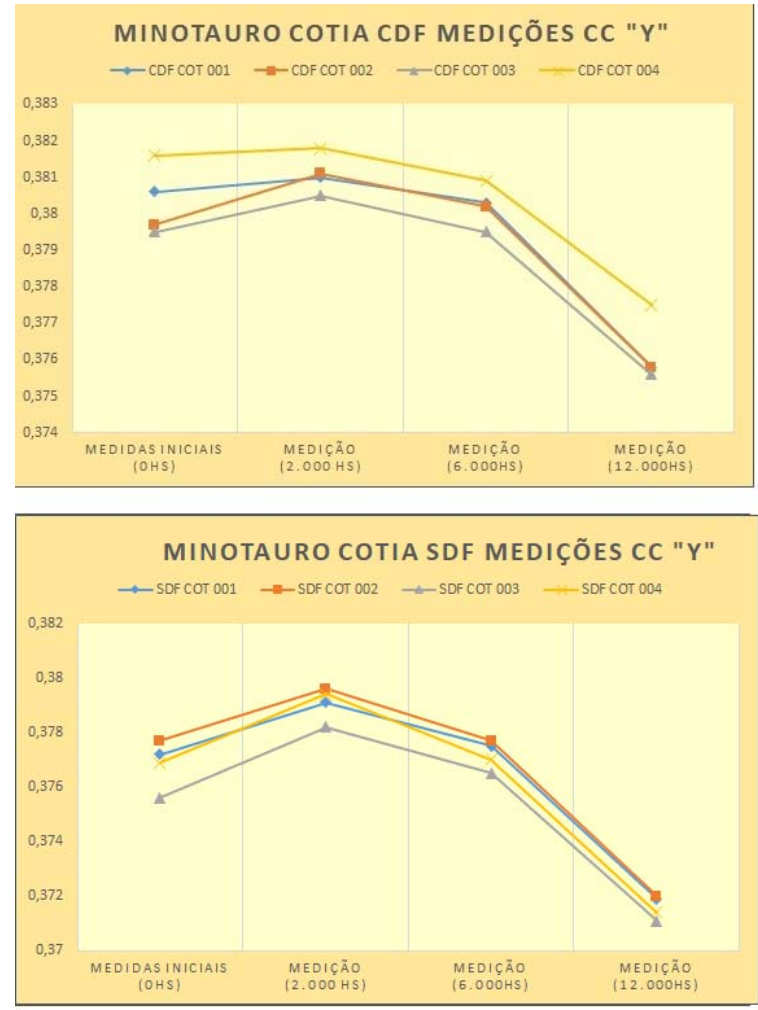

Gráfico 32: Medições de coordenadas de cromaticidade "y" MINOTAURO FOR CDF e SDF 001, 002, 003 e 004.
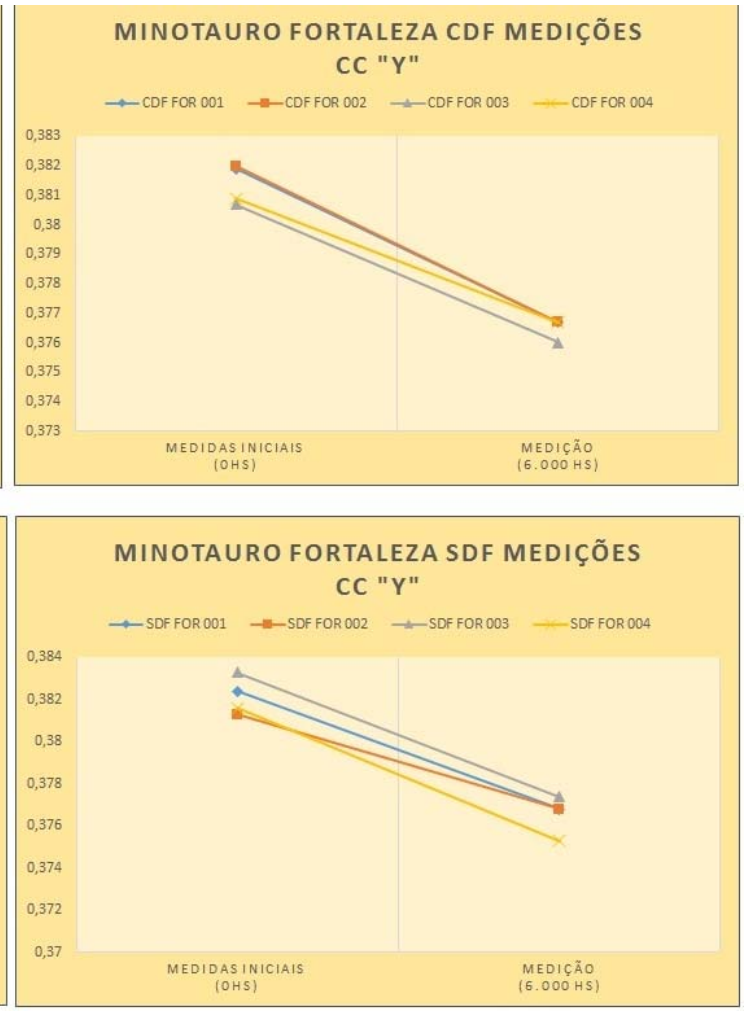

Fonte: a autora, 2020.

Observamos a diminuição das coordenadas de cromaticidade "y" em todos os modelos MINOTAURO COT CDF e SDF 001, 002, 003, 004, e dos modelos MINOTAURO FOR CDF e SDF 001, 002, 003, 004, indicando que a temperatura de cor correlata se direciona para uma temperatura de cor correlata mais fria (elevada); conforme apontado na seção 7.2.7. pelos gráficos 35 e 36, que apresentam o ponto de cromaticidade " $x, y$ " mediano de 0 hora e 12.000 horas para MONITAURO COT CDF e SDF. 
7.2.16. Medições de coordenada de cromaticidade " $Y$ " dos objetos de ensaios ORBI COT CDF e SDF 001, 002, 003 e 004 versus ORBI FOR CDF e SDF 001, 002, 003 e 004.

Gráfico 33: Medições de coordenadas de cromaticidade "y" ORBI COT CDF e SDF 001, 002,003 e 004.
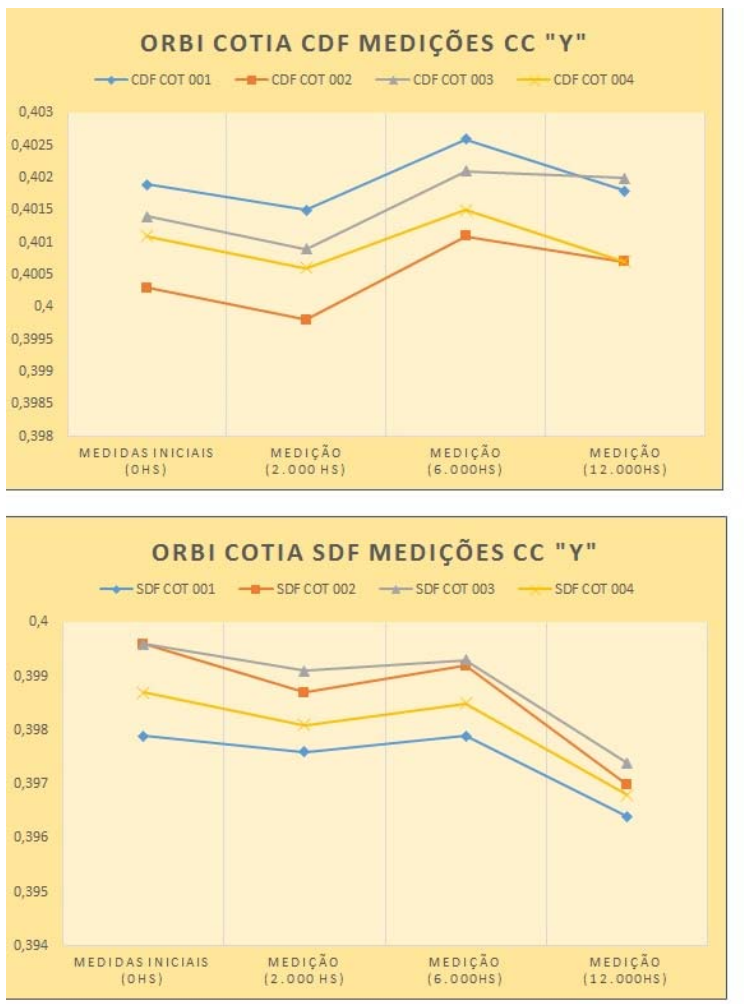

Fonte: a autora, 2020.
Gráfico 34: Medições de coordenadas de cromaticidade "y" ORBI FOR CDF e SDF 001, 002,003 e 004.

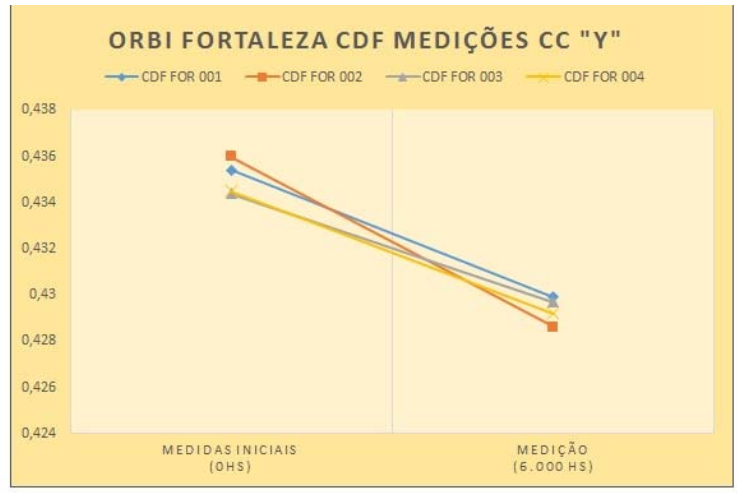

ORBI FORTALEZA SDF MEDIÇÕES CC " $Y "$

$\rightarrow$ SDFFOR $001 \rightarrow$-SDFFOR $002 \rightarrow$ SDFFOR $003 \longrightarrow$ SDFFO 004

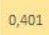

0,401

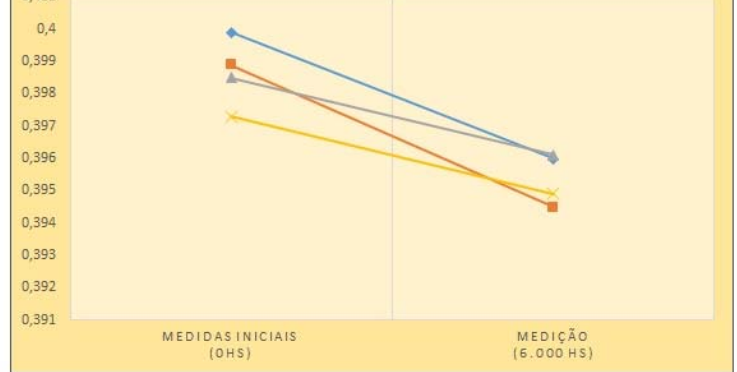

Observamos a diminuição das coordenadas de cromaticidade " $y$ " em todos os modelos ORBI COT CDF e SDF 001, 002, 003, 004, e dos modelos ORBI FOR CDF e SDF 001, 002, 003, 004, indicando que a temperatura de cor correlata se direciona para uma temperatura de cor correlata mais fria (elevada) conforme apontado na seção 7.2.8. pelos gráficos 37 e 38 , que apresentam o ponto de cromaticidade " $x, y$ " mediano de 0 hora e 12.000 horas para ORBI COT CDF e SDF. 
Gráfico 35: Ponto de cromaticidade "x, y" mediano 0 hora e 12.000 horas, objetos de ensaios MINOTAURO COT CDF.

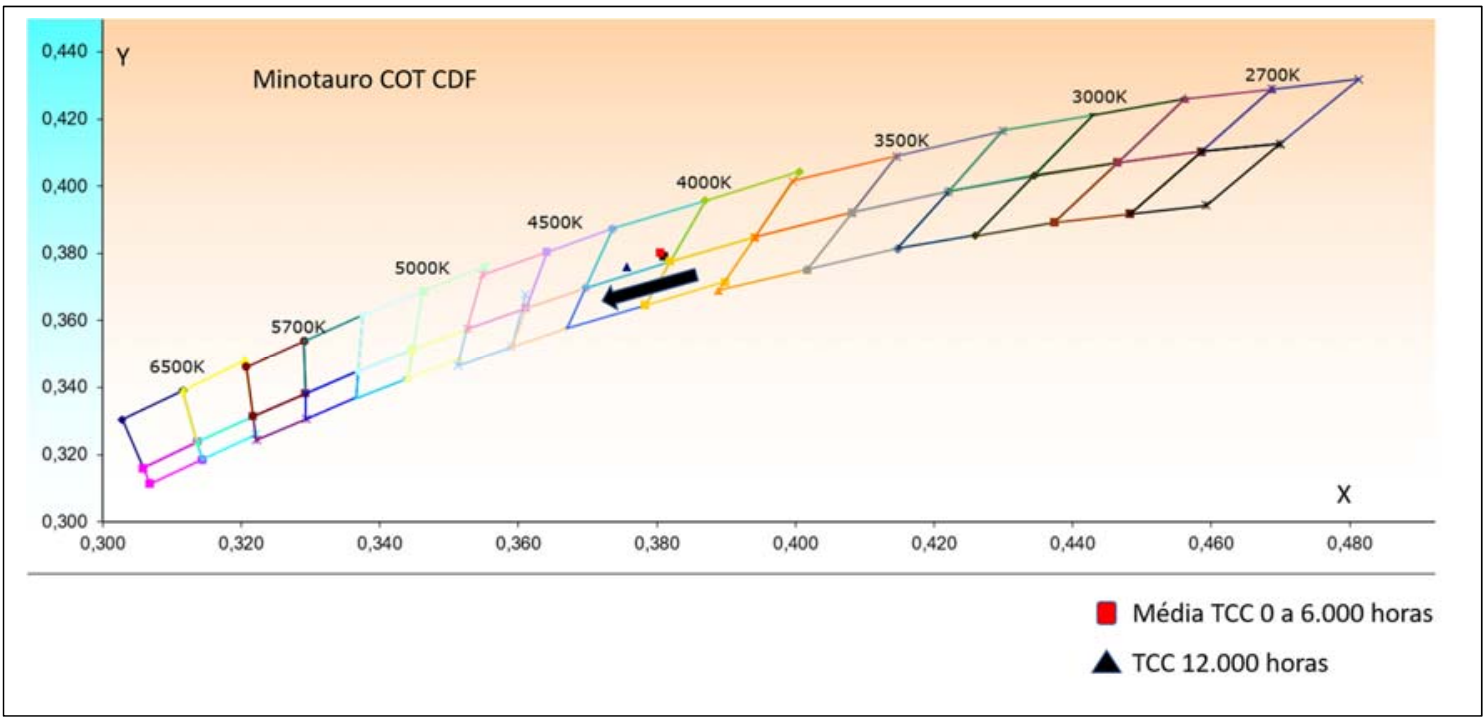

Fonte: Scopacasa, 2020.

Gráfico 36: Ponto de cromaticidade " $x$, y" mediano 0 hora e 12.000 horas, objetos de ensaios MINOTAURO COT SDF.

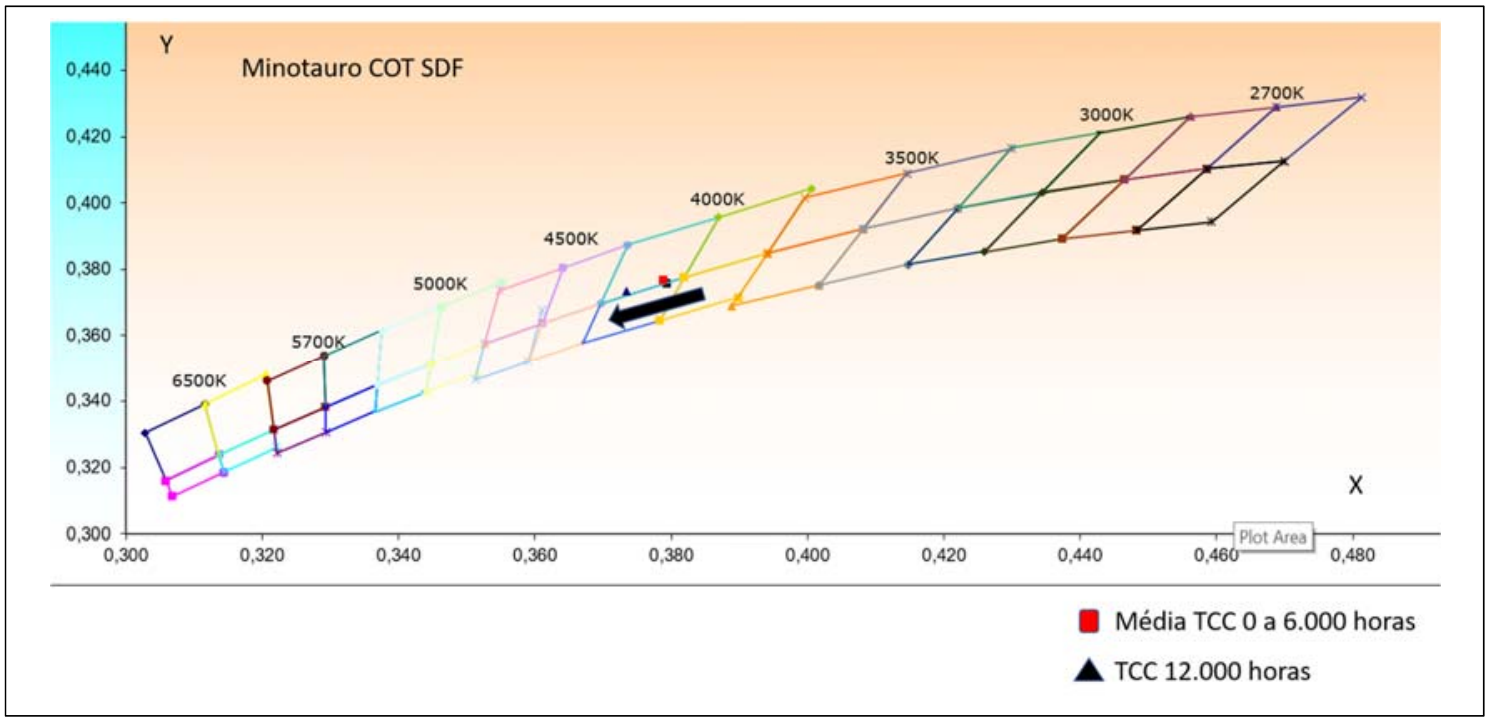

Fonte: Scopacasa, 2020. 
Gráfico 37: Ponto de cromaticidade " $x$, y" mediano 0 hora e 12.000 horas, objetos de ensaios ORBI COT CDF.

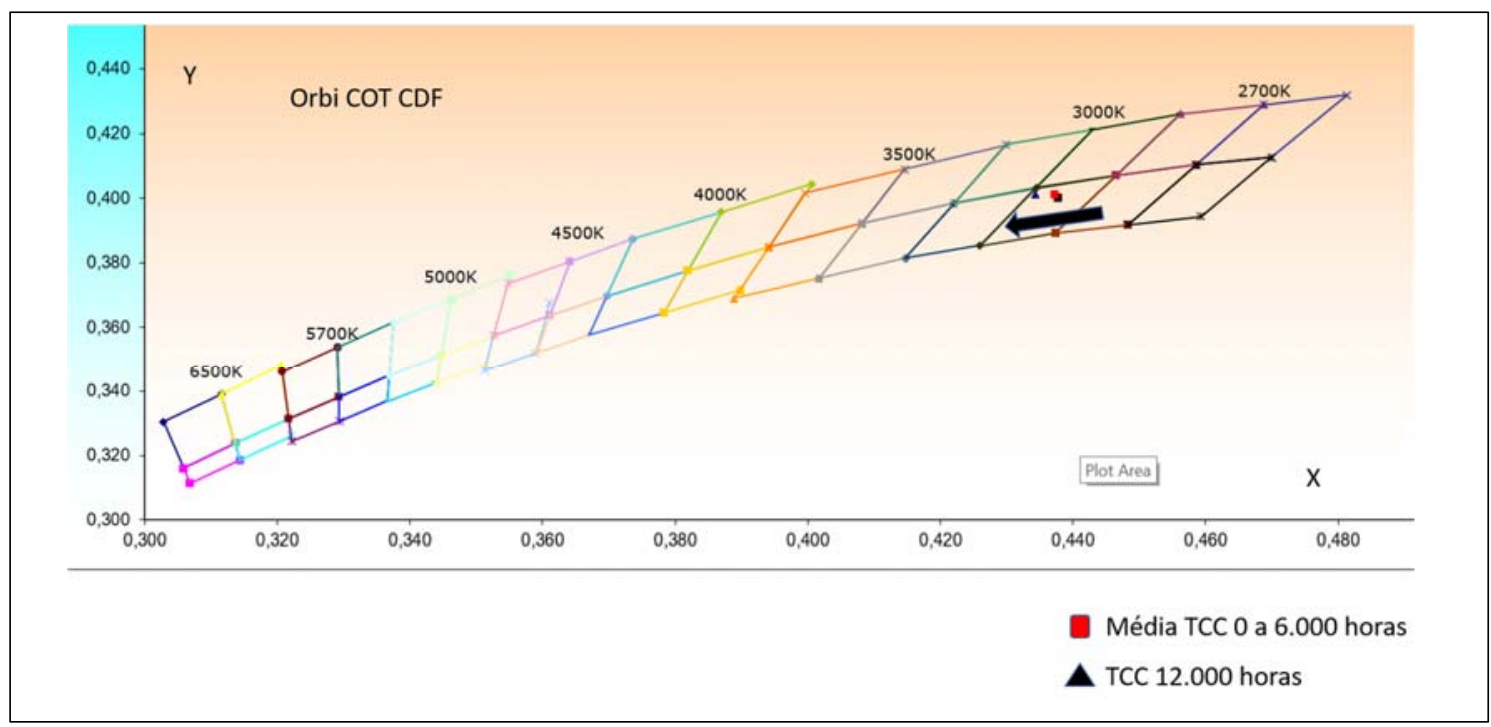

Fonte: Scopacasa, 2020.

Gráfico 38: Ponto de cromaticidade " $x, y$ " mediano 0 hora e 12.000 horas, objetos de ensaios ORBI COT SDF.

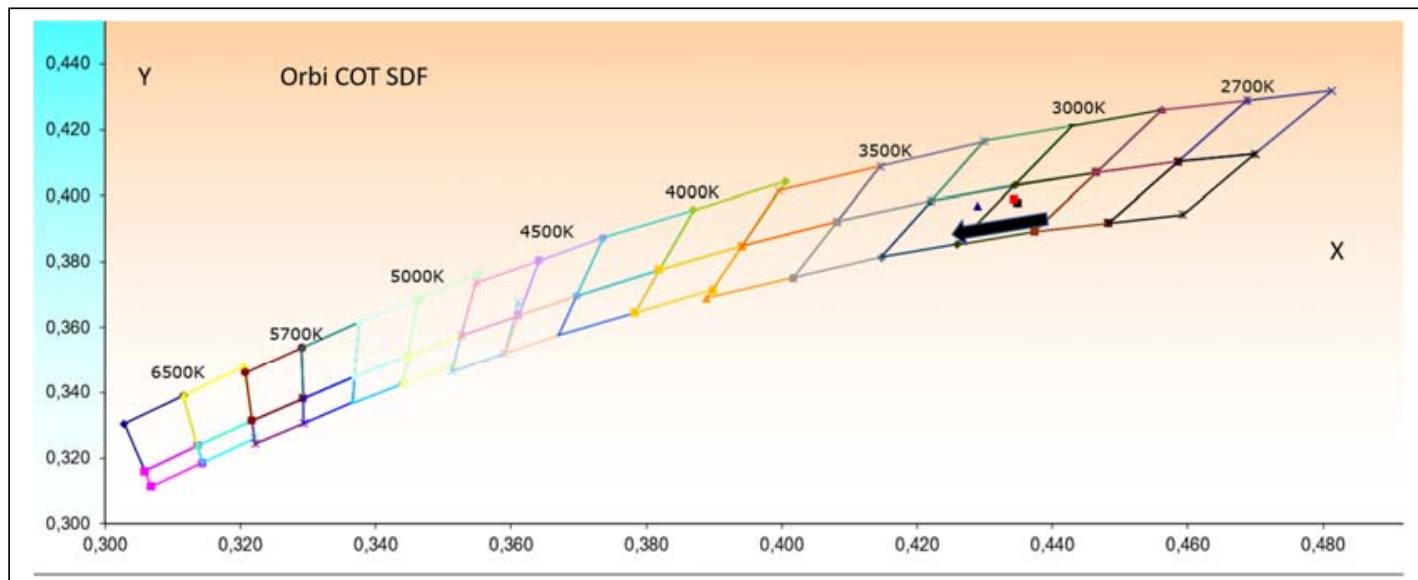

Média TCC 0 a 6.000 horas

$\Delta$ TCC 12.000 horas

Fonte: Scopacasa, 2020. 
7.2.17. Resultados das medições de Índice de fidelidade (Rf) e índice de Gamut (Rg) dos objetos de ensaios MINOTAURO COT CDF e SDF 001 a 004, MINOTAURO FOR CDF e SDF 001 a 004, ORBI COT CDF e SDF 001 a 004, ORBI FOR CDF e SDF 001 a 004.

Conforme os resultados obtidos nos ensaios de IRC e Ra, as medições de Índice de fidelidade (Rf) e índice de Gamut (Rg) dos objetos de ensaios MINOTAURO COT CDF e SDF 001, 002, 003 e 004, MINOTAURO FOR CDF e SDF 001, 002, 003 e 004, ORBI COT CDF e SDF 001, 002, 003 e 004, ORBI FOR CDF e SDF 001, 002, 003 e 004 tiveram um comportamento análogo.

Como os dois procedimentos (CIE - IRC e IES TM-30) avaliam características de reprodução de cor - mesmo utilizando métodos distintos - era de se esperar que os resultados tivessem uma certa coerência, o que foi constatado no nosso estudo.

Conforme abordado nas seções 7.2.9 a 7.2.12 não observamos variações consideráveis na reprodução de cor em todos os objetos de ensaios e assim como de localidade de experimentos, sendo que o mesmo ocorreu com os valores de Rf e Rg.

Eventuais discrepâncias no parâmetro $\mathrm{Rf}$ são explicadas em função da alteração do software da esfera integradora EVERFINE, para atendimento da recomendação IES TM30-18, que se ajustou à IEC 224-17, com alterações do método de medições. 


\subsection{Registro fotográfico e análise visual dos objetos de ensaios}

Após finalização dos ensaios em laboratório, foi realizada uma avaliação visual dos objetos de ensaios, com o objetivo de identificar possíveis alterações nos componentes. Serão aqui referenciados os componentes que apresentaram deterioração ao longo do experimento.

$\rightarrow$ Objetos de ensaios MINOTAURO COT CDF

\section{- MINOTAURO COT CDF 001 a 004}

Todos os objetos de ensaios COT CDF 001, 002, 003 e 004 têm seus difusores preservados, apresentando somente uma pequena fissura no modelo COT CDF 002, como pode ser observado na Figura 84, provavelmente devido a manuseio inadequado quando da retirada do difusor da caixa.

Figura 84: Difusores preservados - MINOTAURO COT CDF 001 a 004

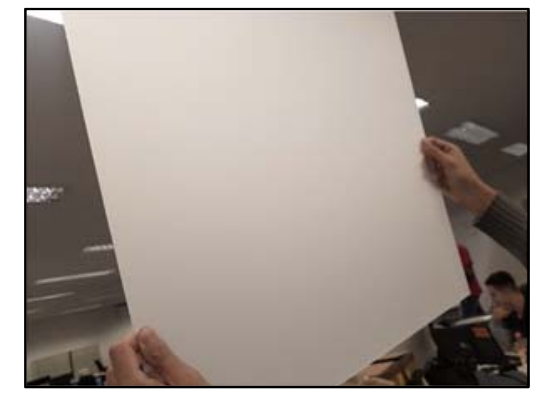

Fonte: Scopacasa, e a autora, 2020.

\section{- MINOTAURO COT CDF 002}

Neste objeto de ensaio podemos observar, conforme Figura 85, que houve a retirada dos ilhoses que fixam a luminária, sem apresentação de oxidação. SMD apresenta escurecimento visualmente significativo, mas sem grande comprometimento das características fotométricas e colorimétricas, conforme medições apresentadas na seção 7.2. 
Figura 85: SMDs com escurecimento - MINOTAURO COT CDF 002

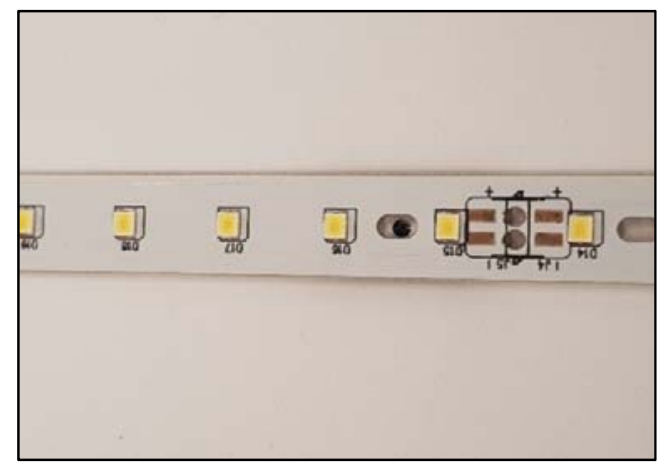

Fonte: Scopacasa, e a autora, 2020.

Além disso, a extremidade onde temos a soldagem dos contatos, bem como o parafuso, se encontram sem oxidação aparente. Parte interna da carcaça, assim como o driver e conector fixados internamente, estão em bom estado de conservação, como pode ser observado, respectivamente, nas Figuras 86 e 87 .

Figura 86: Soldagem dos contatos MINOTAURO COT CDF 002

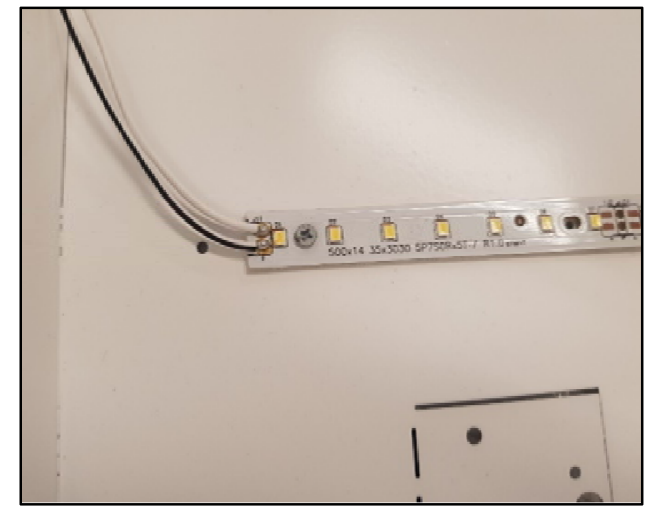

Fonte: Scopacasa, e a autora, 2020.
Figura 87: Driver preservado MINOTAURO FOR CDF 002

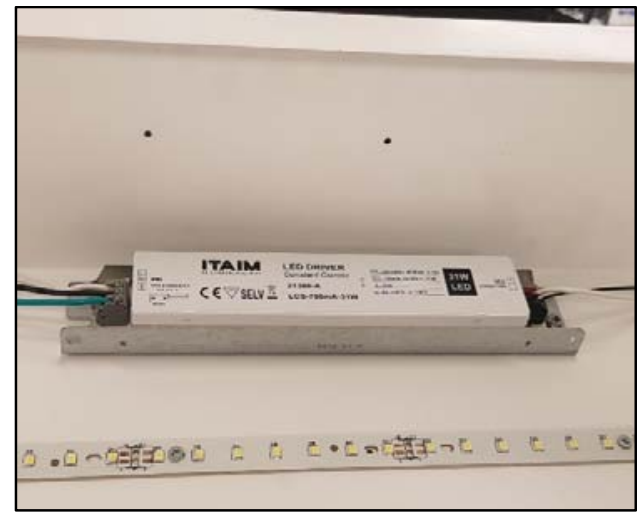




\section{$\rightarrow$ Objetos de ensaios MINOTAURO COT SDF}

\section{- MINOTAURO COT SDF 001}

Conforme pode ser observado na Figura 88, a extremidade onde temos a soldagem dos contatos apresenta leve oxidação. $O$ fato não alterou o comportamento do objeto de ensaio. Como mostra a Figura 89, há um escurecimento (de cor amarronzada) nos chips do SMD Mid-Power montados no módulo linear. Isso foi devido a uma depreciação no Lead frame, apresentando o que chamamos de "tarnish"; provavelmente o enxofre, comum a qualquer ambiente, oxidou em contato com o Lead frame, causando tal escurecimento. Isso foi observado nas medições de 12.000 horas, quando tivemos maior queda no fluxo luminoso.

Figura 88: Solda do contato com leve oxidação MINOTAURO COT SDF 001

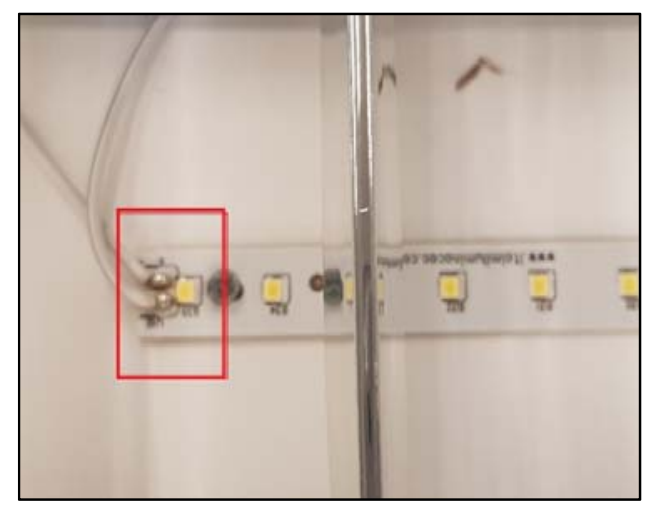

Figura 89: Escurecimento do chip, depreciação do Lead frame MINOTAURO COT SDF 001

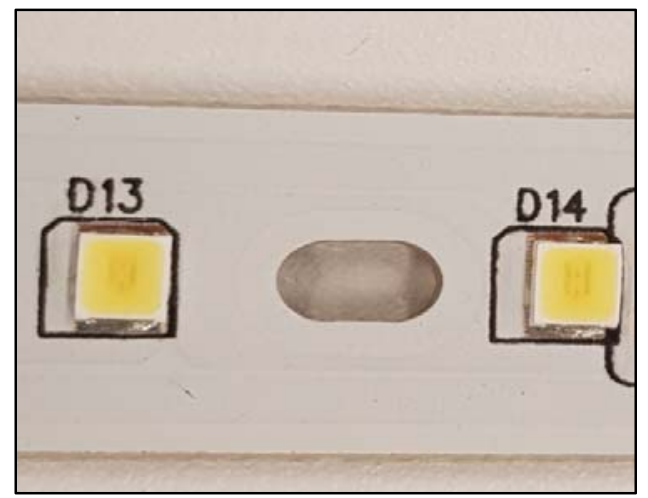

Fonte: Scopacasa, e a autora, 2020.

Na Figura 90 observamos o driver, conector e módulos lineares fixados internamente, em bom estado de conservação. Na Figura 91 visualizamos o refletor óptico com manchas, provavelmente provocadas pelo manuseio do objeto de ensaio. Este fato não comprometeu as características fotométricas e colorimétricas, conforme medições apresentadas na seção 7.2. 
Figura 90: Driver, conector e módulos lineares em bom estado de conservação.

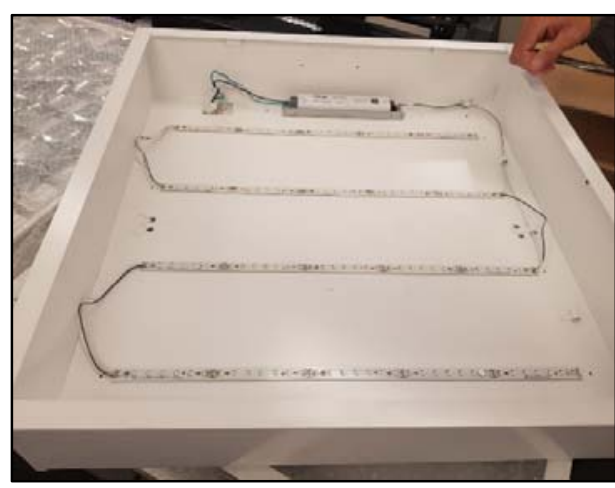

Fonte: Scopacasa, e a autora, 2020.
Figura 91: Refletor óptico apresentando manchas

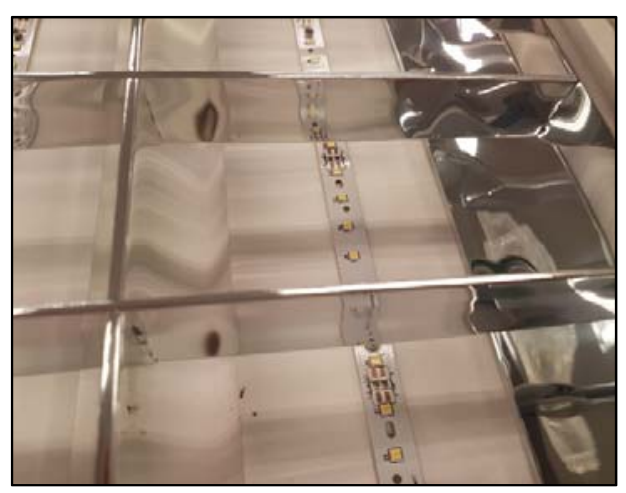

\section{$\rightarrow$ Objetos de ensaios ORBI COT CDF}

\section{- ORBI COT CDF 003}

Neste objeto de ensaio o holder apresenta-se trincado, embora isso não tenha causado comprometimento no funcionamento do COB; os contatos e interface térmica estão preservados e a fissura no holder não danificou o sistema de encaixe do refletor, como pode ser notado na Figura 92. Na Figura 93 podemos observar que o refletor se encontra preservado, sem alterações na óptica secundária.

Figura 92 Holder trincado - ORBI COT CDF 003

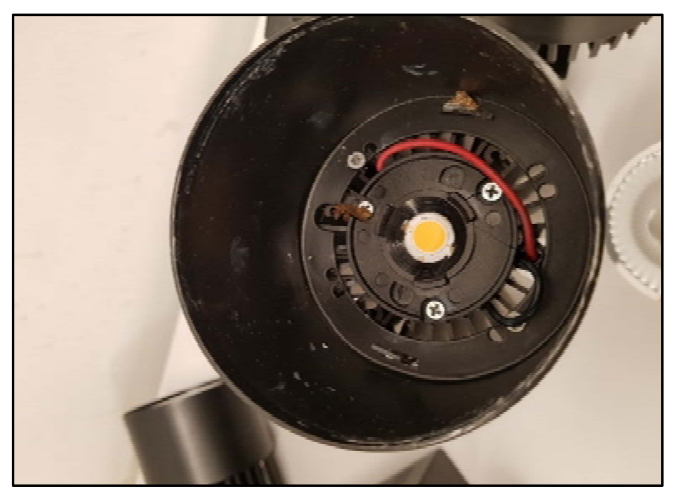

Figura 93: Refletor preservado - ORBI COT CDF 003

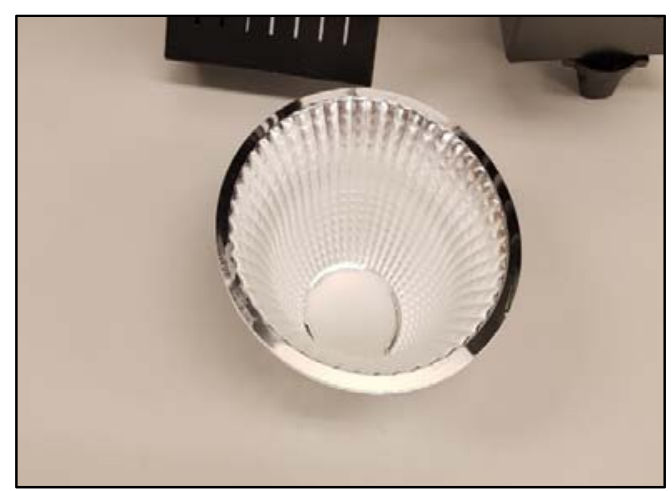

Fonte: Scopacasa, e a autora, 2020. 
A Figura 94 mostra o conjunto óptico e difusor preservados. Esse objeto de ensaio apresentou a maior variação de fluxo luminoso $(-7,36 \%)$ após 6.000 horas, sendo que, após esse período, até 12.000 horas, a variação diminuiu $(-3,04 \%)$.

Figura 94: Difusor ORBI COT CDF 003

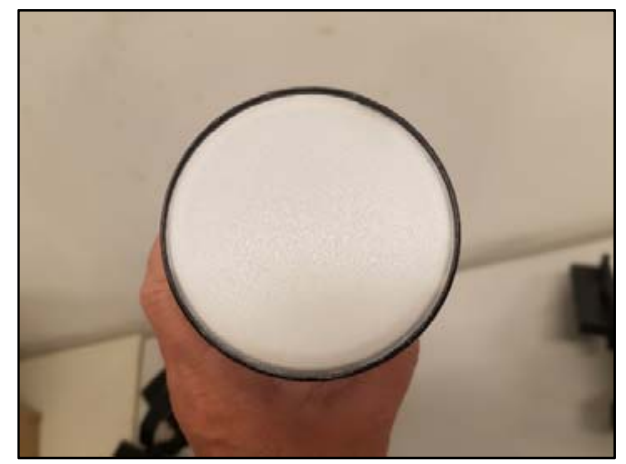

Fonte: Scopacasa, e a autora, 2020.

Na Figura 95 podemos observar que o difusor apresenta leve deformação; isso provavelmente ocorreu devido ao acúmulo de calor, uma vez que, conforme observado no Capítulo 2, esse modelo de produto não foi dimensionado para receber um difusor frontal, tendo sido adaptado para o teste.

Figura 95: Difusor com leve deformação - ORBI COT CDF 003

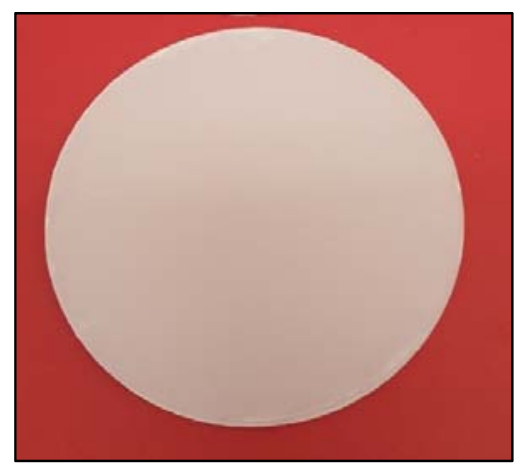

Fonte: Scopacasa, e a autora, 2020.

\section{$\rightarrow$ Objetos de ensaios ORBI COT SDF}




\section{- ORBI COT SDF 003}

A Figura 96 mostra o refletor óptico preservado. A Figura 97 apresenta o LED COB também preservado; pequenas manchas que podem ser observadas na extremidade são, provavelmente, decorrentes de resíduos de poeira, que foram removidos com um cotonete embebido em álcool isopropílico.

Figura 96: Refletor óptico preservado ORBI COT SDF 003

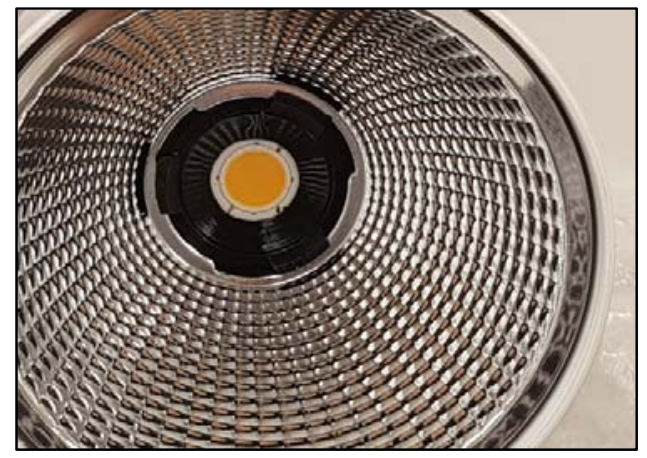

Figura 97: LED COB preservado com pequena mancha - ORBI COT SDF003

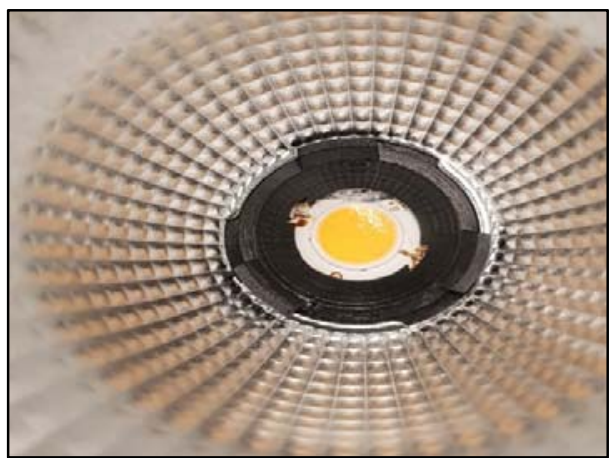

Fonte: Scopacasa, e a autora, 2020.

\section{$\rightarrow$ Objetos de ensaios MINOTAURO FOR CDF}

\section{$\rightarrow$ MINOTAURO FOR CDF 001}

A Figura 98 mostra as soldas entre os módulos lineares com pequenos pontos residuais de fluxo de solda, que são comuns no processo de soldagem/montagem. A Figura 99 expõe pequenos pontos amarelados observados sobre os SMDs que, possivelmente, são resíduos de fluxo de solda que não foram devidamente retirados no final do processo. Estes fatos não alteraram o comportamento do objeto de ensaio. 
Figura 98: Solda entre contatosMINOTAURO FOR CDF 001

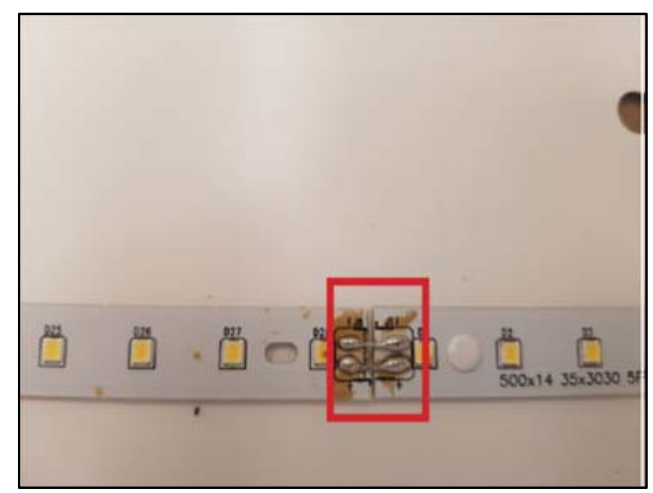

Figura 99: Pontos amarelados sobre os SMDs - MINOTAURO FOR CDF 001

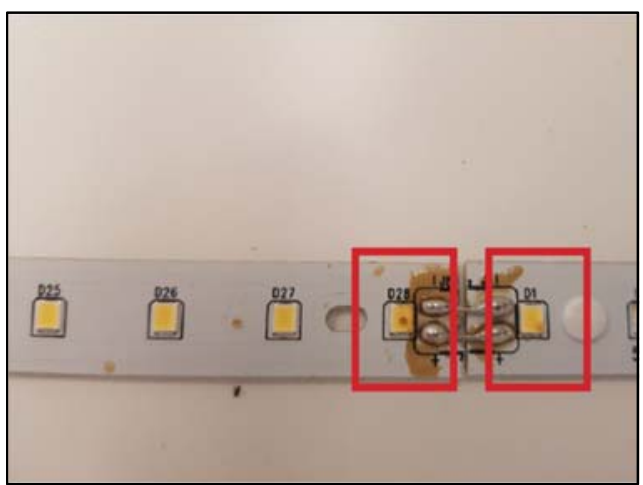

Fonte: Scopacasa, e a autora, 2020.

A Figura 100 apresenta o driver fixado na parte interna do objeto de ensaio e lateralmente aos módulos lineares, sendo que ambos os elementos apresentam boas condições de conservação. A Figura 101 mostra o difusor preservado e sem manchas.

Figura 100: Driver e módulos lineares MINOTAURO FOR CDF 001

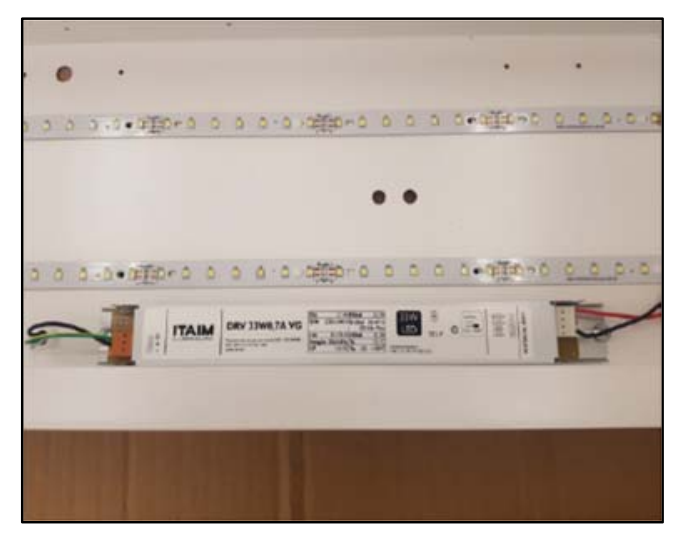

Figura 101: Difusor - MINOTAURO FOR CDF 001

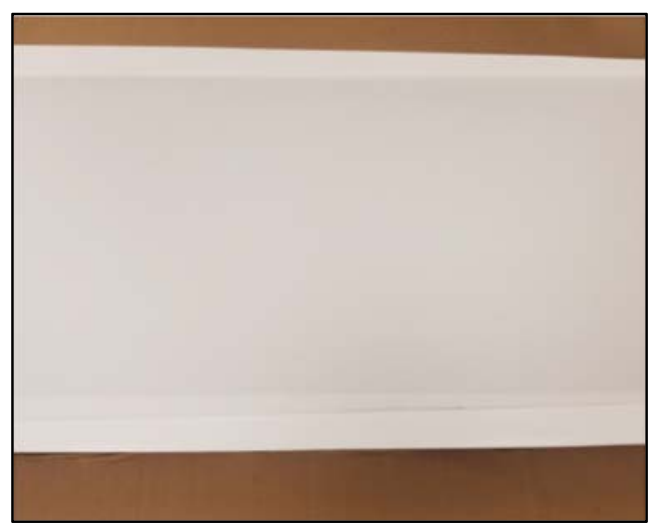

Fonte: Scopacasa, e a autora, 2020. 


\section{$\rightarrow$ MINOTAURO FOR CDF 002}

As junções entre os módulos apresentando oxidação são mostrados na Figura 102, sendo observada a entrada de água neste objeto de ensaio. Isso se deve, provavelmente, ao fato de termos tido uma obra de revitalização da fachada e da estrutura do telhado na Fujisan no período dos experimentos. Os SMDs inseridos nos módulos lineares não apresentam alterações, conforme Figura 103. A área de fixação dos módulos por meio de ilhoses plásticos na carcaça não apresenta oxidação.

Figura 102: Solda entre contatos oxidada - MINOTAURO FOR CDF 002

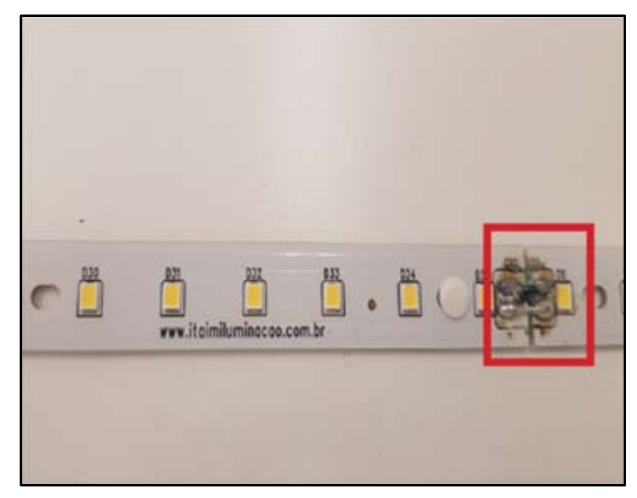

Figura 103: SMDs bem conservadosMINOTAURO FOR CDF 002

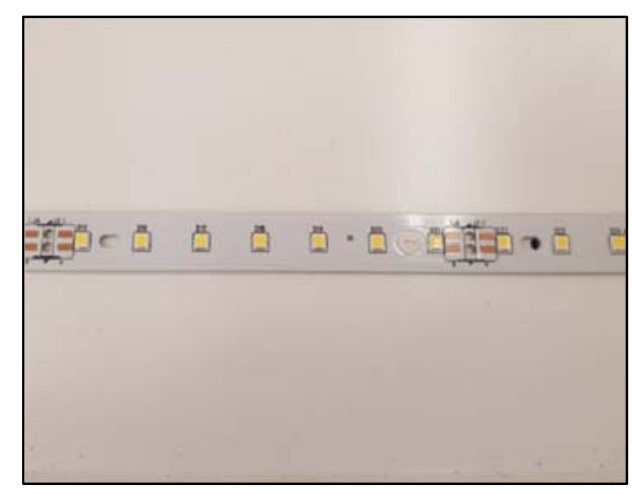

Fonte: Scopacasa, e a autora, 2020.

No centro da carcaça do objeto de ensaio MINOTAURO FOR CDF 002 observou-se manchas de oxidação da superfície, em função de contato com a água, conforme mostra a Figura 104. A Figura 105 apresenta a lateral da carcaça com áreas maiores oxidadas. A entrada de água não alterou o comportamento do objeto de ensaio. 
Figura 104: Centro da carcaça com oxidação - MINOTAURO FOR CDF 002

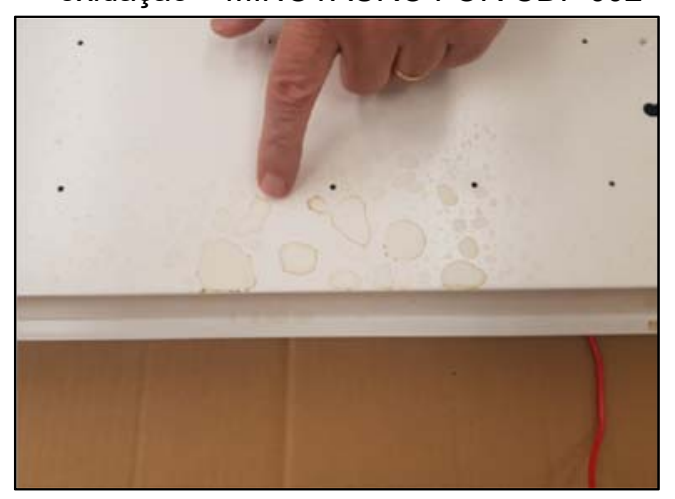

Figura 105: Lateral da carcaça com oxidação - MINOTAURO FOR CDF 002

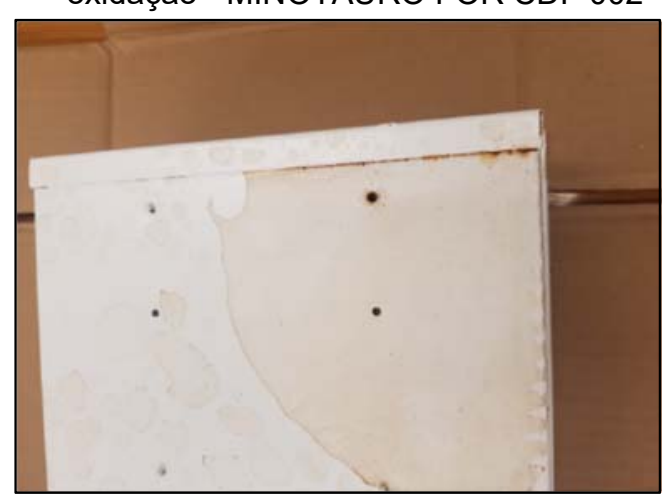

Fonte: Scopacasa, e a autora, 2020.

A Figura 106 mostra o driver e conector fixados externamente em bom estado de preservação, sem vestígios de corrosão. A Figura 107 apresenta uma mancha observada no difusor, na extremidade oposta onde temos evidências de oxidação, mas, conforme medições, isso não alterou o comportamento do objeto de ensaio.

Figura 106: Driver e conectores preservados - MINOTAURO FOR CDF 002

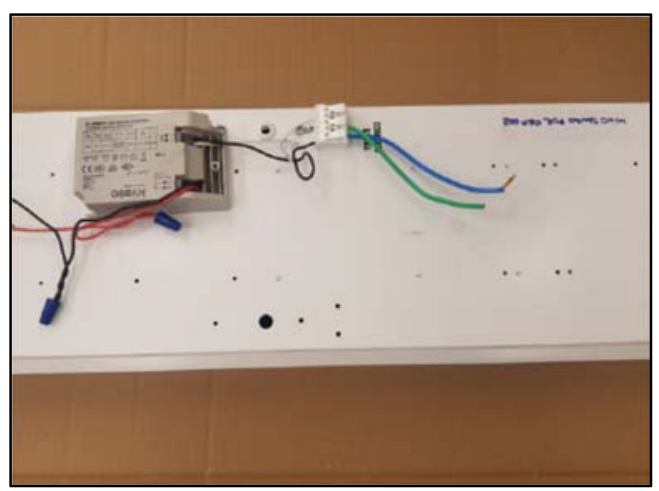

Fonte: Scopacasa, e a autora, 2020.
Figura 107: Difusor manchado em uma das extremidades - MINOTAURO FOR CDF 002

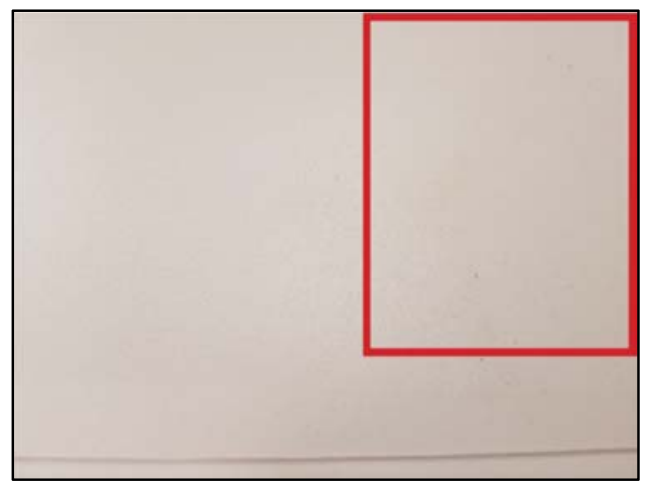


$\rightarrow$ MINOTAURO FOR CDF 003

A Figura 108 mostra as junções entre módulos lineares com presença de zinabre na área de solda, possivelmente em decorrência de umidade ou condensação de água no objeto de ensaio. Este fato não alterou o comportamento do objeto de ensaio. O ponto amarelo sobre o SMD mostrado na Figura 109 é, provavelmente, resíduo de fluxo de solda. As medições não mostram alterações que devam ser levadas em consideração.

Figura 108: Junções do módulo com presença de zinabre - MINOTAURO FOR CDF 003

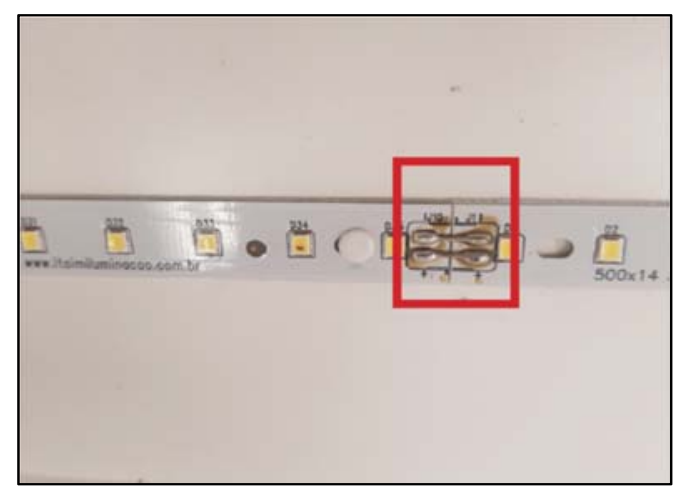

Figura 109: Ponto amarelo, resíduo de fluxo de solda- MINOTAURO FOR CDF 003

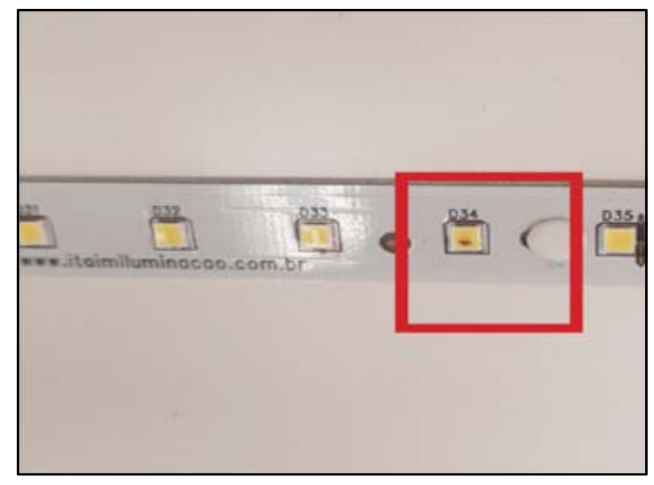

Fonte: Scopacasa, e a autora, 2020.

A Figura 110 mostra oxidação nas furações onde temos os ilhoses plásticos de fixação. Observou-se entrada de água no objeto de ensaio. A Figura 111 apresenta o driver e conector, posicionados externamente, em boas condições de conservação. $A$ região próxima ao driver mostra uma pequena área oxidada, provavelmente por contato com água ou condensação. 
Figura 110: Fixação do módulo na carcaça com zinabre - MINOTAURO FOR CDF 003

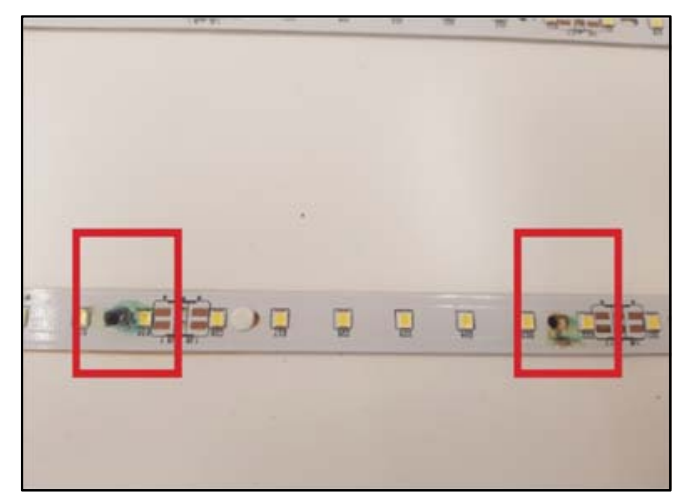

Figura 111: Área oxidada próxima ao driver - MINOTAURO FOR CDF 003

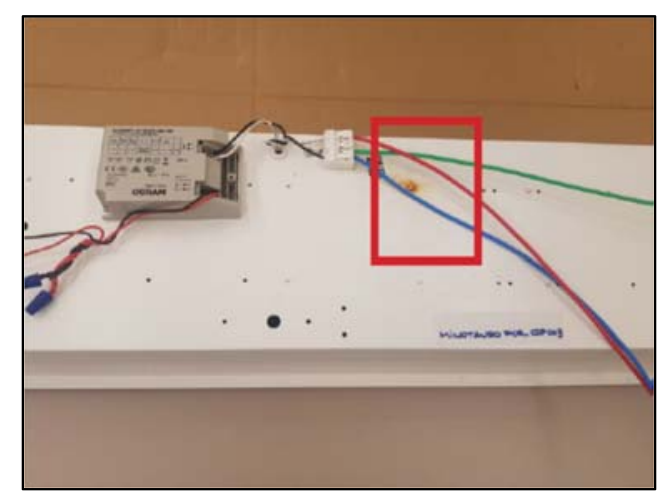

Fonte: Scopacasa, e a autora, 2020.

Pode-se observar mancha, por umidade, no difusor deste objeto de ensaio conforme Figura 112 -, mas as medições não mostram alterações que devam ser levadas em consideração.

Figura 112: Difusor manchado -

MINOTAURO FOR CDF 003

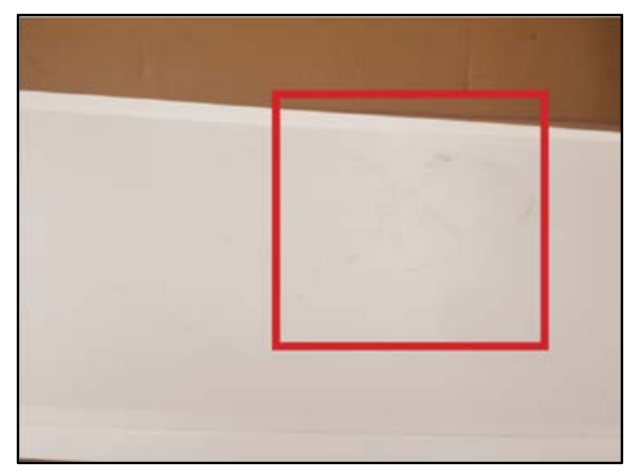

Fonte: Scopacasa, e a autora, 2020.

\section{- MINOTAURO FOR SDF 001}

A junção na área da solda no objeto de ensaio mostra-se preservada, conforme apresentado na Figura 113. Um ponto marrom é visível no SMD, próximo à junção, 
provavelmente por resíduo de fluxo de solda. A Figura 114 mostra o refletor óptico com várias manchas, aparentemente causadas por umidade, ou contato com a água.

Figura 113: Junções preservadas na área da solda - MINOTAURO FOR SDF 001

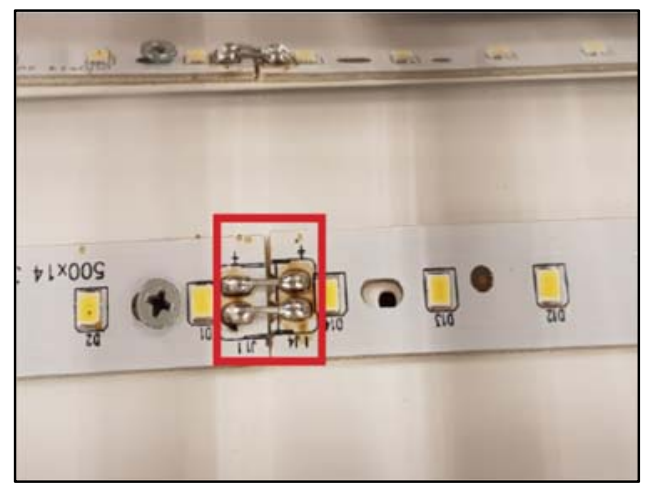

Fonte: Scopacasa, e a autora, 2020.
Figura 114: Refletor manchado MINOTAURO FOR SDF001

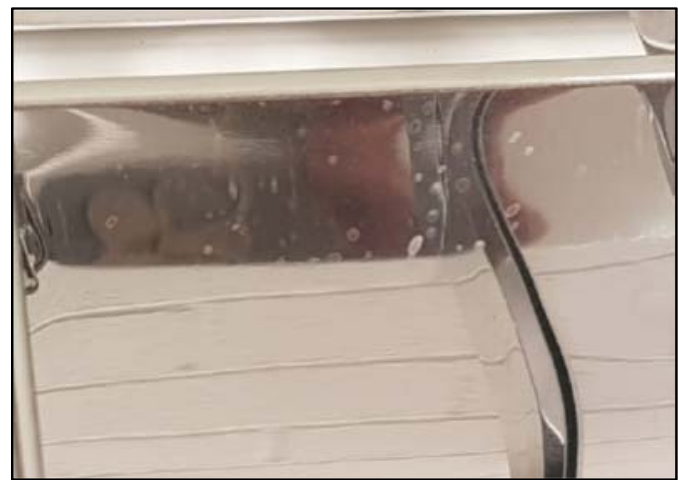

A Figura 115 apresenta o driver e conector, fixados externamente no objeto de ensaio, preservados. Percebe-se o início de uma mancha de oxidação na carcaça do objeto de ensaio. A Figura 116 mostra a lateral da carcaça e da cabeceira oxidadas.

Figura 115: Driver e conector preservado - MINOTAURO FOR SDF 001

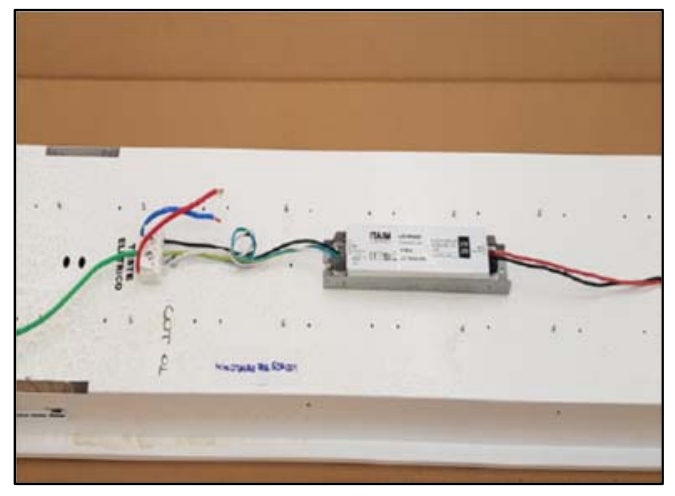

Fonte: Scopacasa, e a autora, 2020.
Figura 116: Lateral da carcaça com oxidação - MINOTAURO FOR SDF 001

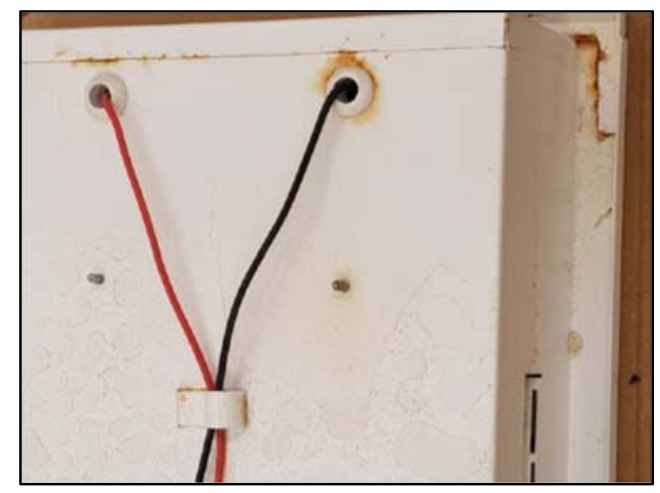

A Figura 117 mostra que somente uma lateral do objeto de ensaio apresenta manchas e oxidação. A causa disso, provavelmente, é a entrada de água. 
Figura 117: Lateral do objeto de ensaio com manchas MINOTAURO FOR SDF 001

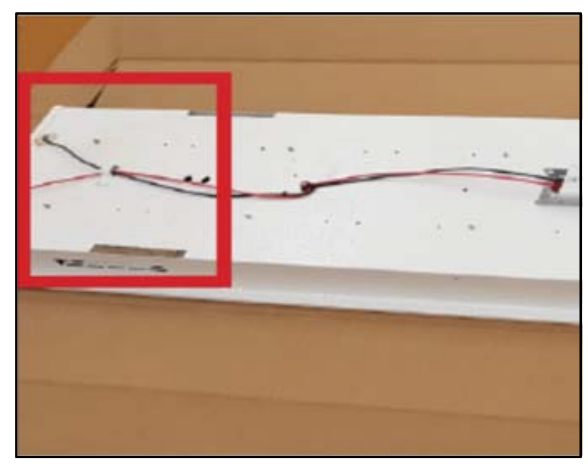

Fonte: Scopacasa, e a autora, 2020.

\section{- MINOTAURO FOR SDF 002}

A Figura 118 mostra as soldas entre a junção dos módulos preservadas (1) e, nas proximidades, sobre o SMD, resíduos de fluxo da solda (2). A Figura 119 reforça que temos respingos de fluxo de solda em outros SMDs.

Figura 118: SMD próximo à área de solda com respingo - MINOTAURO FOR SDF 002

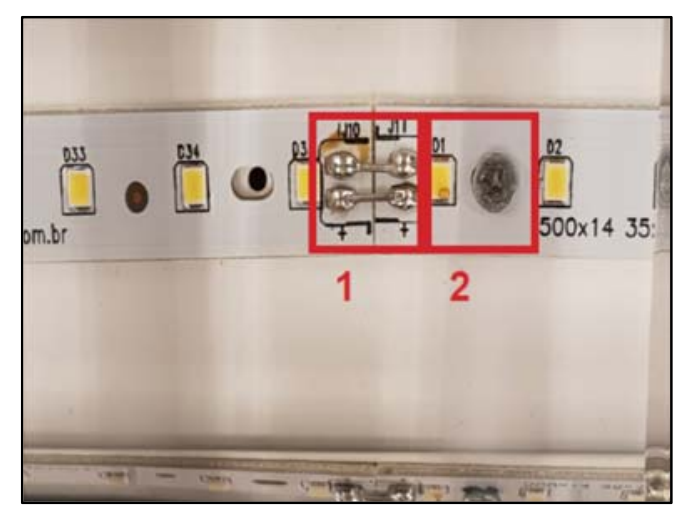

Figura 119: Respingo no SMD MINOTAURO FOR CDF 002

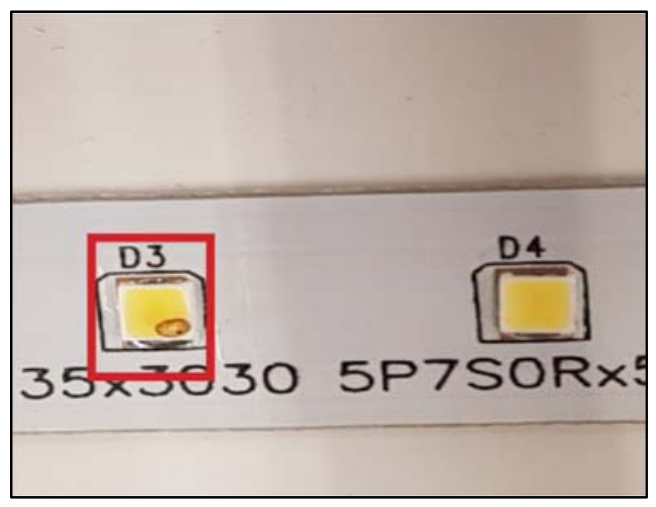

Fonte: Scopacasa, e a autora, 2020.

A Figura 120 mostra que tanto a carcaça, como a cabeceira e o refletor do objeto de ensaio foram preservados. 
Figura 120: Cabeceira, carcaça e refletor preservados MINOTAURO FOR SDF 002

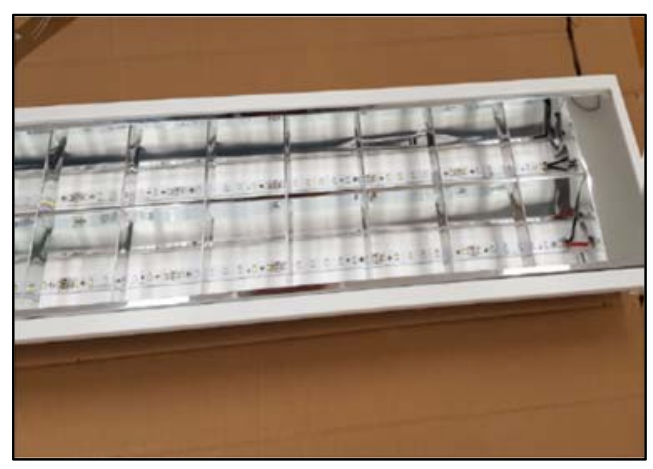

Fonte: Scopacasa, e a autora, 2020. 


\section{- MINOTAURO FOR SDF 003}

A Figura 121 mostra que as soldas feitas na junção do modulo linear foram preservadas, não apresentando oxidação. Na Figura 122 observou-se manchas aparentes nos SMDs (1) e no PCB do módulo linear (2), aparentemente decorrentes de respingo de fluxo de solda.

Figura 121: SMD próximo à área de solda com respingo - MINOTAURO FOR SDF 003

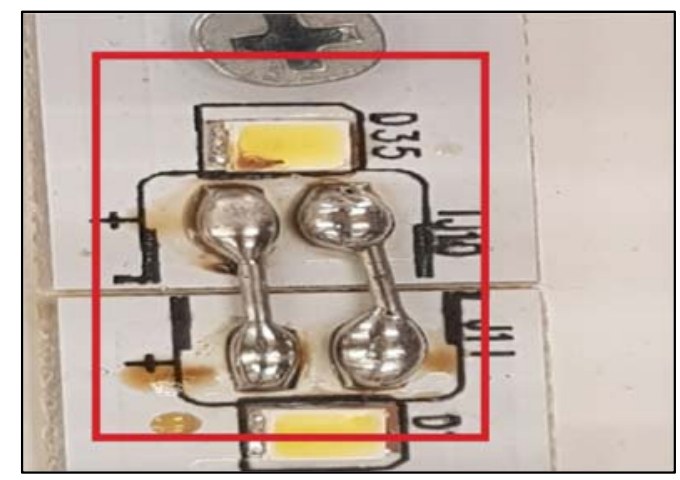

Figura 122: Respingo nos SMDs próximos à soldagem - MINOTAURO FOR SDF 003

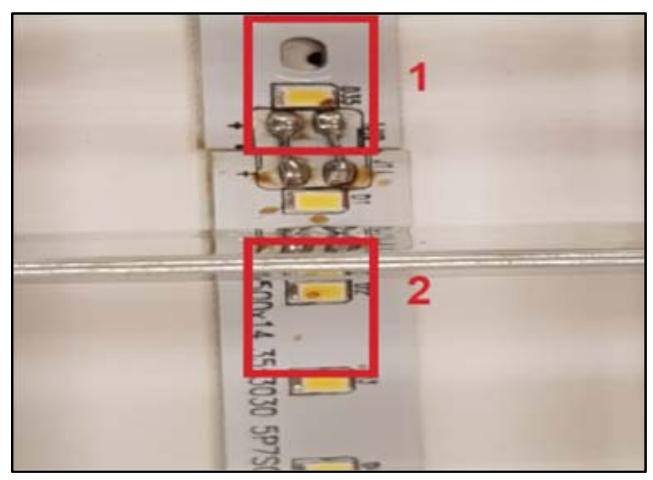

Fonte: Scopacasa, e a autora, 2020.

A Figura 123 mostra manchas de oxidação no centro externo da carcaça, provavelmente por contato com a água, ou umidade, por breve período.

Figura 123: Carcaça com pequena mancha - MINOTAURO FOR SDF 003

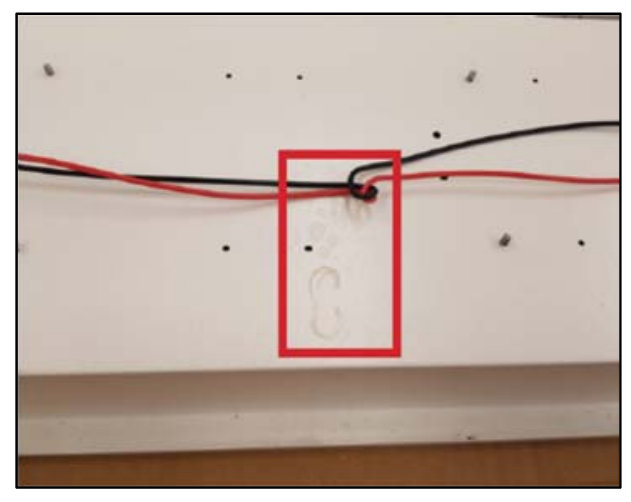

Fonte: Scopacasa, e a autora, 2020. 


\section{- MINOTAURO FOR SDF 004}

Na Figura 124 pode-se observar que as soldas entre os módulos lineares se encontram preservadas (1); nota-se também pequena mancha, decorrente de respingo de fluxo de solda (2). A Figura 125 mostra a carcaça do objeto de ensaio com várias manchas, por contato com a água por longo período. Independente desses fatos, driver e conector próximo estão preservados.

Figura 124: Área de solda preservada, SMD com respingo e parafuso oxidado MINOTAURO FOR SDF 004

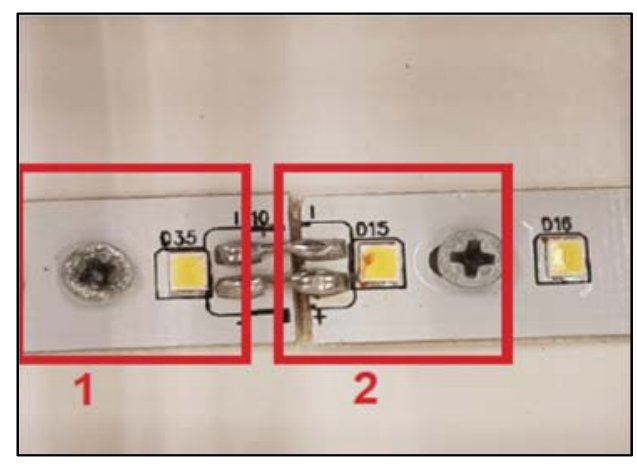

Figura 125: Carcaça externa com manchas- MINOTAURO FOR SDF 004

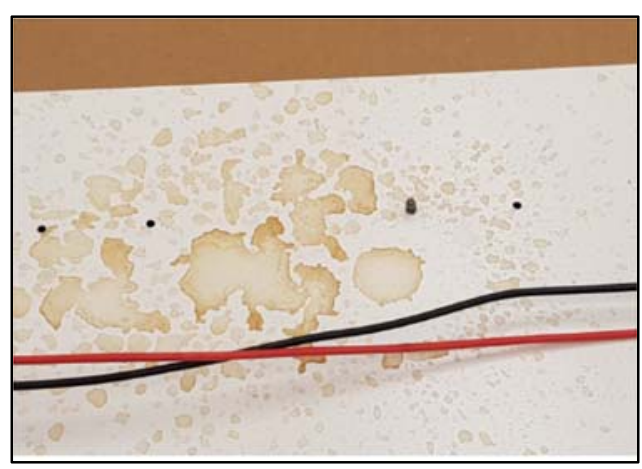

Fonte: Scopacasa, e a autora, 2020.

A Figura 126 mostra refletor, cabeceira e carcaça do objeto de ensaio preservados.

Figura 126: Carcaça e refletor preservado - MINOTAURO FOR SDF 004

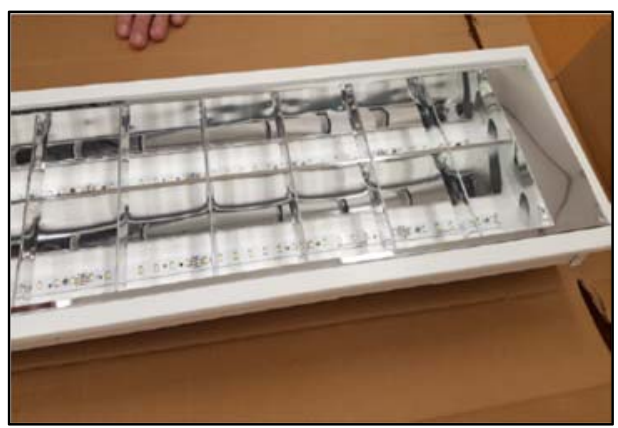

Fonte: Scopacasa, e a autora, 2020. 


\section{- ORBI FOR CDF 001}

As Figuras 127 e 128 mostram o difusor do objeto de ensaio ORBI FOR CDF 001 deformado, provavelmente por maior concentração de calor em uma menor área. Este fato não alterou o comportamento dos objetos de ensaios, conforme medições apresentadas. Vale ressaltar, como mencionado no Capítulo 2, que este produto foi adaptado para o teste, por não ter sido projetado para utilizar difusor.

Figura 127: Objeto de ensaio com difusor deformado - ORBI FOR CDF 001

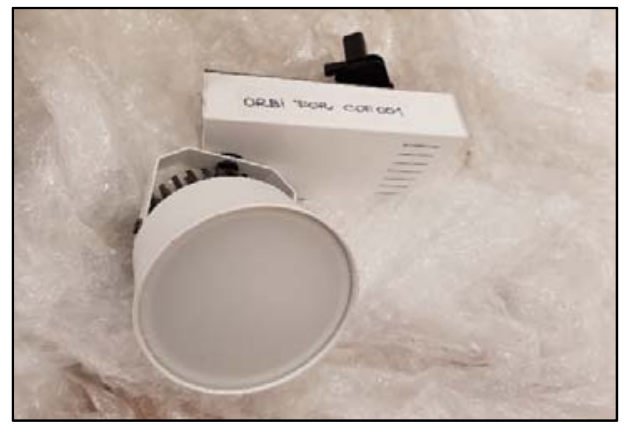

Figura 128: Difusor deformado - ORBI FOR CDF 001

Fonte: Scopacasa, e a autora, 2020.

\section{- ORBI FOR SDF 001}

A Figura 128 apresenta o refletor 100\% preservado. Na Figura 129 pode-se observar o $\mathrm{COB}$ com pequenos pontos alaranjados (2), tendo uma mancha maior perceptível (1). Esses pontos observados são detritos, que foram removidos com cotonete e álcool isopropílico. 
Figura 128: Refletor em alumínio anodizado preservado - ORBI FOR SDF 001

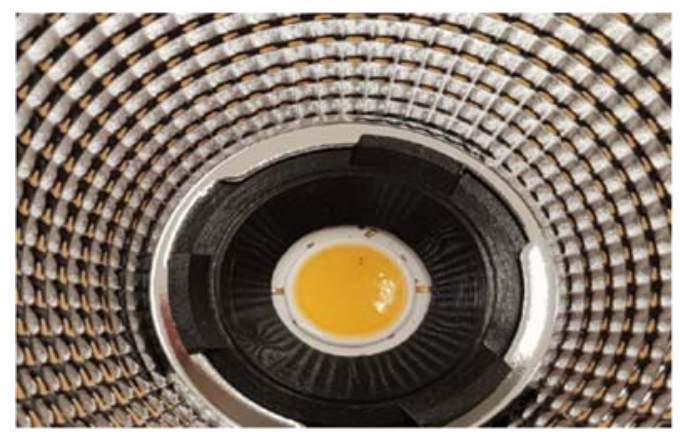

Figura 129: $\mathrm{COB}$ com pequenos pontos de respingos - MINOTAURO

FOR SDF 004

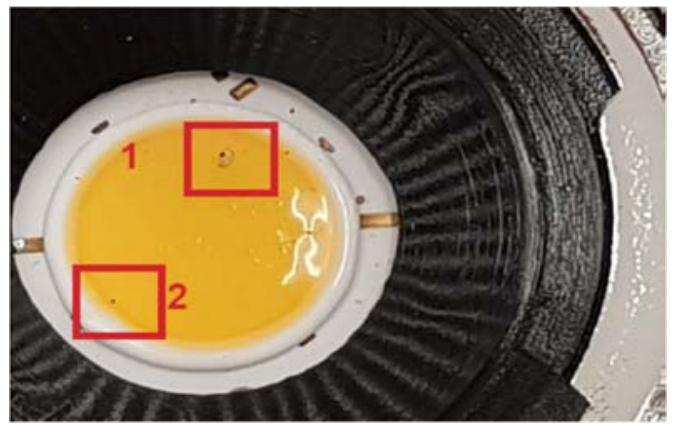

Fonte: Scopacasa, e a autora, 2020.

A Figura 131 apresenta o objeto de ensaio preservado, assim como os componentes internos em bom estado de conservação.

ra 131: Estrutura externa do objeto de ensaio preservada ORBI FOR SDF 001

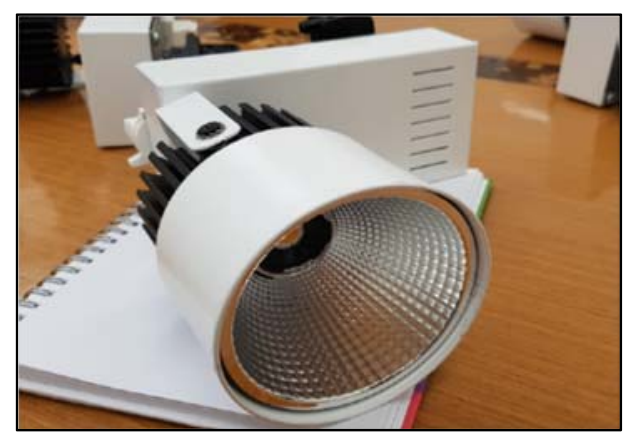

Fonte: Scopacasa, e a autora, 2020. 


\section{CONSIDERAÇÕES FINAIS E CONCLUSÕES}

\subsection{Considerações finais}

Este trabalho teve por objetivo apresentar uma metodologia para análise do comportamento do LED aplicado na iluminação do setor comercial, particularmente em relação ao desempenho dos componentes integrados em luminárias LED. Para tanto, foram considerados como critérios de análise as diversas normas e recomendações existentes para a determinação da manutenção do fluxo luminoso e alterações das características de cromaticidade com o tempo e tensão nas luminárias LED, conforme LM-80-18, IES TM-21-11; TM-28-14; LM-84-14, para obtenção de informações mais precisas sobre luminárias LED.

Atualmente, muitos fabricantes desenvolveram meios próprios para estimar a vida útil do produto em seus próprios projetos, usando dados sobre os principais componentes, mas voltados ao desempenho do LED e módulos de LEDs, não considerando os componentes inseridos na luminária; embora haja um esforço por parte da indústria, no Brasil não há pesquisas relacionadas às luminárias LED e não há protocolos de consenso no setor no momento. Entender o comportamento e causa das falhas do sistema requer o desenvolvimento de testes para reproduzir instalações de luminárias comuns ao mercado.

Neste sentindo, observou-se a necessidade de gerar uma metodologia que apresente mais parâmetros de avaliação do desempenho desses objetos, além dos estabelecidos pelo mercado, dado que quando os LEDs são instalados em uma luminária ou sistema, muitos fatores adicionais, como mencionado anteriormente, podem afetar a manutenção do fluxo luminoso ou levar a falhas catastróficas. Isso inclui temperaturas extremas e umidade, sendo que a metodologia adotada, não pode considerar todos os fatores desejáveis, tais como flutuações de tensão ou corrente, falha do driver ou outros componentes elétricos, danos ou degradação do material de encapsulamento que cobre os LEDs, possíveis danos às interconexões entre os LEDs e o equipamento, degradação dos fósforos, amarelecimento das lentes ópticas, e até mesmo perda de reflexão por parte dos refletores. 
O desenvolvimento de mais métodos de teste para prever com precisão a vida útil e comportamento do sistema é uma importante área, que requer mais esforços e pesquisas.

Embora a manutenção de fluxo luminoso venha dominando as discussões sobre a vida útil do LED, a estabilidade da cor (ou estabilidade da cromaticidade) é outro atributo importante de desempenho que pode vir a se tornar uma barreira para a aquisição das luminárias, ou resultar em expectativas não atendidas

Desta forma, a metodologia criada considerou alguns parâmetros geográficos, temporais e ambientais, apresentados no capítulo 2. Os testes em campo e laboratório foram realizados ao longo de 26 meses, com 32 objetos de ensaios distribuídos em duas localidades, Cotia/SP e Fortaleza/CE, e seus resultados foram apresentados no capítulo 7 .

O trabalho e as medições somente foram possíveis em razão de termos, por parte da indústria apoiadora Itaim Lighting Concept, que há anos utiliza o que há de melhor em tecnologia no mercado, um grande interesse em aprimorar os seus produtos, uma vez que tem por missão oferecer a melhor solução em iluminação para seus clientes. As informações geradas neste trabalho serão de grande valia para a divulgação de vida útil muito mais elevada dos produtos em questão, do que a divulgada atualmente pela Itaim.

Vale ainda ressaltar que a escolha da empresa Itaim Lighting Concept se deu após análise criteriosa de modelos oferecidos pelo mercado nacional e internacional voltados à aplicação em espaços comerciais, corporativos, hospitalares, instituições de ensinos, entre outros.

\subsection{Principais conclusões}

$\rightarrow$ Constatou-se que, de fato, nas medições de manutenção de fluxo luminoso para todos os objetos de ensaios dentro do intervalo de 0 hora até 6.000 horas as variações não se alteraram muito em relação ao fluxo original, mas nas medições de 12.000 horas, para os modelos de COTIA, temos uma notável diminuição, independente do uso de difusores frontais ou refletores metálicos 
sem difusor. Uma possível explicação para tal resultado é a redução do fluxo luminoso, em função do maior tempo de operação. A recomendação LM-80-18 corrobora com esses dados.

$\rightarrow$ Os testes apresentaram períodos representativos, conforme as recomendações das IES TM-21-11, TM-28-14, LM-84-14, e LM-80-18, que definem, basicamente, todos os parâmetros de interesse. Observou-se que não houve variações nos critérios elétricos e pouquíssimas variações nos parâmetros colorimétricos entre 0 hora e 6.000 horas; após esse período constatou-se uma considerável variação, tanto de fluxo como de cromaticidade, sem prejuízo à reprodução de cor.

$\rightarrow$ A manutenção da reprodução de cor se deu basicamente em função da manutenção da distribuição espectral de potência da luz, por ter uma ligação direta com a reprodução de cor.

$\rightarrow$ Todo os objetos de ensaios apresentaram elevação na temperatura de cor TCC $(K)$, variação caracterizada pelo fenômeno de degradação natural do fósforo em um período maior de operação, onde ocorre o vazamento da luz azul.

$\rightarrow$ Nos objetos de ensaios com difusores modelos ORBI COT E FOR CDF, observamos, em algumas situações, pequenas variações no comportamento, que acreditamos serem relacionada a uma questão térmica, uma vez que com os difusores, tende-se a ter um maior aquecimento por acúmulo de calor nas partes internas dos refletores, comprometendo a característica de convecção.

$\rightarrow$ Temos diferenças entre os objetos de ensaio sendo que, internamente, nas luminárias MINOTAURO temos barras de LEDs SMD, e nas luminárias ORBI temos LEDs COB (Chip on Board). O fato de termos menor perda de fluxo luminoso nas versões MINOTAURO quadrada ou retangular, pode ser consequência do melhor desempenho térmico;

$\rightarrow$ Os modelos ORBI são sistemas mais críticos, pois os LEDs COB possuem uma menor área de dissipação térmica, necessitando de condições ambientais ideais para garantir que o componente tenha desempenho do ponto de vista do gerenciamento térmico. Em condições de calor extremo, é possível serem observadas as alterações e depreciação do fluxo luminoso, provavelmente por 
termos uma maior densidade de emissão de luz $\left(\mathrm{Im} / \mathrm{mm}^{2}\right)$, maior densidade de potência $\left(\mathrm{W} / \mathrm{mm}^{2}\right)$ e, consequentemente, maior densidade de calor, o que demanda maiores cuidados com o projeto térmico, pois a transferência de calor dissipado passa a ocorrer em áreas cada vez menores. A condição ambiental externa também pode ter causado a perda de fluxo luminoso mas, em contrapartida, observou-se uma variação menor no IRC e Ra nos modelos ORBI, provavelmente em função de uma tecnologia mais aprimorada por parte dos LEDs COB em relação aos modelos MINOTAURO que fazem uso de LED Mid-Power plástico.

$\rightarrow$ Os LEDs COB quando não sujeitos a condições críticas de calor, são mais estáveis quanto aos critérios de manutenção de fluxo, como também aos dos parâmetros cromáticos, principalmente, em função de maior conteúdo tecnológico.

$\rightarrow$ As medições dos índices de fidelidade sofreram algumas alterações entre os primeiros períodos de testes em laboratório e as medições finais, em função da alteração do software da esfera integradora EVERFINE, para atendimento da recomendação IES TM30-18, que se ajustou à IEC 224-17, com alterações nos métodos de medições.

$\rightarrow$ As medições de índice de fidelidade e Gamut sofreram mínimas variações, situando-se dentro da sensibilidade dos equipamentos do padrão de incerteza.

$\rightarrow$ Os resultados das coordenadas de cromaticidade " $x$, y" sofreram variações pouco expressivas; observou-se que os valores das coordenadas " $x, y$ " variaram no mesmo sentido, com direção a temperatura de cor mais fria. Fato esse que era previsível.

$\rightarrow$ Durante as compilações e análises dos dados de manutenção de fluxo luminoso dos objetos de ensaios MINOTAURO FOR SDF, notou-se diferenças nas medições, e o erro foi identificado nas medições feitas em laboratório no dia 11/07/2018, considerado como período de 0 horas, e somente nestes modelos. O motivo foi o uso de difusores entre os refletores parabólicos e os módulos lineares de LED, sendo que a variação média superou 15\%. Quando da identificação desse problema, não mais foi possível realizar novos ensaios 
laboratoriais, em função dos objetos já terem depreciado por mais de 6.000 horas de operação.

$\rightarrow$ Para os todos os objetos de ensaios foram feitas inspeções visuais que revelaram algumas situações a serem observadas, tais como: oxidação nos contatos entre os trechos dos módulos lineares dos objetos de ensaios, podendo ser justificado pela condição ambiental da área de experimentação, por meio de entrada de água e/ou aerossol salino, e manchas nos difusores, por condensação de água ou umidade. Independente destes fatores, não se observou nenhuma influência negativa nos resultados dos testes;

$\rightarrow$ Inspeções visuais e fotográficas dos objetos de ensaios MINOTAURO COT SDF mostram um contorno mais escuro no chip modelo Mid-Power. Isso pode ter ocorrido em função do lead frame ter depreciado, apresentando a condição denominada "tarnish", em função de algum tipo de contaminação externa, por exemplo, enxofre, que se transforma em um óxido de cor meio marrom. Isso foi mostrado nas medições de 12.000 horas, onde temos maior queda no fluxo.

$\rightarrow$ Em função dos resultados neste estudo podemos afirmar que a vida útil projetada destes objetos de ensaios está de acordo as previsões das recomendações IES TM-21-11; TM-28-14.

$\rightarrow$ Não foi observada qualquer tipo de falha catastrófica em nenhum dos objetos de ensaios.

\subsection{Comprovação das hipóteses}

$\rightarrow$ Em relação à hipótese de que as características atmosféricas ambientais podem alterar as propriedades fotométricas e colorimétricas das luminárias LED, as alterações observadas nos objetos de ensaios não tiveram grande influência da temperatura e umidade relativa do ar, como se idealizou inicialmente.

$\rightarrow$ O uso das lentes terciárias inseridas nas luminárias LED, podem influenciar as condições térmicas em função do seu desenho e aplicação. 
$\rightarrow$ Sobre o uso da lente terciária aplicada nos objetos de ensaios, o que se percebe é que, nas condições propostas, o seu uso permitiu uma maior proteção do sistema óptico e menor variação das características colorimétricas. Mas ainda não há como afirmar essas informações, em função de serem variações mínimas, e que podem ser justificadas pelo desvio dos equipamentos de medição do laboratório.

$\rightarrow$ Os resultados apresentados dos objetos de ensaios localizados na cidade de Fortaleza/CE, não permitem afirmar que houve comprometimento no comportamento dos objetos de ensaios devido a oxidação pelo aerossol salino ou devido à umidade relativa do ar, como hipótese inicial apresentada; entretanto, para confirmação dessa informação seria necessário estender o prazo de ensaios em campo para 12.000 horas quando, provavelmente, objetos de ensaios demonstrariam uma maior depreciação do sistema óptico secundário, principalmente dos modelos com refletor e sem difusor frontal.

\subsection{Contribuição da tese}

$\rightarrow$ A intenção do trabalho foi o de permitir melhorias dos produtos ofertados pela indústria brasileira, em função de termos apresentado informações inéditas de medições por um período de 12.000 horas subdivididos em 0 hora, 2.000 horas, 6.000 horas e 12.000 horas em condições de temperatura ambiente média de $25^{\circ} \mathrm{C}$ a $31^{\circ} \mathrm{C}$, umidade relativa do ar entre 55 e $70 \%$, dentro de um padrão exequível para instalações no setor comercial. Com as informações coletadas será possível o desenvolvimento de novos produtos, ou até mesmo a requalificação dos existentes.

$\rightarrow$ Não podemos deixar de reforçar que os dados apontados neste trabalho reforçam que, sem dúvida, a tecnologia LED superou tecnicamente as lâmpadas fluorescentes tubulares T5, em eficácia, durabilidade, manutenção do fluxo e cromaticidade, como também podemos dizer o mesmo em relação às fontes tradicionais e de luz direcional, tais como as lâmpadas vapor metálico ou halógenas; 
$\rightarrow$ Os resultados deste trabalho também se destinam aos arquitetos e demais profissionais de áreas afins, que precisam aprofundar seus conhecimentos na área de iluminação. $O$ trabalho cria embasamentos técnicos para aperfeiçoamento da esfera acadêmica, contribuindo como um veículo fundamental de desenvolvimento científico e tecnológico;

$\rightarrow$ É de suma importância que a indústria discuta a possibilidade de ampliação dos testes efetuados por elas, não somente nos LEDs e módulos de LEDS, mas do conjunto como um todo, e ampliem a divulgação desses dados.

\subsection{Desdobramento desta pesquisa}

$\rightarrow$ Proposição de estudos comparando novas instalações, de preferência à beira mar e em distintas regiões do Brasil, e análise criteriosa da intensidade e direção do vento, em consequência da atmosfera marinha estar carregada com partículas de cloreto de sódio trazidas pelos ventos, e pelo fato de que a quantidade de contaminação em sal decrescer rapidamente com a distância do mar e o comportamento dos ventos.

$\rightarrow \mathrm{O}$ desenvolvimento de outras considerações não identificadas diretamente neste trabalho, por exemplo, possíveis contaminantes ambientais, tais como enxofre. 


\section{REFERÊNCIAS BIBLIOGRAFICAS}

\subsection{Bibliografias Referenciada}

- ALMECO Group- Refletores em alumínio, $<$ https://www.almecogroup.com/it/pages/375-superfici-riflettenti>.2019.

- ASSOCIAÇÃO BRASILEIRA DE NORMAS TÉCNICAS - ABNT IEC/TS 62504:2013 - Termos e definições para LED e os módulos de LED de iluminação geral. Rio de Janeiro, 2013.12p.

- ASSOCIAÇÃO BRASILEIRA DE NORMAS TÉCNICAS ABNT IEC 62031:2013 - Módulos de LED para iluminação geral-Especificações de segurança. Rio de Janeiro, 2013. 11p.

- ASSOCIAÇÃO bRASILEIRA DE NORMAS tÉCNICAS ABNT IEC/TS 62504:2013 - Termos e definições para LEDs e os módulos de LED de iluminação geral. Rio de Janeiro, 2013. 12p.

- ASSOCIAÇÃO BRASILEIRA DE NORMAS TÉCNICAS ABNT NBR IEC 627222-1:2016 - Desempenho de luminárias - Parte 2-1: Rio de Janeiro, 2016. 15p.

- ASSOCIAÇÃO BRASILEIRA DE NORMAS TÉCNICAS ABNT NBR ISO/CIE 8995-1 - Iluminação em Ambientes de Trabalho - Parte 1 :Interior, Rio de Janeiro, 2013. 46p.

- AMBRIZZI, T. O clima da Terra: Processos, Mudanças e Impacto Departamento de Ciências Atmosféricas - IAG- Universidade de São Paulo, 2016.

- AYOADE J. O. Introdução à Climatologia para os Trópicos, Editora: Bertrand Brasil, 1988.

- BARBOSA, J.L. F. Metodologia de Otimização de Lentes para Lâmpadas de LED. Dissertação em Engenharia Elétrica e de Computação pela Universidade Federal de Goiás, Goiânia, 2013. 135 f. 
- BIGONI, S. Eficiência dos Conjuntos Óticos de Alumínio Especular de Alto Desempenho energético, Dissertação apresentada à Faculdade de Arquitetura e Urbanismo da Universidade de São Paulo, 2013.

- CAMARGO, R. Introdução às ciências atmosféricas - Departamento de Ciências Atmosféricas - IAG- Universidade de São Paulo, 2016.

- CIE -224-17_Color Fidelity Index Acurrate Scientific Use, 2017. 43p

- DIESEL. L.E, Climatologia e Meteorologia, Londrina. Editora Educacional. 2018

- DOE, U.S.Department of Energy, Solid-State Lighting - Sugegested Research Topics Supplement: Tecnology and Market Context, <energy.gov/eere/ssl/solidstate-lighting $>2017$.

- ELETROBRÁS/PROCEL. Pesquisa de Posse de Equipamentos de Hábitos de Uso - Ano Base 2005, Brasil, 2008.

- FACUldade de filosofia, letras e CIÊNCIAS humANAS Departamento de Geográfia, < https://goo.gl/kMdCkk>. Acesso 15/01/2015 2017.

- FORNARO. A. Introdução à Química Atmosférica - Disciplina ACA0410 apresentada para o Departamento de Ciências Atmosféricas - IAGUniversidade de São Paulo, São Paulo,2017.

- IEA - International Energy Agency. Energy Effciency 2019, Rio de Janeiro,2019. $<$ https://www.iea.org/reports/energy-efficiency-2019> . Lighting sales by type in the Sustainable Development Scenario, 20102030. < https://www.iea.org/data-and-statistics/charts/lighting-sales-by-type-inthe-sustainable-development-scenario-2010-2030 > acesso 06/01/2020.

- IES LM-79-19 Electrical and Photometric Measurements of Solid-State Lighting Products;

- IES LM-80-18 - Measuring Lumen Maintenance of LED Light Source; 2018.

- IES LM-84-14 Measuring Luminous Flux and Color Maintenance of LED Lamps, Light Engines, and Luminaires.6p.

- IES TM-21-11 - Projecting Long Term Lumen Maintenance of LED Light Sources.2011. 24p. 
- IES TM-28-14 - Projecting Long-Term Luminous Flux Maintenance of LED Lamps and Luminaries.2014.13p.

- IES TM-30-18 - Method for Evaluating Light Source Color Rendition.26p.

- IFSC /USO - Prêmio Nobel de Física 2014 < https://www2.ifsc.usp.br/portalifsc/premio-nobel-de-fisica-2014> acesso 02/11/2019

- INSTITUTO NACIONAL DE METEOROLOGIA - INMET $<$ 'http://www.inmet.gov.br/portal/index.php?r=estacoes/estacoesAutomaticas, 0 7/01/2017> acesso 07/01/2017.

- ITAIM Lighting Concept - $\quad$ Catálogo Geral. $<$ https://itaimlc.com.br/pt/produtos/led-integrado/produto-minotaurome/,acesso, 15/03/2019.

- __ _ _https://itaimlc.com.br/pt/produtos/led-integrado/produto-orbi-tr$\mathrm{m} />$,acesso, 15/03/2019.

- ___ _ _https://itaimlc.com.br/pt/produtos/led-integrado/produto-2003led/>,acesso, 15/03/2019.

- _ _ <https://itaimlc.com.br/pt/produtos/led-integrado/produto-2005-re-led/>, acesso, 15/03/2019.

- IWASHITA, Juliana. Eficiência Energética em Sistemas de lluminação de Interiores: Análise de Luminárias Comerciais. Dissertação apresentada à Escola Politécnica da Universidade de São Paulo, 2004.

- IWAHITA, J; SCOPACASA, V. Workshop Desenvolvimento de Produtos Led, São Paulo, 2018.

- IWAHITA, J; Um novo método para análise da reprodução da cor, Edição 116, São Paulo, 2015. < https://www.osetoreletrico.com.br/um-novo-metodo-paraanalise-da-reproducao-de-cor/>. Acesso 23/01/2018.

- JACOB. E. Workshop LEDs - Lucchi, São Paulo, 2008.

- JAGLBAUER, V. Contribuição a Melhoria das Condições Ambientes Através do Aprimoramento da lluminação em Galpões e Pátios Cobertos na Industria Mineral. Dissertação apresentada para Escola Politécnica da Universidade de São Paulo, 2007.

- KAISER, W. Lâmpadas e Conversores Eletrônicos. Disciplina PEA5704 apresentada na Escola Politécnica da Universidade de São Paulo, 2011. 
- KRAFTMAKHER, Y. Nobel Prize for Blue Leds. European Journal of Physics, 2015. 36p.

- KHATOD. Optical Solutions for LED Lighting Components. $<$ https://www.khatod.com/product_list.php?ApplicationPrg=3\&lang=EN\&AserP $\mathrm{rg}=1035$ \&lang=EN $>$ acesso 03/11/2019

- LAMBERTS, R.; DUTRA, L.; PEREIRA, F.O.R. Eficiência Energética na Arquitetura. 1.ed, São Paulo, Editora PW Editores,1997. p.74/82/171.

- LARSON, S. GaN on GaN - Uma tecnologia LED inovadora. Curso: SOR2 Soraa, 2015.

- LUCCHI, Trilhos Eletrificados Trifásicos ONETRACK $<$ http://www.lucchi.com.br/trilhos-eletrificados/trilho-eletrificado-trifasicoonetrack-c-6-condutores-2-metros-versao-de-sobrepor>, acesso 20/02/2020. 2020.

- MEHL, E.L.M - Conceitos Fundamentais sobre Placas de Circuito Impresso, Universidade Federal do Paraná, 2011< http://www.eletrica.ufpr.br/mehl/te232/textos/PCl_Conceitos_fundamentais.pdf $>$ acesso 02/11/2019.

- MELLO, H. Dispositivos semicondutores: diodos, transistores, fotossensiveis, circuitos integrados 3. Edição - Rio de Janeiro: LTC - Livros Técnicos e Científicos, 1980

- MENDONÇA, F.; DANNI-OLIVEIRA I.M; Climatologia Noções Básicas e Climas do Brasil. Oficina de Textos, $3^{\circ}$ Edição. 2016.

- MOREIRA, B. Revista Setor Elétrico. Atitude Editorial. Edição 109, fevereiro 2015.

- MOREIRA, V.A. Iluminação Elétrica, Ed. Edgar Blucher Ltda, 1999.

- NAGY.B.V. Fotometria e Colorimetria - Disciplina PSE5936 apresentada na Universidade de São Paulo. 2016.

- NAKAMURA, S. Revista Lume Arquitetura. Editora De Maio. Edição 47, 2010. 
- NASCIMENTO, A. Análise do Uso da Tecnologia LED Aplicada à lluminação Pública. Estudo das Perspectivas de Aplicação da Cidade de São Paulo. Dissertação apresentada para Universidade Federal do ABC, 2012.

- NOGUEIRA, T. Meteorologia para Licenciatura. Disciplina apresentada no Instituto de Astronomia, Geofísica e Ciências Atmosféricas,2018.

- OHNO, Y. Color Quality Metrics and Spectral Design of SSL Sources. USA, 2018.

- OKAMOTO, J. Percepção ambiental e comportamento: visão holística da percepção ambiental na arquitetura e na comunicação. São Paulo: Instituto Presbiteriano Mackenzie, 2002. p.21.

- PHILIP, S. Strategies Unlimited, Strategies in Light, Anaheim, CA, 2017.

- PHOTOMETRIC \& OPTICAL TESTING <http://www.photometrictesting.co.uk/> acesso 03/01/2020.

- PONTE. H.A. Fundamentos da Corrosão. Disciplina: Eletroquímica Aplicada e Corrosão, TQ-417, apresentada na Universidade Federal do Paraná, 2004.

- REVISTA LUME ARQUITETURA, Shuji Nakamura, Edição 71, 2017.

- SCOPACASA.V. Entendendo os Leds. O Setor Elétrico. São Paulo, Capítulo III, Edição 122, 4p, 2016.

- G_ Gerenciamento Térmico dos Leds. O Setor Elétrico. São Paulo, Capítulo V, Edição 124, 4p, 2016.

- L Leds evolução e inovação. O Setor Elétrico. São Paulo, Capítulo VI, Edição 125, 4p, 2016.

. Gerenciamento Térmico - Conclusão. O Setor Elétrico. São Paulo, Capítulo VII, Edição 126, 4p, 2016. . Gerenciamento Térmico - Conclusão. O Setor Elétrico. São Paulo, Capítulo VII, Edição 126, 4p, 2016.

- Consistência de cor nos Leds branco. O Setor Elétrico. São Paulo, Capítulo XI, Edição 130, 4p, 2016.

- _ Entendendo a IESNA LM-80-08 e TM-21-11. O Setor Elétrico. São Paulo, Capítulo XII, Edição 131, 4p, 2016.

- SCOPACASA, V. Tecnologia Led, São Paulo, 2017. 
- SCOPACASA, V. IESNA TM30-15 e CIE 224:2017 - Qualidade e reprodução de cor, 2019.

- IWAHITA, J; SCOPACASA, V. Workshop Desenvolvimento de Produtos Led, São Paulo, 2018.

- SOARES FILHO, R. B. Resposta humana à luz: alterações não visuais e o projeto luminotécnico residencial com LED, Universidade de São Paulo, 2018.

- VIANELlO, R. L.; ALVES, A. R. Meteorologia básica e aplicações. $2^{\mathrm{a}}$ ed. Viçosa: Ed. UFV, 2012. 460 p.

- VIEIRA, M.S.F. Compostos nitrogenados na atmosfera de São Paulo: aspectos ambientais e termodinâmicos. Tese apresentada no Instituto de Astronomia, Geofísica e Ciências Atmosféricas, 2015.

- YNOUE.R.Y.et al. Meteorologia Noções Básicas Oficina de Textos, 2017. 


\subsection{Bibliografias Consultada}

- ABNT IEC/TS 62504:2013 - Termos e definições para LEDs e os módulos de LED de iluminação geral. 12p.

- ABNT IEC 62031:2013 - Módulos de LED para iluminação geralEspecificações de segurança. 11p.

- ABNT NBR IEC 62722-2-1:2016 - Desempenho de luminárias - Parte 2-1: Requisitos particulares para luminárias LED.15p.

- ABNT NBR 14155/2010- Alumínio e suas ligas - Tratamento de superfície ASTM D2247- 2 - Standard Practice for Testing Water Resistance of Coatings in $100 \%$ Relative Humidity

- CELERA - https://www.led-professional.com/technology/thermalmanagement/get-your-thermals-sorted, acesso 06/11/2019.

- DIN 5031-1- Optical radiation physics and illuminating engineering; quantities, symbols and units of radiation physics;

- DIN 5031-2 - Optical radiation physics and illuminating engineering; evaluation of radiation by different detectors;

- DIN 5031-3 - Optical radiation physics and illuminating engineering; quantities; DIN 5036-3 - Radiometric and photometric properties of materials; methods of measurement for photometric and spectral radiometric characteristics;

- GHISI E.; PESSOA J.L.N. Relatório Técnico: Eficiência luminosa de produto LED Encontrados no Mercado Brasileiro. CB3E - Centro Brasileiro de Eficiência Energética em Edificações. Universidade Federal de Santa Catarina. Florianópolis, 2014.

- GALVANI, E. Departamento de Geografia FLG 0253 - Climatologia I Laboratório de Climatologia e Biogeografia - LCB- Universidade de São Paulo.

- IES. Illuminating Engineering Society of North America. IES Lighting Handbook -References and Applications, 10th Edition, New York, IESNA, 2011. 37.24p.

- IEA - International Energy Agency, 2020. <https://www.iea.org>

- KAISER, W. Lâmpadas e Conversores Eletronicos. Disciplina PEA5704 apresentada na Escola Politécnica da Universidade de São Paulo, 2011. 
- MORASSI, O.J. Workshop Polímeros, termoplásticos, termo fixos e elastômeros<

https://www.crq4.org.br/sms/files/file/apostila_pol\%C3\%ADmeros_091008201 3_site.pdf> São Paulo, 2013, acesso 03/11/2019.

- MOREIRA, Vinícius de Araújo. Iluminação Elétrica, Ed. Edgar Blucher Ltda, 1999, p.25/31/46/97.

- PINTO, Rinaldo Caldeira- Goniofotômetro e determinação de fluxo luminoso, aula 5- Curso de fotometria On-line LUMIERE/IEE, 2004.

- PINTO, Rinaldo Caldeira- Fotometria de luminárias para interiores, aula 6Curso de fotometria On-line LUMIERE/IEE, 2004.

- PINTO, Rinaldo Caldeira- Curva de luminância e fotometrias de luminárias para interiores, aula 7- Curso de fotometria On-line LUMIERE/IEE, 2004.

- VIANNA, S.Nelson; GONÇALVES, Joana Carla. Iluminação e Arquitetura, $3^{a}$. ed. São Paulo, Editora Geros s/c Ltda,200.

- PHILIPS, Manual de Iluminação- Centro de Projetos e Engenharia de Iluminação da Philips Lighting Divison em Eindhoven, Holanda, 1986. Pag.67/72/74.

- RAMANATHAN, L. V., Corrosão e seu Controle. Editora Lemus, 1990.

- SATO, C.M. Eficiência em tecnologias de iluminação artificial: o LED e a tecnologia fluorescente. Tese de doutorado apresentada à Faculdade de Arquitetura e Urbanismo da Universidade de São Paulo, 2018

- STEINKE, E.T. Climatologia Fácil. São Paulo. Oficina de Textos,2012. 


\section{ANEXO 1}

$\rightarrow$ Medições e variações dos objetos de ensaios MINOTAURO e ORBI nas cidades de Cotia/SP e Fortaleza/CE.

- Localidade: Cotia/SP

1) Medições e variações - Fluxo Luminoso (Im) - MINOTAURO COT CDF E SDF

\begin{tabular}{|c|c|c|c|c|c|c|c|}
\hline \multicolumn{8}{|c|}{ MINOTAURO COTIA CDF VARIAÇÕES FLUXO LUMINOSO } \\
\hline Parâmetro & $\begin{array}{l}\text { Medidas Iniciais } \\
\text { (Ohs) }\end{array}$ & $\begin{array}{c}\text { Medição } \\
(2.000 \mathrm{hs})\end{array}$ & $\begin{array}{l}\text { Variaçãa \% após } \\
(2.000 \mathrm{hs})\end{array}$ & $\begin{array}{l}\text { Medição } \\
\text { (6.000hs) }\end{array}$ & $\begin{array}{c}\text { Variação \% } \\
\text { após } \\
(6.000 \mathrm{hs})\end{array}$ & $\begin{array}{l}\text { Medição } \\
\text { (12.000hs) }\end{array}$ & $\begin{array}{l}\text { Variação \% após } \\
\text { (12.000 hs) }\end{array}$ \\
\hline CDF COT 001 & 3128,9 & 3106,8 & $-0,71$ & 3090 & $-1,24$ & 2881 & $-7,92$ \\
\hline CDF COT 002 & 3144,1 & 3172,3 & 0,90 & 3122,3 & $-0,69$ & 2926 & $-6,94$ \\
\hline CDF COT 003 & 3050,1 & 3028,8 & $-0,70$ & 2995,3 & $-1,80$ & 2828 & $-7,28$ \\
\hline \multirow[t]{2}{*}{ CDF COT 004} & 3161,9 & 3092,1 & $-2,21$ & 3057,3 & $-3,31$ & 2891 & $-8,57$ \\
\hline & \multicolumn{3}{|c|}{ Média - 2.000 horas } & Média - 6.000 horas & $-1,76$ & Média - 12.000 horas & $-7,68$ \\
\hline \multicolumn{8}{|c|}{ MINOTAURO COTIA SDF VARIAÇÕES FLUXO LUMINOSO } \\
\hline Parâmetro & $\begin{array}{c}\text { Medidas Iniciais } \\
\text { (Ohs) }\end{array}$ & $\begin{array}{c}\text { Medição } \\
(2.000 \text { hs })\end{array}$ & $\begin{array}{l}\text { Variaçãa \% após } \\
(2.000 \mathrm{hs})\end{array}$ & $\begin{array}{l}\text { Medição } \\
\text { (6.000hs) }\end{array}$ & $\begin{array}{l}\text { Variação \% } \\
\text { após } \\
(6.000 \mathrm{hs})\end{array}$ & $\begin{array}{c}\text { Medição } \\
\text { (12.000hs) }\end{array}$ & $\begin{array}{l}\text { Variação \% após } \\
\text { (12.000 hs) }\end{array}$ \\
\hline SDF COT 001 & 2972,7 & 3042,1 & 2,33 & 2981,5 & 0,30 & 2778 & $-6,55$ \\
\hline SDF COT 002 & 3049,4 & 3106,7 & 1,88 & 3022,4 & $-0,89$ & 2827 & $-7,29$ \\
\hline SDF COT 003 & 2988,9 & 3076,3 & 2,92 & 3020,4 & 1,05 & 2822 & $-5,58$ \\
\hline SDF COT 004 & 3026,8 & 3061,7 & 1,15 & 3012,2 & $-0,48$ & 2806 & $-7,29$ \\
\hline & & Média - 2.000 horas & 2,07 & Média - 6.000 horas & $-0,004$ & Média - 12.000 horas & $-6,680$ \\
\hline
\end{tabular}

Fonte: a autora,2020.

\section{2) Medições e variações - Potência total (W) - MINOTAURO COT CDF E SDF}

\begin{tabular}{|c|c|c|c|c|c|c|c|}
\hline Parâmetro & $\begin{array}{l}\text { Medidas Iniciais } \\
\text { (Ohs) }\end{array}$ & $\begin{array}{l}\text { Medição } \\
\text { (2.000 hs) }\end{array}$ & $\begin{array}{c}\text { Variação \% } \\
\text { após } \\
(2.000 \mathrm{hs})\end{array}$ & $\begin{array}{l}\text { Medição } \\
\text { (6.0oOhs) }\end{array}$ & $\begin{array}{c}\text { Variação \% } \\
\text { após } \\
(6.000 \mathrm{hs})\end{array}$ & $\begin{array}{l}\text { Medição } \\
\text { (12.00Ohs) }\end{array}$ & $\begin{array}{c}\text { Variação } 9 \\
\text { após } \\
(12.000 \mathrm{hs} \\
\end{array}$ \\
\hline CDF COT 001 & 32,2 & 32,33 & 0,40 & 32,23 & 0,09 & 32,32 & 0,37 \\
\hline CDF COT 002 & 32,4 & 32,7 & 0,93 & 32,53 & 0,40 & 32,55 & 0,46 \\
\hline CDF COT 003 & 32,3 & 32,56 & 0,80 & 32,45 & 0,46 & 32,45 & 0,46 \\
\hline \multirow[t]{2}{*}{ CDF COT 004} & 32,4 & 32,4 & 0,00 & 32,36 & $-0,12$ & 32,51 & 0,34 \\
\hline & & Média - 2.000 horas & 0,534 & Média - 6.000 horas & 0,21 & Média - 12.000 horas & 0,41 \\
\hline \multicolumn{8}{|c|}{ MINOTAURO COTIA SDF VARIAÇŌES POTÊNCIA TOTAL } \\
\hline Parâmetro & $\begin{array}{l}\text { Medidas Iniciais } \\
\text { (Ohs) }\end{array}$ & $\begin{array}{l}\text { Medição } \\
\text { (2.000 hs) }\end{array}$ & $\begin{array}{c}\text { Variação \% } \\
\text { após } \\
(2.000 \mathrm{hs})\end{array}$ & $\begin{array}{l}\text { Medição } \\
\text { (6.000hs) }\end{array}$ & $\begin{array}{c}\text { Variação \% } \\
\text { após } \\
(6.000 \mathrm{hs})\end{array}$ & $\begin{array}{c}\text { Medição } \\
\text { (12.0oOhs) }\end{array}$ & $\begin{array}{c}\text { Variação } 9 \\
\text { após } \\
(12.000 \mathrm{hs}\end{array}$ \\
\hline SDF COT 001 & 32,4 & 32,81 & 1,27 & 32,49 & 0,28 & 32,44 & 0,12 \\
\hline SDF COT 002 & 32,4 & 32,56 & 0,49 & 62,57 & 93,12 & 32,44 & 0,12 \\
\hline SDF COT 003 & 32,4 & 32,58 & 0,56 & 32,5 & 0,31 & 32,43 & 0,09 \\
\hline SDF COT 004 & 32,4 & 32,62 & 0,68 & 32,41 & 0,03 & 32,43 & 0,09 \\
\hline
\end{tabular}

Fonte: a autora,2020. 


\section{3) Medições e variações - Eficácia (Im/W) - MINOTAURO COT CDF E SDF}

\begin{tabular}{|c|c|c|c|c|c|c|c|}
\hline LUMINÁRIA & $\begin{array}{l}\text { Medidas Iniciais } \\
\text { (Ohs) }\end{array}$ & $\begin{array}{c}\text { Medição } \\
(2.000 \mathrm{hs})\end{array}$ & $\begin{array}{c}\text { Variação \% } \\
\text { após } \\
\text { (2000 hs) }\end{array}$ & $\begin{array}{l}\text { Medição } \\
\text { (6.00ohs) }\end{array}$ & $\begin{array}{c}\text { Variação \% } \\
\text { após } \\
\text { (6000 hs) }\end{array}$ & $\begin{array}{l}\text { Medição } \\
\text { (12.00Ohs) }\end{array}$ & $\begin{array}{c}\text { Variação \% } \\
\text { após } \\
(12000 \text { hs })\end{array}$ \\
\hline CDF COT 001 & 97,14 & 95,87 & $-1,31$ & 93,86 & $-3,38$ & 89,15 & $-8,23$ \\
\hline CDF COT 002 & 96,82 & 96,67 & $-0,15$ & 95,97 & $-0,88$ & 89,88 & $-7,17$ \\
\hline CDF COT 003 & 94,29 & 93,01 & $-1,36$ & 92,3 & $-2,11$ & 87,13 & $-7,59$ \\
\hline CDF COT 004 & 98,16 & 95,52 & $-2,69$ & 94,47 & $-3,76$ & 88,93 & $-9,40$ \\
\hline & & Média - 2.000 horas & $-1,377$ & Média - 6.000 haras & $-2,53$ & Média - 12.000 haras & $-8,10$ \\
\hline \multicolumn{8}{|c|}{ MINOTAURO COTIA SDF VARIAÇÕES DE EFICÁCIA } \\
\hline LUMINÁRIA & $\begin{array}{l}\text { Medidas Iniciais } \\
\text { (Ohs) }\end{array}$ & $\begin{array}{l}\text { Medição } \\
\text { (2.000 hs) }\end{array}$ & $\begin{array}{c}\text { Variação \% } \\
\text { após } \\
\text { (2000 hs) }\end{array}$ & $\begin{array}{l}\text { Medição } \\
\text { (6.000hs) }\end{array}$ & $\begin{array}{c}\text { Variação \% } \\
\text { após } \\
\text { (G000 hs) }\end{array}$ & $\begin{array}{l}\text { Medição } \\
\text { (12.00ohs) }\end{array}$ & $\begin{array}{c}\text { Variação \% } \\
\text { após } \\
(12000 \text { hs })\end{array}$ \\
\hline SDF COT 001 & 91,72 & 91,75 & 0,03 & 91,75 & 0,03 & 85,63 & $-6,64$ \\
\hline SDF COT 002 & 94,2 & 95,41 & 1,28 & 92,81 & $-1,48$ & 87,14 & $-7,49$ \\
\hline SDF COT O03 & 92,09 & 94,42 & 2,53 & 92,95 & 0,93 & 87 & $-5,53$ \\
\hline SDF COT OO4 & 93,25 & 93,87 & 0,66 & 92,95 & $-0,32$ & 86,5 & $-7,24$ \\
\hline
\end{tabular}

Fonte: a autora,2020.

4) Medições e variações - TCC (K) - MINOTAURO COT CDF E SDF

\begin{tabular}{|c|c|c|c|c|c|c|c|}
\hline \multicolumn{8}{|c|}{ MINOTAURO COTIA CDF VARIAÇÕES TCC } \\
\hline LUMINÁRIA & $\begin{array}{l}\text { Medidas Iniciais } \\
\text { (Ohs) }\end{array}$ & $\begin{array}{l}\text { Medição } \\
\text { (2.000 hs) }\end{array}$ & $\begin{array}{c}\text { Variação \% } \\
\text { após } \\
(2000 \text { hs }) \\
\end{array}$ & $\begin{array}{l}\text { Medição } \\
\text { (6.000hs) }\end{array}$ & $\begin{array}{l}\text { Variação \% } \\
\text { após } \\
\text { (6000 hs) }\end{array}$ & $\begin{array}{l}\text { Medição } \\
\text { (12.000hs) }\end{array}$ & $\begin{array}{c}\text { Variação \% } \\
\text { após } \\
(12000 \text { hs })\end{array}$ \\
\hline CDF COT 001 & 4021 & 4041 & 0,50 & 4033 & 0,30 & 4109 & 2,19 \\
\hline CDF COT 002 & 4035 & 4046 & 0,27 & 4041 & 0,15 & 4141 & 2,63 \\
\hline CDF COT 003 & 4024 & 4041 & 0,42 & 4038 & 0,35 & 4134 & 2,73 \\
\hline CDF COT 004 & 4010 & 4028 & 0,45 & 4024 & 0,35 & 4127 & 2,92 \\
\hline & & Média - 2.000 horas & 0,410 & Média - 6.000 horas & 0,29 & Média - 12.000 horas & 2,62 \\
\hline \multicolumn{8}{|c|}{ MINOTAURO COTIA SDF VARIAÇÕES TCC } \\
\hline LUMINÁRIA & $\begin{array}{l}\text { Medidas Iniciais } \\
\text { (Ohs) }\end{array}$ & $\begin{array}{l}\text { Medição } \\
\text { (2.000 hs) }\end{array}$ & $\begin{array}{c}\text { Variação \% } \\
\text { após } \\
(2000 \mathrm{hs}) \\
\end{array}$ & $\begin{array}{l}\text { Medição } \\
\text { (6.00Ohs) }\end{array}$ & $\begin{array}{l}\text { Variação \% } \\
\text { após } \\
\text { (6000 hs) }\end{array}$ & $\begin{array}{l}\text { Medição } \\
\text { (12.000hs) }\end{array}$ & $\begin{array}{l}\text { Variação \% } \\
\text { após } \\
(12000 \text { hs) }\end{array}$ \\
\hline SDF COT 001 & 4038 & 4035 & $-0,07$ & 4055 & 0,42 & 4166 & 3,17 \\
\hline SDF COT 002 & 4035 & 4031 & $-0,10$ & 4055 & 0,50 & 4149 & 2,83 \\
\hline SDF COT 003 & 4065 & 4058 & $-0,17$ & 4078 & 0,32 & 4166 & 2,48 \\
\hline SDF COT 004 & 4041 & 4038 & $-0,07$ & 4062 & 0,52 & 4156 & 2,85 \\
\hline & & Média - 2.000 horas & $-0,10$ & Média -6.000 horas & 0,439 & Média - 12.000 horas & 2,831 \\
\hline
\end{tabular}

Fonte: a autora,2020.

5) Medições e variações - IRC - MINOTAURO COT CDF E SDF

\begin{tabular}{|c|c|c|c|c|c|c|c|}
\hline \multicolumn{8}{|c|}{ MINOTAURO COTIA CDF IRC } \\
\hline Parâmetro & $\begin{array}{c}\text { Medidas Iniciais } \\
\text { (Ohs) }\end{array}$ & $\begin{array}{l}\text { Mediçãå } \\
\text { (2.00o hs) }\end{array}$ & $\begin{array}{c}\text { Variação \% } \\
\text { após } \\
(2.000 \text { hs })\end{array}$ & $\begin{array}{l}\text { Medição } \\
\text { (6.0oohs) }\end{array}$ & $\begin{array}{c}\text { Variação \% } \\
\text { após } \\
(6.000 \text { hs) }\end{array}$ & $\begin{array}{l}\text { Medição } \\
\text { (12.000hs) }\end{array}$ & $\begin{array}{c}\text { Variação } \\
\text { após } \\
(12.000 \mathrm{~h}\end{array}$ \\
\hline CDF COT 001 & 76,1 & 76 & $-0,13$ & 76 & $-0,13$ & 76,1 & 0,00 \\
\hline CDF COT 002 & 76,2 & 75,8 & $-0,52$ & 75,9 & $-0,39$ & 76,1 & $-0,13$ \\
\hline CDF COT 003 & 76,2 & 75,9 & $-0,39$ & 75,9 & $-0,39$ & 76,1 & $-0,13$ \\
\hline CDF COT 004 & 76 & 75,8 & $-0,26$ & 75,9 & $-0,13$ & 76 & 0,00 \\
\hline & & Média - 2.000 horas & $-0,328$ & Média- 6.000 horas & $-0,26$ & Média - 12.000 horas & $-0,07$ \\
\hline \multicolumn{8}{|c|}{ MINOTAURO COTIA SDF IRC } \\
\hline Parâmetro & $\begin{array}{c}\text { Medidas Iniciais } \\
\text { (Ohs) }\end{array}$ & $\begin{array}{c}\text { Medição } \\
\text { (2.00o hs) }\end{array}$ & $\begin{array}{c}\text { Variação \% } \\
\text { após } \\
(2.000 \mathrm{hs})\end{array}$ & $\begin{array}{l}\text { Medição } \\
\text { (6.0oohs) }\end{array}$ & $\begin{array}{c}\text { Variação \% } \\
\text { após } \\
\text { (6.000 hs) }\end{array}$ & $\begin{array}{c}\text { Medição } \\
\text { (12.000hs) }\end{array}$ & $\begin{array}{c}\text { Variação } \\
\text { após } \\
(12.000 \mathrm{~h}\end{array}$ \\
\hline SDF COT 001 & 76,5 & 76 & $-0,65$ & 76,1 & $-0,52$ & 76,7 & 0,26 \\
\hline SDF COT 002 & 76,4 & 75,9 & $-0,65$ & 76,1 & $-0,39$ & 76,4 & 0,00 \\
\hline SDF COT 003 & 76,7 & 76,1 & $-0,78$ & 76,3 & $-0,52$ & 76,7 & 0,00 \\
\hline SDF COT 004 & 76,6 & 76 & $-0,78$ & 76,4 & $-0,26$ & 76,7 & 0,13 \\
\hline & & Média - 2.000 horas & $-0,72$ & Média - 6.000 horas & $-0,425$ & Média - 12.000 horas & 0,098 \\
\hline
\end{tabular}

Fonte: a autora,2020. 


\section{6) Medições e variações - Ra - MINOTAURO COT CDF E SDF}

\begin{tabular}{|c|c|c|c|c|c|c|c|}
\hline \multicolumn{8}{|c|}{ MINOTAURO COTIA CDF VARIAÇÕES Ra } \\
\hline Parâmetro & $\begin{array}{l}\text { Medidas Iniciais } \\
\text { (Ohs) }\end{array}$ & $\begin{array}{l}\text { Medição } \\
(2.000 \mathrm{hs})\end{array}$ & $\begin{array}{c}\text { Variação \% } \\
\text { após } \\
(2.000 \mathrm{hs})\end{array}$ & $\begin{array}{l}\text { Medição } \\
\text { (6.000hs) }\end{array}$ & $\begin{array}{l}\text { Variação \% } \\
\text { após } \\
\text { (6.000 hs) }\end{array}$ & $\begin{array}{c}\text { Medição } \\
\text { (12.000hs) }\end{array}$ & $\begin{array}{c}\text { Variação \% } \\
\text { após } \\
(12.000 \text { hs) }\end{array}$ \\
\hline CDF COT OO1 & 82,9 & 82,7 & $-0,24$ & 82,8 & $-0,12$ & 82,8 & $-0,12$ \\
\hline CDF COT 002 & 82,9 & 82,7 & $-0,24$ & 82,8 & $-0,12$ & 82,9 & 0,00 \\
\hline CDF COT 003 & 82,9 & 82,7 & $-0,24$ & 82,8 & $-0,12$ & 82,9 & 0,00 \\
\hline CDF COT 004 & 82,7 & 82,6 & $-0,12$ & 82,7 & 0,00 & 82,8 & 0,12 \\
\hline & & Média - 2.000 horas & $-0,211$ & Média - 6.000 haras & $-0,09$ & Média -12.000 horas & 0,00 \\
\hline \multicolumn{8}{|c|}{ MINOTAURO COTIA SDF VARIAÇÕES Ra } \\
\hline Parâmetro & $\begin{array}{l}\text { Medidas Iniciais } \\
\text { (Ohs) }\end{array}$ & $\begin{array}{l}\text { Medição } \\
\text { (2.000 hs) }\end{array}$ & $\begin{array}{c}\text { Variação \% } \\
\text { após } \\
(2.000 \mathrm{hs})\end{array}$ & $\begin{array}{l}\text { Medição } \\
\text { (6.000hs) }\end{array}$ & $\begin{array}{l}\text { Variação \% } \\
\text { após } \\
\text { (6.000 hs) }\end{array}$ & $\begin{array}{c}\text { Medição } \\
\text { (12.000hs) }\end{array}$ & $\begin{array}{c}\text { Variação \% } \\
\text { após } \\
(12.000 \mathrm{hs})\end{array}$ \\
\hline SDF COT 001 & 83 & 83 & 0,00 & 82,9 & $-0,12$ & 83,3 & 0,36 \\
\hline SDF COT 002 & 83 & 82,6 & $-0,48$ & 82,9 & $-0,12$ & 83,1 & 0,12 \\
\hline SDF COT 003 & 83,2 & 82,8 & $-0,48$ & 83 & $-0,24$ & 83,2 & 0,00 \\
\hline SDF COT 004 & 83,1 & 82,8 & $-0,36$ & 83 & $-0,12$ & 83,2 & 0,12 \\
\hline & & Média -2.000 horas & $-0,33$ & Média - 6.000 horas & $-0,150$ & Média - 12.000 & 0,151 \\
\hline
\end{tabular}

Fonte: a autora,2020.

\section{7) Medições e variações - Coordenada de cromaticidade " $x, y$, - MINOTAURO COT CDF}

\begin{tabular}{|c|c|c|c|c|c|c|c|}
\hline \multicolumn{8}{|c|}{ MINOTAURO CDF VARIAÇÕES CC "X" } \\
\hline LUMINÁRIA & $\begin{array}{l}\text { Medidas Iniciais } \\
\text { (Ohs) }\end{array}$ & $\begin{array}{c}\text { Medição } \\
\text { (2.000 hs) }\end{array}$ & $\begin{array}{l}\text { Variação \% } \\
\text { após } \\
(2.000 \mathrm{hs})\end{array}$ & $\begin{array}{l}\text { Medição } \\
\text { (6.000hs) }\end{array}$ & $\begin{array}{l}\text { Variação \% } \\
\text { após } \\
\text { (6.000 hs) }\end{array}$ & $\begin{array}{c}\text { Medição } \\
\text { (12.00Ohs) }\end{array}$ & $\begin{array}{c}\text { Variação \% } \\
\text { após } \\
(12.000 \mathrm{hs})\end{array}$ \\
\hline CDF COT 001 & 0,3807 & 0,38 & $-0,18$ & 0,3802 & $-0,13$ & 0,3762 & $-1,18$ \\
\hline CDF COT 002 & 0,38 & 0,3799 & $-0,03$ & 0,3799 & $-0,03$ & 0,3751 & $-1,29$ \\
\hline CDF COT 003 & 0,3803 & 0,3799 & $-0,11$ & 0,3798 & $-0,13$ & 0,3753 & $-1,31$ \\
\hline \multirow[t]{2}{*}{ CDF COT 004} & 0,3813 & 0,3807 & $-0,16$ & 0,3806 & 0,38 & 0,3761 & $-1,36$ \\
\hline & & Média - 2.000 horas & $-0,118$ & Média - 6.000 horas & 0,02 & Média - 12.000 horas & $-1,29$ \\
\hline \multicolumn{8}{|c|}{ MINOTAURO CDF VARIAÇÕES CC "Y" } \\
\hline LUMINÁRIA & $\begin{array}{l}\text { Medidas Iniciais } \\
\text { (Ohs) }\end{array}$ & $\begin{array}{c}\text { Medição } \\
\text { (2.000 hs) }\end{array}$ & $\begin{array}{c}\text { Variação \% } \\
\text { após } \\
(2.000 \mathrm{hs})\end{array}$ & $\begin{array}{l}\text { Medição } \\
\text { (6.000hs) }\end{array}$ & $\begin{array}{l}\text { Variação \% } \\
\text { após } \\
\text { (6.000 hs) }\end{array}$ & $\begin{array}{c}\text { Medição } \\
\text { (12.00Ohs) }\end{array}$ & $\begin{array}{c}\text { Variação \% } \\
\text { após } \\
(12.000 \mathrm{hs})\end{array}$ \\
\hline CDF COT 001 & 0,3806 & 0,381 & 0,11 & 0,3803 & $-0,08$ & 0,3758 & $-1,26$ \\
\hline CDF COT 002 & 0,3797 & 0,3811 & 0,37 & 0,3802 & 0,13 & 0,3758 & $-1,03$ \\
\hline CDF COT 003 & 0,3795 & 0,3805 & 0,26 & 0,3795 & 0,00 & 0,3756 & $-1,03$ \\
\hline CDF COT 004 & 0,3816 & 0,3818 & 0,05 & 0,3809 & $-0,18$ & 0,3775 & $-1,07$ \\
\hline & & Média - 2.000 horas & 0,20 & Média - 6.000 horas & $-0,033$ & Média - 12.000 horas & $-1,098$ \\
\hline
\end{tabular}

Fonte: a autora,2020.

\section{8) Medições e variações - Coordenada de cromaticidade " $x$, y" - MINOTAURO COT SDF}

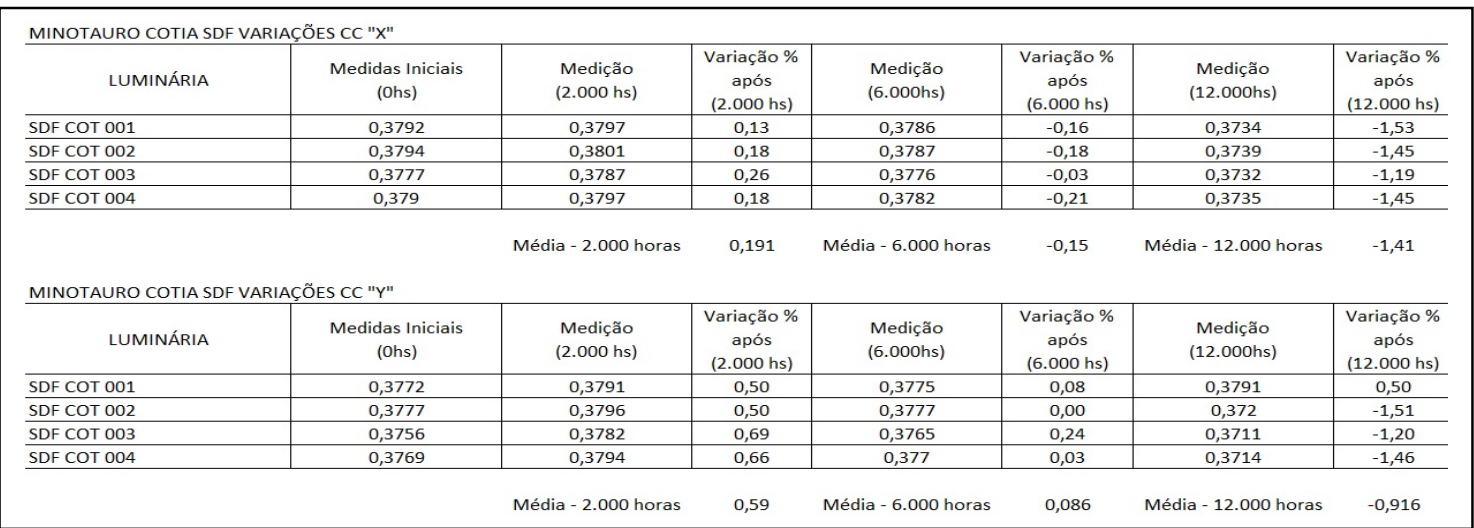

Fonte: a autora,2020. 
9) Medições e variações - Índice de fidelidade (Rf) e índice Gamut (Rg)MINOTAURO COT CDF

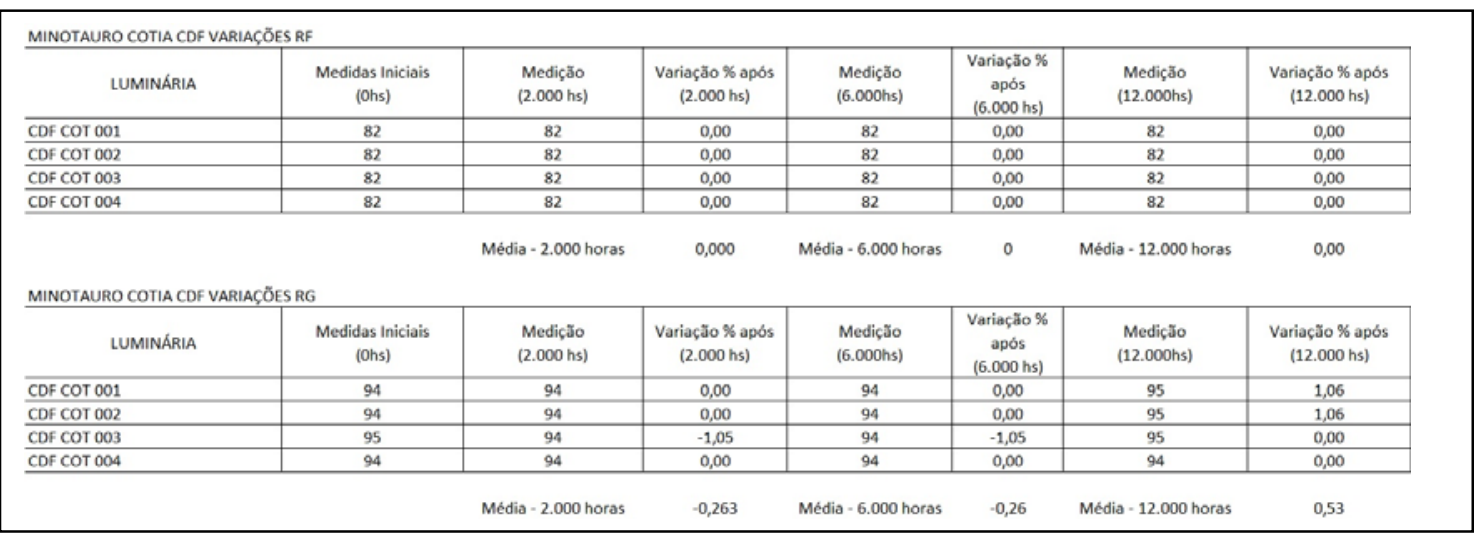

Fonte: a autora,2020.

10)Medições e variações - Índice de fidelidade (Rf) e Índice de Gamut (Rg) MINOTAURO COT SDF.

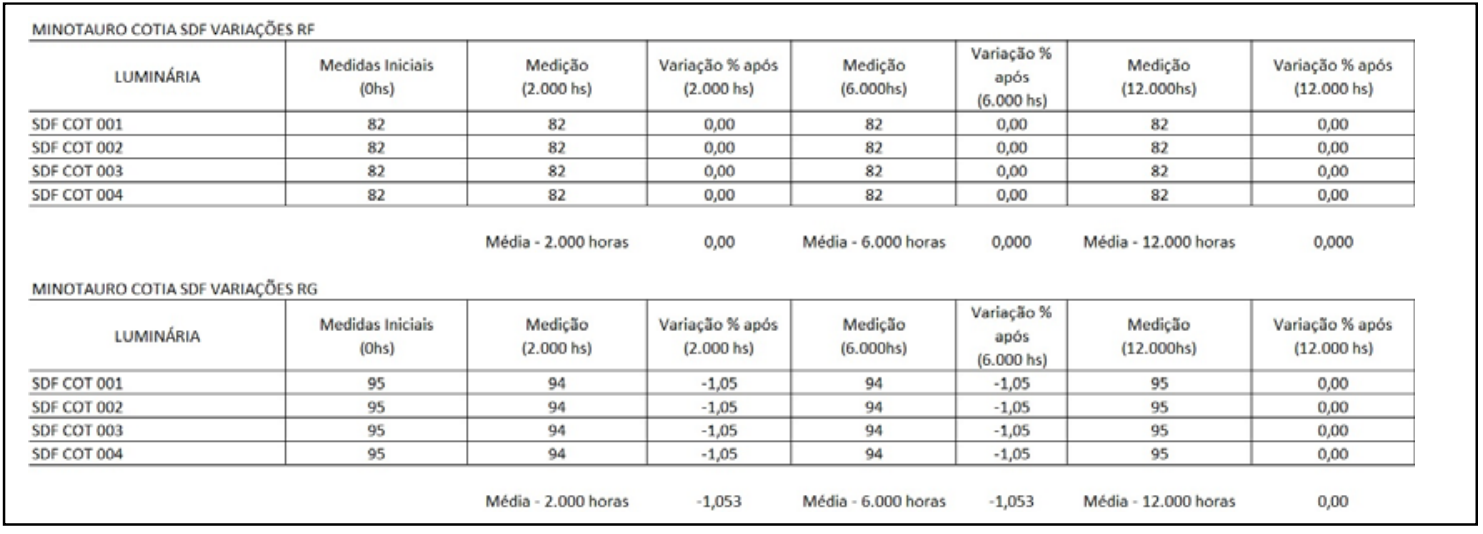

Fonte: a autora,2020.

11)Medições e variações - Fluxo Luminoso (Im) - ORBI COT CDF E SDF

\begin{tabular}{|c|c|c|c|c|c|c|c|}
\hline LUMINÁRIA & Medidas Iniciais (Ohs) & Medição (2.000 hs) & Variação(\%) & Medição (6.000hs) & Variação(\%) & Medição (12.000hs) & Variação(\%) \\
\hline CDF COT 001 & 1313,5 & 1227,7 & $-6,53$ & 1221,9 & $-6,97$ & 1243 & $-5,37$ \\
\hline CDF COT 002 & 1346,4 & 1265,3 & $-6,02$ & 1257,3 & $-6,62$ & 1287 & $-4,41$ \\
\hline CDF COT 003 & 1389,2 & 1300,4 & $-6,39$ & 1286,9 & $-7,36$ & 1347 & $-3,04$ \\
\hline \multirow[t]{2}{*}{ CDF COT 004} & 1292,1 & 1222,8 & $-5,36$ & 1214 & $-6,04$ & 1238 & $-4,19$ \\
\hline & & Média - 2.000 horas & $-6,08$ & Média - 6.000 horas & $-6,75$ & Média - 12.000 horas & $-4,25$ \\
\hline \multicolumn{8}{|c|}{ ORBI COTIASDF VARIAÇÕES FLUXO LUMINOSO } \\
\hline LUMINÁRIA & Medidas Iniciais (Ohs) & Medição (2.000 hs) & Variação(\%) & Medição (6.000hs) & Variação(\%) & Medição (12.000hs) & Variação(\%) \\
\hline SDF COT 001 & 1699,2 & 1643,5 & $-3,28$ & 1623,8 & $-4,44$ & 1683 & $-0,95$ \\
\hline SDF COT 002 & 1782,3 & 1673,8 & $-6,09$ & 1687,0 & $-5,35$ & 1683 & $-5,57$ \\
\hline SDF COT 003 & 1744,9 & 1659,7 & $-4,88$ & 1646,4 & $-5,65$ & 1698 & $-2,69$ \\
\hline SDF COT 004 & 1743,7 & 1653,1 & $-5,20$ & 1647,4 & $-5,52$ & 1710 & $-1,93$ \\
\hline
\end{tabular}

Fonte: a autora,2020. 
12)Medições e variações - Potência total (W) - ORBI COT CDF E SDF

\begin{tabular}{|c|c|c|c|c|c|c|c|}
\hline \multicolumn{8}{|c|}{ ORBI CDF MEDIÇÕES POTÊNCIA TOTAL } \\
\hline LUMINÁRIA & $\begin{array}{l}\text { Medidas Iniciais } \\
\text { (Ohs) }\end{array}$ & $\begin{array}{c}\text { Medição } \\
\text { (2.000 hs) }\end{array}$ & $\begin{array}{l}\text { Variação \% } \\
\text { após } \\
(2.000 \text { hs) }\end{array}$ & $\begin{array}{l}\text { Medição } \\
\text { (6.000hs) }\end{array}$ & $\begin{array}{c}\text { Variação \% } \\
\text { após } \\
(6.000 \mathrm{hs})\end{array}$ & $\begin{array}{c}\text { Medição } \\
\text { (12.00Ohs) }\end{array}$ & $\begin{array}{c}\text { Variação \% } \\
\text { após } \\
(12.000 \mathrm{hs})\end{array}$ \\
\hline CDF COT 001 & 19,1 & 19,3 & 1,05 & 18,91 & $-0,99$ & 19,01 & $-0,47$ \\
\hline CDF COT 002 & 19,4 & 19,28 & $-0,62$ & 19,29 & $-0,57$ & 19,34 & $-0,31$ \\
\hline CDF COT 003 & 19,4 & 19,28 & $-0,62$ & 19,17 & $-1,19$ & 19,42 & 0,10 \\
\hline CDF COT 004 & 19,18 & 19,09 & $-0,47$ & 18,99 & $-0,99$ & 19,12 & $-0,31$ \\
\hline \multirow{2}{*}{\multicolumn{8}{|c|}{ ORBI SDF MEDIÇÕES POTÊNCIA TOTAL }} \\
\hline & & & & & & & \\
\hline LUMINÁRIA & $\begin{array}{l}\text { Medidas Iniciais } \\
\text { (Ohs) }\end{array}$ & $\begin{array}{c}\text { Medição } \\
\text { (2.000 hs) }\end{array}$ & $\begin{array}{c}\text { Variação \% } \\
\text { após } \\
(2.000 \mathrm{hs})\end{array}$ & $\begin{array}{l}\text { Medição } \\
\text { (6.00Ohs) }\end{array}$ & $\begin{array}{c}\text { Variação \% } \\
\text { após } \\
\text { (6.000 hs) }\end{array}$ & $\begin{array}{c}\text { Medição } \\
\text { (12.00Ohs) }\end{array}$ & $\begin{array}{c}\text { Variação \% } \\
\text { após } \\
(12.000 \text { hs })\end{array}$ \\
\hline SDF COT 001 & 19 & 18,87 & $-0,68$ & 18,85 & $-0,79$ & 19,05 & 0,26 \\
\hline SDF COT 002 & 21,06 & 21,01 & $-0,24$ & 20,91 & $-0,71$ & 20,72 & $-1,61$ \\
\hline SDF COT 003 & 19,91 & 19,98 & 0,35 & 19,93 & 0,10 & 19,79 & $-0,60$ \\
\hline SDF COT 004 & 19,4 & 19,3 & $-0,52$ & 19,2 & $-1,03$ & 19,53 & 0,67 \\
\hline & & Média - 2.000 horas & $-0,27$ & Média - 6.000 horas & $-0,608$ & Média - 12.000 horas & $-0,321$ \\
\hline
\end{tabular}

Fonte: a autora,2020.

\section{3)Medições e variações - Eficácia (Im/W) - ORBI COT CDF E SDF.}

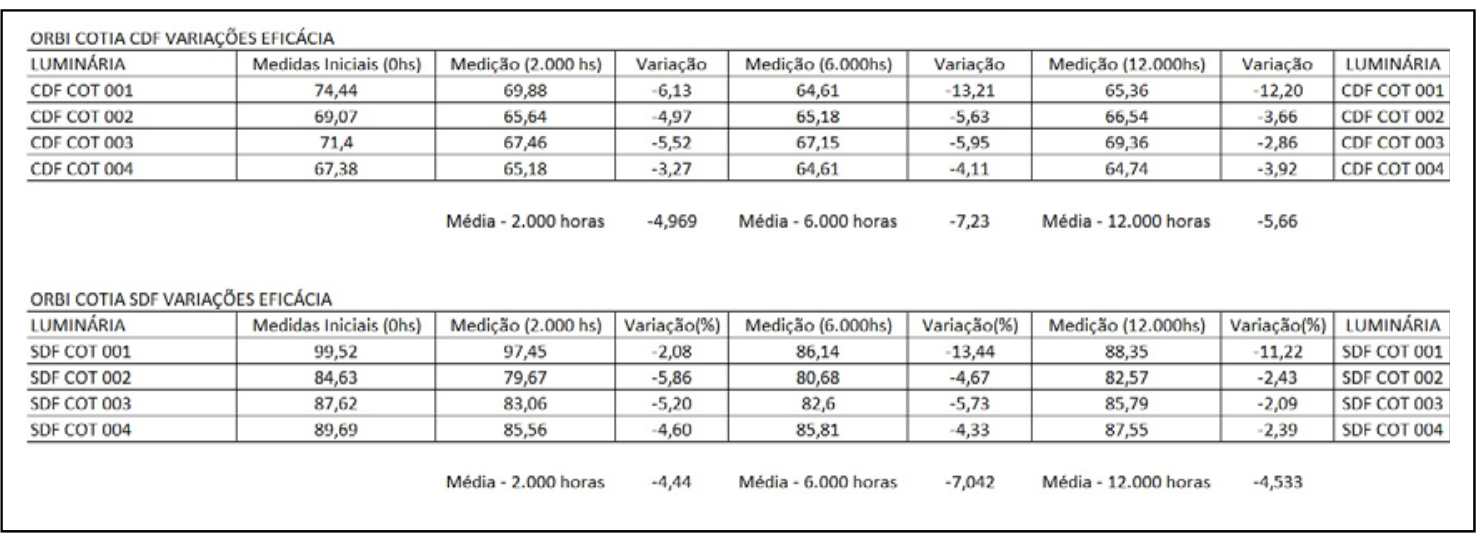

Fonte: a autora,2020.

\section{4)Medições e variações - TCC (K) - ORBI COT CDF E SDF}

\begin{tabular}{|c|c|c|c|c|c|c|c|}
\hline \multicolumn{8}{|c|}{ ORBI CDF VARIAÇÕES TCC } \\
\hline LUMINÁRIA & $\begin{array}{l}\text { Medidas Iniciais } \\
\text { (Ohs) }\end{array}$ & $\begin{array}{c}\text { Medição } \\
\text { (2.000 hs) }\end{array}$ & $\begin{array}{c}\text { Variação \% } \\
\text { após } \\
(2.000 \mathrm{hs})\end{array}$ & $\begin{array}{l}\text { Medição } \\
\text { (6.00Ohs) }\end{array}$ & $\begin{array}{c}\text { Variação \% } \\
\text { após } \\
(6.000 \mathrm{hs})\end{array}$ & $\begin{array}{c}\text { Medição } \\
\text { (12.00Ohs) }\end{array}$ & \begin{tabular}{|c} 
Variação \% \\
após \\
$(12.000 \mathrm{hs})$
\end{tabular} \\
\hline CDF COT 001 & 2973 & 2989 & 0,54 & 2959 & $-0,47$ & 3024 & 1,72 \\
\hline CDF COT 002 & 2969 & 2983 & 0,47 & 2959 & $-0,34$ & 3016 & 1,58 \\
\hline CDF COT 003 & 2979 & 2989 & 0,34 & 2964 & $-0,50$ & 3024 & 1,51 \\
\hline \multirow[t]{2}{*}{ CDF COT 004} & 2964 & 2981 & 0,57 & 2972 & 0,27 & 3023 & 1,99 \\
\hline & & Média - 2.000 horas & 0,480 & Média - 6.000 horas & $-0,26$ & Média - 12.000 horas & 1,70 \\
\hline \multicolumn{8}{|c|}{ ORBI SDF VARIAÇÕES TCC } \\
\hline LUMINÁRIA & $\begin{array}{l}\text { Medidas Iniciais } \\
\text { (Ohs) }\end{array}$ & $\begin{array}{c}\text { Medição } \\
\text { (2.000 hs) }\end{array}$ & $\begin{array}{c}\text { Variação \% } \\
\text { após } \\
(2.000 \text { hs) }\end{array}$ & $\begin{array}{l}\text { Medição } \\
\text { (6.00Ohs) }\end{array}$ & $\begin{array}{c}\text { Variação \% } \\
\text { após } \\
(6.000 \text { hs) }\end{array}$ & $\begin{array}{c}\text { Medição } \\
\text { (12.00Ohs) }\end{array}$ & $\begin{array}{c}\text { Variação \% } \\
\text { após } \\
(12.000 \mathrm{hs})\end{array}$ \\
\hline SDF COT 001 & 3004 & 3027 & 0,77 & 3017 & 0,43 & 3078 & 2,46 \\
\hline SDF COT 002 & 2998 & 3021 & 0,77 & 3009 & 0,37 & 3073 & 2,50 \\
\hline SDF COT 003 & 2999 & 3023 & 0,80 & 3008 & 0,30 & 3073 & 2,47 \\
\hline SDF COT 004 & 3009 & 3039 & 1,00 & 3020 & 0,37 & 3089 & 2,66 \\
\hline & & Média - 2.000 horas & 0,83 & Média - 6.000 horas & 0,366 & Média - 12.000 horas & 2,523 \\
\hline
\end{tabular}

Fonte: a autora,2020. 
15)Medições e variações - IRC - ORBI COT CDF E SDF

\begin{tabular}{|c|c|c|c|c|c|c|c|}
\hline \multicolumn{8}{|c|}{ ORBI COTIA CDF VARIAÇÕES IRC } \\
\hline LUMINÁRIA & Medidas Iniciais (Ohs) & Medição $(2.000 \mathrm{hs})$ & Variação & Medição (6.000hs) & Variação & Medição (12.000hs) & Variação \\
\hline CDF COT 001 & 77 & 76,8 & $-0,26$ & 76,2 & $-1,04$ & 76 & $-1,30$ \\
\hline CDF COT 002 & 77,3 & 77,1 & $-0,26$ & 76,5 & $-1,03$ & 76,3 & $-1,29$ \\
\hline CDF COT 003 & 77,1 & 76,9 & $-0,26$ & 76,3 & $-1,04$ & 76,1 & $-1,30$ \\
\hline \multirow[t]{3}{*}{ CDF COT 004} & 76,9 & 76,7 & $-0,26$ & 76,2 & $-0,91$ & 76 & $-1,17$ \\
\hline & & Média - 2.000 horas & $-0,259$ & Média - 6.000 horas & $-1,01$ & Média - 12.000 horas & $-1,26$ \\
\hline & & & & & & & \\
\hline \multicolumn{8}{|c|}{ ORBI COTIA SDF VARIAÇÕES IRC } \\
\hline LUMINÁRIA & Medidas Iniciais (Ohs) & Medição (2.000 hs) & Variação(\%) & Medição (6.000hs) & Variação(\%) & Medição (12.000hs) & Variação(\%) \\
\hline SDF COT 001 & 77,9 & 78 & 0,13 & 77,6 & $-0,39$ & 77,5 & $-0,51$ \\
\hline SDF COT 002 & 77,7 & 77,7 & 0,00 & 77,4 & $-0,39$ & 77,4 & $-0,39$ \\
\hline SDF COT 003 & 77,8 & 77,7 & $-0,13$ & 77,3 & $-0,64$ & 77,2 & $-0,77$ \\
\hline \multirow[t]{2}{*}{ SDF COT 004} & 78,4 & 78,4 & 0,00 & 78 & $-0,51$ & 78 & $-0,51$ \\
\hline & & Média -2.000 horas & 0,00 & Média -6.000 horas & $-0,481$ & Média - 12.000 horas & $-0,545$ \\
\hline
\end{tabular}

Fonte: a autora,2020.

16)Medições e variações - Ra - ORBI COT CDF E SDF

\begin{tabular}{|c|c|c|c|c|c|c|c|}
\hline \multicolumn{8}{|c|}{ ORBI COTIA CDF } \\
\hline LUMINÁRIA & Medidas Iniciais (Ohs) & Medição $(2.000$ hs) & Variação & Medição (6.000hs) & Variação & Medição (12.000hs) & Variação \\
\hline CDF COT 001 & 82,4 & 82,2 & $-0,24$ & 81,9 & $-0,61$ & 81,8 & $-0,73$ \\
\hline CDF COT 002 & 82,5 & 82,4 & $-0,12$ & 82,1 & $-0,48$ & 82 & $-0,61$ \\
\hline CDF COT 003 & 82,4 & 82,3 & $-0,12$ & 81,9 & $-0,61$ & 81,9 & $-0,61$ \\
\hline \multirow[t]{2}{*}{ CDF COT 004} & 82,2 & 82,1 & $-0,12$ & 81,9 & $-0,36$ & 81,8 & $-0,49$ \\
\hline & & Média - 2.000 horas & $-0,152$ & Média -6.000 horas & $-0,52$ & Média - 12.000 horas & $-0,61$ \\
\hline \multicolumn{8}{|c|}{ ORBI COTIA SDF VARIAÇÕES RA } \\
\hline LUMINÁRIA & Medidas Iniciais (Ohs) & Medição $(2.000$ hs) & Variação(\%) & Medição (6.000hs) & Variação(\%) & Medição (12.000hs) & Variação(\%) \\
\hline SDF COT 001 & 82,9 & 83 & 0,12 & 82,9 & 0,00 & 82,9 & 0,00 \\
\hline SDF COT 002 & 82,8 & 82,8 & 0,00 & 82,8 & 0,00 & 82,8 & 0,00 \\
\hline SDF COT 003 & 82,9 & 82,9 & 0,00 & 82,7 & $-0,24$ & 82,6 & $-0,36$ \\
\hline SDF COT 004 & 83,3 & 83,3 & 0,00 & 83,2 & $-0,12$ & 83,3 & 0,00 \\
\hline & & Média - 2.000 horas & 0,03 & Média - 6.000 horas & $-0,090$ & Média - 12.000 horas & $-0,090$ \\
\hline
\end{tabular}

Fonte: a autora,2020.

17)Medições e variações - Coordenada de cromaticidade " $x$, $y$ " - ORBI COT CDF

\begin{tabular}{|c|c|c|c|c|c|c|c|}
\hline \multicolumn{8}{|c|}{ ORBI COTIA CDF VARIAÇÕES CC "X" } \\
\hline LUMINÁRIA & Medidas Iniciais (Ohs) & Medição (2.000 hs) & Variação & Medição (6.000hs) & Variação & Medição (12.000hs) & Variação \\
\hline CDF COT 001 & 0,4375 & 0,4363 & $-0,27$ & 0,4387 & 0,27 & 0,4344 & $-0,71$ \\
\hline CDF COT 002 & 0,4369 & 0,4359 & $-0,23$ & 0,4379 & 0,23 & 0,4344 & $-0,57$ \\
\hline CDF COT 003 & 0,4369 & 0,436 & $-0,21$ & 0,4381 & 0,27 & 0,4345 & $-0,55$ \\
\hline \multirow[t]{2}{*}{ CDF COT 004} & 0,4376 & 0,4364 & $-0,27$ & 0,4374 & $-0,05$ & 0,434 & $-0,82$ \\
\hline & & Média - 2.000 horas & $-0,246$ & Média -6.000 horas & 0,18 & Média - 12.000 horas & $-0,66$ \\
\hline \multicolumn{8}{|c|}{ ORBI COTIA CDF VARIAÇ̃̃ES CC "Y" } \\
\hline LUMINÁRIA & Medidas Iniciais (Ohs) & Medição (2.000 hs) & Variação(\%) & Medição (6.000hs) & Variação(\%) & Medição (12.000hs) & Variação(\%) \\
\hline CDF COT 001 & 0,4019 & 0,4015 & $-0,10$ & 0,4026 & 0,17 & 0,4018 & $-0,02$ \\
\hline CDF COT 002 & 0,4003 & 0,3998 & $-0,12$ & 0,4011 & 0,20 & 0,4007 & 0,10 \\
\hline CDF COT 003 & 0,4014 & 0,4009 & $-0,12$ & 0,4021 & 0,17 & 0,402 & 0,15 \\
\hline \multirow{2}{*}{ CDF COT 004} & 0,4011 & 0,4006 & $-0,12$ & 0,4015 & 0,10 & 0,4007 & $-0,10$ \\
\hline & & Média - 2.000 horas & $-0,12$ & Média -6.000 horas & 0,162 & Média - 12.000 horas & 0,031 \\
\hline
\end{tabular}

Fonte: a autora,2020. 
18)Medições e variações - Coordenada de cromaticidade " $x$, " $y$ " - ORBI COT SDF

\begin{tabular}{|c|c|c|c|c|c|c|c|}
\hline \multicolumn{8}{|c|}{ ORBI COTIA SDF VARIAÇÕES CC " $X "$} \\
\hline LUMINÁRIA & Medidas Iniciais (Ohs) & Medição (2.000 hs) & Variação & Medição (6.000hs) & Variação & Medição (12.000hs) & Variação \\
\hline SDF COT 001 & 0,4337 & 0,4323 & $-0,32$ & 0,433 & $-0,16$ & 0,4288 & $-1,13$ \\
\hline SDF COT 002 & 0,4349 & 0,4331 & $-0,41$ & 0,4341 & $-0,18$ & 0,4294 & $-1,26$ \\
\hline SDF COT 003 & 0,4349 & 0,4332 & $-0,39$ & 0,4342 & $-0,16$ & 0,4296 & $-1,22$ \\
\hline SDF COT 004 & 0,4338 & 0,4318 & $-0,46$ & 0,4331 & $-0,16$ & 0,4284 & $-1,24$ \\
\hline & & Média - 2.000 horas & $-0,397$ & Média - 6.000 horas & $-0,17$ & Média - 12.000 horas & $-1,21$ \\
\hline \multicolumn{8}{|c|}{ ORBI COTIA SDF VARIAÇÕES CC "Y" } \\
\hline LUMINÁRIA & Medidas Iniciais (Ohs) & Medição (2.000 hs) & Variação(\%) & Medição (6.000hs) & Variação(\%) & Medição (12.000hs) & Variação(\%) \\
\hline SDF COT 001 & 0,3979 & 0,3976 & $-0,08$ & 0,3979 & 0,00 & 0,3964 & $-0,38$ \\
\hline SDF COT 002 & 0,3996 & 0,3987 & $-0,23$ & 0,3992 & $-0,10$ & 0,397 & $-0,65$ \\
\hline SDF COT 003 & 0,3996 & 0,3991 & $-0,13$ & 0,3993 & $-0,08$ & 0,3974 & $-0,55$ \\
\hline \multirow[t]{2}{*}{ SDF COT 004} & 0,3987 & 0,3981 & $-0,15$ & 0,3985 & $-0,05$ & 0,3968 & $-0,48$ \\
\hline & & Média -2.000 horas & $-0,14$ & Média -6.000 horas & $-0,056$ & Média - 12.000 horas & $-0,514$ \\
\hline
\end{tabular}

Fonte: a autora,2020.

19)Medições e variações - Índice de fidelidade (Rf) e índice Gamut (Rg) - ORBI COT CDF.

\begin{tabular}{|c|c|c|c|c|c|c|c|}
\hline \multicolumn{8}{|c|}{ ORBI COTIA CDF VARIAÇỐES RF } \\
\hline LUMINÁRIA & Medidas Iniciais (Ohs) & Mediç̧̋。 (2.000 hs) & Variação & Mediçăo (6.000hs) & Variaçă。 & Mediçăo (12.000hs) & Variaçăo \\
\hline CDF COT 001 & 81 & 81 & 0,00 & 81 & 0,00 & 83 & 2,47 \\
\hline CDF COT 002 & 81 & 81 & 0,00 & 81 & 0,00 & 83 & 2,47 \\
\hline CDF COT 003 & 81 & 81 & 0,00 & 81 & 0,00 & 83 & 2,47 \\
\hline CDF COT 004 & 81 & 81 & 0,00 & 81 & 0,00 & 83 & 2,47 \\
\hline & & Média -2.000 horas & 0,000 & Média -6.000 horas & 0 & Média - 12.000 horas & 2,47 \\
\hline \multicolumn{8}{|c|}{ ORBI COTIA CDF VARIAÇŌES RG } \\
\hline LUMINÁRIA & Medidas Iniciais (Ohs) & Mediçăo (2.000 hs) & Variaçăo & Medição (6.000hs) & Variação & Medição (12.000hs) & Variaçăo \\
\hline CDF COT 001 & 97 & 97 & 0,00 & 97 & 0,00 & 96 & $-1,03$ \\
\hline CDF COT 002 & 97 & 97 & 0,00 & 97 & 0,00 & 97 & 0,00 \\
\hline CDF COT 003 & 97 & 97 & 0,00 & 96 & $-1,03$ & 96 & $-1,03$ \\
\hline \multirow[t]{2}{*}{ CDF COT 004} & 97 & 97 & 0,00 & 96 & $-1,03$ & 96 & $-1,03$ \\
\hline & & Média - 2.000 horas & 0,000 & Média - 6.000 horas & $-0,515463918$ & Média - 12.000 horas & $-0,77$ \\
\hline
\end{tabular}

Fonte: a autora,2020.

\section{0)Medições e variações - Índice de fidelidade (Rf) e Índice de Gamut (Rg) - ORBI COT SDF.}

\begin{tabular}{|c|c|c|c|c|c|c|c|}
\hline LUMINÁRIA & Medidas Iniciais (Ohs) & Mediçă (2.000 hs) & Variaçăo & Mediçåo (6.000hs) & Variaçă。 & Mediçăo (12.000hs) & Variaçăo \\
\hline SDF COT 001 & 82 & 82 & 0,00 & 82 & 0,00 & 84 & 2,44 \\
\hline SDF COT 002 & 82 & 82 & 0,00 & 82 & 0,00 & 84 & 2,44 \\
\hline SDF COT 003 & 82 & 82 & 0,00 & 82 & 0,00 & 84 & 2,44 \\
\hline \multirow[t]{2}{*}{ SDF COT 004} & 82 & 82 & 0,00 & 82 & 0,00 & 84 & 2,44 \\
\hline & & Média -2.000 horas & 0,00 & Média -6.000 horas & 0,000 & Média - 12.000 horas & 2,439 \\
\hline \multicolumn{8}{|c|}{ ORBI COTIA SDF VARIAÇŐES RG } \\
\hline LUMINÁRIA & Medidas Iniciais (Ohs) & Mediçăo (2.000 hs) & Variação & Medição (6.000hs) & Variação & Mediçăo (12.000hs) & Variação \\
\hline SDF COT 001 & 97 & 97 & 0,00 & 97 & 0,00 & 97 & 0,00 \\
\hline SDF COT 002 & 96 & 96 & 0,00 & 96 & 0,00 & 96 & 0,00 \\
\hline SDF COT 003 & 96 & 96 & 0,00 & 96 & 0,00 & 96 & 0,00 \\
\hline SDF COT 004 & 96 & 96 & 0,00 & 96 & 0,00 & 96 & 0,00 \\
\hline
\end{tabular}




\section{- Localidade Fortaleza/CE}

21)Medições e variações - Fluxo Luminoso (Im) - MINOTAURO FOR CDF E SDF

\begin{tabular}{|c|c|c|c|}
\hline LUMINÁRIA & $\begin{array}{c}\text { Medidas Iniciais } \\
\text { (Ohs) }\end{array}$ & $\begin{array}{l}\text { Medição } \\
(6.000 \text { hs) }\end{array}$ & $\begin{array}{c}\text { Variação \% após } \\
\text { (6.000 hs) }\end{array}$ \\
\hline CDF FOR 001 & 3091 & 3116 & 0,81 \\
\hline CDF FOR 002 & 3198 & 3357 & 4,97 \\
\hline CDF FOR 003 & 3189 & 3112 & $-2,41$ \\
\hline CDF FOR 004 & 3147 & 3128 & $-0,60$ \\
\hline
\end{tabular}

MINOTAURO SDF FORT VARIAÇÕES FLUXO LUMINOSO

\begin{tabular}{|c|c|c|c|}
\hline LUMINÁRIA & $\begin{array}{c}\text { Medidas Iniciais } \\
\text { (Ohs) }\end{array}$ & $\begin{array}{c}\text { Medição } \\
(6.000 \mathrm{hs})\end{array}$ & $\begin{array}{c}\text { Variação \% após } \\
(6.000 \text { hs })\end{array}$ \\
\hline SDF FOR O01 & 2897 & 3325 & 14,77 \\
\hline SDF FOR O02 & 2840 & 3255 & 14,61 \\
\hline SDF FOR O03 & 2847 & 3318 & 16,54 \\
\hline SDF FOR 004 & 2836 & 3321 & 17,10 \\
\hline
\end{tabular}

Média -6.000 horas

15,758

Fonte: a autora,2020.

22)Medições e variações - Potência total (W) - MINOTAURO FOR CDF E SDF

\begin{tabular}{l|c|c|c|}
\hline MINOTAURO CDF VARIAÇÖES POTÊNCIA TOTAL \\
\hline $\begin{array}{c}\text { LUMINÁRIA } \\
\text { CDEdidas Iniciais } \\
\text { (Ohs) }\end{array}$ & $\begin{array}{c}\text { Mediçåo } \\
(6.000 \mathrm{hs})\end{array}$ & $\begin{array}{c}\text { Variação } \% \\
\text { após } \\
(6.000 \mathrm{hs})\end{array}$ \\
\hline CDFFOR OO1 & 32,78 & 32,7 & $-0,24$ \\
\hline CDFFOR OO2 & 32,16 & 31,97 & $-0,59$ \\
\hline CDF FOR OO4 & 32,46 & 32,5 & 0,12 \\
\hline
\end{tabular}

Média -6.000 horas $\quad-0,06$

\begin{tabular}{l|c|c|c|} 
MINOTAURO SDF VARIAÇÕES POTÊNCIA TOTAL \\
\hline LUMINÁRIA & $\begin{array}{c}\text { Medidas Iniciais } \\
\text { (Ohs) }\end{array}$ & $\begin{array}{c}\text { Mediçå } \\
(6.000 \mathrm{hs})\end{array}$ & $\begin{array}{c}\text { Variação } \% \\
\text { após } \\
(6.000 \mathrm{hs})\end{array}$ \\
\hline SDF FOR OO1 & 32,4 & 32,28 & $-0,37$ \\
\hline SDF FOR OO2 & 30,69 & 30,81 & 0,39 \\
\hline SDF FOR O03 & 31,26 & 31,33 & 0,22 \\
\hline SDF FOR O04 & 31,14 & 31,12 & $-0,06$ \\
\hline
\end{tabular}

Média - 6.000 horas 0,045

Fonte: a autora,2020.

23)Medições e variações - Eficácia (Im/W) - MINOTAURO FOR CDF E SDF

\begin{tabular}{l|c|c|c|}
\hline MINOTAURO CDF VARIAÇÕES DE EFICÁCIA \\
\hline LUMINÁRIA & $\begin{array}{c}\text { Medidas Iniciais } \\
\text { (Ohs) }\end{array}$ & $\begin{array}{c}\text { Medição } \\
(6.000 \mathrm{hs})\end{array}$ & $\begin{array}{c}\text { Variação } \% \\
\text { após } \\
(6.000 \mathrm{hs})\end{array}$ \\
\hline CDFFOR OO1 & 95,4 & 96,54 & 1,19 \\
\hline CDFFOR OO2 & 104,22 & 108,95 & 4,54 \\
\hline CDFFOR OO3 & 102,01 & 99,33 & $-2,63$ \\
\hline CDF FOR OO4 & 101,08 & 100,43 & $-0,64$ \\
\hline
\end{tabular}

Média- 6.000 horas $\quad 0,62$

\begin{tabular}{|c|c|c|c|}
\hline LUMINÁRIA & $\begin{array}{l}\text { Medidas Iniciais } \\
\text { (Ohs) }\end{array}$ & $\begin{array}{l}\text { Medição } \\
\text { (6.00o hs) }\end{array}$ & $\begin{array}{c}\text { Variação \% } \\
\text { após } \\
\text { (6.000 hs) }\end{array}$ \\
\hline SDF FOR 001 & 88,38 & 101,7 & 15,07 \\
\hline SDF FOR 002 & 88,31 & 101,83 & 15,31 \\
\hline SDF FOR 003 & 87,73 & 102,09 & 16,37 \\
\hline SDF FOR 004 & 87.65 & 102,14 & 16,53 \\
\hline
\end{tabular}

Média -6.000 horas

15,820 


\section{4)Medições e variações - TCC (K) - MINOTAURO FOR CDF E SDF}

\begin{tabular}{|c|c|c|c|}
\hline \multicolumn{4}{|c|}{ MINOTAURO FORTALEZA CDF VARIAÇÕES TCC } \\
\hline LUMINÁRIA & $\begin{array}{l}\text { Medidas Iniciais } \\
\text { (Ohs) }\end{array}$ & $\begin{array}{l}\text { Medição } \\
\text { (6.00o hs) }\end{array}$ & $\begin{array}{l}\text { Variação \% } \\
\text { após } \\
\text { (6.00o hs) }\end{array}$ \\
\hline CDF FOR 001 & 4031 & 4146 & 2,85 \\
\hline CDF FOR 002 & 4014 & 4163 & 3,71 \\
\hline CDF FOR OO3 & 4031 & 4161 & 3,23 \\
\hline CDF FOR 004 & 4028 & 4183 & 3,85 \\
\hline & & Média $-6.000 \mathrm{~h}$ & 3,41 \\
\hline \multicolumn{4}{|c|}{ MINOTAURO FORTALEZA SDF VARIAÇÕES TCC } \\
\hline LUMINÁRIA & $\begin{array}{l}\text { Medidas Iniciais } \\
\text { (Ohs) }\end{array}$ & $\begin{array}{l}\text { Medição } \\
\text { (6.00o hs) }\end{array}$ & $\begin{array}{c}\text { Variação \% } \\
\text { após } \\
\text { (6.00o hs) }\end{array}$ \\
\hline SDF FOR 001 & 4024 & 4152 & 3,18 \\
\hline SDF FOR 002 & 4060 & 4146 & 2,12 \\
\hline SDF FOR 003 & 3999 & 4087 & 2,20 \\
\hline SDF FOR 004 & 4038 & 4163 & 3,10 \\
\hline & & Média $-6.000 \mathrm{~h}$ & 2,649 \\
\hline
\end{tabular}

Fonte: a autora,2020.

\section{5)Medições e variações - IRC - MINOTAURO FOR CDF E SDF}

\begin{tabular}{l} 
MINOTAURO FORTALEZA CDF VARIAÇÕES IRC \\
\hline \begin{tabular}{c|c|c|c} 
LUMINÁRIA & $\begin{array}{c}\text { Medidas Iniciais } \\
\text { (Ohs) }\end{array}$ & $\begin{array}{c}\text { Medição } \\
(6.000 \mathrm{hs})\end{array}$ & $\begin{array}{c}\text { Variação } \% \\
\text { após } \\
(6.000 \mathrm{hs})\end{array}$ \\
\hline CDF FOR 001 & 75,7 & 75,2 & $-0,66$ \\
\hline CDFFOR OO2 & 75,7 & 75,3 & $-0,53$ \\
\hline CDF FOR O03 & 75,9 & 75,2 & $-0,92$ \\
\hline CDFFOR O04 & 75,9 & 75,6 & $-0,40$ \\
\hline
\end{tabular}
\end{tabular}

Média -6.000 horas $\quad-0,63$

MINOTAURO FORTALEZA SDF VARIAÇÕES IRC
\begin{tabular}{l|c|c|c|}
\hline LUMINÁRIA & $\begin{array}{c}\text { Medidas Iniciais } \\
\text { (Ohs) }\end{array}$ & $\begin{array}{c}\text { Medição } \\
\text { (6.000 hs) }\end{array}$ & $\begin{array}{c}\text { Variação } \% \\
\text { após } \\
\text { (6.0oo hs) }\end{array}$ \\
\hline SDF FOR OO1 & 76,1 & 76,6 & 0,66 \\
\hline SDFFOR OO2 & 76,2 & 76,3 & 0,13 \\
\hline SDF FOR 003 & 76,3 & 76,6 & 0,39 \\
\hline SDF FOR 004 & 76,3 & 76,7 & 0,52 \\
\hline
\end{tabular}

Média -6.000 horas $\quad 0,426$

Fonte: a autora,2020.

\section{6)Medições e variações - Ra - MINOTAURO FOR CDF E SDF}

\begin{tabular}{|c|c|c|c|}
\hline LUMINÁRIA & $\begin{array}{l}\text { Medidas Iniciais } \\
\text { (Ohs) }\end{array}$ & $\begin{array}{l}\text { Medição } \\
(6.000 \mathrm{hs})\end{array}$ & $\begin{array}{c}\text { Variação \% } \\
\text { após } \\
\text { (6.00o hs) }\end{array}$ \\
\hline CDF FOR 001 & 82,7 & 82,2 & $-0,60$ \\
\hline CDF FOR 002 & 82,7 & 82,3 & $-0,48$ \\
\hline CDF FOR 003 & 82,8 & 82,2 & $-0,72$ \\
\hline CDF FOR 004 & 82,8 & 82,5 & $-0,36$ \\
\hline
\end{tabular}

Média - 6.000 horas $\quad-0,5,4$

\begin{tabular}{|c|c|c|c|}
\hline LUMINÁRIA & $\begin{array}{c}\text { Medidas Iniciais } \\
\text { (Ohs) }\end{array}$ & $\begin{array}{l}\text { Medição } \\
\text { (6.00o hs) }\end{array}$ & $\begin{array}{c}\text { Variação \% } \\
\text { após } \\
\text { (6.000 hs) }\end{array}$ \\
\hline SDF FOR O01 & 82,9 & 83,3 & 0,48 \\
\hline SDF FOR 002 & 83 & 83 & 0,00 \\
\hline SDF FOR 003 & 83,1 & 83,2 & 0,12 \\
\hline SDF FOR OO4 & 83,1 & 83,4 & 0,36 \\
\hline
\end{tabular}

Média -6.000 horas

0,241

Fonte: a autora,2020. 
27)Medições e variações - Coordenada de cromaticidade " $x$, y" - MINOTAURO FOR CDF

\begin{tabular}{|c|c|c|c|}
\hline LUMINÁRIA & $\begin{array}{c}\text { Medidas Iniciais } \\
\text { (Ohs) }\end{array}$ & $\begin{array}{l}\text { Medição } \\
\text { (6.000 hs) }\end{array}$ & $\begin{array}{c}\text { Variação \% } \\
\text { após } \\
\text { (6.000 hs) }\end{array}$ \\
\hline CDF FOR 001 & 0,3807 & 0,3752 & $-1,44$ \\
\hline CDF FOR 002 & 0,3813 & 0,3746 & $-1,76$ \\
\hline CDF FOR 003 & 0,3804 & 0,3745 & $-1,55$ \\
\hline CDF FOR 004 & 0,3805 & 0,3752 & $-1,39$ \\
\hline
\end{tabular}

Média - 6.000 horas $\quad-1,54$

MINOTAURO FORTALEZA CDF VARIAÇÕES CC "Y"

\begin{tabular}{l|c|c|c|}
\hline LUMINÁRIA & $\begin{array}{c}\text { Medidas Iniciais } \\
\text { (Ohs) }\end{array}$ & $\begin{array}{c}\text { Medição } \\
(6.000 \mathrm{hs})\end{array}$ & $\begin{array}{c}\text { Variação \% } \\
\text { após } \\
\text { (6.000 hs) }\end{array}$ \\
\hline CDFFOR 001 & 0,3819 & 0,3767 & $-1,36$ \\
\hline CDFFOR 002 & 0,382 & 0,3767 & $-1,39$ \\
\hline CDFFOR 003 & 0,3807 & 0,376 & $-1,23$ \\
\hline CDF FOR 004 & 0,3809 & 0,3767 & $-1,10$ \\
\hline
\end{tabular}

Média - 6.000 horas

$-1,272$

Fonte: a autora,2020.

28)Medições e variações - Coordenada de cromaticidade " $x$, y" - MINOTAURO FOR SDF

\begin{tabular}{l|c|c|c|}
\multicolumn{1}{c|}{ MINOTAURO FORTALEZA SDF VARIAÇÕES CC "X" } \\
\hline LUMINARIA & $\begin{array}{c}\text { Medidas Iniciais } \\
(\text { Ohs })\end{array}$ & $\begin{array}{c}\text { Medição } \\
(6.000 \mathrm{hs})\end{array}$ & $\begin{array}{c}\text { Variação \% } \\
\text { após } \\
(6.000 \mathrm{hs})\end{array}$ \\
\hline SDF FOR O01 & 0,381 & 0,375 & $-\mathbf{1 , 5 7}$ \\
\hline SDF FOR 002 & 0,3794 & 0,3751 & $-\mathbf{1 , 1 3}$ \\
\hline SDF FOR 003 & 0,3822 & 0,3775 & $-\mathbf{1 , 2 3}$ \\
\hline SDF FOR 004 & 0,3803 & 0,3742 & $-\mathbf{1 , 6 0}$ \\
\hline
\end{tabular}

Média -6.000 horas $\quad-1,39$

MINOTAURO FORTALEZA SDF VARIAÇÕES CC "Y"

\begin{tabular}{l|c|c|c|}
\hline LUMINÁRIA & $\begin{array}{c}\text { Medidas Iniciais } \\
\text { (Ohs) }\end{array}$ & $\begin{array}{c}\text { Medição } \\
(6.000 \mathrm{hs})\end{array}$ & $\begin{array}{c}\text { Variação \% } \\
\text { após } \\
(6.000 \mathrm{hs})\end{array}$ \\
\hline SDF FOR O01 & 0,3824 & 0,3768 & $-1,46$ \\
\hline SDF FOR 002 & 0,3813 & 0,3768 & $-1,18$ \\
\hline SDF FOR 003 & 0,3833 & 0,3774 & $-1,54$ \\
\hline SDF FOR O04 & 0,3816 & 0,3753 & $-1,65$ \\
\hline
\end{tabular}

Média - 6.000 horas

$-1,459$

Fonte: a autora,2020.

29)Medições e variações - Índice de fidelidade (Rf) e índice Gamut (Rg)MINOTAURO FOR CDF

MINOTAURO FORTALEZA CDF VARIAÇÕES RF

\begin{tabular}{l|c|c|c|}
\hline LUMINÁRIA & $\begin{array}{c}\text { Medidas Iniciais } \\
\text { (Ohs) }\end{array}$ & $\begin{array}{c}\text { Medição } \\
\text { (6.000 hs) }\end{array}$ & $\begin{array}{c}\text { Variação \% } \\
\text { após } \\
(6.000 \mathrm{hs})\end{array}$ \\
\hline CDF FOR O01 & 82 & 83 & 1,22 \\
\hline CDF FOR O02 & 82 & 83 & 1,22 \\
\hline CDF FOR O03 & 82 & 83 & 1,22 \\
\hline CDF FOR O04 & 82 & 84 & 2,44 \\
\hline
\end{tabular}

Média - 6.000 horas $\quad 1,52$

MINOTAURO FORTALEZA CDF VARIAÇÕES RG

\begin{tabular}{l|c|c|c|}
\hline LUMINÁRIA & $\begin{array}{c}\text { Medidas Iniciais } \\
\text { (Ohs) }\end{array}$ & $\begin{array}{c}\text { Medição } \\
\text { (6.000 hs) }\end{array}$ & $\begin{array}{c}\text { Variação \% } \\
\text { após } \\
\text { (6.000 hs) }\end{array}$ \\
\hline CDF FOR O01 & 94 & 94 & 0,00 \\
\hline CDF FOR OO2 & 94 & 94 & 0,00 \\
\hline CDF FOR O03 & 94 & 94 & 0,00 \\
\hline CDF FOR OO4 & 94 & 95 & $\mathbf{1 , 0 6}$ \\
\hline
\end{tabular}

Média - 6.000 horas

0,27 
30)Medições e variações - Índice de fidelidade (Rf) e Índice de Gamut (Rg) MINOTAURO FOR SDF

\begin{tabular}{|c|c|c|c|}
\hline LUMINARIA & $\begin{array}{l}\text { Medidas Iniciais } \\
\text { (Ohs) }\end{array}$ & $\begin{array}{l}\text { Medição } \\
\text { (6.00o hs) }\end{array}$ & $\begin{array}{c}\text { Variação \% } \\
\text { após } \\
\text { (6.000 hs) }\end{array}$ \\
\hline SDF FOR 001 & 83 & 84 & 1,20 \\
\hline SDF FOR 002 & 82 & 84 & 2,44 \\
\hline SDF FOR 003 & 83 & 84 & 1,20 \\
\hline SDF FOR 004 & 82 & 84 & 2,44 \\
\hline
\end{tabular}

Média- 6.000 horas $\quad 1,822$

MINOTAURO FORTALEZA SDF VARIAÇÕES RG

\begin{tabular}{l|c|c|c|}
\hline LUMINÁRIA & $\begin{array}{c}\text { Medidas Iniciais } \\
\text { (Ohs) }\end{array}$ & $\begin{array}{c}\text { Medição } \\
\text { (6.000 hs) }\end{array}$ & $\begin{array}{c}\text { Variação \% } \\
\text { após } \\
\text { (6.000 hs) }\end{array}$ \\
\hline SDF FOR O01 & 94 & 94 & 0,00 \\
\hline SDFFOR O02 & 94 & 94 & 0,00 \\
\hline SDF FOR O03 & 94 & 94 & 0,00 \\
\hline SDF FOR O04 & 94 & 95 & 1,06 \\
\hline
\end{tabular}

Média - 6.000 horas

0,266

Fonte: a autora,2020.

31)Medições e variações - Fluxo Luminoso (Im) - ORBI FOR CDF E SDF

ORBI CDF FORT VARIAÇÕES FLUXO LUMINOSO

\begin{tabular}{l|c|c|c|}
\hline LUMINÁRIA & Medidas Iniciais (Ohs) & Medição (6.000hs) & Variação (\%) \\
\hline CDF FOR 001 & 1469 & 1528 & 4,02 \\
\hline CDF FOR 002 & 1383 & 1476 & 6,72 \\
\hline CDF FOR 003 & 1452 & 1501 & 3,37 \\
\hline CDF FOR 004 & 1457 & 1482 & 1,72 \\
\hline
\end{tabular}

Média - 6.000 horas $\quad 3,96$

ORBI SDF FORT VARIAÇÕES FLUXO LUMINOSO

\begin{tabular}{l|c|c|c|}
\hline LUMINÁRIA & Medidas Iniciais (Ohs) & Medição (6.000hs) & Variação(\%) \\
\hline SDF FOR 001 & 1599 & 1683 & 5,25 \\
\hline SDF FOR 002 & 1643 & 1710 & 4,08 \\
\hline SDF FOR 003 & 1682 & 1721 & 2,32 \\
\hline SDF FOR 004 & 1641 & 1703 & 3,78 \\
\hline
\end{tabular}

Média - 6.000 horas

3,857

Fonte: a autora,2020.

32)Medições e variações - Potência total (W) - ORBI FOR CDF E SDF

ORBI CDF VARIAČ̃̃ES POTÊNCIA TOTAL

\begin{tabular}{l|c|c|c|}
\hline LUMINÁRIA & Medidas Iniciais (Ohs) & Medição (6.00Ohs) & Variação \\
\hline CDF FOR OO1 & 20,05 & 19,99 & $-0,30$ \\
\hline CDF FOR OO2 & 19,6 & 19,94 & 1,73 \\
\hline CDF FOR OO3 & 19,76 & 20,05 & 1,47 \\
\hline CDF FOR OO4 & 20,09 & 19,88 & $-1,05$ \\
\hline
\end{tabular}

Média - 6.000 horas $\quad 0,46$

ORBI SDF VARIAÇÕES POTÊNCIA TOTAL

\begin{tabular}{l|c|c|c|}
\hline LUMINÁRIA & Medidas Iniciais (Ohs) & Medição (6.00Ohs) & Variação(\%) \\
\hline SDF FOR OO1 & 19,83 & 19,92 & 0,45 \\
\hline SDF FOR OO2 & 19,89 & 19,76 & $-0,65$ \\
\hline SDF FOR OO3 & 19,91 & 19,97 & 0,30 \\
\hline SDF FOR OO4 & 19,66 & 19,71 & 0,25 \\
\hline
\end{tabular}

Média - 6.000 horas

0,089 
33)Medições e variações - Eficácia (Im/W) - ORBI FOR CDF E SDF.

\begin{tabular}{|c|c|c|c|}
\hline LUMINÁRIA & Medidas Iniciais (Ohs) & Medição (6.000hs) & Variação \\
\hline CDF FOR 001 & 73,26 & 76,43 & 4,33 \\
\hline CDF FOR 002 & 70,56 & 74,02 & 4,90 \\
\hline CDF FOR 003 & 73,49 & 74,86 & 1,86 \\
\hline CDF FOR 004 & 72,5 & 74,54 & 2,81 \\
\hline
\end{tabular}

ORBI SDF VARIAÇÕES DE EFICÁCIA

\begin{tabular}{l|c|c|c|}
\hline LUMINÁRIA & Medidas Iniciais (Ohs) & Medição (6.00Ohs) & Variação(\%) \\
\hline SDF FOR OO1 & 80,64 & 84,48 & 4,76 \\
\hline SDF FOR OO2 & 82,56 & 86,54 & 4,82 \\
\hline SDF FOR OO3 & 84,52 & 86,18 & 1,96 \\
\hline SDF FOR O04 & 83,48 & 86,4 & 3,50 \\
\hline
\end{tabular}

Média -6.000 horas

3,761

Fonte: a autora,2020.

34)Medições e variações - TCC (K) - ORBI FOR CDF E SDF

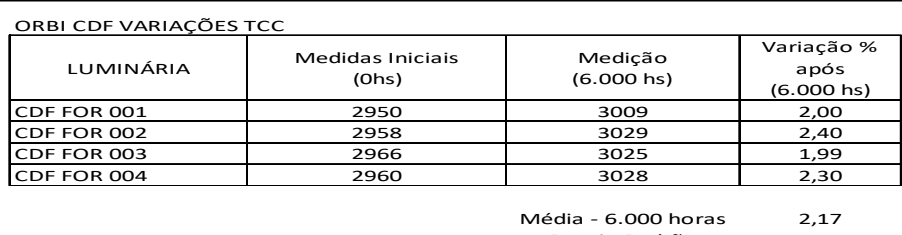

Média - 6.000 horas $\quad 2,17$ Desvio Padrão

ORBI SDF VARIAÇÕES TCC
\begin{tabular}{|l|c|c|c|}
\hline LUMINÁRIA & $\begin{array}{c}\text { Medidas Iniciais } \\
\text { (Ohs) }\end{array}$ & $\begin{array}{c}\text { Medição } \\
(6.000 \mathrm{hs})\end{array}$ & $\begin{array}{c}\text { Variação } \% \\
\text { após } \\
(6.000 \text { hs })\end{array}$ \\
\hline SDF FOR OO1 & 2984 & 3055 & 2,38 \\
\hline SDF FOR OO2 & 2973 & 3066 & 3,13 \\
\hline SDF FOR OO3 & 2998 & 3059 & 2,03 \\
\hline SDF FOR OO4 & 2986 & 3059 & 2,44 \\
\hline
\end{tabular}

Média - 6.000 horas $\quad 2,497$

Desvio Padrão

Fonte: a autora,2020.

35)Medições e variações - IRC - ORBI FOR CDF E SDF

\begin{tabular}{|c|c|c|c|}
\hline LUMINÁRIA & Medidas Iniciais (Ohs) & Medição (6.00Ohs) & Variação \\
\hline CDF FOR 001 & 76,7 & 76,4 & $-0,39$ \\
\hline CDF FOR 002 & 77,1 & 77 & $-0,13$ \\
\hline CDF FOR 003 & 76,9 & 76,7 & $-0,26$ \\
\hline CDF FOR 004 & 76,9 & 76,7 & $-0,26$ \\
\hline \multirow{2}{*}{\multicolumn{4}{|c|}{ ORBI SDF VARIAÇÕES IRC }} \\
\hline & & & \\
\hline LUMINÁRIA & Medidas Iniciais (Ohs) & Medição (6.000hs) & Variação(\%) \\
\hline SDF FOR 001 & 76,9 & 76,8 & $-0,13$ \\
\hline SDF FOR 002 & 76,9 & 77,6 & 0,91 \\
\hline SDF FOR 003 & 77,2 & 77 & $-0,26$ \\
\hline SDF FOR 004 & 77,3 & 77,1 & $-0,26$ \\
\hline
\end{tabular}

Fonte: a autora,2020. 
36)Medições e variações - Ra - ORBI COT CDF E SDF

\begin{tabular}{|c|c|c|c|}
\hline \multicolumn{4}{|c|}{ ORBI CDF VARIAÇÕES Ra } \\
\hline LUMINÁRIA & Medidas Iniciais (Ohs) & Medição (6.000hs) & Variação \\
\hline CDF COT 001 & 82,1 & 81,9 & $-0,24$ \\
\hline CDF COT 002 & 82,5 & 82,4 & $-0,12$ \\
\hline CDF COT 003 & 82,3 & 82,2 & $-0,12$ \\
\hline CDF COT 004 & 82,3 & 82,2 & $-0,12$ \\
\hline \multirow{2}{*}{\multicolumn{4}{|c|}{ Média - 6.000 horas }} \\
\hline & & & \\
\hline LUMINÁRIA & Medidas Iniciais (Ohs) & Medição (6.000hs) & Variação(\%) \\
\hline SDF COT 001 & 82,4 & 82,3 & $-0,12$ \\
\hline SDF COT 002 & 82,3 & 82,8 & 0,61 \\
\hline SDF COT 003 & 82,6 & 82,5 & $-0,12$ \\
\hline SDF COT 004 & 82,6 & 82,5 & $-0,12$ \\
\hline & & Média -6.000 horas & 0,061 \\
\hline
\end{tabular}

Fonte: a autora,2020.

\section{7)Medições e variações - Coordenada de cromaticidade " $x$, $y$ " - ORBI FOR CDF}

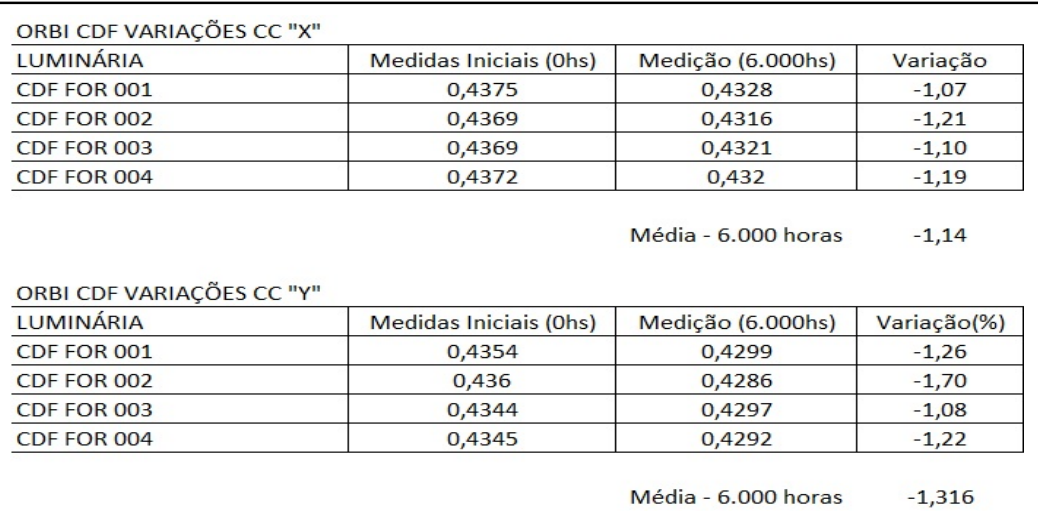

Fonte: a autora,2020.

38)Medições e variações - Coordenada de cromaticidade " $x$, y" - ORBI FOR SDF

\begin{tabular}{|c|c|c|c|}
\hline LUMINÁRIA & Medidas Iniciais (Ohs) & Medição (6.000hs) & Variação \\
\hline SDF FOR 001 & 0,4354 & 0,4299 & $-1,26$ \\
\hline SDF FOR 002 & 0,436 & 0,4286 & $-1,70$ \\
\hline SDF FOR 003 & 0,4344 & 0,4297 & $-1,08$ \\
\hline \multirow[t]{2}{*}{ SDF FOR 004} & 0,4345 & 0,4292 & $-1,22$ \\
\hline & \multicolumn{2}{|r|}{ Média - 6.000 horas } & $-1,32$ \\
\hline \multicolumn{4}{|c|}{ ORBI SDF VARIAÇÕES CC "Y" } \\
\hline LUMINÁRIA & Medidas Iniciais (Ohs) & Medição (6.000hs) & Variação(\%) \\
\hline SDF FOR 001 & 0,3999 & 0,396 & $-0,98$ \\
\hline SDF FOR 002 & 0,3989 & 0,3945 & $-1,10$ \\
\hline SDF FOR 003 & 0,3985 & 0,3961 & $-0,60$ \\
\hline SDF FOR 004 & 0,3973 & 0,3949 & $-0,60$ \\
\hline
\end{tabular}

Má́dia - a nnn harace

- $\operatorname{sen1}$

Fonte: a autora,2020. 
39)Medições e variações - Índice de fidelidade (Rf) e índice Gamut (Rg) - ORBI FOR CDF.

\begin{tabular}{|c|c|c|c|}
\hline LUMINÁRIA & Medidas Iniciais (Ohs) & Medição (6.000hs) & Variação \\
\hline CDF FOR 001 & 80 & 82 & 2,50 \\
\hline CDF FOR 002 & 81 & 83 & 2,47 \\
\hline CDF FOR 003 & 81 & 83 & 2,47 \\
\hline CDF FOR 004 & 81 & 83 & 2,47 \\
\hline & & Média -6.000 horas & 2,48 \\
\hline \multicolumn{4}{|c|}{ ORBIO CDF VARIAÇÕES RG } \\
\hline LUMINÁRIA & Medidas Iniciais (Ohs) & Medição (6.000hs) & Variação \\
\hline CDF FOR 001 & 98 & 97 & $-1,02$ \\
\hline CDF FOR 002 & 97 & 97 & 0,00 \\
\hline CDF FOR 003 & 97 & 97 & 0,00 \\
\hline CDF FOR 004 & 97 & 97 & 0,00 \\
\hline
\end{tabular}

Fonte: a autora,2020.

40)Medições e variações - Índice de fidelidade (Rf) e Índice de Gamut (Rg) - ORBI FOR SDF.

\begin{tabular}{|c|c|c|c|}
\hline LUMINÁRIA & Medidas Iniciais (Ohs) & Medição (6.000hs) & Variação \\
\hline SDF FOR 001 & 81 & 83 & 2,47 \\
\hline SDF FOR 002 & 81 & 84 & 3,70 \\
\hline SDF FOR 003 & 81 & 83 & 2,47 \\
\hline \multirow[t]{2}{*}{ SDF FOR 004} & 81 & 83 & 2,47 \\
\hline & \multicolumn{2}{|r|}{ Média - 6.000 horas } & 2,778 \\
\hline \multicolumn{4}{|c|}{ ORBI SDF VARIAÇÕES RG } \\
\hline LUMINÁRIA & Medidas Iniciais (Ohs) & Medição (6.000hs) & Variação \\
\hline SDF FOR 001 & 97 & 97 & 0,00 \\
\hline SDF FOR 002 & 97 & 97 & 0,00 \\
\hline SDF FOR 003 & 97 & 97 & 0,00 \\
\hline SDF FOR 004 & 98 & 98 & 0,00 \\
\hline
\end{tabular}

Média -6.000 horas

o

Fonte: a autora,2020. 


\section{ANEXO 2}

$\rightarrow$ Levantamento fotográfico referente a instalação de Cotia /SP
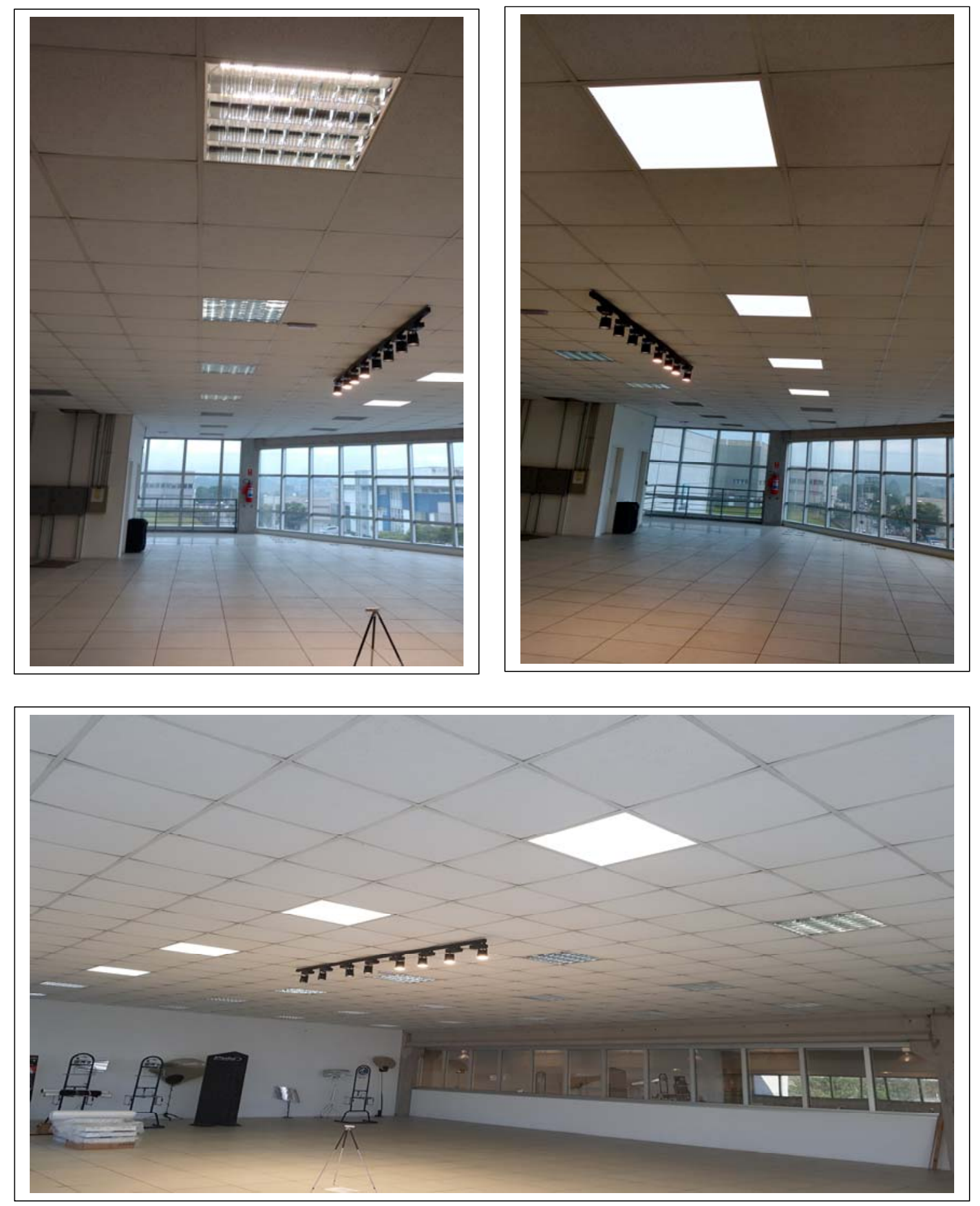
$\rightarrow$ Levantamento fotográfico referente a instalação de Fortaleza/CE
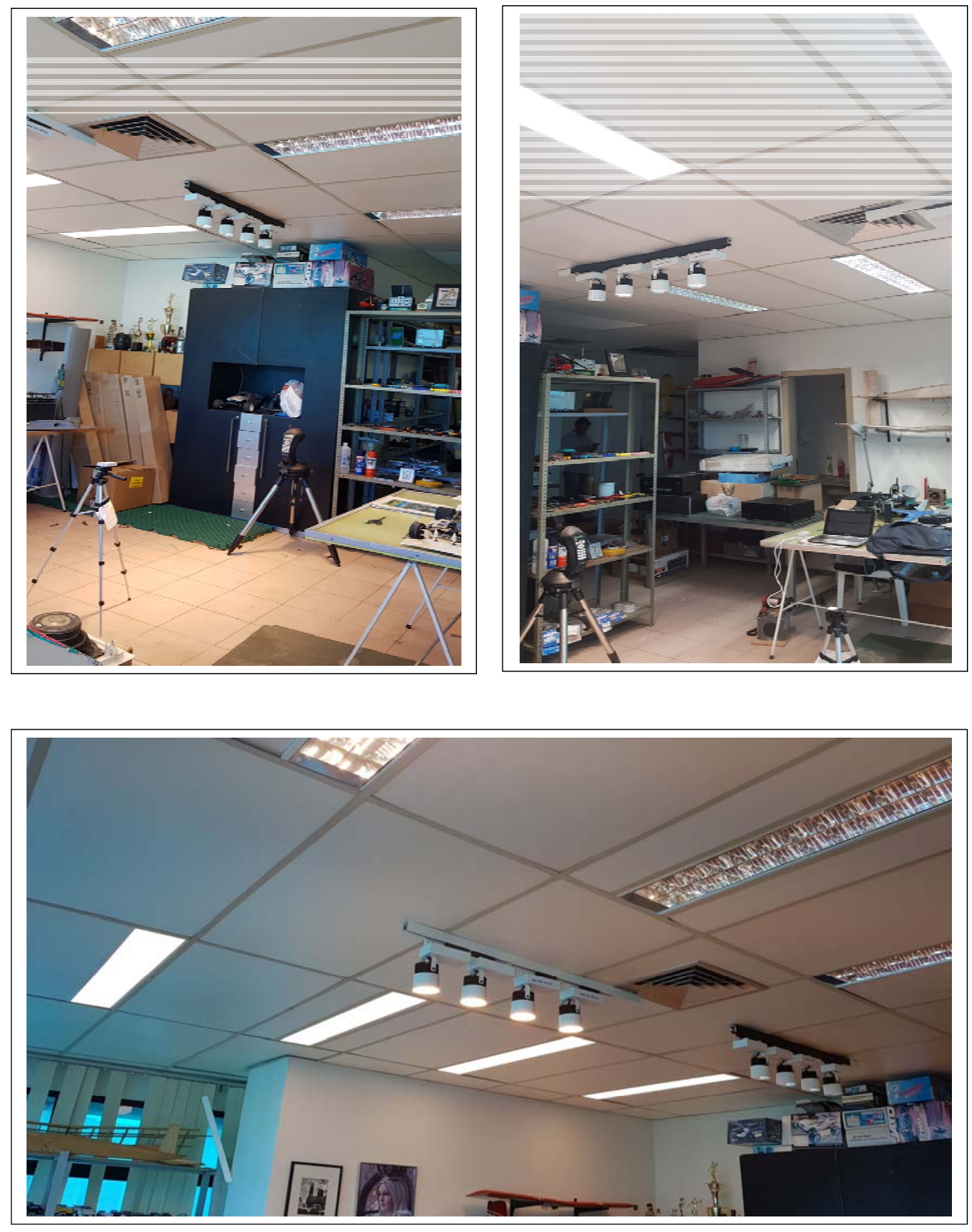